DOE/EIA-0614

Distribution Category UC-950

\title{
Electricity Prices in a Competitive Environment: Marginal Cost Pricing of Generation Services and Financial Status of Electric Utilities
}

\section{A Preliminary Analysis Through 2015}

\section{August 1997}

\section{Energy Information Administration}

Office of Integrated Analysis and Forecasting

U.S. Department of Energy

Washington, DC 20585 


\section{Contacts}

This report was prepared by the staff of the Nuclear and Electricity Analysis Branch, Energy Supply and Conversion Division, Office of Integrated Analysis and Forecasting. General information regarding this publication may be obtained from Mary Hutzler, Director, Office of Integrated Analysis and Forecasting (202/5862222, e-mail mhutzler@eia.doe.gov); Scott Sitzer, Director, Energy Supply and Conversion Division (202/586-
2308, e-mail ssitzer@eia.doe.gov); or Robert T. Eynon, Chief, Nuclear and Electricity Analysis Branch (202/ 586-2315, e-mail reynon@eia.doe.gov). Specific questions about the preparation and content of the report should be directed to Art Holland, project manager for the publication (202/586-2026, e-mail aholland@eia.doe. gov), or to the following analysts:
Price Forecasting Models ........ Laura Church Mathematical Specifications ........ Pete Whitman Chapters 1, 3, and 5 .......... Art Holland Chapter 2............... J. Alan Beamon Chapter $4 \ldots \ldots \ldots \ldots \ldots$. . . James G. Hewlett
202/586-1494

202/586-1940

$202 / 586-2026$

202/586-2025

$202 / 586-9536$ lchurch@eia.doe.gov

pwhitman@eia.doe.gov

aholland@eia.doe.gov

jbeamon@eia.doe.gov

jhewlett@eia.doe.gov 


\section{DISCLAIMER}

This report was prepared as an account of work sponsored by an agency of the United States Government. Neither the United States Government nor any agency thereof, nor any of their employees, make any warranty, express or implied, or assumes any legal liability or responsibility for the accuracy, completeness, or usefulness of any information, apparatus, product, or process disclosed, or represents that its use would not infringe privately owned rights. Reference herein to any specific commercial product, process, or service by trade name, trademark, manufacturer, or otherwise does not necessarily constitute or imply its endorsement, recommendation, or favoring by the United States Government or any agency thereof. The views and opinions of authors expressed herein do not necessarily state or reflect those of the United States Government or any agency thereof. 


\section{DESCLAMIXR}

Portions of this document may be illegible in electronic image products. Images are produced from the best available original document. 


\section{Preface}

Section 205(a)(2) of the Department of Energy Organization Act (Public Law 95-91) requires the Administrator of the Energy Information Administration (EIA) to carry out a comprehensive program that will collect, evaluate, assemble, analyze, and disseminate data and information relevant to energy resources, reserves, production, demand, technology, and related economic and statistical information. To meet these responsibilities in the area of electric power, EIA has prepared this report entitled Electricity Prices in a Competitive Environment: Marginal Cost Pricing of Generation Services and Financial Status of Electric Utilities.

The report contains five chapters. Chapter 1 includes a description of the events that led to current initiatives to restructure the electric power industry, as well as a discussion of the institutional and structural changes that will be required to support the competitive pricing of electricity. Chapter 2 describes the analysis assumptions and methodology. Chapter 3 discusses the uses and results of the analysis, including a comparison of electricity prices under regulation and prices under competition and a discussion of the sensitivities of the results to key parameters in the analysis cases. Chapter 4 contains an analysis of the cash flow implications of the new competitive prices for utilities. Chapter 5 includes a conclusion and a final word on the limitations of the analysis. The Appendices provide technical descriptions of the methodology used to calculate competitive electricity prices.

The report is intended for a general audience. It should be of particular interest to public utility analysts, policy and financial analysts, investment firms, trade associations, Federal and State regulators, and legislators.

The projections in the report were made using the National Energy Modeling System (NEMS) and a prototype version of the Value of Capacity (VALCAP) model. The Reference Case used in the analysis is the Reference Case published in the Annual Energy Outlook 1997, DOE/EIA-0383(97) (Washington, DC, December 1996).

Because a model cannot address the complexities of the real world, this report does not provide unqualified predictions of the future. The projections presented in this report represent expectations of what could occur under a given set of assumptions. If conditions change, the projections will be affected accordingly. The uncertainty inherent in the projections contained in this report should be recognized, so that the projections can be used in the proper context.

The U.S. electric power industry is in the early stages of a comprehensive restructuring that will bring farreaching changes to regulations, legal statutes, and institutions that have been in place for decades. Consequently, there is a great deal of uncertainty about the ultimate form of the transformed industry. The method of calculating and projecting competitive prices, as presented in this report, is one of several that are consistent with the economics of deregulated markets. However, because of the high level of uncertainty surrounding the future structure of the U.S. electric power industry, it is not possible to determine the precise conditions that will set electricity prices in the future.

Price projections in this report are not meant to be forecasts of competitive electricity prices, Rather, they are illustrations of the potential effects of changes in certain parameters on the price for electricity that may emerge under competition, given the assumptions stated in this report. The areas of uncertainty include, but are not limited to, consumer responsiveness to electricity price changes, the development of time-of-use pricing for electricity, the market value of electric service reliability, and future generating technology improvements. Further, the illustrative prices in this report do not represent upper or lower bounds on competitive prices. Rather, they are the results of sensitivity tests on some of these major areas of uncertainty:

Users of this report are encouraged to review other literature on the topic of the restructuring of the U.S. electric power industry before using the results of any of the analyses. The users should also carefully review the assumptions of the studies and the restilting sensitivity to those assumptions: 
The fluid nature of the progress of the restructuring of the U.S. electric power industry presents particular uncertainty with respect to forecasts. There are many details of the new competitive industry still to be determined by legislators and regulators, and there is additional uncertainty as to how consumers and producers will respond to these changes.

The legislation that created EIA vested this organization with an element of statutory independence. In accord- ance with Public Law 95-91, the analyses offered in this report are based on an objective, independent examination and do not purport to represent the policy positions of the U.S. Department of Energy or the Administration. The EIA does not take positions on policy questions. Rather, EIA's responsibility is to provide timely, accurate information and to perform objective, credible analyses in support of deliberations by both public and government decisionmakers. 


\section{Contents}

Highlights $\ldots \ldots \ldots \ldots \ldots \ldots \ldots \ldots \ldots \ldots \ldots \ldots \ldots \ldots \ldots \ldots \ldots \ldots \ldots \ldots \ldots \ldots \ldots$

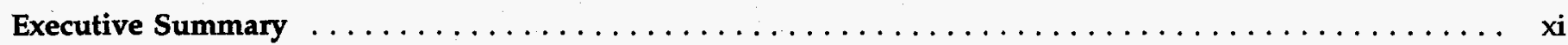

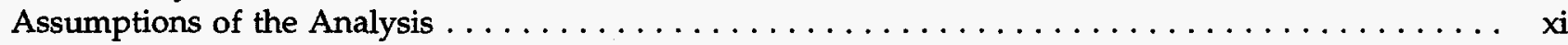

Results of the Analysis $\ldots \ldots \ldots \ldots \ldots \ldots \ldots \ldots \ldots \ldots \ldots \ldots \ldots \ldots \ldots \ldots \ldots \ldots \ldots \ldots \ldots$

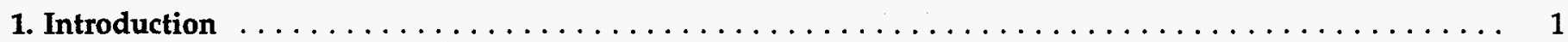

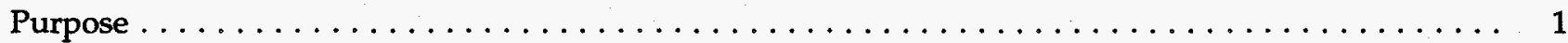

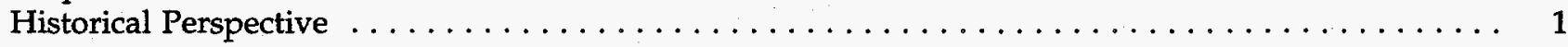

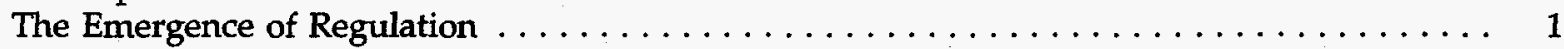

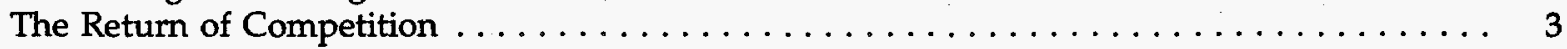

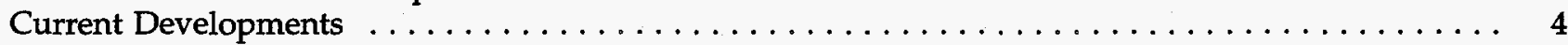

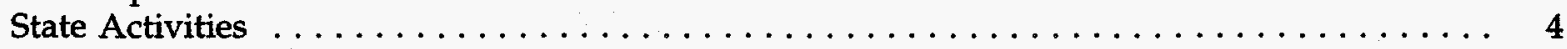

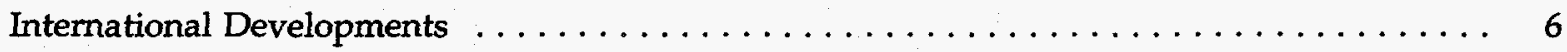

The Transition to a Competitive Industry $\ldots \ldots \ldots \ldots \ldots \ldots \ldots \ldots \ldots \ldots \ldots \ldots \ldots \ldots \ldots \ldots \ldots \ldots$

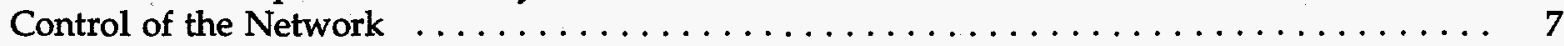

Types of Transactions Allowed $\ldots \ldots \ldots \ldots \ldots \ldots \ldots \ldots \ldots \ldots \ldots \ldots \ldots \ldots \ldots$

Wholesale or Retail Competition $\ldots \ldots \ldots \ldots \ldots \ldots \ldots \ldots \ldots \ldots \ldots \ldots \ldots \ldots$

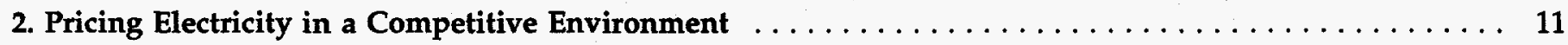

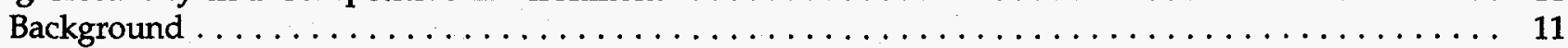

Modeling Competitive Electricity Pricing $\ldots \ldots \ldots \ldots \ldots \ldots \ldots \ldots \ldots \ldots \ldots \ldots \ldots \ldots$

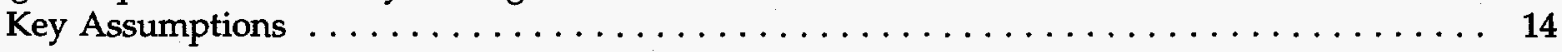

Calculating Competitive Electricity Prices $\ldots \ldots \ldots \ldots \ldots \ldots \ldots \ldots \ldots \ldots \ldots \ldots \ldots \ldots \ldots$

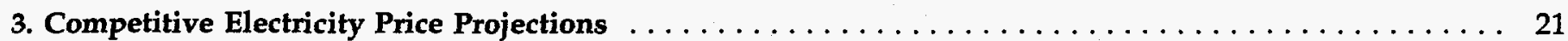

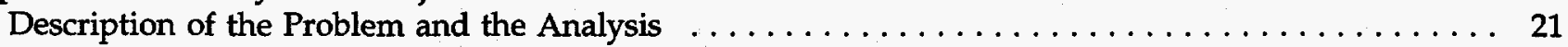

Average Costs, Marginal Costs, Time-of-Use Pricing, and Efficiency Improvements . . . . . . . . 25

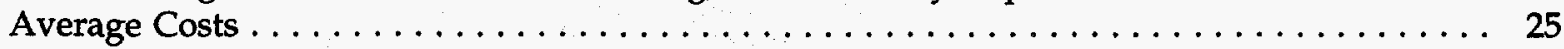

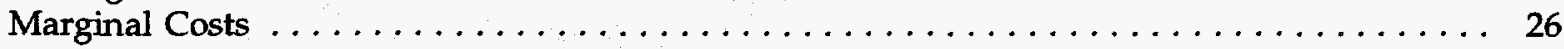

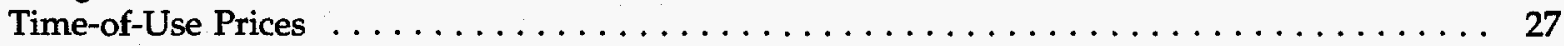

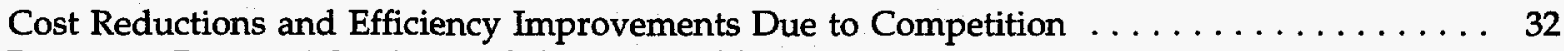

Capital Recovery, Reserve Margins, and Capacity Additions $\ldots \ldots \ldots \ldots \ldots \ldots \ldots \ldots \ldots \ldots$

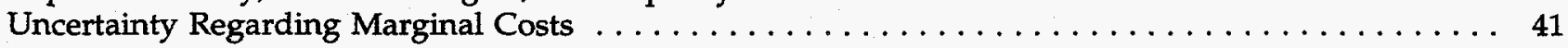

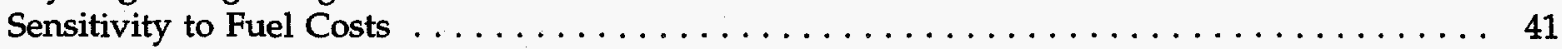

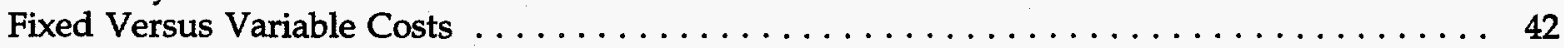

Regional Prices and Stranded Costs $\ldots \ldots \ldots \ldots \ldots \ldots \ldots \ldots \ldots \ldots \ldots \ldots \ldots \ldots \ldots \ldots$

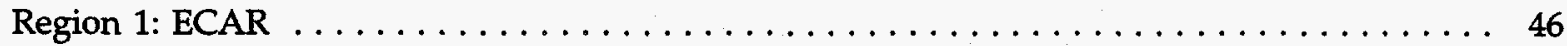

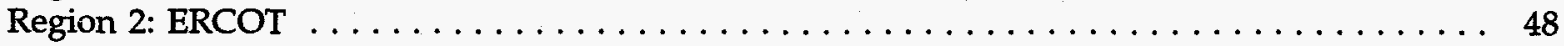

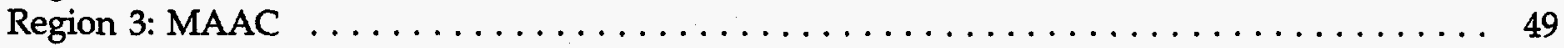

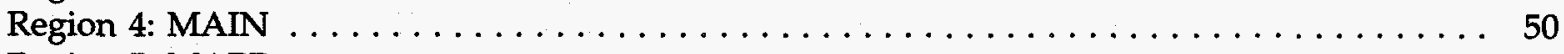

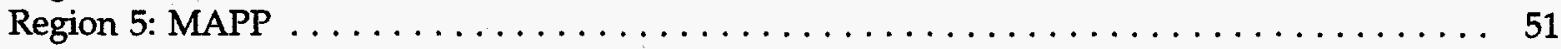

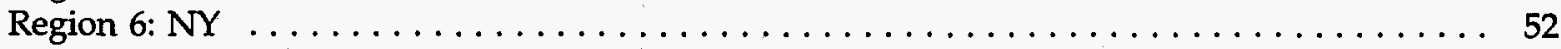

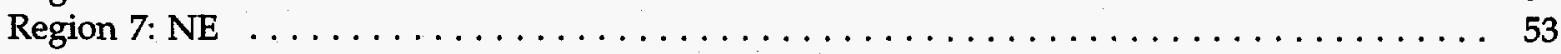

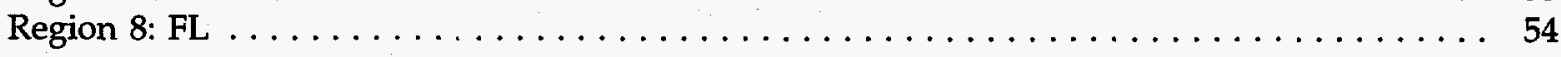




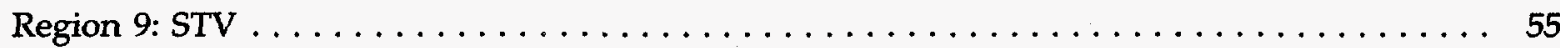

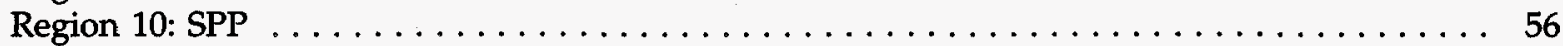

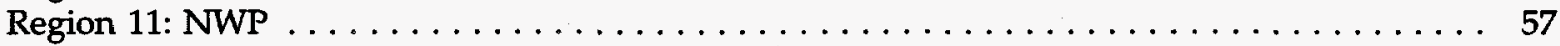

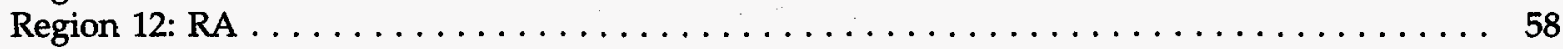

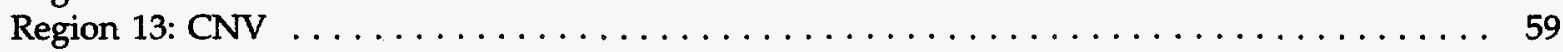

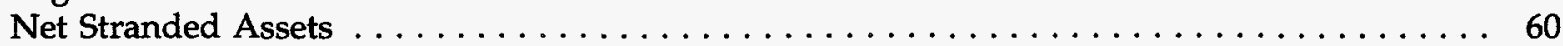

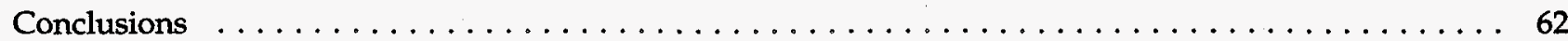

4. Financial Implications of the Competitive, Marginal Cost Pricing of Electricity Generation . . . . . . 63

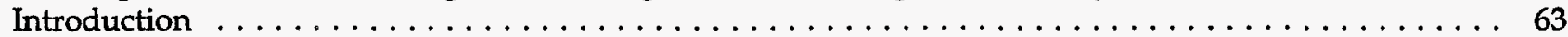

Competitive, Marginal Cost Pricing of Electricity and Bankruptcy $\ldots \ldots \ldots \ldots \ldots \ldots \ldots \ldots \ldots$

Financial Implications for a Typical Regional Utility $\ldots \ldots \ldots \ldots \ldots \ldots \ldots \ldots \ldots \ldots \ldots \ldots \ldots$

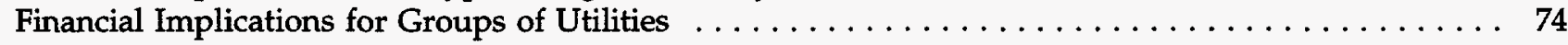

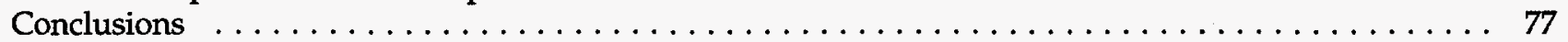

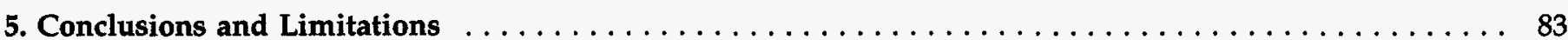

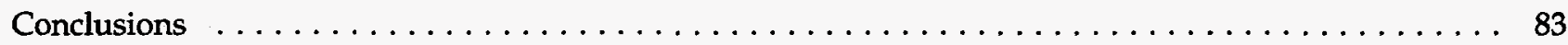

Limitations and Uncertainty $\ldots \ldots \ldots \ldots \ldots \ldots \ldots \ldots \ldots \ldots \ldots \ldots \ldots \ldots \ldots \ldots \ldots$

Appendices

A. Calculation of Competitive Market Prices for Generation Services $\ldots \ldots \ldots \ldots \ldots \ldots \ldots \ldots$

B. Stranded Costs and Stranded Cost Recovery $\ldots \ldots \ldots \ldots \ldots \ldots \ldots \ldots \ldots \ldots \ldots \ldots \ldots$

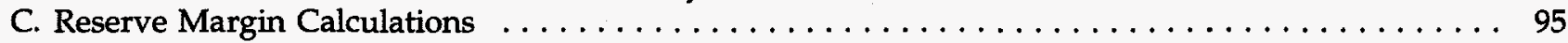

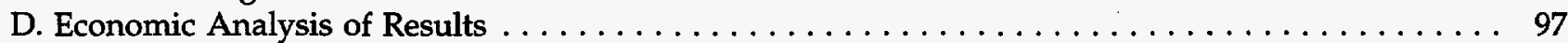

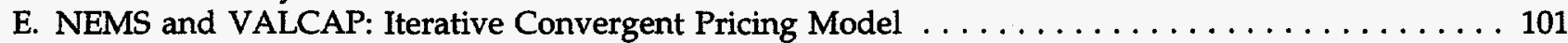

F. Calculation of Marginal Expected Unserved Energy in VALCAP: Mathematical Specifications . . . 103

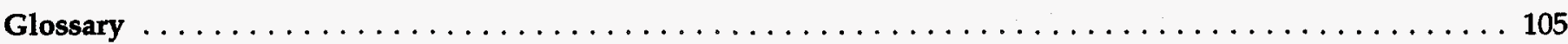

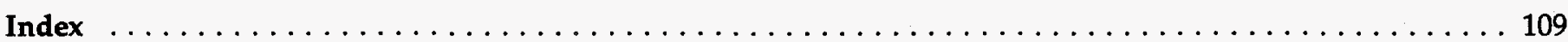

\section{Tables}

ES1. Summary Results for the Major Cases in the Analysis $\ldots \ldots \ldots \ldots \ldots \ldots \ldots \ldots \ldots \ldots \ldots$ xiii

1. Most Frequently Discussed Forms for a Restructured U.S. Electric Power Industry . . . . . . . . . 8

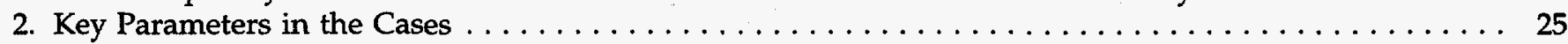

3. Regional Target Reserve Margins Under Competitive Pricing in Five Cases . . . . . . . . . . . . . . 39

4. Reserve Margins, Generating Capacity, and Electricity Demand in Three Cases . . . . . . . . . . 40

5. Region 1 (ECAR): Net Stranded Costs, $1998-2015 \ldots \ldots \ldots \ldots \ldots \ldots \ldots \ldots \ldots \ldots \ldots \ldots \ldots \ldots$

6. Region 2 (ERCOT): Net Stranded Costs, $1998-2015 \ldots \ldots \ldots \ldots \ldots \ldots \ldots \ldots \ldots \ldots \ldots \ldots \ldots \ldots . \ldots \ldots$

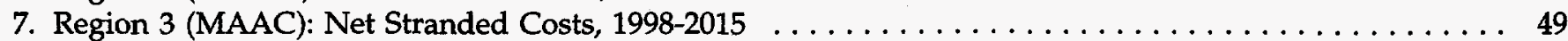

8. Region 4 (MAIN): Net Stranded Costs, $1998-2015 \ldots \ldots \ldots \ldots \ldots \ldots \ldots \ldots \ldots \ldots \ldots \ldots \ldots \ldots \ldots$

9. Region 5 (MAPP): Net Stranded Costs, $1998-2015 \ldots \ldots \ldots \ldots \ldots \ldots \ldots \ldots \ldots \ldots \ldots \ldots \ldots \ldots \ldots$

10. Region 6 (NY): Net Stranded Costs, $1998-2015 \ldots \ldots \ldots \ldots \ldots \ldots \ldots \ldots \ldots \ldots \ldots \ldots \ldots \ldots \ldots$

11. Region 7 (NE): Net Stranded Costs, $1998-2015 \ldots \ldots \ldots \ldots \ldots \ldots \ldots \ldots \ldots \ldots \ldots \ldots \ldots \ldots \ldots$

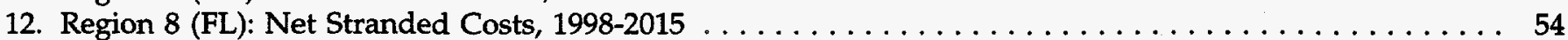

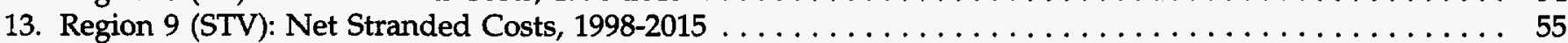

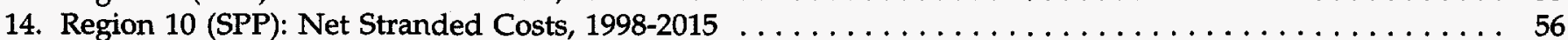

15. Region 11 (NWP): Net Stranded Costs, $1998-2015 \ldots \ldots \ldots \ldots \ldots \ldots \ldots \ldots \ldots \ldots \ldots \ldots \ldots \ldots . \ldots \ldots$

16. Region 12 (RA): Net Stranded Costs, $1998-2015 \ldots \ldots \ldots \ldots \ldots \ldots \ldots \ldots \ldots \ldots \ldots \ldots \ldots \ldots \ldots$

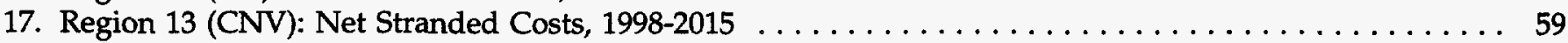

18. Net Stranded Assets Through 2015 by Region Under Competitive Pricing of Generation Services in Four Cases 
19. Comparison of Estimates of National Total Net Stranded Assets Through $2015 \ldots \ldots \ldots \ldots$. . . . 61

20. U.S. Business Bankruptcies by Year, $1987-1994 \ldots \ldots \ldots \ldots \ldots \ldots \ldots \ldots \ldots \ldots \ldots \ldots \ldots \ldots . \ldots \ldots$

21. Regulated and Competitive Prices for Electricity by Region and Projected Reductions

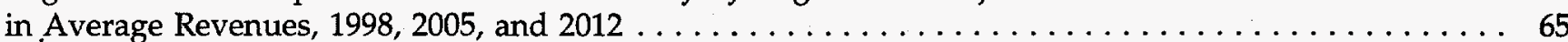

22. Aggregate Statement of Income by Region, $1994 \ldots \ldots \ldots \ldots \ldots \ldots \ldots \ldots \ldots \ldots \ldots \ldots \ldots \ldots \ldots$

23. Aggregate Statement of Income by Region, $1994 \ldots \ldots \ldots \ldots \ldots \ldots \ldots \ldots \ldots \ldots \ldots \ldots \ldots \ldots \ldots 70$

24. Effects of a 20-Percent Reduction in Revenues for Utilities in Region $2 \ldots \ldots \ldots \ldots \ldots \ldots \ldots \ldots \ldots$

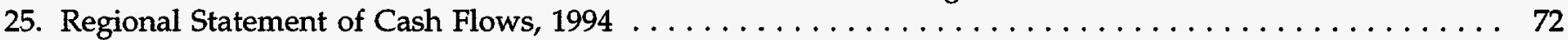

26. Estimated Changes in After-Tax Income, 1998, 2005, and $2012 \ldots \ldots \ldots \ldots \ldots \ldots \ldots \ldots \ldots \ldots \ldots$

27. Distribution of Utilities by Region and Average Revenue, $1994 \ldots \ldots \ldots \ldots \ldots \ldots \ldots \ldots \ldots \ldots \ldots$

28. Projected Changes in Average Utility Revenues by Region and Grouping, $1998 \ldots \ldots \ldots \ldots \ldots \ldots$

29. Aggregate Statement of Income for Region 1 by Utility Grouping, $1994 \ldots \ldots \ldots \ldots \ldots \ldots \ldots \ldots \ldots$

30. Aggregate Statement of Income for Region 3 by Utility Grouping, $1994 \ldots \ldots \ldots \ldots \ldots \ldots \ldots \ldots .79$

31. Aggregate Statement of Income for Region 4 by Utility Grouping, $1994 \ldots \ldots \ldots \ldots \ldots \ldots \ldots \ldots$

32. Aggregate Statement of Income for Region 10 by Utility Grouping, $1994 \ldots \ldots \ldots \ldots \ldots \ldots \ldots$

\section{Figures}

ES1. Electricity Market Module Regions $\ldots \ldots \ldots \ldots \ldots \ldots \ldots \ldots \ldots \ldots \ldots \ldots \ldots \ldots \ldots \ldots \ldots \ldots$

ES2. Projected Regional Retail Electricity Prices Under Regulation and Competition, $2000 \ldots \ldots \ldots \ldots$ xv

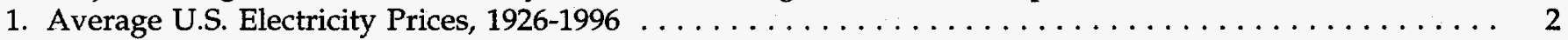

2. State Legislative and Regulatory Initiatives $\ldots \ldots \ldots \ldots \ldots \ldots \ldots \ldots \ldots \ldots \ldots \ldots \ldots \ldots \ldots$

3. 1995 Price of Electricity by Cost Category and Line of Business $\ldots \ldots \ldots \ldots \ldots \ldots \ldots \ldots \ldots \ldots \ldots$

4. Hourly Load Curve for the South Atlantic Region $\ldots \ldots \ldots \ldots \ldots \ldots \ldots \ldots \ldots \ldots \ldots \ldots \ldots \ldots$

5. National Average Electricity Costs and Prices in the Reference Case

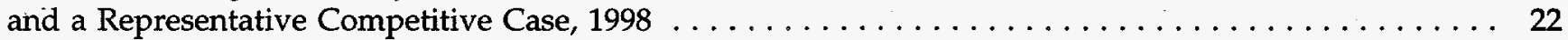

6. Recent Reductions in Employment and Costs for Investor-Owned Electric Utilities . . . . . . . . . . . 26

7. Assumed Reductions in Regulated Electricity Prices (Average Costs)

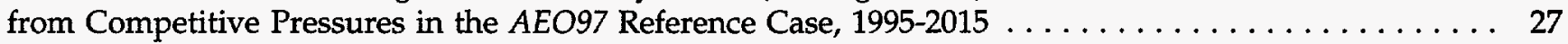

8. Competitive Prices in the Flat Rates Case Compared with Regulated Prices, 1998-2015 . . . . . . . . 28

9. Seasonal Capacity, Demands, and Competitive Time-of-Use Prices . . . . . . . . . . . . . . . . . . . 29

10. Competitive Time-of-Use Prices with Moderate Consumer Response, Compared with the Flat Rates

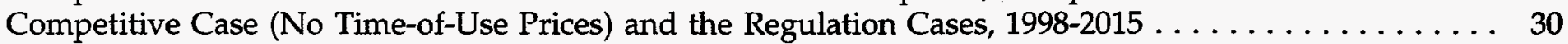

11. Competitive Prices in Two Demand Response Cases, 1998-2015 . . . . . . . . . . . . . . . . . 31

12. National Average Electricity Prices in Two Regulation Cases and Two Competitive Cases,

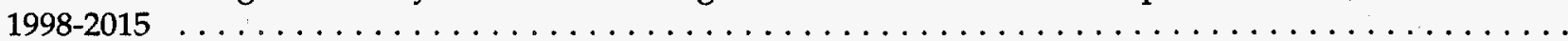

13. National Average Prices for Electricity Generation Services in Six Cases,

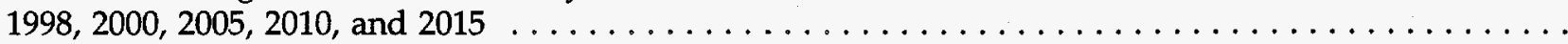

14. Capacity, Demands, and Competitive Time-of-Use Prices with Surplus Generating Capacity, 1998 ..... .

15. Capacity, Demands, and Competitive Time-of-Use Prices with Generating Capacity Shortages, 2005 ... 37

16. Average Costs of Electricity Production and Delivery and Competitive Prices

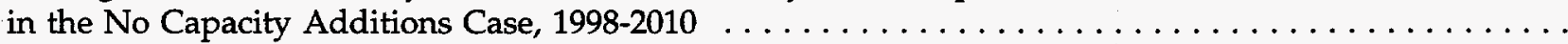

17. Cumulative Capacity Additions in the AEO97 Reference Case and

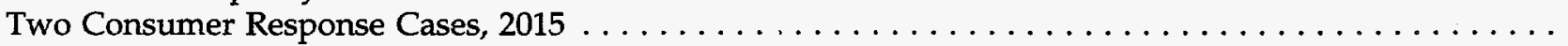

18. Average Costs and Competitive Electricity Prices in the Moderate Consumer Response Case

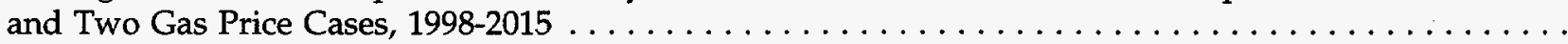

19. Cumulative Capacity Additions in the Low and High Gas Price Cases, $2015 \ldots \ldots \ldots \ldots \ldots \ldots$

20. Competitive Electricity Prices in the Moderate Consumer Response Case and Two Cost Uncertainty Cases, $1998-2015 \ldots \ldots \ldots \ldots \ldots \ldots \ldots \ldots \ldots \ldots \ldots \ldots$

21. National Average Costs and Competitive Prices in the Moderate Consumer Response and High Efficiency Cases, 1998-2015

22. Region 1 (ECAR): Average Costs of Electricity Production and Delivery and Competitive Prices in the Moderate Consumer Response and High Efficiency Cases, 1998-2015 
23. Region 2 (ERCOT): Average Costs of Electricity Production and Delivery and Competitive Prices in the Moderate Consumer Response and High Efficiency Cases, 1998-2015 . . . . . . . . . . . . 48

24. Region 3 (MAAC): Average Costs of Electricity Production and Delivery and Competitive Prices in the Moderate Consumer Response and High Efficiency Cases, 1998-2015 . . . . . . . . . . . . 49

25. Region 4 (MAIN): Average Costs of Electricity Production and Delivery and Competitive Prices in the Moderate Consumer Response and High Efficiency Cases, 1998-2015 . . . . . . . . . . . . . 50

26. Region 5 (MAPP): Average Costs of Electricity Production and Delivery and Competitive Prices in the Moderate Consumer Response and High Efficiency Cases, 1998-2015 . . . . . . . . . . . . 51

27. Region 6 (NY): Average Costs of Electricity Production and Delivery and Competitive Prices in the Moderate Consumer Response and High Efficiency Cases, 1998-2015 . . . . . . . . . . . . . 52

28. Region 7 (NE): Average Costs of Electricity Production and Delivery and Competitive Prices in the Moderate Consumer Response and High Efficiency Cases, 1998-2015 . . . . . . . . . . . . 53

29. Region 8 (FL): Average Costs of Electricity Production and Delivery and Competitive Prices in the Moderate Consumer Response and High Efficiency Cases, 1998-2015 . . . . . . . . . . . . 54

30. Region 9 (STV): Average Costs of Electricity Production and Delivery and Competitive Prices in the Moderate Consumer Response and High Efficiency Cases, 1998-2015 . . . . . . . . . . . 55

31. Region 10 (SPP): Average Costs of Electricity Production and Delivery and Competitive Prices in the Moderate Consumer Response and High Efficiency Cases, 1998-2015 . . . . . . . . . . . . 56

32. Region 11 (NWP): Average Costs of Electricity Production and Delivery and Competitive Prices in the Moderate Consumer Response and High Efficiency Cases, 1998-2015 . . . . . . . . . . . . . 57

33. Region 12 (RA): Average Costs of Electricity Production and Delivery and Competitive Prices in the Moderate Consumer Response and High Efficiency Cases, 1998-2015 . . . . . . . . . . . . . 58

34. Region 13 (CNV): Average Costs of Electricity Production and Delivery and Competitive Prices in the Moderate Consumer Response and High Efficiency Cases, 1998-2015 . . . . . . . . . . . . . . . 59

35. Distribution of Utilities with Projected Revenue Increases and Decreases, $1998 \ldots \ldots \ldots \ldots \ldots$. . . . . 77

D1. Illustration of the Economic Consequences of Deregulation $\ldots \ldots \ldots \ldots \ldots \ldots \ldots \ldots \ldots \ldots \ldots . \ldots 7$

D2. Effect of Deregulation with Small Aggregate Demand Shift $\ldots \ldots \ldots \ldots \ldots \ldots \ldots \ldots \ldots \ldots \ldots . \ldots 8$

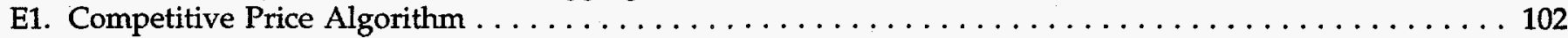




\section{Highlights}

\section{If competitive markets for electricity generation emerge in the \\ United States . . .}

... over the short term, average electricity prices could be lower in most regions of the country ...

\section{. . . but some current suppliers could face sizable reductions in market value and shareholder wealth, and Federal tax revenues from utilities could be reduced.}

This report presents some of the potential impacts of the competitive pricing of electricity in the United States, based on widely accepted principles of economic theory. The assumptions that form the basis of the analysis may or may not reflect actual developments resulting from the emergence of fully competitive electricity markets.

One important assumption in this analysis is that there will be an absence of market power in the coming competitive market for electric power. "Market power" means that a supplier or consumer has the ability independently to influence prices by virtue of size or control over an important aspect of the market, such as access to transmission lines. If there is no market power, then economic theory suggests that prices will fall to the marginal costs of production, and the cost of operating the most expensive generating plant in operation at any point in time will set the price for electricity.

Given this assumption, the cases considered in the analysis, and the assumption that full-scale competition in generation services begins on January 1,1998, retail prices for electricity could be lower on average by as much as 6 to 13 percent within 2 years, compared with prices under current laws and regulations. This is in addition to the price reductions already taking place as a result of limited wholesale competition, producers' preparation for retail competition, and incentive regulations implemented by State regulators. If the price reductions already occurring were added to those resulting from full-scale competition in generation services, prices by 2000 could be 8 to 15 percent below where they would have been in the absence of competition and incentive regulations. The price changes would vary from region to region, and some regions could even see price increases.

Under conditions of intense competition, where many producers have access to customers and engage in price cutting strategies to win market share, prices could fall by as much as 24 percent instead of the 8 to 15 percent cited above. However, a price decline of this magnitude will not be achieved unless utilities are able to reduce their costs substantially from current levels and maintain those cost reductions.

Uneconomic costs, also called "stranded costs," are costs incurred under regulation that cannot be recovered through lower competitive prices. Such costs include investments in expensive generating plants and high-cost contracts for fuel and wholesale electric power. Unless policymakers mandate stranded cost recovery through regulatory means, U.S. suppliers could experience a total reduction in market value (stranded assets) of as much as $\$ 72$ to $\$ 169$ billion, and there could be a number of bankruptcies. Over the 2-year period from January 1, 1998, to January 1,2000, the stranded assets faced by utilities could be reduced by as much as $\$ 30$ or $\$ 40$ billion as utility customers pay down uneconomic costs through regulated electricity prices.

In the intense competition case cited above, severe stranded costs could erode the entire $\$ 400$ billion book value of the industry in the absence of successful costcutting measures. However, price decreases of this magnitude would likely be accompanied by intensive cost cutting and efficiency improvements, which could reduce a significant portion of the $\$ 25$ to $\$ 30$ billion that electricity suppliers incur 
In the long term, prices will be reduced by competition as a result of efficiency improvements or other cost reductions. each year in nonfuel, non-capital-related costs. These estimates of stranded costs are net of any benefits accruing to low-cost suppliers; if such benefits are excluded from the calculation, the stranded costs for high-cost suppliers could be as much as 20 percent higher than those stated above.

If policymakers mandate full recovery of stranded costs, there will be little difference between competitive and regulated prices in the short term, and little change in tax revenues (although there could be substantial benefits over the longer term). If policymakers do not mandate any stranded cost recovery, Federal tax revenues from utilities could be reduced by $\$ 2.5$ billion per year on average under the assumptions of the most likely range of cases in this report. (At the same time, Government expenditures on electricity would fall, and there could be macroeconomic effects resulting from lower electricity prices-both of which would at least partially offset some of the reduction in Federal tax revenues.) Most restructuring plans to date at the State and Federal levels allow for at least some recovery of stranded costs through prices.

Most analysts and policymakers believe that the benefits from competition in the long run will result from efficiency gains and cost reductions due to competitive pressures. That is, over the longer term, with efficiency improvements under competition and the absence of further uneconomic costs under regulation, electricity prices will fall relative to where they would have been under regulation. This analysis does not assess the extent to which competitive pressures could reduce costs and prices over the long term, but a sensitivity analysis examines the effects of greater efficiency improvements. 


\section{Executive Summary}

The emergence of competitive markets for electricity generation services is changing the way that electricity is and will be priced in the United States. This report presents the results of an analysis that focuses on two questions: (1) How are prices for competitive generation services likely to differ from regulated prices if competitive prices are based on marginal costs rather than regulated "cost-of-service" pricing? (2) What impacts will the competitive pricing of generation services (based on marginal costs) have on electricity consumption patterns, production costs, and the financial integrity of electricity suppliers? This study is not intended to be a cost-benefit analysis of wholesale or retail competition, nor does this report include an analysis of the macroeconomic impacts of competitive electricity prices.

\section{Assumptions of the Analysis}

\section{Prices for generation services are based on marginal costs under competition}

Economic theory states that competition drives price to marginal costs if there are many producers and consumers. ${ }^{1}$ For electricity, this means that competitive prices for generation services would be based on the costs of producing the last kilowatthour of electricity. This method of pricing is different from the cost-ofservice regulatory practice, which uses average costs (total costs divided by total sales) as the basis of prices. The application of marginal costs as the basis of prices assumes that no supplier or consumer exercises market power. Market power exists when a supplier or consumer influences prices by virtue of size or control over important aspects of the market, such as access to transmission lines. If suppliers exercise market power, prices could be higher than marginal costs. If a consumer segment exercises market power, then that segment could have a price advantage over other customers.
In this analysis, regulated prices for generation services are based on average costs, and competitive prices for generation services are based on marginal costs. Average costs are defined as the total costs of production, including a return on investment equal to the producer's cost of capital, divided by sales to ultimate consumers. Marginal costs are defined as the operations and maintenance (O\&M) costs of the most expensive generating plant needed to supply the immediate demand for electricity (the marginal cost of generation). ${ }^{2}$ During periods of high demand, when demand approaches the limits of generating capacity, prices may rise above the marginal cost of generation. In this analysis, during those high demand periods a "reliability price adjustment" is added, which represents the value that consumers place on the reliability of electricity service. The marginal cost of generation and the reliability price adjustment are added to unit taxes (per kilowatthour) to estimate the competitive price for generation services. In this report, the competitive price for generation services and the regulated price of transmission and distribution ${ }^{3}$ equal the retail competitive price of electricity.

\section{Time-of-use prices could affect the timing of electricity usage}

Because electricity cannot be stored, as its demand rises and falls by season or during the portions of a day, additional generating plants in reserve must be immediately brought on line ("dispatched") to serve increases in demand. As a result, the costs of electricity production-and thus the marginal cost and competitive price-rise and fall with changes in the demand for power, as generating plants are dispatched or taken off line. Competitive prices that vary with demand may lead to changes in consumer electricity usage patterns. Time-of-use prices give consumers an incentive to reduce usage during high demand ("peak") periods and

\footnotetext{
${ }^{1}$ The necessary conditions to achieve what economists call "perfect competition," which results in prices approaching marginal costs, are: (1) many buyers and sellers, (2) a homogeneous (or standard) product, (3) perfect information, and (4) no barriers to entry.

${ }^{2}$ There is a great deal of uncertainty regarding what are considered to be fixed costs (unavoidable, even with reduced output) and what are considered to be variable costs (avoidable when output is reduced) for the purposes of analyzing competitive pricing. A sensitivity analysis of the delineation of fixed versus variable costs is included in Chapter 3 of this report, and a brief summary of the analysis is included in this Executive Summary.

${ }^{3}$ Most proposals under discussion in the States call for continued cost-of-service regulation of transmission and distribution services.
} 
increase usage during low demand ("off-peak") periods. It is uncertain what effects time-of-use prices will have on demand patterns. Therefore, several estimates of short-term consumer responsiveness to changes in price are used in this analysis to examine the effects of time-of-use prices.

\section{The costs of new generating capacity are recovered through competitive prices}

For most of the competitive cases presented in this analysis, generating capacity is added only if it provides an increase in system reliability ${ }^{4}$ sufficient to recover the cost of building the capacity. Investments in new capacity used only during peak demand periods ("peaking" capacity) are recovered through the reliability price adjustment. Investment costs for other new capacity (non-peaking capacity) are recovered through the premiums received during periods when more expensive plants are running and setting the price. In this way, the analysis is conducted so that the costs of all new generating capacity are recovered through competitive prices. Other than the 109 gigawatts of fossil fuel and nuclear capacity assumed to be retired for economic and other reasons in the Annual Energy Outlook 1997 (AEO97) Reference Case, ${ }^{5}$ there is no additional economic replacement of generating capacity in any case in this analysis. That is, new generating plants that are cheaper to operate are not built solely to replace the existing stock of generating capacity.

\section{Competition is assumed to begin in 1998}

Finally, the analysis assumes that regional competitive markets for generation services are in place on January 1,1998 . In reality, it is not clear how fast the restructuring of the U.S. electric power industry will proceed. Some States will move more quickly than others to establish rules and institutions to facilitate a competitive market for generation services. The speed at which competitive markets for generation services will emerge is a political issue and an economic issue. Political forces will establish the ground rules, and market forces will respond according to those ground rules. Consequently, the rate of change is very difficult to estimate. This simplifying assumption is used to facilitate the purpose of the analysis-i.e., to compare competitive electricity prices based on marginal costs with regulated electricity prices based on average costs. The estimates of future prices in this analysis are not forecasts, but they represent a range of possible outcomes consistent with the variations in the assumptions for the cases.

\section{Results of the Analysis}

Table ES1 summarizes the major findings of this analysis. Average annual electricity prices are displayed for two regulation cases and five competitive cases. The regulation cases are the $A E O 97$ Reference Case and the No Competition Case. The No Competition Case is identical to the AEO97 Reference Case, except that no reductions in nonfuel O\&M and general and administrative (G\&A) costs over time are assumed. In the AEO97 Reference Case, cost reductions are assumed to result from competitive pressures in the wholesale market for electric power, as well as from supplier preparations for retail competition, and result in a 7percent reduction in the price of electricity in 2005.

The competitive cases are the Flat Rates Case (similar to the AEO97 Reference Case, but with prices based on marginal costs instead of average costs, and no time-ofuse rates); the Moderate Consumer Response Case (testing the effects of moderate consumer responsiveness to competitive time-of-use electricity prices); the High Consumer Response Case (same as the previous case but testing a higher assumed level of consumer responsiveness); the High Efficiency Case (illustrating the price impact of a set of higher competition-induced cost savings and efficiency improvements); and the Intense Competition Case (showing the effects of severe competitive pressures, which drive prices for generation services down to a level that is only slightly higher than the cost of the fuel used to generate power).

\section{Short-term competitive prices could be lower due to uneconomic costs in regulated prices}

Over the short term ( 2 to 3 years), if stranded costs are not recovered through prices, ${ }^{6}$ average electricity prices nationwide under competition could be 6 to 13 percent lower than regulated prices, as indicated by the results for the year 2000 from the competitive cases (excluding the Intense Competition Case), compared with those from the AEO97 Reference Case. As shown in Table ES1, the AEO97 Reference Case represents the effects of price reductions under regulation that result

\footnotetext{
${ }^{4}$ In this analysis, system reliability is measured by expected unserved energy, which is the difference between electricity generating capacity and demand when demand exceeds capacity as a result of unforeseen circumstances (such as unexpectedly high demand, or capacity unexpectedly out of service).

${ }^{5}$ Energy Information Administration, Annual Energy Outlook 1997, DOE/EIA-0383(97) (Washington, DC, December 1996).

${ }^{6}$ Stranded costs are the uneconomic costs of producing electric power. These are fixed costs, such as investments in generating plants or contractual commitments for wholesale purchases of power or fuel, that cannot be recovered though lower competitive prices. In this analysis, it is assumed that stranded costs are not recovered through prices.
} 
Table ES1. Summary Results for the Major Cases in the Analysis

\begin{tabular}{|c|c|c|c|c|c|}
\hline \multirow[b]{2}{*}{ Case Name } & \multicolumn{5}{|c|}{$\begin{array}{c}\text { Average Retail Prices } \\
\text { (1995 Cents per Kilowatthour) }\end{array}$} \\
\hline & 1998 & 2000 & 2005 & 2010 & 2015 \\
\hline \multicolumn{6}{|l|}{ Regulated Prices } \\
\hline AEO97 Reference Case (Limited Competition) & 6.9 & 6.9 & 6.6 & 6.4 & 6.3 \\
\hline No Competition . & 7.1 & 7.1 & 7.1 & 7.0 & 6.7 \\
\hline \multicolumn{6}{|c|}{ Competitive Prices (Do Not Include Stranded Cost Recovery) } \\
\hline Flat Rates (No Time-of-Use Rates) & 6.5 & 6.5 & 6.2 & 6.2 & 6.2 \\
\hline Moderate Consumer Response & 6.3 & 6.2 & 6.1 & 6.1 & 6.1 \\
\hline High Consumer Response ... & 6.3 & 6.4 & 6.2 & 6.1 & 6.1 \\
\hline High Efficiency & 6.2 & 6.0 & 5.7 & 5.6 & 5.6 \\
\hline Intense Competition & 5.3 & 5.4 & 5.5 & 5.4 & 5.4 \\
\hline
\end{tabular}

Source: Energy Information Administration, Office of Integrated Analysis and Forecasting, National Energy Modeling System (NEMS), runs AEO97B.D100296K (AEO97 Reference Case) and GAFLAT.D060497A (No Competition Case) and run sets AEOAVG2 (Flat Rates Case), E15V03 (Moderate Consumer Response Case), E50V03 (High Consumer Response Case), HIEFF (High Efficiency Case), and NOFXGNA (Intense Competition Case).

from the limited competition that currently exists in the wholesale market for electric power. These reductions are shown in the relative prices for the AEO97 Reference Case and the No Competition Case. Hence, the 6to 13 -percent reduction in electricity prices due to full competition in the generation services market is in addition to the price reductions that are occurring due to the current level of competitive pressures reflected in the AEO97 Reference Case. ${ }^{7}$

The Intense Competition Case represents conditions under which competition becomes so fierce that producers price their power at virtually the cost of the fuel used for generating it. End-use price projections in this case range from 5.3 to 5.5 cents per kilowatthour (1995 cents), compared with 6.1 to 6.3 cents per kilowatthour in the Moderate Consumer Response Case. This result is a 22-percent price reduction relative to the $A E O 97$ Reference Case and a 24-percent reduction relative to the No Competition Case in the short term (the year 2000 )-a price reduction greater than that which results from the 40-percent cost reductions assumed in the High Efficiency Case.

Low-cost producers may recover their fixed costs through the premiums they receive during high demand periods when more expensive producers are setting the price, but it is possible that the low average annual price in the Intense Competition Case would not be high enough to provide full cost recovery for any but the most efficient generating technologies (combined cycle, for example), operated as efficiently as possible (as baseload capacity). It is not evident that this low price would provide cost recovery for less efficient technologies operated under less than optimal conditions, such as combustion turbine technologies generating electricity only during peak periods. Consequently, it is likely that generating plants with higher operating costs would be forced to retire. The consequences of such economic retirements are not included in this analysis.

As the need for new capacity increases, competitive prices will rise until capacity expansion becomes profitable. Therefore, the prices projected in the Intense Competition Case are not considered to be sustainable over the long term.

Figure ES1 shows the competitive regional markets for electric power that were analyzed in this study. Regional markets based on the North American Electric Reliability Council (NERC) regions and subregions formed the basis for the analysis of prices. Some regions of the country could experience larger price reductions, some smaller, and some could see prices rise under competition (Figure ES2). The 6- to 13-percent price reduction in the short term is the result of the assumption of no stranded cost recovery through prices. Most current

\footnotetext{
${ }^{7}$ The cost reductions seen in the historical data that provide the basis for the assumed competition-induced cost reduction between the No Competition Case and AEO97 Reference Case could be the result of both competitive pressures and more effective regulation (i.e., performance-based rates).
} 
Figure ES1. Electricity Market Module Regions

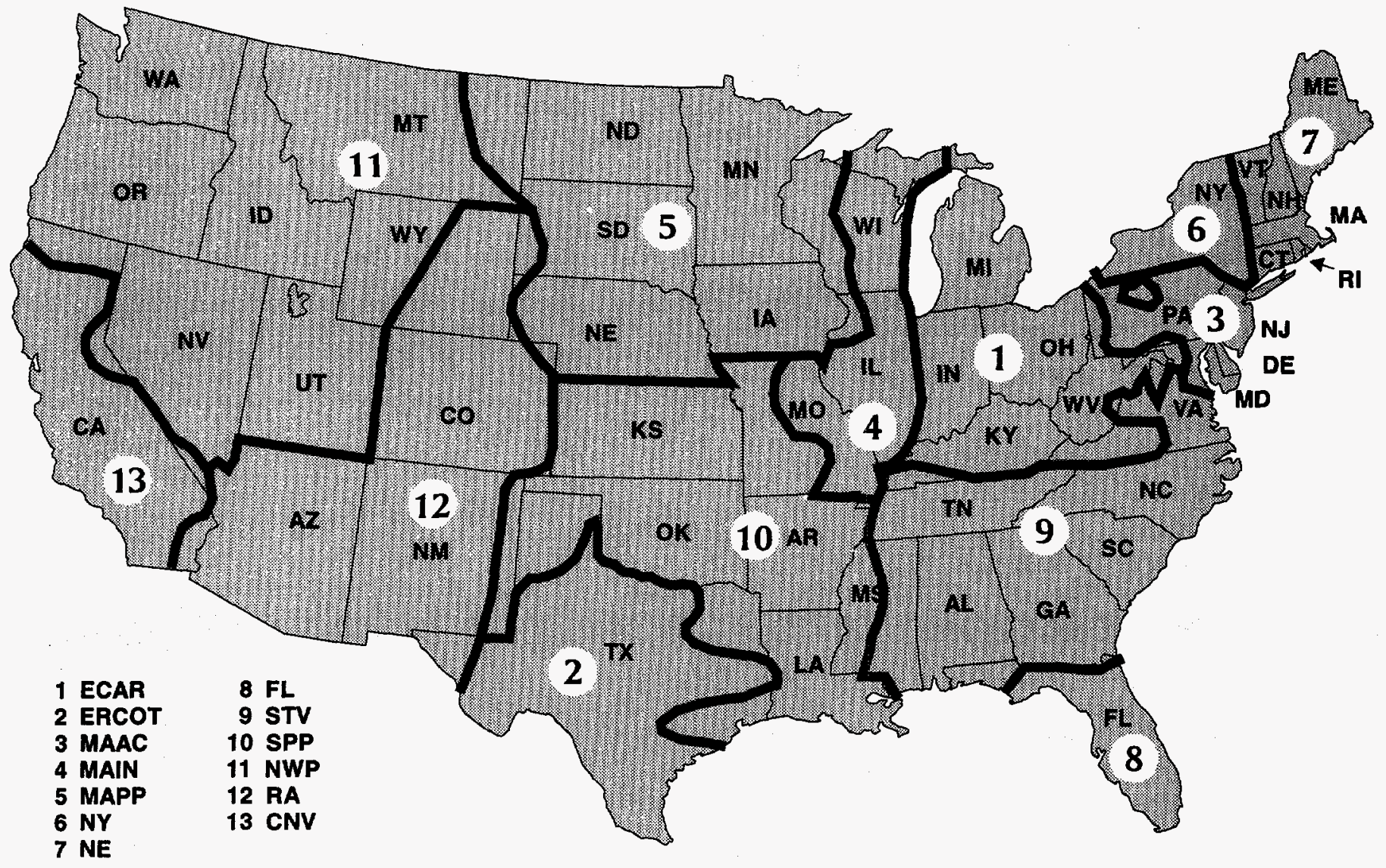

Notes: $E C A R$ = East Central Area Reliability Coordination Agreement Region; ERCOT = Electric Reliability Council of Texas; MAAC = Mid-Atlantic Area Council; MAIN = Mid-America Interconnected Network; MAPP = Mid-Continent Area Power Pool; NY = New York Power Pool; NE = New England Power Pool; FL = Florida subregion of the Southeastern Electric Reliability Council; STV = Southeastern Electric Reliability Council excluding Florida; SPP = Southwest Power Pool; NWP = Northwest Pool subregion of the Western Systems Coordinating Council; RA = Rocky Mountain and Arizona-New Mexico Power Areas; CNV = CaliforniaSouthern Nevada Power Area.

Source: Energy Information Administration, Office of Integrated Analysis and Forecasting.

Federal and State legislative initiatives, however, including the California restructuring bill ( $A B$ 1890), and recent rulings from the Federal Energy Regulatory Commission (FERC), allow at least some level of stranded cost recovery. Therefore, over the short term, the degree to which electricity prices may fall under competition depends on how much regulatory and legislative relief producers receive for stranded costs. In cases where policymakers grant suppliers 100 percent stranded cost recovery, average competitive prices will closely resemble regulated prices in the short term.

If there is no stranded cost recovery, the price projections presented in this analysis suggest that the reduction in market value of current generating assets (stranded assets) that results from the inability to recover stranded costs could range between about $\$ 72$ and $\$ 169$ billion (1995 dollars). In the Intense Competition Case, estimates of net stranded assets are as high as $\$ 408$ billion. ${ }^{8}$ However, this estimate of stranded assets assumes that there will be no reduction in costs as a result of competitive pressures (beyond those assumed in the AEO97 Reference Case), whereas it is likely that price reductions of 20 to 25 percent under competition would result in intensive efforts on the part of suppliers to reduce costs. A significant portion of the $\$ 25$ to $\$ 30$ billion that electricity suppliers incur each year in nonfuel, non-capital-related costs would not be recovered through prices in the Intense Competition Case. These costs would become stranded unless

\footnotetext{
${ }^{8}$ All stranded asset calculations for the Intense Competition Case assume a 6-percent discount rate.
} 
Figure ES2. Projected Regional Retail Electricity Prices Under Regulation and Competition, 2000

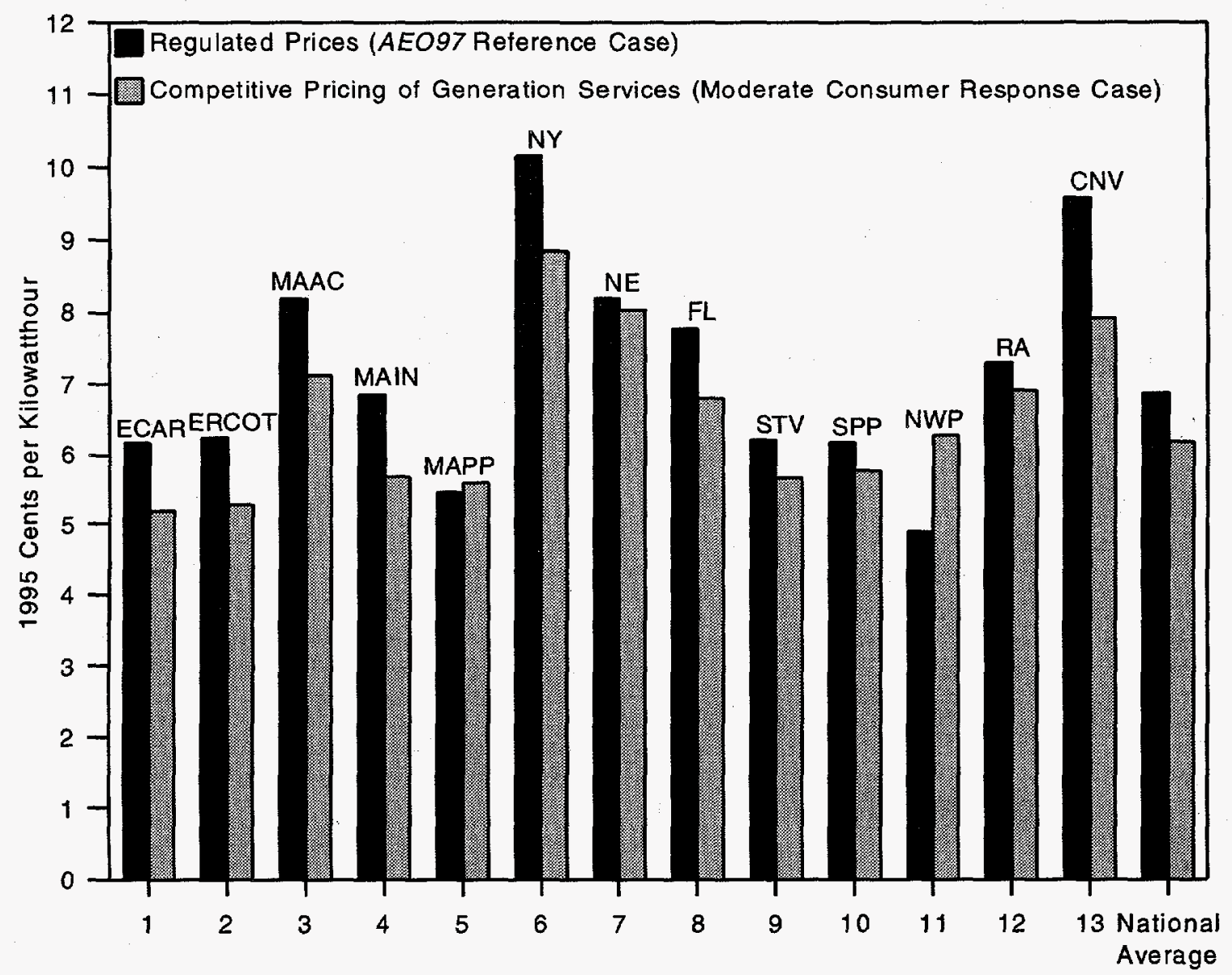

Source: Energy Information Administration, Office of Integrated Analysis and Forecasting, National Energy Modeling System, run AEO97B.D100296K (AEO97 Reference Case) and National Energy Modeling System and Prototype Value of Capacity Model, run set E15V03 (Moderate Consumer Response Case).

suppliers became more efficient. As mentioned above, the prices projected in the Intense Competition Case are not considered to be sustainable over the long term.

If the $O \& M$ and $G \& A$ costs that are removed from competitive prices in the Intense Competition Case were eliminated completely from generating costs as well, then net stranded assets would be much lower$\$ 110$ billion as opposed to $\$ 408$ billion. In other words, the O\&M and G\&A costs that are potentially fixed, and therefore not included for pricing purposes, could contribute roughly $\$ 298$ billion to net stranded assets through 2015 if the costs were incurred but not recovered through prices. As producers find ways to reduce costs under the intense competitive pressures assumed in this case, it is likely that these O\&M and G\&A costs would be reduced, and that the realized level of stranded assets would be between the $\$ 110$ and $\$ 408$ billion cited above. Also, as mentioned previously, it is likely that the low prices illustrated in the Intense Competition Case could not be maintained without substantial cost reductions.

The stranded asset estimates are "netted out" within the regions used in this analysis. In other words, this calculation assumes that the revenue gains of winners (with average costs lower than competitive prices) offset the losses of other suppliers in the same region. Absent this netting out effect, stranded assets could be as much as 20 percent higher than the calculations presented in this analysis. Also, in the absence of stranded cost recovery, Federal income tax receipts could fall by as much as $\$ 2.5$ billion per year on average under the range of most likely cases in this report, as a result of reductions in the taxable income of electric utilities. It is likely, however, that these firstorder revenue reductions would be partially offset by reduced Government outlays for electric power. ${ }^{9}$

\footnotetext{
${ }^{9}$ In Chapter 4 of this report, the reduction in Federal Government outlays for power is estimated to be about $\$ 300$ million per year.
} 
Additionally, it is possible that the macroeconomic effects of competitive pricing could result in higher tax revenues.

\section{Long-term competitive prices will be lower if there are efficiency gains and cost reductions}

Over the long term (10 to 20 years), prices under competition will likely be lower than prices under regulation would have been for a number of reasons. New uneconomic costs that producers incur under competition will not be recoverable through prices as they have been under regulation. Either suppliers will avoid the uneconomic costs that they incurred under regulation in the past (high-cost generating plants, high-cost contractual agreements), or their shareholders, not their customers, will bear the consequences. Additionally, prices under competition will be lower than regulated prices to the extent that suppliers reduce costs and improve operating efficiencies in response to competitive pressures.

Future cost reductions and efficiency improvements under competition are very difficult to estimate. The reductions in nonfuel O\&M costs, reductions in the costs of new generating capacity, and improvements in operating efficiencies (heat rates) assumed in the High Efficiency Case lead to estimated reductions in competitive electricity prices of 11 percent relative to the AEO97 Reference Case by 2015 (Table ES1). ${ }^{10}$

\section{Customer response to time-of-use prices affects average prices}

If time-of-use prices for electricity do reduce electricity consumption during high usage (peak) periods and increase consumption during low usage (off-peak) periods, the result will be a more constant level of demand for electricity across seasons and portions of the day. The extent to which consumers might change their electricity usage habits when faced with prices that change over time, or when offered the availability of lower rates for interruptible service, is unknown. Nevertheless, this analysis suggests that if consumers respond, competitive prices will be affected. Average annual competitive prices could be pushed lower if consumers respond to time-of-use prices by reducing peak period consumption, thus reducing marginal costs and competitive prices as the most expensive generating plants are used less frequently.

The price effects achieved through a reduction in peak period demand could be at least partially offset if total demand for the year increases. In other words, while prices could be reduced by the effects of lower peak period electricity usage, lower prices during off-peak periods could increase off-peak usage, and off-peak prices could be higher than they would have been with a lower level of consumer price responsiveness.

If consumers display a high level of responsiveness to changes in prices, the increase in demand during offpeak periods (due to lower off-peak prices) could be greater than the decrease in demand during peak periods (due to higher peak period prices). Higher off-peak demand would push competitive prices higher than they otherwise would have been. As a result, competitive prices could be higher given a higher level of consumer responsiveness, although they would not rise to the level of regulated prices. Average annual competitive electricity prices in 2000 vary by about 0.3 cent (a 5-percent range) over the range of consumer response cases used in this analysis (Flat Rates, Moderate Consumer Response, and High Consumer Response cases) (Table ES1).

\section{On average, utility profits will decrease during the transition to competition in the absence of stranded cost recovery, but the financial effects will vary from utility to utility}

On average, the move to competition without any stranded cost recovery would cause prices to fall by about 6 to 13 percent over the range of most likely cases presented in this report. In the aggregate, utility profits and the taxes directly associated with them are about 20 percent of revenues. Thus, the revenue reductions caused by a 10 percent decrease in prices would result in substantial reductions in profits (and taxes). Common stock dividends and common stock prices would fall, but the industry as a whole would remain solvent.

There are, however, very large variations in prices (and average costs) within and between regions, and the financial effects will vary depending upon the utility and its costs. In the very short term (e.g., 1998), the revenues of roughly 25 percent of the privately-owned utilities supplying financial data to the FERC would actually increase. Conversely, about 20 percent of privately owned utilities would observe revenue reductions of over 30 percent, and these relatively high cost utilities would be financially distressed. Without substantial cost reductions or stranded cost recovery, some of these utilities may not be able to remain solvent and would have to declare bankruptcy.

\footnotetext{
${ }^{10}$ This price reduction of 11 percent is illustrative of the assumptions in the High Efficiency Case, and is not a forecast of price reductions due to expected efficiency improvements or cost reductions due to full competition.
} 


\section{Introduction}

\section{Purpose}

The emergence of competitive markets for electricity generation services is changing the way that electricity is and will be priced in the United States. This report presents the results of an analysis that focuses on two questions: (1) How are prices for competitive generation services likely to differ from regulated prices if competitive prices are based on marginal costs rather than regulated "cost-of-service" pricing? (2) What impacts will the competitive pricing of generation services (based on marginal costs) have on electricity consumption patterns, production costs, and the financial integrity of electricity suppliers? This study is not intended to be a cost-benefit analysis of wholesale or retail competition, nor does it include an analysis of the macroeconomic impacts of competitive electricity prices.

The report is structured as follows: Chapter 1 summarizes the events that prompted current initiatives to restructure the U.S. electric power industry and discusses the institutional and structural changes that will be necessary to support competitive pricing of electricity. Chapter 2 describes the assumptions and methodology used for the analysis. Chapter 3 discusses the results of the analysis, including comparisons of electricity price projections based on a sensitivity analysis of key parameters that provides estimates of stranded costs. Chapter 4 presents an analysis of the financial implications of competitive pricing for electricity providers, particularly, the impacts of stranded costs on the financial status of electric utilities. Chapter 5 summarizes the conclusions and limitations of the analysis. The appendices contain technical descriptions of the methodology used for the study.

\section{Historical Perspective}

\section{The Emergence of Regulation}

Thomas Edison's Pearl Street Station began service to 85 customers in New York City on September 4, 1882. By 1892, the basic economics of the electric power industry were fairly well understood-the cost of electricity generation from most technologies consisted of high fixed costs and low variable operating costs. Fixed costs have two major components: recovery of and on capital investments in plants and equipment, and maintenance that must be performed whether or not plants are used. These costs are incurred even if no power is produced. Variable operating costs-the costs of running the power plants-consist mainly of the fuel costs for generating plants when they are producing power.

To recover the two types of costs, a simple pricing system was designed by Samuel Insull, builder of the huge Insull electricity empire. Under a "declining rate schedule," the fixed costs for generating plants were recovered in the first block of electricity sold. In subsequent blocks, the operating costs were recovered. The key to profitability for Insull's Chicago Edison utility was to keep the power plants running as much as possible (that is, to maintain high capacity factors). He employed sales campaigns, price competition, load diversity, ${ }^{1}$ and economies of scale to increase profits. ${ }^{2}$

In the early 1900 s, vertically integrated electric utilities, controlling not only generation but also transmission and distribution operations, began to operate in "exclusive franchise areas." By 1916, 33 States had established regulatory agencies to oversee the utilities in their jurisdictions, with the authority to franchise utilities, regulate their rates, financing, and service, and establish utility accounting systems. ${ }^{3}$ The State commissions provided protection to consumers from the possibility of monopolistic practices by the utilities, as well as ensuring reliability of electricity supplies. In addition, they allowed utilities to receive a fair rate of return. Although it is unclear whether State regulation of electric power emerged to protect the public or to protect the profits of the electric utilities in the face of the cutthroat competition induced by the economies of the business, it is clear that, given the intense competition between electric power providers, there was growing concern that downward pressure on prices would prevent investors from making the capital investments

\footnotetext{
${ }^{1}$ Load diversity means that different customers consume electricity at different times of the day so that the difference between peak and off-peak demand levels is reduced. Load diversity reduces the cost of operating the system and reduces the capital investments needed to ensure its reliability.

${ }^{2}$ L.S. Hyman, America's Electric Utilities: Past, Present and Future (Arlington, VA: Public Utilities Reports, Inc., 1994).

${ }^{3}$ Energy Information Administration, Annual Outlook for U.S. Electric Power 1985, DOE/EIA-0474(85) (Washington, DC, August 1985).
} 
necessary to ensure the reliability of electricity supplies. 4,5

By the early 1930s, electricity prices had fallen (Figure 1 ), and service had been extended to two-thirds of the U.S. population (although only 10 percent of farms had power service). As demand for electricity increased, centralized ownership of operating companies by holding companies facilitated access to the capital required for expansion and for exploiting economies of scale; but while many States regulated local operating companies, there was no effective regulation of the increasingly expansive holding companies. Consequently, when the Great Depression arrived, many holding companies

Figure 1. Average U.S. Electricity Prices, 1926-1996

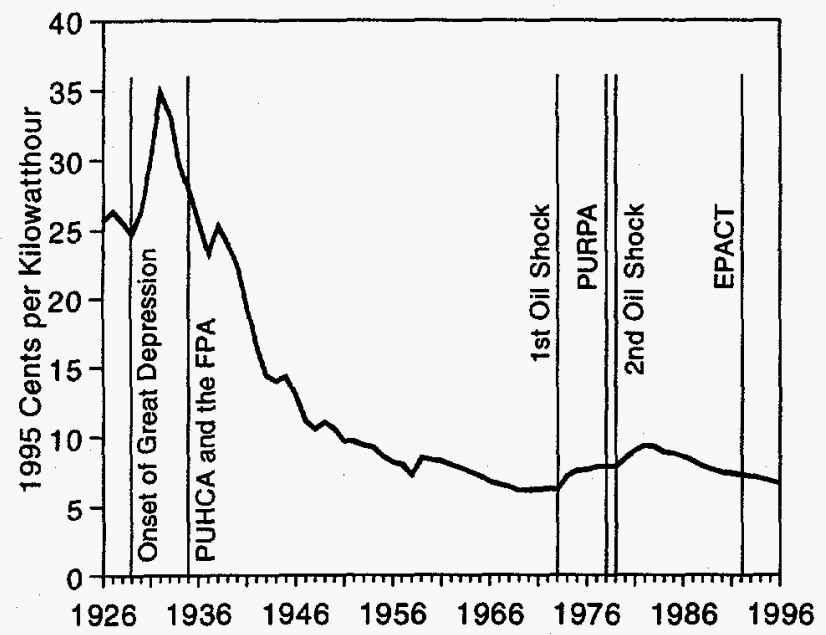

Notes: PUHCA = Public Utility Holding Company Act of 1935. FPA = Federal Power Act. PURPA = Public Utility Regulatory Policies Act of 1978. EPACT = Energy Policy Act of 1992.

Sources: Edison Electric Institute, EEI Pocketbook of Electric Utility Industry Statistics (1994); Energy Information Administration, Annual Energy Review, DOE/EIA-0384 (Washington, DC, various issues); Energy Information Administration, Electric Power Monthly, DOE/EIA-226(96/12) (Washington, DC, December 1996). failed as a result of high-leverage, unsecured financing and investments in businesses unrelated to energy services.

In response, Congress passed the Public Utility Holding Company Act of 1935 (PUHCA). ${ }^{6}$ The effect of this legislation was to give control of electricity service to local operating companies and, as a result, facilitate effective electric power regulation for retail transactions at the State level. From another perspective, PUHCA restricted the electric power generating business to domestic utilities that built and operated power plants to serve franchises (service territories). In effect, under PUHCA, public utilities had no competition in supplying electricity.

Congress passed the Federal Power Act as Title II of PUHCA, granting the Federal Government explicit authority over most interstate wholesale electric power sales. ${ }^{7}$ The Federal Power Commission was given authority to set interstate wholesale prices in much the same way that the States performed that function for intrastate retail transactions. ${ }^{8}$ Thus, by the end of 1935, almost all electric power transactions in the United States were regulated under a scheme called "rate of return" or "cost of service" regulation.

Under traditional rate of return regulation, electricity prices are set to allow the providers just enough sales revenue to recover the expected total costs incurred in producing or acquiring electricity, including a rate of return equal to the utility's cost of capital. In other words, investors receive a return just high enough to compensate them for the risks they incur by investing in the electric power industry. Since electricity service is typically provided by a vertically integrated operating company, there is no necessity for separate pricing of the component parts of electricity production and delivery (generation, transmission, distribution, and ancillary services ${ }^{9}$ ).

The process of determining electricity prices based on the cost of service is expensive and litigious. A great

\footnotetext{
${ }^{4}$ Cambridge Energy Research Associates, Final Report, Scenarios of Restructuring in the US Power Industry: Implications for Natural Gas, GRI-96/0003 (Cambridge, MA: Gas Research Institute, November 1995).

${ }^{5}$ Also, distribution through regulated utilities arose partly because of financial losses of publicly owned utilities in the 1910 s.

${ }^{6}$ Under PUHCA, any interstate company that owns 10 percent or more of the voting securities of a gas or electric utility falls under the jurisdiction of the Securities and Exchange Commission. Also, noncontiguous holding companies were broken up and intermediate holding companies were removed from the financial structure.

${ }^{7}$ Developments in generation and transmission technologies had given power producers the capability of transmitting electricity over long distances. This prompted the U.S. Supreme Court to invoke the Commerce Clause of the Constitution in the 1927 case, Rhode Island Public Utilities Commission v. Attleboro Steam and Electric Company, saying that a State could not regulate the price for electricity sold in another State.

${ }^{8}$ Energy. Information Administration, The Changing Structure of the Electric Power Industry 1970-1991, DOE/EIA-0562 (Washington, DC, March 1993). These duties are carried out by the Federal Energy Regulatory Commission (FERC) today.

${ }^{9}$ See Chapter 2 for a discussion of ancillary services.
} 
deal of time is required for commissions to determine production costs, and prices are set after extensive debate among utility representatives, consumer advocates, and other "intervenors" before regulatory authorities. ${ }^{10}$ Nonetheless, this regulatory scheme has facilitated the production and sale of low-cost, reliable electricity in the United States for more than 50 years.

\section{The Return of Competition}

Oil supply disruptions during the 1973 Arab oil embargo and the 1978-79 Iranian revolution led to widespread cost increases for energy supplies. Additionally, fuel, capital, and distribution costs for U.S. utilities increased dramatically, and the rate of growth in demand for electric power began to slow. When, as a result of these changes, Consolidated Edison ran into financial difficulties and omitted its common stock dividend in April 1974 , confidence in electric utilities suffered. ${ }^{11}$ Utility stocks lost 38 percent of their value in less than 6 months. Congress subsequently passed the Public Utility Regulatory Policies Act of 1978 (PURPA), Section 2 of the National Energy Act, which was intended to ensure energy security through conservation and increased efficiency. In fact, however, the end result of the legislation was different from that anticipated.

PURPA opened the door to competition in the U.S. electricity supply market. Under Title I, utilities and State regulators were required to consider energy conservation in their resource planning. Title II required utilities to purchase electricity from qualifying facilities (QFs) and defined QFs as either (1) generating plants that use cogeneration technology or (2) generating plants of less than 50 megawatts capacity that use renewable technologies. An important provision of the legislation was that it required utilities to pay their own avoided generating cost (or the avoided cost of acquiring the energy from another utility) for power purchased from QFs.

The calculation of avoided costs was difficult and subject to regulatory interpretation. Therefore, several States decided that avoided costs could be determined by bids from QFs competing for sales to utilities-a practice that created a new set of incentives and oppor- tunities to stimulate new institutional, technical, and economic diversity in the generation of electricity. ${ }^{12}$ For the first time since the passage of PUHCA, PURPA allowed organizations other than public utilities to sell electric power. ${ }^{13}$

Competitive pricing and reduced barriers to entry into the electricity supply market gained even stronger legislative endorsement under the Energy Policy Act of 1992 (EPACT). First, the law created a new class of electricity suppliers-exempt wholesale generators (EWGs)-exempt from the cost of service regulation to which utilities are subject. Through an amendment to PUHCA, EWGs are allowed to compete for the right to sell electricity at wholesale to utilities. Second, through an amendment to the Federal Power Act, Congress mandated that utilities provide wholesale power transmission service to third parties at cost-based rates, even if doing so required them to expand their transmission capacity. The Federal Energy Regulatory Commission (FERC) was given the responsibility of implementing open transmission access under EPACT in order to foster competition in the wholesale electricity market.

FERC's authority includes (1) approval of wholesale power agreements (including prices) and (2) regulatory review of mergers and acquisitions. ${ }^{14}$ To foster wholesale competition, the FERC required utilities to file nondiscriminatory tariff schedules when seeking approval for market-based wholesale prices. The objective of the tariff filings is to ensure that the rates charged by utilities for the use of their transmission facilities are not discriminatory. Also, it was hoped that the highly visible tariffs would foster wholesale competition.

On April 24, 1996, the FERC took another step toward a restructured U.S. electricity market with the introduction of its Order No. 888 (Docket Nos. RM95-8-000, Promoting Wholesale Competition Through Open Access Nondiscriminatory Transmission Services by Public Utilities, and RM94-7-001, Recovery of Stranded Costs by Public Utilities and Transmitting Utilities) and Order No. 889 (Docket No. RM95-9-000, Open Access Same-Time Information System (formerly Real-Time Information Networks) and Standards of Conduct). ${ }^{15}$ The orders had three

\footnotetext{
${ }^{10}$ In particular, the setting of allowed rates of return and hearings on the prudence of management decisions often involve extensive debate.

${ }^{11}$ L.S. Hyman, America's Electric Utilities: Past, Present and Future.

${ }_{12}^{12}$ Energy Information Administration, The Changing Structure of the Electric Power Industry 1970-1991.

${ }^{13}$ Industrial generators that sell power to industrial customers existed, but sales from these generators were not resold.

${ }^{14}$ Although several Federal and State regulatory bodies approve proposed utility mergers and acquisitions, most regulatory authorities have historically deferred to the FERC's judgement on such issues. FERC's newly revised utility merger policy is premised on three standards: (1) the effect on competition (FERC adopted the Federal Trade Commission/Department of Justice merger guidelines as the analytical framework), (2) the effect on rates, and (3) the effect on regulation.

${ }^{15}$ As a Notice of Proposed Rulemaking (preliminary to a Final Order), these rules were alternately called the "comparability NOPR," the "mega-NOPR," and the "giga-NOPR."
} 
objectives: (1) to further the cause of fair and open access to the transmission network, (2) to provide a mechanism for recovery of "stranded costs," and (3) to improve the operation of a competitive electricity market through the creation of a "same time information network." The final orders codified what the FERC had been doing on a case-by-case basis under the EPACT provisions.

\section{Current Developments}

\section{State Activities}

Acting on the belief that competitive electricity markets will lower prices to their residents and businesses, many States are now addressing electricity market restructuring. Their progress varies significantly. Some States are just beginning to study what a competitive electricity market might mean; others are beginning pilot programs; and still others have designed restructured electricity markets and passed enabling legislation (Figure 2). Even among States that have already made the decision to allow their consumers eventually to choose electricity suppliers-including California, Massachusetts, New Hampshire, New York, Pennsylvania, Rhode Island, Maine, New Jersey, Oklahoma, Wisconsin, and Montana-much remains to be decided and implemented. As the saying goes, "the devil is in the details." Many of the details of State restructuring programs remain to be finalized. ${ }^{16}$ The key characteristics of current State plans include timing; treatment of stranded costs; pricing of transmission and distribution services; and the market structure required to ensure that the benefits of competition flow to all consumers.

In California, where plans are furthest along, the Public Utility Commission (PUC) and State legislators have established a program to provide competitive electricity markets and consumer choice beginning in 1998. In principle, the plan calls for full recovery of utilities' stranded costs over a 10-year period through a "nonbypassable competitive transition charge." ("Nonbypassable" means that the charge will be imposed in such a way that consumers cannot avoid paying it, whether they stay with their current utility or choose a new supplier.) The charges for most stranded assets are expected to be collected by January 1, 2001. However, stranded costs have not yet been calculated for individual utilities, and the utilities are required to make efforts to mitigate their potential stranded costs.
To ensure that small customers will benefit, the California plan calls for their rates to be cut by no less than 10 percent (net of stranded cost recovery) beginning January 1, 1998, and 20 percent by January 1, 2002. With respect to the pricing of transmission services, zonal rates based on cost of service are being designed in accordance with FERC Order 888. Prices will be differentiated by geographic locations within the State, because transmission capacity between zones is limited. As a result, market clearing prices will differ among the zones. Distribution services (the functions associated with the delivery of power from high-voltage transmission lines to homes and businesses) are to be priced according to a performance-based rate mechanism (PBR). In a typical PBR system, prices are linked to a key economic index adjusted for expected increases in productivity. For example, distribution system prices in 2001 might be set to 2000 distribution prices, plus an adjustment for expected inflation between 2000 and 2001, minus an adjustment for expected improvements in the productivity of the distribution system. PBR systems offer advantages to distribution companies and to customers. The distribution company can earn profits by reducing its costs at a rate greater than the expected increase in productivity. Some of these efficiency gains can be shared with customers eventually, when the PBR mechanism is recalibrated after several years.

To ensure that the electricity market in California will operate competitively, the plan calls for utilities to functionally unbundle their operations. In other words, they must run their transmission, distribution, and generation operations as if they were separate companies. They are also required to sell off a portion of their fossil-fired generating plants to increase the number of competitive generation suppliers in the market. Operation of the transmission grid and the dispatching of generating plants to meet demand are to be performed by a new, nonprofit institution-the independent system operator (ISO). The transmission facilities will still be owned by the utilities, but their operation will be controlled by the ISO. A separate nonprofit institution-the power exchange (PX)-will be formed to provide an efficient, competitive auction open to all suppliers. The purpose of the PX will be to facilitate a short-term pool for electricity transactions.

In Massachusetts, regulators have called for a phase-in of retail access beginning January 1, 1998. In preparation, utilities are required to unbundle their rates, providing separate charges for generation, transmission,

\footnotetext{
${ }^{16}$ For a more extensive list of State plans see Energy Information Administration, The Changing Structure of the Electric Power Industry: An Update, DOE/EIA-0562(96) (Washington, DC, December 1996), and Edison Electric Institute, Retail Wheeling and Restructuring Report, Vol. 3, No. 3 (December 1996). Because of the fluid nature of the restructuring debates going on in many States, any discussion of State plans will be outdated before it can be published. For online access to State-level regulatory activity, refer to the home page of the National Association of Regulatory Utility Commissioners (NARUC), web site www.erols.com/naruc/stateweb.htm.
} 


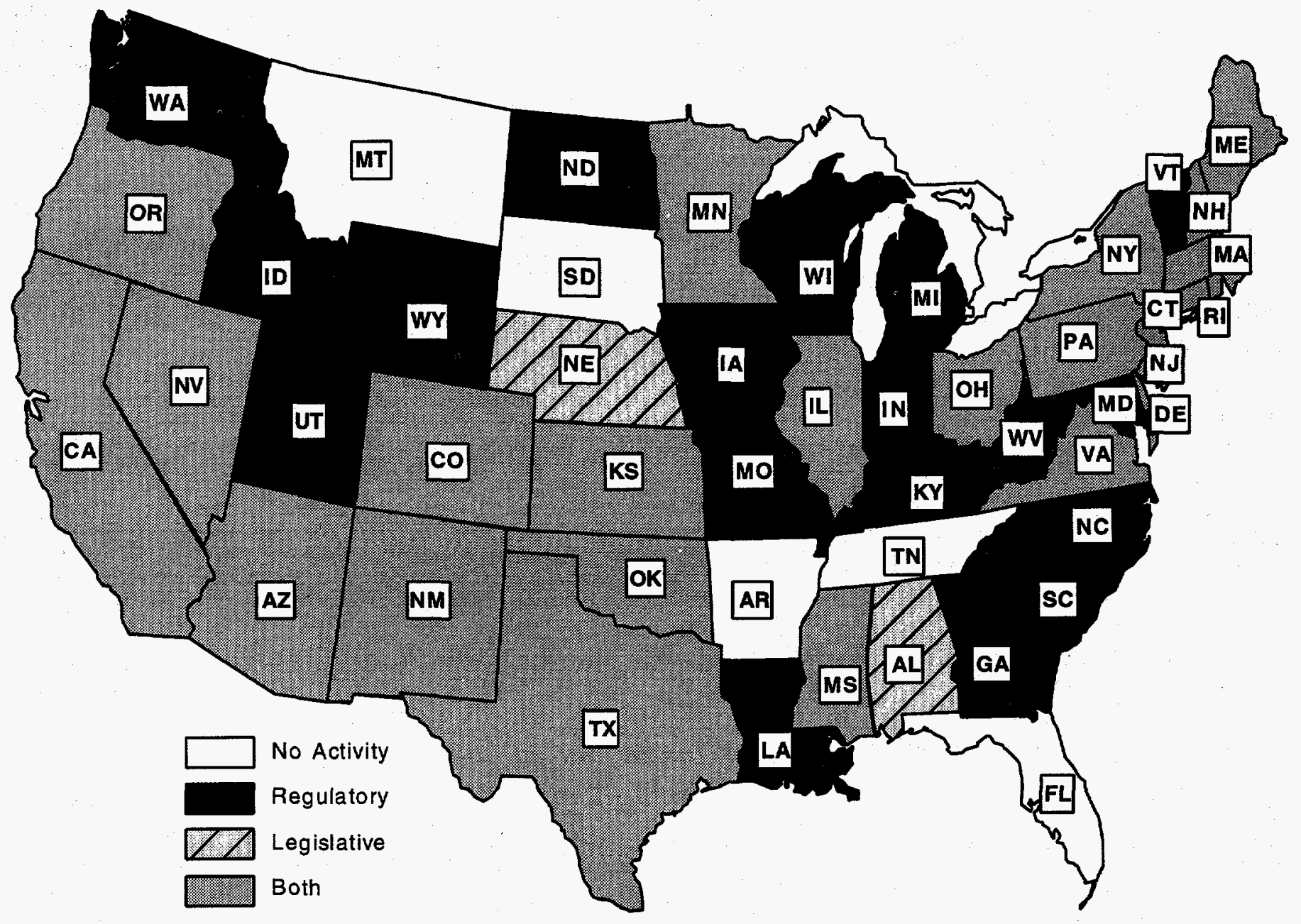

Source: Energy Information Administration, The Changing Structure of the Electric Power Industry: An Update, DOE/EIA-0562(96) (Washington, DC, December 1996).

and distribution services. As in California, Massachusetts utilities will recover their nonmitigable stranded costs through a nonbypassable charge (referred to in Massachusetts as a "stranded cost access charge") over a 10-year period; however, the regulators in Massachusetts have made it clear that they do not believe utilities have a legal right to recover stranded costs, and that the utilities must take all reasonable actions to mitigate their stranded costs before they will be granted recovery. Transmission services are to be priced as called for in FERC Order 888. The PUC anticipates a regional network tariff with adjustments among zones to reflect physical transmission constraints.

Like California, Massachusetts plans to price distribution services using a PBR approach. In terms of market structure, utilities are encouraged to divest their generation assets, but it is not required. The PUC argues that divestiture will allow the market to determine the value of a utility's generation assets and, thus, will give the clearest indication of stranded costs. As in California, the transmission and dispatch functions will be performed by an ISO and a PX, although it is not clear whether the ISO and PX will be separate entities in Massachusetts.

The New Hampshire PUC issued its restructuring plan on February 28, 1997, calling for all customers to have retail choice by January 1, 1998 (it may be delayed to July 1, 1998). Utilities will be allowed to recover some of their stranded costs, but full recovery is unlikely because, as the plan points out, the primary goal of 
restructuring is to lower electricity rates. ${ }^{17}$ Transmission services are expected to be priced with a regional transmission tariff with adjustments for transmission constraints. Distribution services are to be priced through an incentive pricing approach such as PBR. New Hampshire also calls for the creation of an ISO and a PX. One interesting facet of the New Hampshire program is that a small retail pricing pilot project has already been started, to test how a retail choice model might work. In a harbinger of things to come for many consumers throughout the country, more than 30 electricity suppliers participating in the pilot program have begun soliciting potential customers.

Restructuring plans in New York, Pennsylvania, Rhode Island, Maine, and New Jersey are all similar to those described for California, Massachusetts, and New Hampshire. With the exception of Pennsylvania, all call for customers to have the right to choose among electricity suppliers by 1998. Pennsylvania plans to phase in full customer choice over the next 5 years (by 2001). Several of the restructuring plans include requirements for continued support of public benefits programs, such as low-income heating assistance, energy efficiency, environmental improvement, and renewable energy. Such programs, while they may be socially beneficial, could be reduced or eliminated in a fully competitive environment if they do not contribute to the profits of individual utilities.

What will it mean to the average consumer when these programs are in place in $\mathbf{1 9 9 8}$ or shortly thereafter? If the retail pilot programs in New Hampshire and other places are any indication, consumers will be solicited by a variety of entities offering to supply their electricity needs. The offers are likely to be more diverse than they are today-from flat rates for all time periods, to rates that vary by time of day and season, to a variety of other combinations. Customers will also face more complicated electricity bills, which may include separate charges for electricity purchases from one supplier and delivery, metering, and on-site service from others. While customer choice is expected to provide many benefits, it will require consumers to spend some time making decisions.

\section{International Developments}

Electric utility industries have already been restructured in a number of other countries-including Sweden,
Norway, Argentina, Chile, New Zealand, parts of Australia, and the United Kingdom (England and Wales)almost all of which have chosen to use mandatory power pools (see discussion in the following section). The marginal cost pricing model used for the analysis described in this report is largely based on the power pool and spot market currently operating in the United Kingdom.

The competitive electricity market in the United Kingdom consists of 3 large generating companies (plus a number of small independent power producers) that produce electricity, and 12 privately owned regional electricity companies that distribute the power to consumers. The transmission facilities are owned by National Grid, which operates a large power pool and runs a spot market. The spot market operates as follows: Each afternoon, the generators submit bids to supply a given amount of power at a given price for each 30 minutes of the next day. The bids are then used to dispatch the power. The marginal cost for the entire system for a given 30 minutes is essentially the bid price of the last unit dispatched. The spot price is the sum of the marginal cost and a reliability component, based on estimates of the probability of an outage and consumers' losses if an outage occurs. ${ }^{18}$ If the bid is accepted, the bidder receives the spot price.

The experience to date suggests that the splitting of generation and transmission does not adversely affect reliability. In fact, in the United Kingdom, independent power producers are constructing new power plants without long-term contracts. Additionally, at least in the United Kingdom, costs have also fallen. Total employment in Britain's three large generating companies has been reduced by more than 40 percent between 1990 and 1994. Because of increased incentives for electricity generators to bargain with equipment suppliers, the price of combined-cycle power plants has fallen by 30 percent. Finally, there have been substantial improvements in the operation of generating facilities, including a 30-percent increase in generation from nuclear power plants. ${ }^{19}$

On the other hand, although the costs of electricity generation have been lowered in the United Kingdom, the cost reductions have largely been retained by the generation companies in the form of higher profits rather than passed through to consumers in the form of lower prices. That is, the evidence to date suggests that

\footnotetext{
${ }^{17}$ Public Service of New Hampshire has brought suit against the State utility commission in Federal court over a disagreement concerning the level of stranded cost recovery in the commission's February 28 order. A mediation of the dispute has commenced.

${ }^{18}$ The method used to compute the reliability price adjustment in the model used for this analysis is similar to the method used in the United Kingdom. However, there is no assumption that this would be either an administratively determined adjustment or a phenomenon that would arise naturally in a competitive market. See Appendix A and the section "Capital Recovery, Reserve Margins, and Capacity Additions" in Chapter 3 for details.
}

${ }^{19}$ See A. Henney, A Study of the Privatization of the Electricity Supply Industry in England and Wales (London, UK: EEI Limited, 1994). 
competition in the United Kingdom has had only a limited effect on retail electricity prices. In the analysis described in this report, it is assumed that competitive prices will equal the incremental cost of producing the power, plus a small reliability component. This assumption presumes that the number of competing utilities will be sufficient to drive prices down to marginal costs. In the United Kingdom, the market participation of only three large utilities and a small number of independent power producers has not fostered a sufficient level of competition. The competitive price to consumers is much greater than the incremental cost of producing the electricity. This is an indication that market power exists. Consequently, it is not clear that allowing competition would always bring a sufficient number of players into the market to eliminate the market power of producers and allow consumers to benefit from lower electricity prices.

\section{The Transition to a Competitive Industry}

Before competition can replace regulation, institutions that support competition must be created by legislative action, regulatory action, or market forces. Such institutions will evolve over time and may differ in form from one State to another. In California, for example, the restructuring bill passed on September 1, 1996 (AB 1890 ) calls for a transition period to end by March 31, $2002 .^{20}$ The length of the transition period is important because it affects the manner in which stranded costs will be paid, and by whom. A longer transition period means that ratepayers will pay the uneconomic costs embedded in regulated prices. A shorter transition period means that shareholders and taxpayers will pay them (in the absence of mandated recovery of stranded costs).

Under fully competitive pricing, some shareholders will not recover their full investments in generating capacity or in contractual agreements for power purchases that are above market prices. Taxpayers will be affected because shareholders will pay lower taxes on reduced capital gains and dividend distributions, and affected utilities will pay less in income taxes if stranded costs reduce their taxable income. ${ }^{21}$ Therefore, the determination of who pays the uneconomic costs now included in regulated prices will depend on both the speed at which competition becomes a reality and the degree to which regulators and legislators mandate the recovery of stranded costs.

There are at least three elements in the structure of the electric power industry that will define the nature of competition and the institutions that are required to support it: (1) who maintains control of the networkan ISO or transmission-owning utilities (TOUs); (2) the types of transactions allowed-pool purchases only (where all wholesale transactions are through the power pool), bilateral trades only (where wholesale power purchases are consummated through two-party contractual agreements, without the market clearing function of the power pool), or either at the discretion of the trading parties; and (3) the level of competition-wholesale only or retail as well. Each of these three elements is discussed in the following sections, as background to an understanding of a competitive electric power industry. This report does not address the pricing implications of various industry structures.

\section{Control of the Network}

Market power, which is at the heart of the debate over ownership and control of the transmission network, has been identified by the FERC as a potential impediment to the development of an unencumbered competitive market for electricity. Market power exists when a producer or consumer is able to influence prices. The ability to influence prices may result from a small number of producers or consumers, a significantly high share of the market (on either the production or demand side), physical factors that influence transactions (such as the presence of transmission constraints that make some generators "must run" units), or control of access to a product's distribution channels (such as control of the transmission system so that some producers of electricity can get their product to market while access is denied to others). Table 1 illustrates how control of the network relates to the types of transactions that are allowed.

The question is whether TOUs should be allowed to maintain control over the access to electricity markets in their geographically defined territories through control of the transmission system, or whether control of the network should be turned over to an ISO in order to ensure fair competition and unbiased access to markets. These proposals are mutually exclusive, but it is possible that the industry may evolve through a system

\footnotetext{
${ }^{20} \mathrm{AB} 1890$ states that the transition period defines the period over which all stranded costs will be recovered and all legislatively mandated electricity rate reductions will be realized.

${ }^{21}$ Some analysts have argued that these tax implications could be overshadowed by the stimulatory effects of lower electricity prices, which could raise national income and, hence, tax revenues.
} 
Table 1. Most Frequently Discussed Forms for a Restructured U.S. Electric Power Industry

\begin{tabular}{|c|c|c|c|c|}
\hline \multirow[b]{3}{*}{ Descriptive Name } & \multicolumn{4}{|c|}{ Characteristics } \\
\hline & \multicolumn{2}{|c|}{ Control of the Network } & \multicolumn{2}{|c|}{ Physical Transactions Allowec } \\
\hline & $\begin{array}{c}\text { Transmission-Owning } \\
\text { UtIllties }\end{array}$ & $\begin{array}{c}\text { Independent } \\
\text { System Operator }\end{array}$ & Pool & $\begin{array}{l}\text { Bilateral } \\
\text { Trades }\end{array}$ \\
\hline Mandatory Power Pool & No & Yes & Yes & No \\
\hline Voluntary Power Pool & No & Yes & Yes & Yes \\
\hline Wheeling $\ldots \ldots \ldots \ldots$ & Yes & No & No & Yes \\
\hline
\end{tabular}

Source: Energy Information Administration, Office of Integrated Analysis and Forecasting.

in which utilities maintain control of the transmission network for a while, then control is assumed by an ISO.

If utilities maintain control of their own networks, then they must "wheel" power into or through their systems-that is, provide third-party access to the transmission system-if other generating companies are to have access to competitive markets. In a "wheeling" model of a restructured electric power industry, TOUs maintain control of the network and allow access to third-party generators for a fee. The alternative is a power pool model, in which a third party (the ISO) assumes control of the network.

\section{Types of Transactions Allowed}

Two types of transactions are generally used to describe the workings of a fully competitive electricity market: purchases through a pool and bilateral trades. A pool is simply a centralized marketplace that performs a market clearing function for buyers and sellers. Sellers of electric power make bids into the pool, which represent the amounts of energy that producers are willing to sell (subject to the terms of the bidding process) at specified prices. The system operator forecasts demand for the following day (or some other time period) and accepts bids that satisfy the projected demand at the lowest cost. During each period of the day (every half hour in the United Kingdom), electricity is priced on the basis of the most expensive generator in operation at the time (the marginal generator), according to the bids submitted in advance. In contrast, bilateral trades are negotiated without the benefit of a central marketplace: buyers and sellers negotiate the terms and conditions of trades, and deals are consummated with or without the support of the system operator.

It is possible to have both pool and bilateral transactions in a single market, called a "voluntary pool." On the other hand, a market in which physical power transfers must pass through the pool mechanism is called a "mandatory pool" (Table 1). It is still possible in a mandatory pool to have the financial transactions take place on a bilateral basis, but bilateral financial arrangements are not a consideration in system operations. Plants are still dispatched on the basis of bids, and after the fact there must be a reconciliation between system operations and the financial transactions entered into outside the pool.

\section{Wholesale or Retail Competition}

Another factor that influences competitive electricity prices is the extent of competition-that is, whether retail competition emerges nationally, or competition is constrained to the wholesale level only. With wholesale competition only, the ultimate consumer continues to purchase electricity from a regulated distribution company (the local electric company) with a franchise monopoly service territory and no competitors. The consumer may choose how much electricity to buy, may choose a higher or lower quality of service in terms of reliability or stricter technical specifications of the power received (less voltage fluctuation, for example), but may not choose the supplier. The local electric company may acquire electricity generation services or other services from competing suppliers, but the retail price of electricity bundles production and delivery costs together.

With retail competition, ultimate consumers may select the providers of generation and other services, they may purchase bundled electricity services from competitive marketers or aggregators, or they may be able to remain with the local electric company and purchase bundled services there just as they always have. The essential difference between wholesale competition and retail competition is who has the freedom to choose the supplier of generation services and other services associated with electricity production and delivery-the electric company or the ultimate consumer.

To examine the questions of electricity pricing in a competitive market and the effects of competition on 
producers and consumers, a series of hypothetical cases were examined in the Electricity Market Module (EMM) of EIA's National Energy Modeling System (NEMS). ${ }^{22}$
The following chapter discusses the general assumptions and methodology used in the analysis. Chapter 3 presents the results.

${ }^{22}$ The mathematical details of the cases and parameters are described in the appendices at the end of this report. 



\section{Pricing Electricity in a Competitive Environment}

\section{Background}

While many issues related to the structure and regulation of competitive electricity markets remain to be resolved, the trend toward increased competition is clear. As this trend continues, especially in the generation market, ${ }^{23}$ the relationship between the cost of producing electricity and the price charged for it will change fundamentally. Under the regulatory system used in the United States since the early 1900 s, electricity prices have generally been equal to "embedded costs"-the average costs of producing the electricity and getting it to the customer, including recovery of and a regulated return on investments in plant and other equipment. All the functions performed by local utilities to produce high-quality, reliable electric service (power production, transmission, distribution, voltage regulation, etc.) are sold as a package, and the bundled costs are divided by the quantity of sales to determine the average price per kilowatthour. Overall, power production (generation) accounts for about three-quarters of the total costs, while delivery (transmission and distribution) accounts for the rest (Figure 3). ${ }^{24}$
If fully competitive electricity markets develop, prices will not be set to average costs. Rather, the various services provided-operating reserves, voltage stabilization (quality control), etc.-will be available and priced separately. ${ }^{25}$ However, consumers will not have to purchase all of these services from separate suppliers. During most time periods in the spot market, the generation price of electricity will be set by the operating costs of the most expensive generating unit needed to meet demand, or what is referred to in economics as the "marginal cost" of production. In general, a supplier will not be willing to sell power below the market price of the most expensive facility operating at a given time, because consumers will be willing to pay the higher price. Similarly, consumers will be unwilling to pay more than the cost of the most expensive operating available generator, since other suppliers will be offering lower prices. With prices set to marginal costs, the market will clear: all suppliers willing to provide power and all consumers willing to purchase power at the market price will be doing so.

\section{Figure 3. 1995 Price of Electricity by Cost Category and Line of Business}
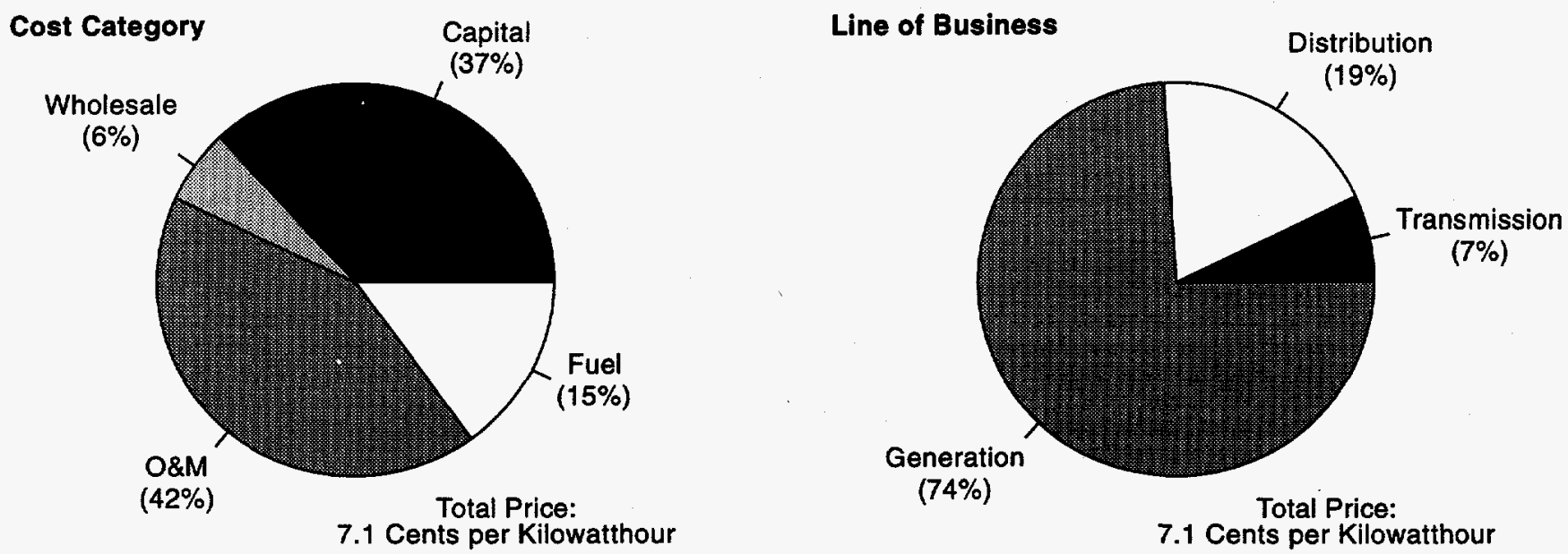

Source: Energy Information Administration, Annual Energy Outlook 1997, DOE/EIA-0383(97) (Washington, DC, December 1996).

\footnotetext{
${ }^{23}$ The discussion in this chapter generally refers to the generation sector of the electricity market.

${ }^{24}$ The system of accounts used by utilities does not explicitly identify costs by line of business. As a result, there is some uncertainty in the values shown here.

${ }^{25}$ This discussion describes a perfectly competitive market with many buyers and sellers who do not have market power. Such markets may take many years to develop.
} 
Only during periods of extremely high demand (peak demand), typically on very hot summer (or cold winter) days, when the demand for electricity approaches the available generating capacity, would prices rise above the operating costs (including fuel costs) of the most expensive generator operating. Because the amount of capacity available at any point in time is fixed, and new generating capacity cannot be built quickly, the only way in which demand and supply could be kept in balance during extremely high demand periods would be through an increase in the price, to a level that would encourage some consumers to reduce their usage.

The price adjustment during periods of peak demand can be thought of as representing the value consumers place on reliability. In this report, it is referred to as a "reliability adjustment." Over the course of a typical year, reliability adjustments are expected to be infrequent. If they became more frequent in the long run, the incentive for investors to support new generating projects would increase, and new capacity would be brought on line. ${ }^{26}$

Although many analysts expect electricity prices to fall as the generation market becomes more competitive, there are situations in which prices could be higher. Moving from regulated cost of service pricing to competitive pricing does not, in and of itself, guarantee that prices will fall for everyone. In general, if marginal costs are lower than the historical average embedded costs (or increased competitive pressures lead to falling production costs), as is the case in most parts of the U.S. market today, prices will fall with increased competition. For example, in many areas, the combination of low-cost new generating technologies and low fossil fuel prices has made power from new plants less expensive than power from some older plants or from older power supply contracts. On the other hand, the operating and capital-related costs for some existing power plants and utilities are very low, and, absent other cost savings induced by competition, their prices could rise in a competitive market. Thus, regions of the country that are largely dependent on older, low-cost plants may see higher end-use electricity prices when the prices are set by the marginal, rather than the average, cost of generation.

The movement from average embedded cost pricing in regulated markets to marginal cost pricing in competitive markets has a number of implications for both consumers and suppliers. Competitive prices are likely to be more volatile than historical average prices. Typically, the demand for electricity is highest during the summer months when air conditioning equipment is used the most, and on a typical summer day the demand for electricity is lowest in the late evening and early morning and highest in the late afternoon (Figure 4). As a result, different generators, from lowest cost to highest cost, are brought on line during the course of the day to meet demand.

With average cost pricing, most consumers are unaware of the variation in operating costs across seasons and times of day. With competitive pricing, consumers may see more price volatility in the form of time-of-use prices, which will vary with the cost of producing power. This may create confusion for consumers, but it will also offer them the opportunity to reduce their electricity bills by altering the timing of their electricity use. As discussed below, technologies are likely to develop to allow consumers to schedule their appliance usage to avoid high price periods.

\section{Figure 4. Hourly Load Curve for the South Atlantic Region}

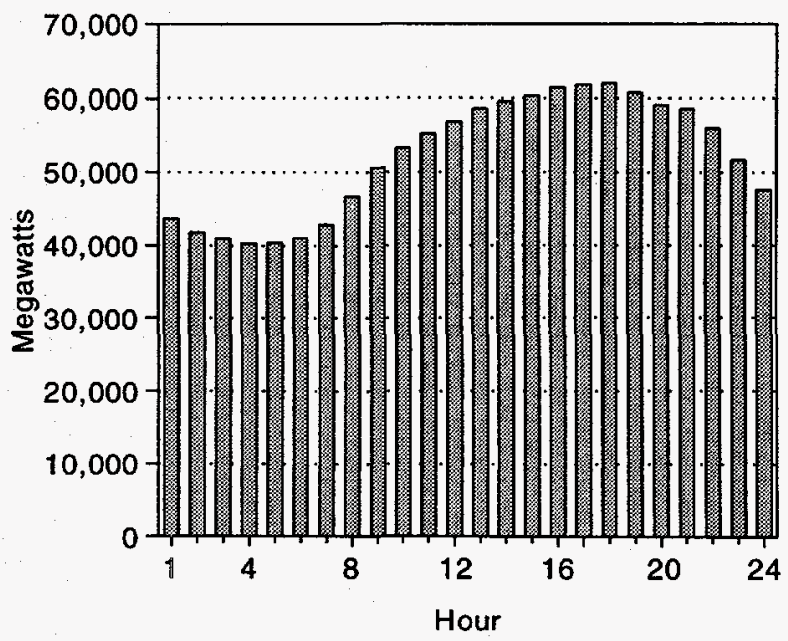

Source: North American Electric Reliability Council.

Another implication of the move to competition is a more customer-oriented market. Competitive pricing is likely to lead to the development of new product offerings from electricity producers and vendors of electricity-consuming equipment. In today's market, nearly all utilities operate under the same standards of reliability and offer similar services to their customers, although there is some product differentiation across customer classes and through the demand-side management programs offered by many utilities. In contrast, in recent experiments with competitive pricing of electricity services to retail customers in New Hampshire and

\footnotetext{
${ }^{26}$ Higher prices during peak load periods might also induce investments in demand-side management, which would allow consumers to reduce their consumption during high cost periods and/or shift it to lower cost periods.
} 
other States, consumers were offered a wide variety of service options.

The service packages offered to eligible consumers in New Hampshire's pilot project include various flat rate options, offers of free kilowatthours or cash incentives to consumers who switch to new suppliers, and offers to provide power only from green resources (no fossil fuel or nuclear). Some of the suppliers, such as Central Maine Power Company and Connecticut Light and Power, have familiar names. Others are new entries to the power supply business. All the companies will be striving to distinguish themselves from the pack with a wide variety of service offerings. Some are trying to develop brand loyalty by changing their company names to ones with more customer appeal, such as Energy One (Utilcorp) and Norstar (Orange and Rockland and Shell Oil). The new service packages offered by suppliers are likely to become the electricity equivalent of the widely advertised packages that have become familiar in the telephone business. As with the variation in prices, these programs are likely to create headaches for consumers, but they also create opportunities.

Consumer responses to price variations and new product offerings in competitive electricity markets are likely to vary, depending on such factors as the type of customer, the value placed on electricity-based services, the price and availability of alternative energy sources, and the availability of new technologies that will permit the levels and timing of electricity consumption to be altered with relative ease. For example, large, electricity-intensive industrial customers, who have a strong incentive to reduce their electricity expenditures, may be willing to alter work schedules to take advantage of lower electricity prices during periods of lower demand; residential customers may be willing to change home heating patterns to reduce consumption during high load hours while they are away from home; but commercial customers who rely on uninterrupted service during the prime business hours of the day may be unwilling or unable to change their consumption patterns to take advantage of price fluctuations unless storage or backup technologies become less expensive and more widely available.

In the long term, new technologies are likely to play a key role in determining the level of consumer response to changing prices. Faced with more volatile prices, equipment vendors will develop, and consumers will seek to purchase, equipment that allows for better control of electricity use. For example, intelligent electric meters, which monitor the electricity use of a household or business minute by minute, are already entering the marketplace. ${ }^{27}$ Combining this equipment with a real-time price signal and the ability to control key appliances or equipment may enable consumers to reduce electricity usage during high cost periods. Many residential customers participating in demand-side management programs are already familiar with the boxes connected to their water heaters and/or air conditioners that allow local utilities to shut them off during periods of high demand. Similarly, some commercial establishments have cool storage systems that make ice during low cost periods and then use it for space cooling when prices are higher. Such systems may become more prevalent where competitive electricity prices and time-of-use rates are implemented. Ultimately, their success will depend on weighing the costs associated with new meters, equipment control boxes, and telecommunication devices for transmitting price signals against the potential savings from lowering the amount of electricity consumed or shifting consumption to lower cost periods.

Consumer responses to marginal cost pricing could have a significant impact on capacity needs and planning. In competitive markets, productive capacity will be added when investors believe that it is profitable to do so. Investors will add new generating capacity when the price of electricity reaches a level that will allow them to recover their costs and provide the level of return they require. For the next few years, however, most regions in the United States are expected to have sufficient capacity to meet consumer needs for electricity. As a result, if competitive markets evolve quickly, there is likely to be intense competition among suppliers for customers, and the price of electricity will approach the short-run marginal cost of supplying it (the cost of operating the last plant used in each time period), assuming that no charges for recovery of stranded costs are added.

This situation could be extended if consumers respond strongly to time-of-use pricing by reducing their consumption during periods of high demand and high generating costs. Over time, as demand grows and output approaches full capacity, electricity prices are likely to increase. The potential for shortages or outages will grow, and prices will exceed short-run marginal costs to keep supply and demand in balance. Prices will increase until investors can profitably add new generating capacity. Thus, in the long run, the price of electricity from new capacity will set the end-use price of generation services.

${ }^{27}$ E Source, Inc., Real-Time Pricing And Electric Utility Industry Restructuring: Is The Future "Out of Control?" (Boulder, CO, 1995). 
Finally, from the supplier perspective, the movement to competitive marginal cost pricing will create intense pressure for cost cutting. In competitive markets, where generators will not make any profits during a specific period unless their production costs are below the costs of the marginal unit, power plant operators will continually make efforts to cut costs. The success of those efforts, combined with the consumers' response to them, will be key to the long-run impact of competitive pricing.

The dynamics of the interplay between supplier and consumer responses to competitive electricity pricing are difficult to predict. Chapter 3 presents cases that illustrate their importance in determining the competitive price of electricity in the long run.

\section{Modeling Competitive Electricity Pricing}

The methodology used in this analysis was designed to calculate the marginal cost of generation by season and time of day. The underlying assumption of the study is that, in the generation sector, competitive electricity prices will move toward marginal costs. In other words, power suppliers will have to price their electricity at marginal costs in order to be competitive. No assumption is made about the appropriate market mechanisms for making this happen. It is assumed that consumers will still pay their local utilities for power delivery to them, at rates based on cost of service. It is also assumed that all safety and environmental regulations are maintained. In the analysis described in Chapter 3, initial marginal electricity prices are calculated for every year from 1998 through 2015, the demand for electricity is adjusted to reflect consumer responses to the changing prices, and final prices are calculated. Some of the key assumptions in the analysis are described below.

\section{Key Assumptions}

Market Structure. As discussed in Chapter 1, many States are currently considering options to develop more competitive electricity markets. Various institutional structures and governance procedures are being debated. This study makes no assessment of the appropriateness of different possible market structures or operating procedures. It is assumed that effective competition among power suppliers will exist in the restructured market (no individual company will be able to exert market power and manipulate the price of electricity), and that consumers will be presented with, and able to respond to, electricity prices that vary by time of use. In reality, the complex network structure of the electricity market may make this difficult to achieve, and the results discussed in the following chapter should be viewed as somewhat idealized. Similarly, the results presented for the Annual Energy Outlook 1997 (AEO97) Reference Case are also somewhat idealized, assuming perfect regulation-i.e., capacity beyond what is already on line is built only when needed, the most economical capacity is always built, and demand and price expectations are close to what actually occurs.

Transmission and Distribution System Pricing. It is assumed that the transmission and distribution sectors of the electricity business will continue under cost of service regulation, and that there will be no degradation of distribution or transmission service reliability due to competition. Most proposals under discussion in the States call for continued cost of service regulation of transmission and distribution services, and no cost improvements in these sectors are represented. It is also assumed that no transmission congestion will occur within regions. ${ }^{28}$ The cost of expanding transmission capacity is treated as a function of sales growth.

Electricity trade among regions is competed on a marginal cost basis and limited by the transmission capacity. In other words, plants are first used to meet the load in their own region. If excess capacity is still available, it can be used to serve a neighboring region's load, provided it is cheaper than that region's capacity, and that transmission capacity is available. To the degree that transmission congestion does occur, competitive prices could be higher. While this might not lead to large changes in the region-wide prices reported in Chapter 3 , there could be large price differences between neighboring areas within regions where significant transmission congestion occurs.

Pricing of Ancillary Services. In today's market, in the course of generating electricity and delivering it to customers, utilities constantly perform certain functions to ensure the reliability of the transmission system. These functions, referred to as "ancillary services," are not priced separately. In a more competitive market, the same services may be priced separately and available from several suppliers. As defined by the Federal Energy Regulatory Commission (FERC), "ancillary services are those services necessary to support the transmission of energy from resources to loads while maintaining

\footnotetext{
${ }^{28}$ Congestion occurs when lower cost power is available in one area but cannot be delivered to another because of limits on transmission capacity.
} 
reliable operation of the Transmission Provider's transmission system in accordance with Good Utility Practice. ${ }^{\prime 29}$ The FERC has identified six distinct services normally included in the electricity service provided to consumers. They include reactive power, load following, loss compensation, energy imbalance, scheduling and dispatch services, and system protection (operating reserves).

- Reactive power support essentially involves maintaining the stability of the transmission system. It can be provided by various devices in a typical electric system, including generators, capacitors, and reactors. However, when averaged across all sales, the costs of reactive power services tend to be quite small at a national or large regional level. Because an aggregate regional representation of system operations is used in this analysis, reactive power support is not explicitly priced.

- Load following, system protection, loss compensation, energy imbalance, and scheduling and dispatch services essentially involve ensuring that, at all times, the amount of electricity put into the transmission system matches the amount taken out. For example, load following refers to matching the output of all the system's generators with the varying demand placed on it by customers. Each time a customer turns on a light, copy machine, or motor, a generator must increase its output to match the increase in demand. Similarly, generators must compensate for losses that occur within the system (loss compensation). If system losses are 2 percent and 100 megawatthours of demand is introduced by a new customer, generators must increase their output by 102 megawatthours to meet the load and compensate for the system losses.

In this analysis these services are not represented explicitly, but they are implicitly included in the methodology used to represent planning, dispatching, and costing. Plants are dispatched to meet the demand for electricity, adjusted for average regional transmission losses. While there is no explicit representation of power contracts, any energy imbalances that might result from unfulfilled power transfer contracts (the supplier does not produce the amount of power called for in the contract or, conversely, the consumer does not take the contracted amount) are implicitly priced at the marginal cost of power. In other words, it is assumed that the spot market price of electricity would be charged for these services.

Load following is represented by restricting the operation of low-cost units to reflect the need for them to follow load. Because low-cost large steam plants (mainly coal-fired plants) cannot be quickly started and stopped without incurring significant costs, utilities generally reduce the output of some of these units during low demand periods rather than shutting some of them down. In the analysis, the output of such units is reduced during relatively low load hours.

- The appropriate level of system protection (operating reserves) is addressed implicitly in the determination of the optimal reserve margin and reliability price adjustment discussed below.

Reserve Margin. The optimal amount of capacity to be built is determined as a function of the assumed value that consumers place on reliable electricity service, the cost of capacity (assumed to be the cost of a simple combustion turbine), the demand profile in each region, and the mix of capacity in each region. While this may seem overly complicated, competitive markets perform this kind of function all the time. For example, as the demand for a normal product with increasing per-unit production costs rises, the price of that product also rises. The degree to which the price rises is a function of consumer demand and what consumers are willing to pay for the product (referred to here as the consumer demand profile and value of reliable service), the costs of bringing on new productive capacity, and the operating costs and availability of existing productive capability (the mix of capacity). New manufacturing facilities are built when prices are sufficient to make them profitable.

Implicitly, utilities have done this for many years. The standard measure of reliability on which systems have been designed is to provide enough generating capacity so that only one day of capacity shortage results every 10 years. The implementation of this standard means that the cheapest capacity (in terms of capital costs) in service-typically, a combustion turbine plant that requires an annual fixed carrying cost (not including the costs of operation) of about $\$ 36$ per kilowatt-is used 8 to 10 hours per year. In other words, utilities have assumed that consumers are willing to pay up to $\$ 3.60$ per kilowatthour $(\$ 36 / 10)$ to avoid an outage. In this analysis, the optimal reserve margin (percent of capacity needed above the expected maximum demand) in each region is set at a level at which the value consumers are willing to pay to avoid an outage will just make it profitable to build a new simple combustion turbine. The capacity planning algorithm chooses the least costly type of capacity to build, from a total system perspective, thus ensuring that capacity is built only when prices are sufficient to make it profitable.

${ }^{29}$ TSIN.COM, “Glossary of Terms," web site www.tsin.com (no date given). 
Because the actual value consumers would be willing to pay is unknown, alternative reserve levels were also tested, as discussed in Chapter $3 .^{30}$

Unit Performance. It is reasonable to expect that increased competition among generators will lead suppliers to increase efforts to improve the performance of their units. For example, over the period 1984 to 1993, during which wholesale competition grew strongly, average availability rates for coal plants improved from 76 percent to 81 percent. ${ }^{31}$ The AEO97 Reference Case assumes that nonfuel operating costs will fall by 25 percent (approximately the difference between plants in the first quartile of operating costs and the average plant) between 1998 and 2005. While many analysts expect it, it is not possible to determine whether additional improvements will be brought about with increased competitive pressure. In this analysis, no further improvements are assumed in most cases; however, the "high efficiency" sensitivity case assumes that nonfuel operating costs will fall by 40 percent, and that the construction costs for new plants will fall by 15 percent.

Recovery of Stranded Costs. As the electricity market becomes more competitive, electricity prices are generally expected to fall. If prices fall below regulated prices, utilities may not be able to recover all the costs they have incurred in the past to serve their customers. The differential costs (including capital recovery on previous investments) will become "stranded." For example, for a particular plant, if the price of electricity falls to 3.5 cents per kilowatthour and the regulated cost of service from the plant is 4.0 cents per kilowatthour (including regulated capital investment recovery), the 0.5 -cent difference will be stranded. While this is expected to be the situation faced by many plants and the utilities owning them, there will be both losers and winners. For some plants, the competitive price of electricity will be higher than the regulated cost of service, and the revenue they generate will be higher with competitive prices than it was with regulated cost of service prices.

The stranded costs associated with particular assets or contract liabilities are not calculated in this analysis. However, net stranded costs-the summation of the positive and negative impacts on winners and losersare calculated for each region by subtracting the calculated competitive price from the regulated production costs. (Chapter 3 provides the implied level of net stranded costs.) The analysis simply calculates the competitive price of electricity and discusses the implied level of stranded costs. The level of stranded costs recovered will be set by State and Federal regulators. The competitive price projections shown in Chapter 3 do not include stranded cost recovery. A simplifying assumption was made that Federal income taxes would be the same with or without stranded cost recovery. In reality, Federal income taxes would be expected to be lower without stranded cost recovery and the implications of this are discussed in Chapter 4 . To the degree that States do permit their utilities to recover stranded costs, it is assumed that they will be recovered through the use of a connection or exit fee, rather than a perkilowatthour charge. This assumption is important, because if stranded costs were collected as a perkilowatthour fee, consumer responses to time-of-use rates and price offers from different suppliers could be significantly distorted. A per-kilowatthour stranded cost fee might reduce consumer incentives to avoid using energy during high price periods.

Timing of Restructuring. For the sake of simplicity, it is assumed in this analysis that electricity markets in the United States will become fully competitive as of January 1, 1998. This assumption has significant impacts, especially on the calculation of prices and stranded costs in the near term. As mentioned above, if competitive prices prove to be lower than regulated prices, utilities will incur stranded costs; however, the level of stranded costs utilities will face will be heavily influenced by the timing of market restructuring. The longer regulated cost of service prices persist, the smaller will be the stranded costs for utilities. Under regulated prices, a utility recovers a portion of its fixed costs each year; thus, if more years of recovery are allowed, the potential for stranded costs faced by utility shareholders will be reduced. (In reality, the level of uneconomic costs does not change with the timing of restructuring. What changes is who pays them. The longer regulated prices persist, the more likely it is that utility ratepayers rather than utility stockholders and taxpayers will incur the costs, and that utilities will not be burdened with them.)

Treatment of Operations and Maintenance Costs. The costs of producing electricity from a power plant are referred to as operations and maintenance (O\&M) costs. The largest of these costs for most fossil plants are fuel costs. Other O\&M costs include labor costs, rents, and

\footnotetext{
${ }^{30}$ See Appendix $\mathrm{C}$ for a mathematical description of the determination of the optimal reserve margin. See also Energy Information Administration, Performance Issues for a Changing Electric Power Industry, DOE/EIA-0586 (Washington, DC, January 1995), Appendix B.

${ }^{31}$ Federal Energy Regulatory Commission, Promoting Wholesale Competition Through Open Access Non-Discriminatory Transmission Services by Public Utilities, RM95-8-000, and Recovery of Stranded Costs by Public Utilities and Transmitting Utilities, RM94-7-001, Final Environmental Impact Statement (Washington, DC, April 1996).
} 
the costs of consumables such as limestone and water. Some of these costs-the costs of fuel and consumables-vary directly with the level of production of the plant from hour to hour. The other costs do not vary with production in the short run, but they are variable over the course of a year.

In a competitive market, a power plant operator will not run its plant unless the price it can get for electricity is at least equal to the plant's short-run variable costs. If it did so it would be losing money on every unit of electricity it sold. Over the longer run, the other costs would also have to be recovered, or it would not pay to keep the plant running from year to year.

Unfortunately, the delineation between which costs are variable in the short run versus the longer run is unclear. There is a large group of costs in the standard utility accounting system whose classification is not clear. For example, in 1995, investor-owned utilities reported total power production O\&M expenditures of $\$ 46.4$ billion (purchased power and all transmission and distribution O\&M expenses are excluded here). Of this total, $\$ 29.1$ billion was for fuel, which is clearly a variable cost, and the remainder was for what is referred to as "nonfuel O\&M." Among the items included in the $\$ 17.3$ billion of nonfuel O\&M costs are boiler plant maintenance, electric plant maintenance, and supervision and engineering expenses. Investor-owned utilities also reported spending $\$ 13.0$ billion for general and administrative (G\&A) expenses in 1995, which cannot easily be allocated to specific functions. ${ }^{32}$

The treatment of this $\$ 30.3$ billion in costs (nonfuel O\&M plus G\&A expenses)-approximately 15 percent of total utility revenue-in a competitive market is unclear. It is likely that some of the costs are a function of hour-to-hour power plant output and will be included by plant operators in their bids to supply power. On the other hand, it is also likely that a significant portion will not find its way into competitive prices, and that utilities will be under great pressure to reduce that portion of the costs.

In this analysis, it is assumed that 50 percent of total nonfuel O\&M costs should be treated as variable and the rest should be treated as overhead costs. To test the sensitivity of the results to this assumption, two special cases are discussed in Chapter 3 . The first case continues to assume that 50 percent of total nonfuel O\&M costs should be treated as variable, but it is assumed that the half formerly treated as overhead is not recovered. The second case assumes that power plant nonfuel $O \& M$ costs and 50 percent of administrative overhead costs are not included in competitive prices.

In effect, the results in Chapter 3 show the impacts on prices and stranded assets of treating these costs as (1) fully variable in the short run, (2) variable to the extent currently reported by investor-owned utilities, and (3) fully fixed. Although the last case is clearly not sustainable in the long term (because of unrecovered costs), the results show the magnitude of the effort that would be needed by the industry to reduce fixed costs in an intensely competitive environment.

Cost of Capital. The movement toward more competitive pricing of electricity may change the level of risk involved in developing new power plants. Some analysts have suggested that competition could increase the level of business risk to suppliers of generation services and, therefore, raise their cost of capital. ${ }^{33}$ Others have argued that a reduction in regulatory risk would, at least partially, offset the increase in business risk. ${ }^{34}$ If the cost of capital does rise, it is likely that less expensive plants with high operating expenses will be favored for new capacity additions over more expensive plants with lower operating costs; however, the magnitude of such a change is very uncertain. For this analysis, the cost of capital was assumed to be the same under competition as under regulation.

\section{Calculating Competitive Electricity Prices}

For every year from 1998 through 2015, and for each electricity supply region (see Figure ES1 in the Executive Summary), the following steps were performed to calculate competitive electricity prices: ${ }^{35}$ (1) starting with reference case demands, calculate the marginal operating cost for each time period; (2) raise the price in periods when the demand for electricity approaches the available capacity, to reflect the increased likelihood of an outage (the value of reliability); (3) add in the average costs of transmission and distribution services; (4) adjust the demand in each time period to reflect consumer response to the change from the former

\footnotetext{
${ }^{32}$ Energy Information Administration, Financial Statistics of Major U.S. Investor-Owned Electric Utilities 1995, DOE/EIA-0437(95)/1 (Washington, DC, December 1996).

${ }^{33}$ The cost of capital refers to the cost of borrowing funds from bondholders and the compensation to shareholders that is required to procure investments in the equities markets (common stock). Failure to compensate bondholders adequately could result in bankruptcy. Failure to compensate common shareholders adequately could make it difficult to raise funds in the future.

${ }^{34}$ Regulatory risk is the risk that regulators will disallow certain costs. In other words, under regulated pricing, suppliers may not be allowed to include some of their costs in prices if regulators believe that the costs were imprudently incurred.

${ }^{35}$ For a mathematical description of the calculation of competitive electricity prices see Appendix A.
} 
regulated price to the competitive price; (5) repeat steps 1 through 4 until the change in demand from the previous iteration is less than a tolerance level of 1 percent.

To perform the calculations above, the demand for electricity was broken into 108 slices of time within each region ( 6 seasons, 3 day types, 3 times of day, and 2 slices per period). In each time slice, power plants were dispatched from lowest cost to highest cost to meet consumer requirements for electricity. The marginal operating costs during each time period were equated to the operating costs of the last plant dispatched-predominantly fuel costs, but also including the nonfuel operations and maintenance costs associated with the last plant dispatched in each time period. $^{36}$

In periods of ample supply (when generating capacity far exceeds consumer demand for electricity), the generation price was set to the marginal operating cost described above, assuming that suppliers would not be able to charge more because consumers would be able to shop around and find a better price. In contrast, when the demand for electricity approaches the capacity of suppliers to produce it, the risk of a system outage grows (reliability falls). Since electricity cannot be economically stored (inventoried for later sale) and new electricity generating capacity cannot be brought on quickly, situations like this must be dealt with by reducing demand.

In today's environment, utilities deal with such a situation in a variety of ways, including calling on customers who are on interruptible rate schedules to reduce their demand, slightly reducing the voltage on the system (rolling brownouts), broadcasting requests by radio or television for consumers to curtail their usage, and instituting rolling blackouts (turning off small areas selectively to reduce demand). In a competitive market, suppliers would deal with the same problem by raising the price to a point at which the number of consumers choosing to reduce their usage would eliminate the excess demand-what is referred to in this report as a "reliability price adjustment." (One only has to think about trying to buy roses on Valentine's day or the most popular new toy at Christmas time to understand how this works.)

In the analysis, reliability adjustments to prices were determined by calculating the change in demand that would not be met if a single kilowatt of capacity went out of service ${ }^{37}$ in each time period and multiplying it by an assumed value of unserved energy. ${ }^{38,39}$ As discussed in Chapter 3, during most time periods the adjustment is expected to be zero. Only during a few hours on very hot summer days (or on very cold winter days in areas of the country where demand for electric heating is high) is the competitive price expected to be affected by a reliability adjustment.

When consumers face variations in electricity prices across seasons and times of day, they are expected to respond by reducing their demand in high cost periods and increasing it in low cost periods. It is possible that many consumers will choose to continue purchasing power at flat prices. On the other hand, distribution companies (which will see the variation in prices in the wholesale power market) may offer incentives to customers willing to reduce or curtail their demand for electricity during high cost periods.

To represent this interaction in the analysis, an assumed level of consumer response, or elasticity, ${ }^{40}$ was applied to the change from regulated to competitive prices in each time period. In reality, different customer classes are not expected to react to the same degree: large industrial customers with high electricity expenditures are generally expected to be more responsive than residential customers with low electricity expenditures. However, because time-of-use prices have not been seen extensively in the past, there is little basis for determining an expected level of response. Consequently, alternative elasticities were used in the analysis to represent the impacts of different levels of responsiveness for all customers as a whole. An extension of this analysis would incorporate different elasticities by class of customer.

\footnotetext{
${ }^{36}$ These are normally referred to as variable operations and maintenance (O\&M) expenses. They are O\&M expenses that vary with plant output.

${ }^{37}$ In addition to capacity already out of service for planned maintenance and unexpected outages.

${ }^{38}$ In F.C. Schweppe, M.C. Caramanis, R.D. Tabors, and R.E. Bohn, Spot Pricing of Electricity (Boston, MA: Kluwer Academic Publishers, 1988), this is discussed in Chapter 6 and referred to as the "quality of supply component." There is no assumption that this would be either an administratively determined adjustment or a phenomenon that would arise naturally in a competitive market. See Appendix A and the section "Capital Recovery, Reserve Margins, and Capacity Additions" in Chapter 3 for details.

${ }^{39}$ As used here, the value of unserved energy represents the amount consumers would be willing to pay for each kilowatthour during high demand periods to avoid an outage. Because there is very little quantitative information on what this value should be, Chapter 3 presents cases varying the value of unserved energy.

${ }^{40} \mathrm{An}$ elasticity is calculated as the ratio of the percentage change in quantity demanded to a given percentage change in price. An elasticity of -0.1 would imply that a 10 -percent increase in price would lead to a 1-percent decline in quantity demanded.
} 
After demand was adjusted to reflect consumer response to price changes, the process of determining marginal costs, reliability adjustments, and prices was repeated until the change in demand became insignificant. As consumer demand changed in each time slice, the marginal operating costs changed in response to the change in demand. In competitive electricity markets, if consumers successfully reduce their need for electricity during the highest cost periods, the reliability adjustment will decline significantly.
The following chapter presents results from the analysis. A number of modeling cases are described, based on different assumptions about utility operating costs and pricing mechanisms, consumer responses to changing prices and the reliability of electricity supplies in competitive markets, and other factors that are expected to have defining roles in the future of the deregulated industry. Results are presented for national and regional projections of generating costs, electricity prices, and utility stranded costs and assets. 



\section{Competitive Electricity Price Projections}

\section{Description of the Problem and the Analysis}

Legislators and regulators have initiated a restructuring of the U.S. electric power industry because they believe that greater competition will result in lower prices and greater efficiency. This chapter presents an analysis of the extent to which prices for generation services in a competitive environment may differ from regulated electricity prices.

As described in Chapter 2, the regulated price of electricity is equal to the average cost of producing it. In theory and in practice, when prices are set under cost-of-service regulation, most producers of electric power receive a total amount of revenue just equal to their total average costs. In a regulated environment, all the costs of production, including the recovery of capital investments and a return on those investments, are summed and divided by sales to determine the average price of electricity. The cost elements included in the regulated price of electricity-the "average costs"-are shown in Figure 5. Those elements include operations and maintenance (O\&M) costs, general and administrative (G\&A) costs (the administrative costs associated with payroll and other overhead costs), taxes, capital recovery (represented by an annual depreciation expense), and an allowed profit (represented by a return on ratebase). ${ }^{41}$
Also described in Chapter 2 is the way in which competitive markets may set prices, using the marginal costs of production and the relationship between supply and demand. The elements of competitive prices, as calculated here, are also shown in Figure 5. Instead of the average O\&M costs, capital recovery, and profit that are included in regulated prices, competitive prices are calculated from the marginal O\&M costs, plus a premium above marginal costs during periods when demand approaches the limits of supply. The premium, or "reliability price adjustment," is based on the market value of reliability (a varying input assumption that represents outage costs to consumers) and the marginal reliability of the system (the increase in reliability that results from an increase in capacity). ${ }^{42}$ The marginal operating costs (including maintenance costs and G\&A $\operatorname{costs}^{43}$ ), taxes, ${ }^{44}$ and the reliability price adjustment simulate what competitive generators would receive in prices regardless of the industry structure or the level of competition (retail versus wholesale) that may eventually emerge (see Chapter 1, "The Transition to a Competitive Industry").

In this analysis, all fossil fuel maintenance costs are treated as variable, in the sense that they would be avoidable if the unit did not operate at all in a given year. However, based upon existing Nuclear Regulatory Commission (NRC) practices, any unit that has an operating (as opposed to a "possession only") license must

\footnotetext{
${ }^{41}$ The annual depreciation expense is the return to shareholders of the capital that they have invested. The return on ratebase is the compensation that shareholders and bondholders receive for the use of that capital. These are real costs to the firm that must be paid if the firm is to remain economically viable.

${ }^{42}$ The increase in reliability is estimated by the reduction in expected unserved energy that results from an incremental increase in generating capacity. In this analysis, expected unserved energy is an estimate of the energy demand that will not be supplied due to a shortage of generating capacity (see Appendix F).

${ }^{43}$ The costs that are included in competitive prices are the costs that are avoidable if the generating plant ceases operations. These costs are considered to be variable over the intermediate term. That is, avoidable costs vary with higher or lower levels of output. If these costs are not recoverable, then the plant will not run, and the owners can avoid incurring the costs. Fixed, or sunk, costs are not included in prices, because the plant will continue operating even if they are only partially recovered. The reason is that the owner would incur a larger cost if the plant were shut down, because none of these fixed costs would then be recovered. Therefore, avoidable costs, variable over the intermediate term, are included in prices, but fixed costs, unavoidable over the intermediate term, are not. Also, since G\&A costs, which are avoidable over the intermediate term, are not attributable to specific generating technologies, the average G\&A costs are allocated to all electricity sales in the competitive price.

${ }^{44}$ The prototype model used to calculate competitive prices does not contain the detailed cost data included in NEMS. Therefore, a direct calculation of Federal income taxes is not possible for inclusion in competitive prices. Federal income taxes are the same for the competitive cases as for the regulated cases (given identical demands). As is discussed in Chapter 4, the reduction in Federal income taxes that would occur because of the non-recovery of stranded costs is less than 0.2 cents per kilowatthour or about 2 to 3 percent of the competitive prices reported in this chapter.
} 
Figure 5. National Average Electricity Costs and Prices in the Reference Case and a Representative Competitive Case, 1998

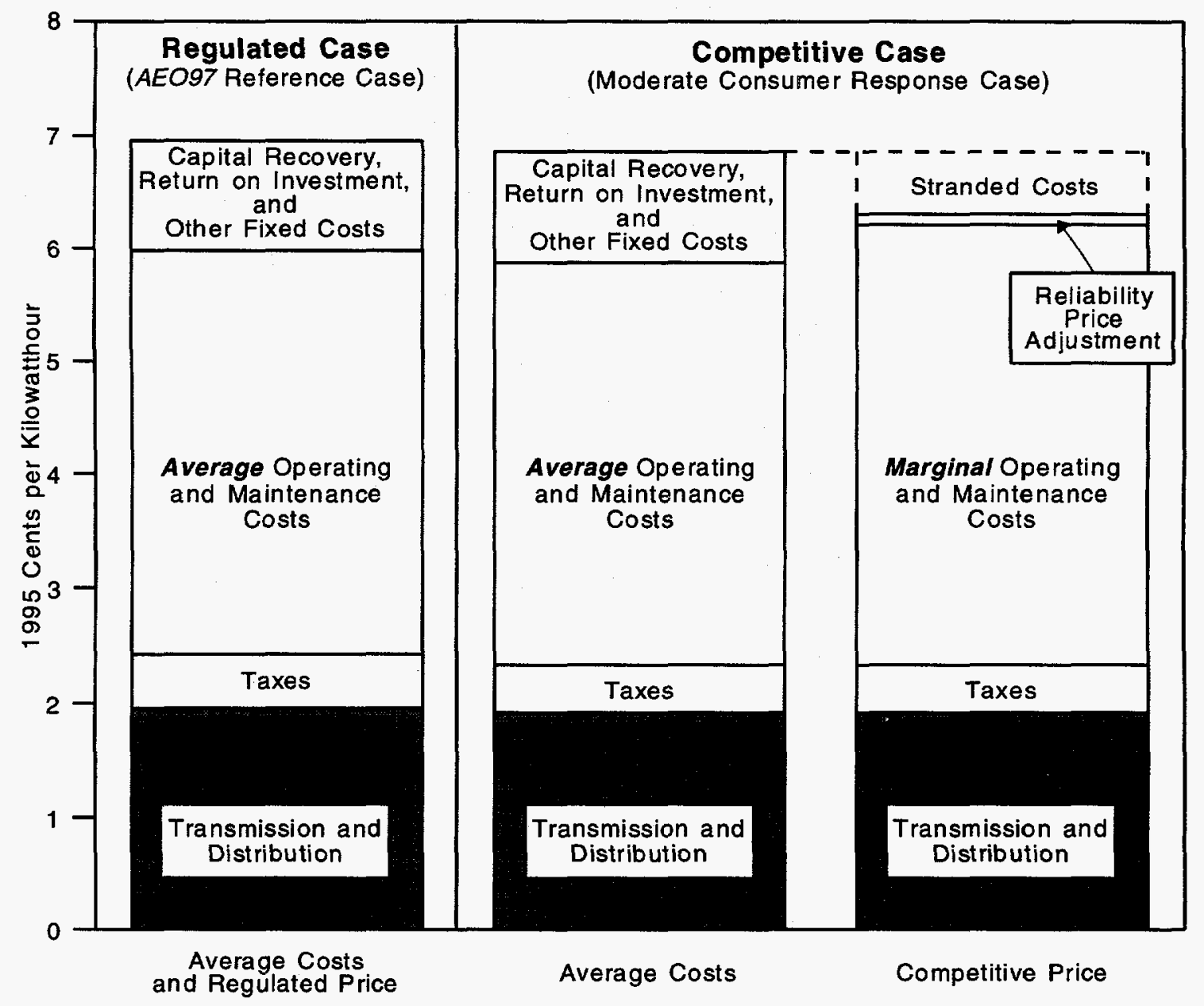

Notes: The estimated average costs of generation services are lower than the 1998 average price published in the Annual Energy Outlook 1997 for two reasons: (1) assumed short-run elasticities of demand in the competitive case reduce average costs relative to the AEO97 costs, and (2) taxes are based on revenues, which are lower under competition than under regulation. "Other fixed costs" include power purchase contracts and regulatory assets, such as deferred rate phase-in revenues.

Source: Energy Information Administration, Office of Integrated Analysis and Forecasting, National Energy Modeling System and Prototype Value of Capacity Model, run set E15V03.

comply with all the safety-related maintenance requirements in that license, regardless of whether the plant generates any power in a given year. Since most of the maintenance activities in a nuclear power plant are safety-related and must be carried out even if the plant does not operate for a given year, for the purposes of this analysis all nuclear maintenance costs are viewed as fixed. Therefore, even if there were occurrences of nuclear capacity being dispatched as the marginal plant-and, therefore the price-setting plant-maintenance costs would not be included in the calculation of marginal costs-and competitive prices-during that period. ${ }^{45}$ Similarly, this analysis assumes that competition has no effect on nuclear safety issues.

During the transition from regulated electricity markets to competition, competitive prices may not provide enough revenue for some producers to recover all the fixed costs that would have been recovered under regulated pricing. Uneconomic, or stranded, costs are fixed costs incurred under regulation that cannot be recovered in a competitive market. Stated another way,

\footnotetext{
${ }^{45}$ The results of this analysis indicate that competitive prices, as projected here, would be sufficient to cover the majority of maintenance costs for nuclear power plants in most cases.
} 
stranded costs are the difference between revenues under competition and the costs of providing service. They include the recovery of capital invested in highcost generating plants and contractual obligations such as power purchase contracts priced above the market value of electricity.

There are several reasons why uneconomic costs were incurred under regulation. First, imperfect projections of future demand caused utilities in some areas of the country to build more capacity than was actually needed. Second, the costs associated with some capacity additions, most notably nuclear capacity, increased during construction to levels far above initial estimates. Some of the construction cost overruns were from additional costs for safety upgrades required at nuclear units after the Three Mile Island incident. Overly optimistic expectations of future prices led some utilities to enter into power purchase contracts at prices above the current market value. Finally, all the previous causes of uneconomic costs have been exacerbated by recent improvements in generating technologies-particularly, natural-gas-fired combined-cycle plants-that give owners of new capacity a significant advantage in the costs of building and operating it.

Net stranded costs are calculated in this analysis as the difference between revenues under regulated prices (based on average costs) and revenues under competitive prices, with production costs, demand quantities, and consumption patterns assumed to be the same under both regulated and competitive prices. ${ }^{46}$ The National Energy Modeling System (NEMS) was used for the analysis. NEMS aggregates costs and revenues to 13 regions based on the North American Electric Reliability Council (NERC) regions (see Figure ES1 in the Executive Summary). Within any region, some of the stranded costs experienced by some power producers may be offset by gains on the part of other power producers whose average costs are below competitive prices. In reality, it is unlikely that companies with stranded costs under competition would be compensated by companies with revenue gains.

Figure 5 illustrates the level of net stranded costs on a per-kilowatthour basis that would be incurred in 1998 if prices were set competitively. While the net stranded costs shown here provide an estimate of the magnitude of the stranded cost problem and the effects that various assumptions may have on stranded costs in general, net stranded costs are not a good estimate of the compensation that would be required to provide full recovery of stranded costs for affected shareholders. In order to make that estimate, stranded costs must be determined at the corporate level of aggregation. That is, costs and revenues must be compared at the holding company level or, in the case of independent utilities, at the operating company level-far below the level of aggregation provided in this chapter.

As described in Chapter 4, a company-specific analysis of 146 privately owned utilities found that, in the near term, roughly 20 percent of the utilities would actually observe revenue increases. Additionally, the total reduction in revenue because of the competitive, marginal pricing of electricity would be approximately 20 percent greater if all the utilities with revenue increases were excluded from the calculations. Since the majority of the revenue decreases in the early years of the analysis was due to the nonrecovery of stranded costs, at least in the early years, gross stranded cost estimates could be about 20 percent greater than the net estimates nationally.

With competitive pricing, some of the costs that are unrecoverable (stranded) when generating capacity is in surplus become recoverable as the need for new capacity increases. As demand begins to approach the limits of generating capacity, prices increase, and consumers pay more for the same level of service. Higher prices allow for the recovery of some costs that would be stranded otherwise. The price forecasting algorithm used in this analysis captures this characteristic of competitive prices, which are calculated from marginal costs plus a premium-the reliability price adjustment-during high demand periods. The reliability adjustment increases as the need for new capacity becomes apparent through an increase in expected unserved energy.

It should be noted that regulatory action already has prevented some uneconomic costs from being included in regulated prices. Beginning in the mid-1980s, State regulators disallowed the recovery of costs associated with some large baseload power generating plants, generally nuclear power stations, because they ruled that the costs were imprudently incurred. The regulated price as calculated in this analysis includes the effect of those disallowances, reducing the level of uneconomic costs embedded in regulated prices, but the regulated price still includes costs that would be unrecoverable under competitive pricing. In other words, regulators have reduced uneconomic cost recovery in regulated prices, but they have not eliminated it.

Time-of-use rates and consumer responses to them, as described in Chapter 2, may have impacts on competitive prices, average costs, demands, and capacity

\footnotetext{
${ }^{46}$ One of the benefits of competition is that it may irnprove efficiencies and reduce costs. The estimates of net stranded costs would be lower if they incorporated competition-induced cost reductions.
} 
requirements. ${ }^{47}$ While it is not clear that all consumers will see time-of-use rates, it is possible that service contract prices and load management techniques may be employed to the same end-i.e., to curtail peak period consumption and increase off-peak consumption. Such programs could work in much the same way as some demand-side management programs now offered by utilities, in which consumers who agree to have electricity service for some appliances (air conditioners, for example) curtailed during peak demand periods pay a lower monthly rate for power. This chapter presents quantitative results from the analysis of the potential effects of time-of-use rates and consumer responses on competitive electricity prices, which are compared with prices under regulation.

Many advocates of electricity industry restructuring believe that reserve margins ${ }^{48}$ may be reduced under competition, resulting in significant cost reductions that may reduce prices. Opponents of restructuring argue that reduced reserve margins could compromise reliability. In this analysis, it is assumed that there is no degradation of service reliability. As discussed in Chapter 2, target reserve margins are calculated in this analysis as the point at which the marginal costs of generating capacity equal the marginal benefits of service reliability. ${ }^{49}$ In any year during which the projected actual reserve margin is lower than the target reserve margin, generating capacity is added until capacity reaches the target reserve margin.

The target reserve margin is used as a measure of the capacity additions that would be needed to maintain the balance between outage costs and capacity costs. ${ }^{50}$ This allows for an analysis of the effects of different assumptions about the consumers' value of reliability on prices, reserve margins, and stranded costs. Changes in demand patterns that result from consumer responsiveness to time-of-use electricity rates also affect reserve margins, because the demand shifts affect the producers' marginal generating costs and the consumers' cost of reliability. The effects of different assumptions about the level of consumer responsiveness on reserve margins are also discussed in this chapter.
The analysis described in the following section, "Average Costs, Marginal Costs, Time-of-Use Pricing, and Efficiency Improvements," includes quantitative comparisons of regulated and competitive electricity price projections under a range of different assumptions, as discussed above. A total of six analytical cases (i.e., sets of assumptions) are used to examine the effects of variations in the following factors:

- Efficiency improvements and cost reductions due to competitive pressures. The Annual Energy Outlook 1997 (AEO97) Reference Case, ${ }^{51}$ including EIA's estimate of future cost savings and efficiency improvements that will take place in response to limited competition, is compared to a No Competition (regulated) Case, representing constant costs, and a High Efficiency (competitive) Case, representing still higher future cost savings due to competitive pressures.

- Average-cost-based prices versus marginal-costbased prices. The AEO97 Reference Case, representing prices based on average costs, is compared to a Flat Rates (competitive) Case, representing prices based on marginal costs. ${ }^{52}$

- The extent to which consumer demand changes in response to changing prices (short-run elasticity of demand). The Flat Rates Case, representing no changes in patterns of consumption (there are small changes in total demands, but no changes in peak period demand compared to off-peak period demand), is compared with two competitive price cases with varying levels of consumer response to price variations, a Moderate Consumer Response Case (price elasticity of demand, -0.15 ) and a High Consumer Response Case (price elasticity of demand, -0.50 ).

The next section of the chapter, "Capital Recovery, Reserve Margins, and Capacity Additions," includes a description and analysis of capital recovery in a competitive electricity market. A special case- the No Capacity Additions Case-is used to illustrate the way in which competitive prices provide signals to investors that generating capacity is needed. This is a special case

\footnotetext{
${ }^{47}$ See Chapter 2 for a description of how consumers may respond to time-of-use electricity rates.

${ }^{48} \mathrm{~A}$ reserve margin, which is the percent of generating capacity needed above the expected maximum demand, serves as a safety margin to minimize the possibility of outages due to uncertainties about maximum demand and plant outages.

${ }^{49}$ Service reliability is estimated by expected unserved energy. See Appendix $C$ for the calculation of reserve margins.

${ }^{50}$ By equalizing capacity costs (borne by suppliers) and outage costs (borne by consumers), total system costs, including the costs of capacity and the costs of outages, are minimized.

${ }^{51}$ Energy Information Administration, Annual Energy Outlook 1997, DOE/EIA-0383(97) (Washington, DC, December 1996).

${ }^{52}$ In the Flat Rates Case, marginal costs and the reliability price adjustments are averaged over the course of the year, so that consumers see a single price per kilowatthour during all time periods of the year. In other words, the Flat Rates Case could also be called the "No Time-of-Use Rates" Case. The effects of marginal cost prices that vary with changes in seasonal and daily demand are examined in later cases.
} 
because it includes the unrealistic assumption that no generating capacity will be built in the future, in order to allow a comparison of the effects of capacity shortages on regulated and competitive prices. In addition, a High Value of Reliability Case illustrates the effects of greater willingness by consumers to pay premiums for reliability of electricity service.

In the next section, "Uncertainty Regarding Marginal Costs," two cases-a High Gas Price Case and a Low Gas Price Case-are used to illustrate the sensitivity of competitive prices to changes in marginal costs, and how this sensitivity may affect the ability of producers to recover their fixed costs. Possible variations in the composition of marginal costs and their inclusion in competitive prices are also examined, in the Half O\&M Case and the Intense Competition Case.

Finally, the "Regional Prices and Stranded Costs" section compares average costs and prices on a regional level in the Moderate Consumer Response Case and the High Efficiency Case, and presents a range of estimates of regional net stranded costs based on the two cases.

Table 2 shows the cases examined in the analysis and the assumptions used for each of the above factors in the various cases. Within each of the cases, both competitive prices and average costs were calculated.

\section{Average Costs, Marginal Costs, Time-of-Use Pricing, and Efficiency Improvements}

\section{Average Costs}

In this analysis, the term "average costs" is used to describe the total unit costs (i.e., costs per kilowatthour) associated with the generation and delivery of electric

Table 2. Key Parameters in the Cases

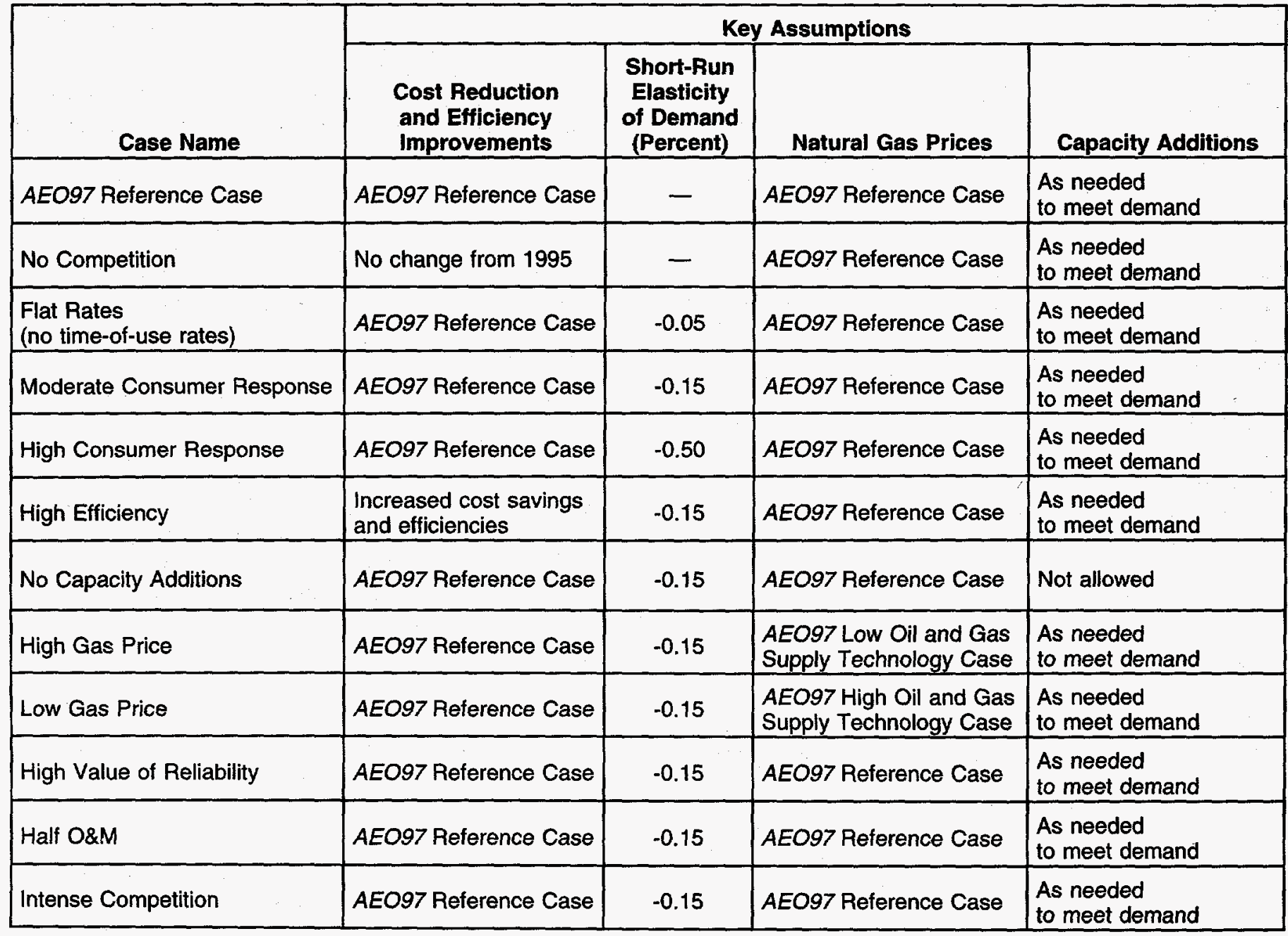

- = not applicable.

Source: Energy Information Administration, Office of Integrated Analysis and Forecasting. 
power. All the costs of producing power, including the recovery of capital investments in power generating plants, and all the costs of delivering power, including the recovery of investments in transmission and distribution equipment, are summed and divided by sales to ultimate consumers to determine average costs. Under regulation, the delivered price of electric power equals average costs as determined by a regulatory authority. In the competitive environment, however, aggregate demand, demand patterns (the relationship between peak and off-peak periods), and available generating capacity may change. As a result, in order to compare average and marginal costs in this analysis, average costs are recalculated under the new competitive conditions in the various competitive cases. ${ }^{53}$

The AEO97 Reference Case represents the continuation of cost-of-service regulation with limited competition. The underlying assumptions that drive the AEO97 Reference Case are that current laws and regulations and the historical cost trends of electricity production and delivery will continue. Thus, the AEO97 price forecast is calculated from average costs, including generating costs and purchased power contracts (the primary sources of stranded costs).

There is evidence that current levels of competition, although limited, and the expectation of more competition in the future are already having an effect on some of the costs of providing electricity service. Historical data indicate that both employment levels and nonfuel O\&M costs dropped between 1990 and 1994 (Figure 6). Therefore, in the AEO97 Reference Case, it was assumed that nonfuel O\&M and G\&A costs would fall by 25 percent between 1997 and 2005. This translates to combined reductions in O\&M and G\&A costs of about 0.4 cent per kilowatthour (just under 6 percent of the national average cost of producing and delivering electricity) by 2005 , which in turn result in a reduction of 0.4 cent per kilowatthour in the retail price of electricity. Figure 7 shows the cost reductions attributable to competitive pressure in the AEO97 Reference Case, by comparing the projected prices under regulation in the AEO97 Reference Case with those in a No Competition Case.

\section{Marginal Costs}

In many regions of the United States, competitive prices based on marginal generating costs could be lower today than regulated prices, given the same production

\section{Figure 6. Recent Reductions in Employment and Costs for Investor-Owned Electric Utilities}

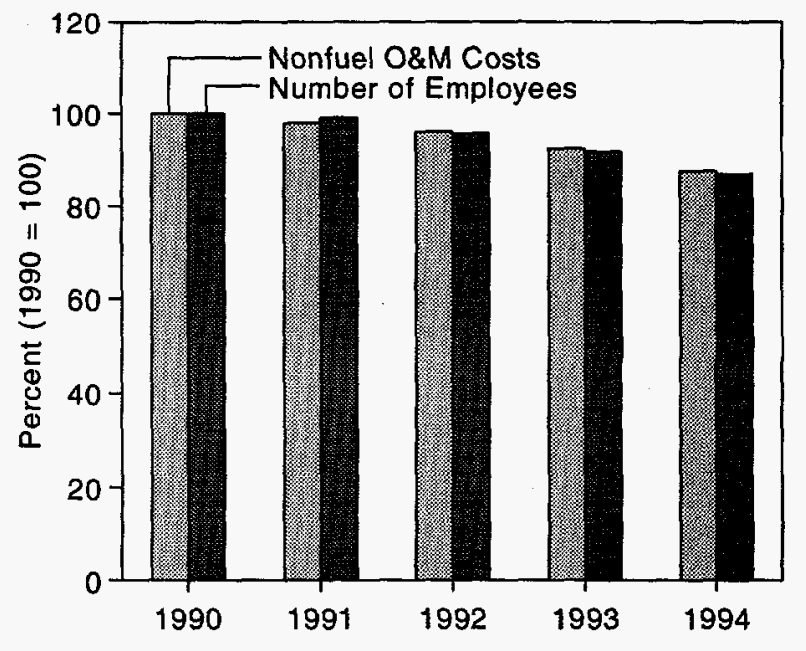

Source: Federal Energy Regulatory Commission (FERC) Form 1.

costs and demands. Figure 8 illustrates the relationship between prices based on average costs with limited competition (the AEO97 Reference Case), prices based on average costs in the No Competition Case, and competitive prices based on marginal costs with flat rates (i.e., no time-of-use rates) and the same cost improvements assumed in the AEO97 Reference Case. In the Flat Rates Case, the algorithm used to calculate the competitive price is as described in Chapter 2, except that competitive prices do not vary during the day or across seasons. On an average national basis, competitive prices could be as much as 0.4 cent lower than regulated prices in 1998 (Figure 8). With production costs and demands very similar, the difference between the Flat Rates Case and the AEO97 Reference Case provides a measure of stranded costs. ${ }^{54}$ Over time, assuming an absence of differential efficiency improvements, competitive prices and regulated prices converge as stranded costs are amortized out of the regulated price (see the section on "Capital Recovery and Reserve Margins" later in this chapter for a discussion of this concept).

Figure 8 gives an indication of the relative magnitude of the efficiency improvement as a result of competitive prices, as well as the stranded cost avoidance component. The difference between the Flat Rates Competitive

\footnotetext{
${ }^{53}$ The average costs in the competitive case are used as the basis for the stranded cost calculation. Average costs for the competitive cases are calculated using the same cost-of-service regulatory model used for the AEO97 Reference Case. Because of the changes mentioned above, however, the results may not be identical to those for the AEO97 Reference Case.

${ }^{54}$ In the sections that follow, net stranded costs are calculated from the average costs in the competitive cases (including the Flat Rates Case), which are close, but not identical, to the $A E O 97$ Reference Case.
} 
Figure 7. Assumed Reductions in Regulated Electricity Prices (Average Costs) from Competitive Pressures in the AEO97 Reference Case, 1995-2015

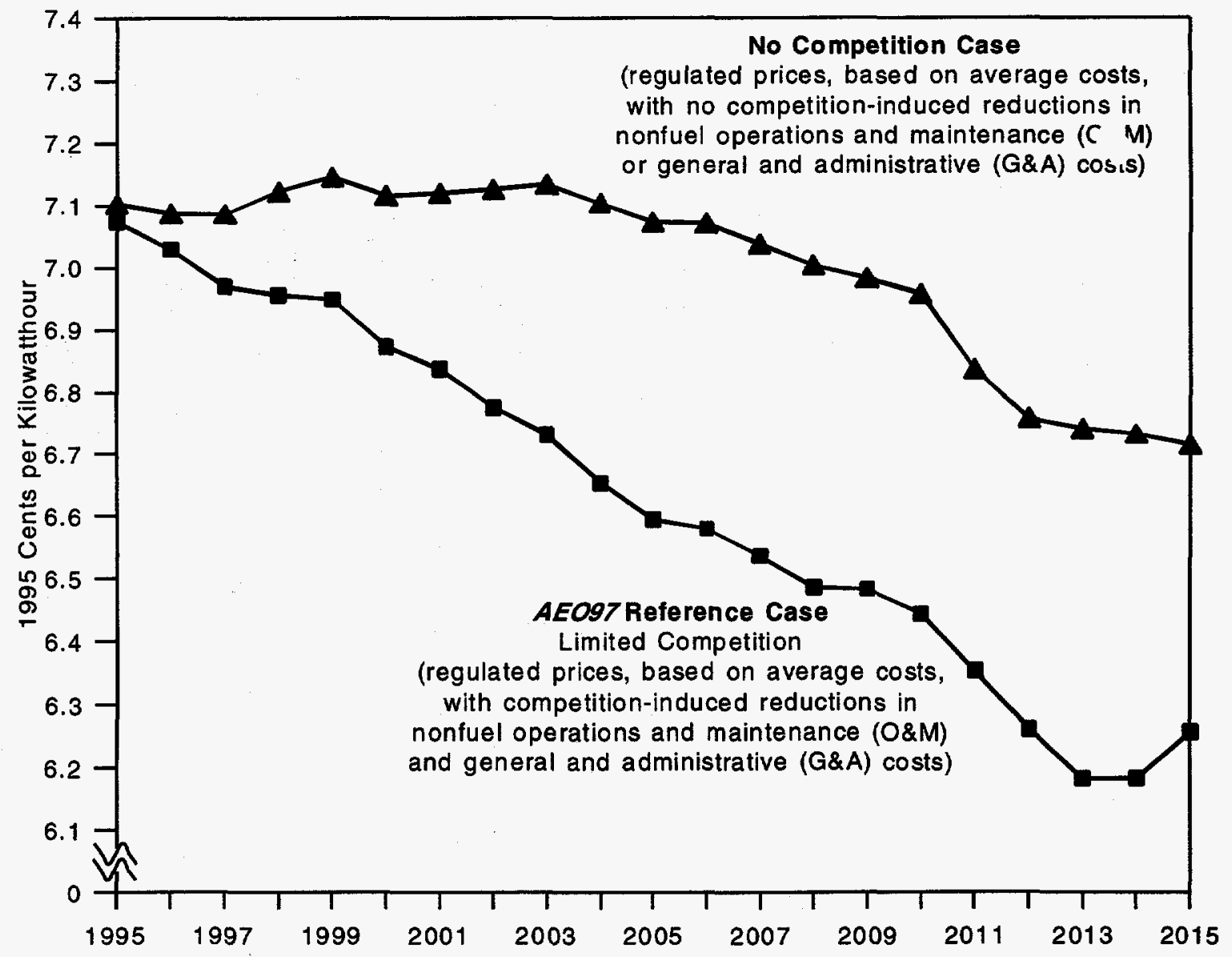

Source: Energy Information Administration, Office of Integrated Analysis and Forecasting, National Energy Modeling System, runs GAFLAT.D060497A and AEO97B.D100296K (October 1996).

Case and the No Competition Case represents the reduction in price that would occur with the replacement of the regulated regime with a competitive regime. The price reduction results from the presence of a number of factors, including stranded costs, which are not covered under competition, and efficiency adjustments, which are induced by competition. The difference between the No Competition Case and the AEO97 Reference Case indicates the extent of the efficiency adjustment. The difference between the AEO97 Reference Case and the Flat Rates Case represents the stranded costs. ${ }^{55}$ It is important to make a distinction between these two elements of price reduction here (and in the remainder of this report). The efficiency improvements induced by competition represent benefits accruing to society. Stranded cost avoidance represents merely a wealth transfer from one group to another (e.g., shareholders subsidize ratepayers in the case of no stranded cost recovery mechanisms). The important benefit from competition is the extent to which prices can be reduced because of efficiencies in supplying electricity. Avoiding stranded costs is a temporary effect that will benefit some and be a cost to others. ${ }^{56}$

\section{Time-of-Use Prices}

It is possible that time-of-use prices may gain greater acceptance under competition, and prices may be reduced as a result of changes in demand patterns (see "Background" in Chapter 2). Figure 9 shows the relationship between generating capacity, electricity demand, and electricity prices under competition for an

\footnotetext{
${ }^{55}$ As noted earlier, the average costs in the Flat Rates Case are close, but not exactly equal, to those in the AEO97 Reference Case. Therefore, this difference is a very rough illustration of net stranded costs.

${ }^{56}$ Correspondence with Howard E. Thompson, School of Business, University of Wisconsin-Madison, June $25,1997$.
} 
Figure 8. Competitive Prices in the Flat Rates Case Compared with Regulated Prices, 1998-2015

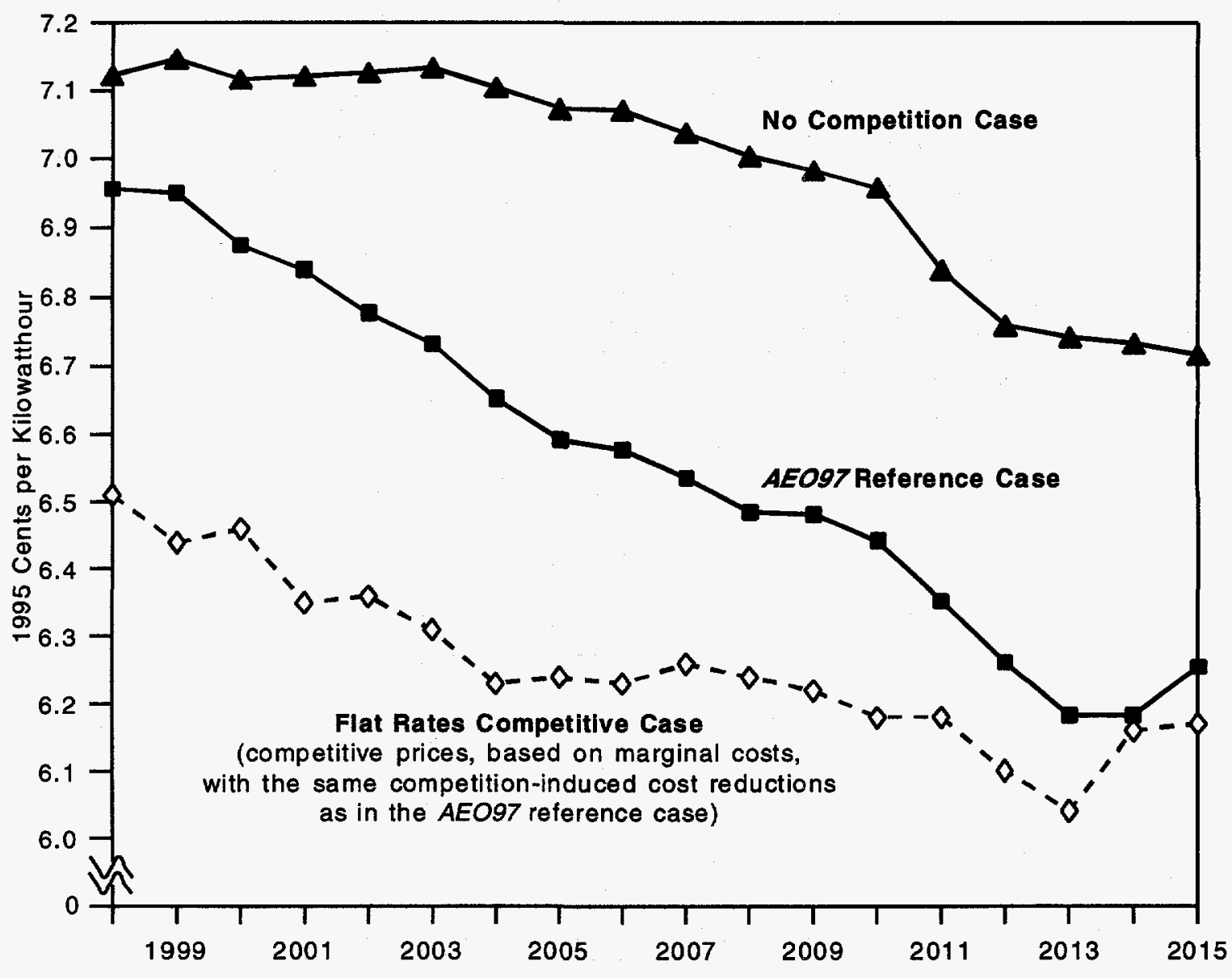

Source: Energy Information Administration, Office of Integrated Analysis and Forecasting, National Energy Modeling System and Prototype Value of Capacity Model, run set AEOAVG2, and National Energy Modeling System, runs GAFLAT.D060497A and AEO97B.D100296K.

illustrative region and year. ${ }^{57}$ The series of dashed lines at the top of the chart show the available capacity on a seasonal basis. The amount of generating capacity varies over the course of the year because capacity is removed from service for planned maintenance. ${ }^{58}$ The seasons with the highest demand (the June/September and July/August time periods in this example) are the seasons with the least capacity out of service for maintenance.

Also in Figure 9, revised demands (shown directly beneath the seasonal capacity lines) show total end-use electricity sales after consumers have adjusted their usage in response to time-of-use prices. The off-peak changes are smaller than the changes during peak periods, but they cover more hours. Therefore, depending on the level of consumer responsiveness to time-of-use prices, the total demand for the year may or may not change due to demand shifting. If the increase in demand during off-peak periods is greater than the decrease in demand during peak periods, total annual demand increases. The relationship between the changes in off-peak demands and prices, and the changes in peak demands and prices, will determine the direction and magnitude of the effects of time-ofuse pricing.

\footnotetext{
${ }^{57}$ In Figure 9, time periods are sorted by season first (labeled at the top of the figure as "January/February", etc.). Each season is further divided into three times of day: midday, morning/evening, and night. The periods of the day are each divided into peak weekday, other weekday, and weekend. For example, under the December/March season in this illustrative region and year, the peak demand period can be clearly seen for midday, morning/evening, and night for both the demands and prices. The relative duration of each of these 108 periods per year is represented by the width of each time period. Finally, the average annual price is equal to the sales-weighted average price for all 108 time periods per year.

${ }^{58}$ Planned maintenance schedules are projected on the basis of projected demand patterns.
} 
Figure 9. Seasonal Capacity, Demands, and Competitive Time-of-Use Prices

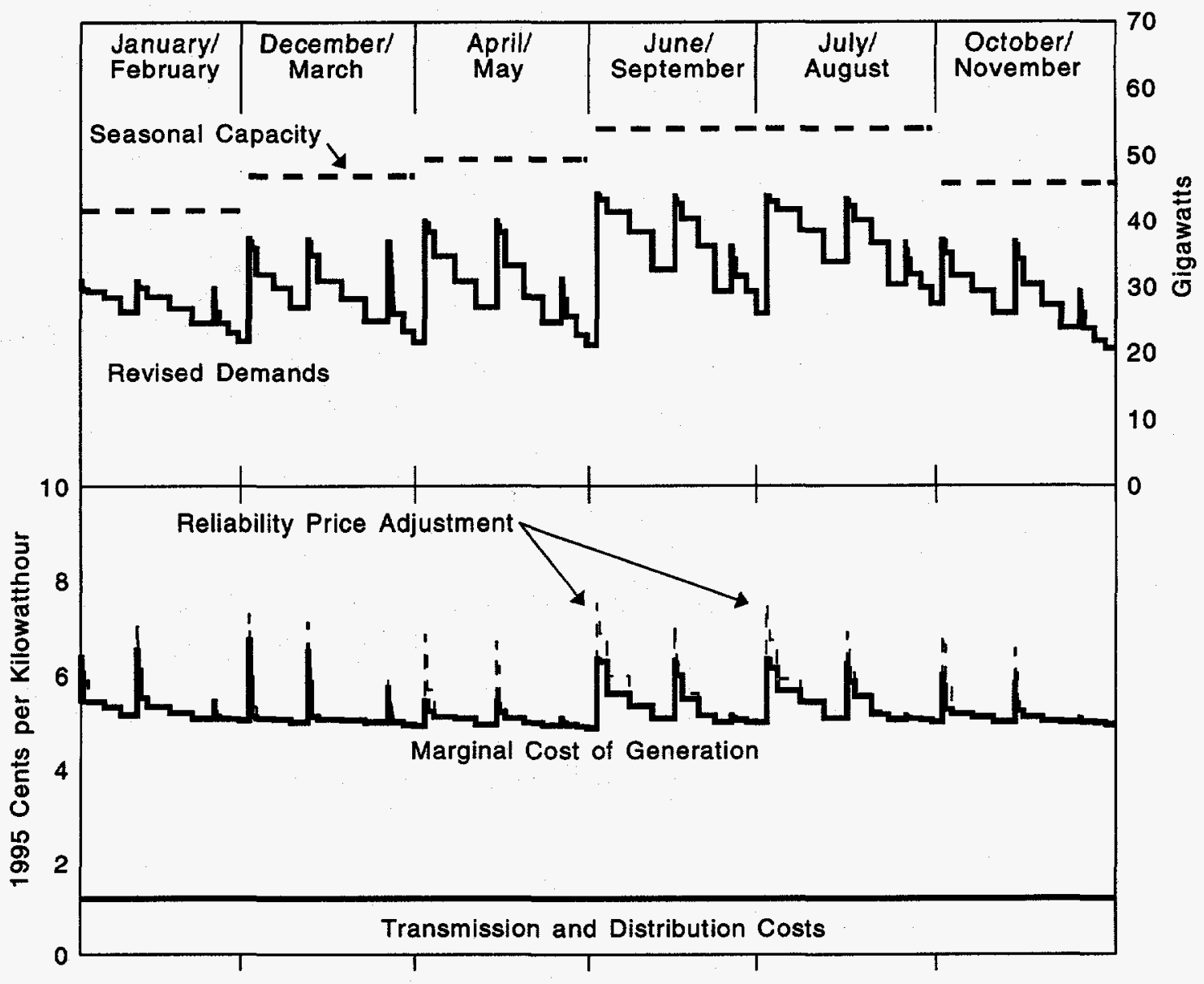

Source: Energy Information Administration, Office of Integrated Analysis and Forecasting, National Energy Modeling System and Prototype Value of Capacity Model, run sets E50V03.

Competitive prices, shown in the bottom half of Figure 9, indicate the impacts of higher marginal costs during peak demand periods. The transmission and distribution (T\&D) charges, based on average costs, are assumed to be flat throughout the year; however, the marginal generating costs rise and fall with increases and decreases in demand, as generating plants that are more expensive to operate are brought into service with increases in demand.

The reliability price adjustment is shown in Figure 9 as price spikes during peak demand periods. When demand approaches the limits of generating capacity, customers may pay more than the marginal cost of generation. Along with changes in the marginal cost of generation, the reliability component provides a pricebased incentive for consumers to reduce demand during peak periods. The duration of the reliability price adjustment shown in Figure 9 is typical for regions with an appropriate amount of generating capacity. ${ }^{59}$ With too little capacity, the reliability price adjustment would occur more often and raise prices higher; with too much generating capacity, it would occur infrequently if at all. As discussed above, the reliability price adjustment is based on the instantaneous reliability of generation supply (measured by expected unserved energy) and the assumed market value of reliability (value of unserved energy, or value of lost load).

The reliability adjustment also provides a price signal to suppliers that capacity is needed. (See "Capital Recovery, Reserve Margins, and Capacity Additions" below for a discussion of how competitive prices provide incentives for producers to acquire additional generating capacity.)

\footnotetext{
${ }^{59}$ The appropriate level of reserve capacity, or optimal reserve margin, is discussed later in this chapter.
} 
There may be significant changes in competitive prices (based on marginal costs) if consumers respond to prices that change as demand rises and falls over the course of a day and between seasons (time-of-use prices). The nature of the change in average annual prices depends on how strongly consumers respond to time-of-use price changes, and whether the changes in demand have a more significant effect on peak or offpeak prices. Two competitive cases are shown in Figure 10 to illustrate the changes in competitive prices that result from moderate changes in consumption patterns due to time-of-use prices: the Flat Rates Case, assuming no time-of-use rates, and the Moderate Consumer Response Case, assuming time-of-use rates and a moderate response in consumer demand (elasticity of demand equal to -0.15 ).
The competitive prices in the Flat Rates Case (no demand shifting) and the Moderate Consumer Response Case differ by as much as 0.2 cent per kilowatthour over the course of the price projection (Figure 10). A decline of 0.2 cent per kilowatthour represents a reduction of 3 percent in the delivered price of electricity. The reason for the impact of this moderate demand response on competitive prices is that changes in demand change the marginal generating costs and reliability price adjustments that determine competitive prices. Demand is shifted away from higher cost peak periods to lower cost off-peak periods. However, with a moderate consumer response in all time periods, the weighted average reduction in peak period prices is greater than the weighted average increase in off-peak

Figure 10. Competitive Time-of-Use Prices with Moderate Consumer Response, Compared with the Flat Rates Competitive Case (No Time-of-Use Prices) and the Regulation Cases, 1998-2015

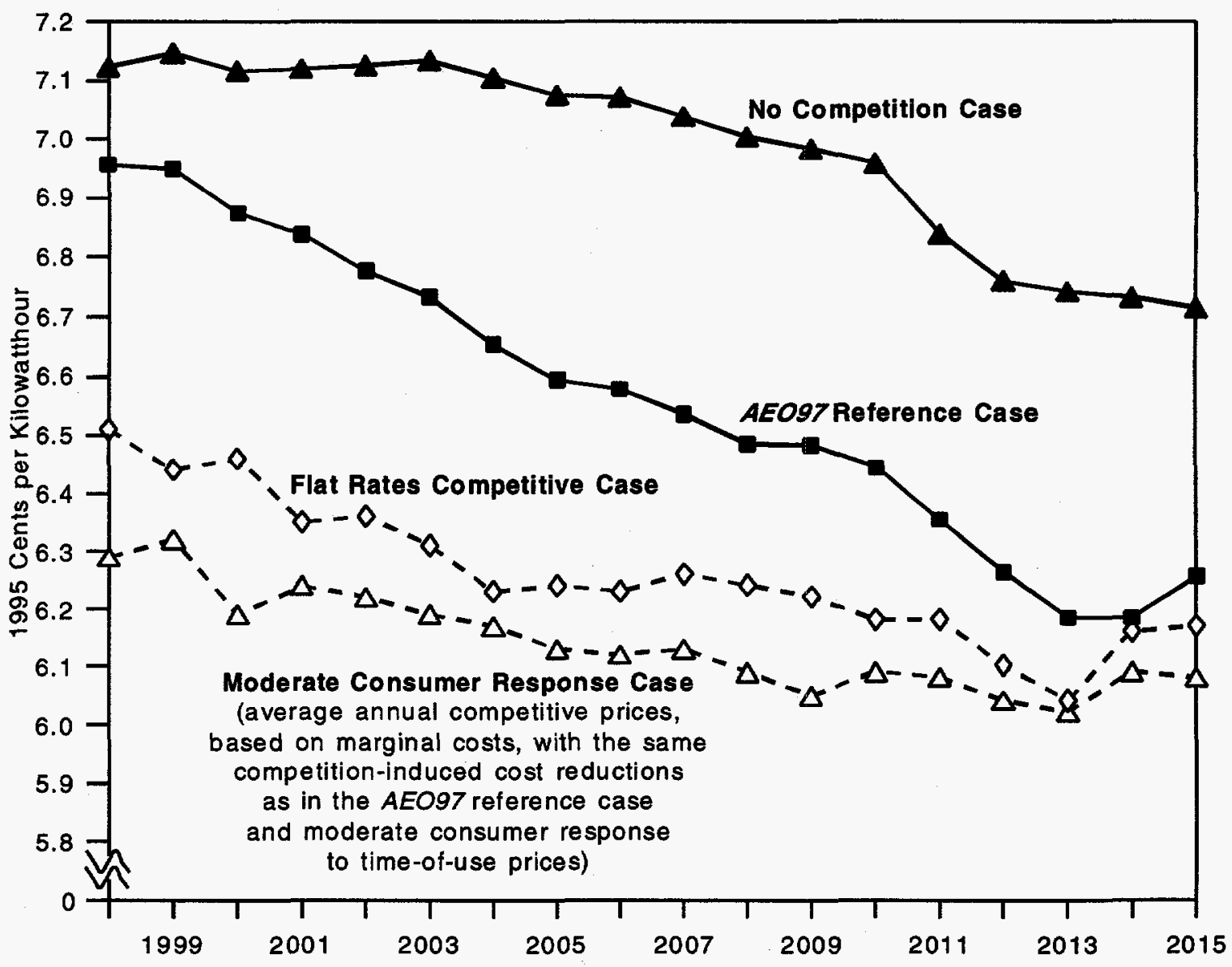

Source: Energy Information Administration, Office of Integrated Analysis and Forecasting, National Energy Modeling System and Prototype Value of Capacity Model, run sets AEOAVG2 and E15V03, and National Energy Modeling System, runs GAFLAT.D060497A and AEO97B.D100296K. 
period prices. $^{60}$ Consequently, the average annual price of electricity is lower with a moderate consumer response to time-of-use pricing than with no time-ofuse pricing. There is very little difference in total annual demand due to price changes between these two competitive cases-less than 2 percent difference nationally in 1998.

On the other hand, with a higher consumer response to time-of-use prices, the opposite effect on average annual electricity prices could be realized. That is, competitive prices could be higher with a stronger consumer response than with a moderate consumer response (Figure 11). Further reductions in weighted average peak period prices resulting from a greater reduction in peak period demand are less significant than the increases in weighted average off-peak period prices resulting from greater increases in off-peak consumption.

In the High Consumer Response Case, assuming timeof-use rates and a high response in consumer demand (elasticity of demand equal to -0.50 ), total annual demands are higher than total demands in the Flat Rates and Moderate Consumer Response Cases by as much 5 percent (total demands of 3,322, 3,159, and 3,201 billion kilowatthours respectively in 1998). The increase in total demand results from an increase in (lower priced) off-peak demands (relative to the Flat Rates Case) that

Figure 11. Competitive Prices in Two Demand Response Cases, 1998-2015

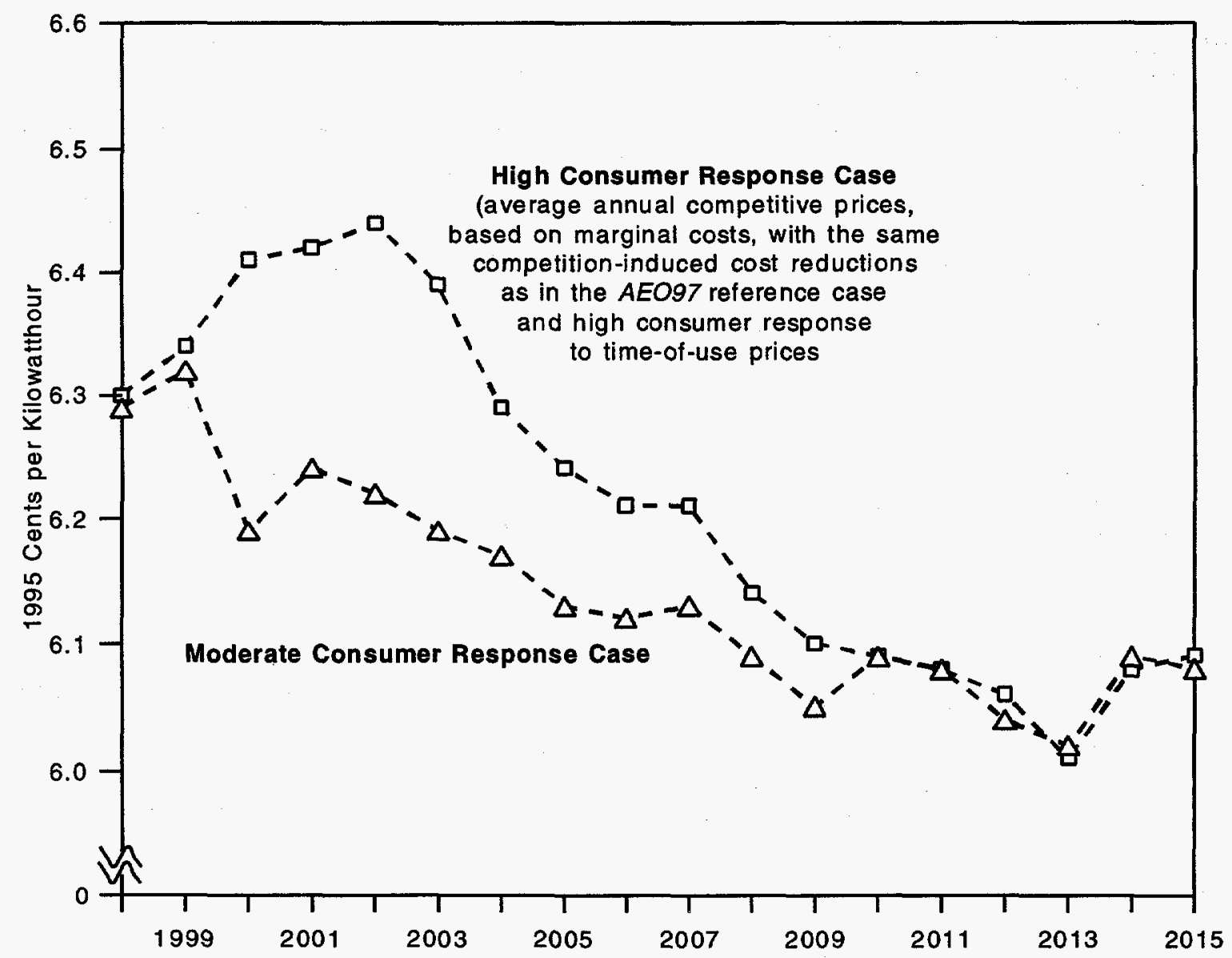

Source: Energy Information Administration, Office of Integrated Analysis and Forecasting, National Energy Modeling System and Prototype Value of Capacity Model, run sets E15V03 and E50V03.

\footnotetext{
${ }^{60} \mathrm{~A}$ simplifying assumption of this analysis is that the consumer response to price changes (price elasticity of demand) is the same in all time periods and all seasons. Also, consumers are assumed to react to the same degree, although in opposite directions in terms of demand changes, to price increases and price decreases. Weights for all average annual competitive prices in this report are based on sales during each of the 108 pricing periods.
} 
is greater than the decrease in (higher priced) peak demands. ${ }^{61}$ Higher off-peak demands result in an increase in marginal costs over a large portion of the year, and in the high response case the off-peak price increases more than offset the reductions in costs that occur during peak periods. Thus, prices in most of the early years of the projection are higher in the high response case than in the moderate response case. ${ }^{62}$

Interestingly, as shown in Figure 11, competitive prices in the Moderate Consumer Response Case and High Consumer Response Case are almost identical in 1998 and 1999 but notably different in 2000, as prices fall in the Moderate Consumer Response Case. The reason that average annual prices in 1998 and 1999 in the High Consumer Response Case are as high as they are in the Moderate Consumer Response Case is the that off-peak prices in the high response case are higher than those in the moderate response case, thus offsetting the higher peak period prices in the moderate response case.

In 2000, however, a significant amount of old oil-fired capacity with high operating costs is assumed to be retired. ${ }^{63}$ The price in the moderate response case falls immediately in 2000, because these oil-fired plants had pushed marginal costs (and prices) higher during peak periods when the oil-fired capacity was needed. When the old oil-fired plants are replaced by combustion turbines, the fuel and other costs associated with operating them is no longer a factor during peak demand periods, and the average price of electricity falls. In contrast, the same oil-fired plants were never a factor in prices in the high response case, because the greater reduction in peak period demand (due to the higher demand response to peak prices) reduced the need for them during peak periods. Thus, when they are retired in 2000, there is little impact on the competitive price in the High Consumer Response Case. Prices eventually merge in the two cases, because the changes in competitive prices relative to the regulated case decline, thus decreasing the effects of the higher elasticity on off-peak periods.

\section{Cost Reductions and Efficiency Improvements Due to Competition}

In addition to time-of-use prices, cost reductions and efficiency improvements are also likely to result from competitive pressures. As mentioned in Chapter 2, power producers will earn profits only if they keep their costs below the cost of the marginal unit in operation at any point in time. By doing so, they will be able to apply the difference between their operating costs and the operating costs of the price-setting marginal unit to their fixed costs. Also, new market entrants will have strong incentive to price their generation services below the prices of existing producers in order to gain market share. In order to do that and recover their costs, they must operate more efficiently and at a lower cost. These cost cutting incentives could affect many aspects of power generation, including O\&M costs, G\&A costs, the costs of new generating equipment, and the efficiency (heat rates) of new and existing power plants.

In order to illustrate the sensitivity of competitive electricity prices to such competition-induced cost reductions, a fourth competitive case is shown in Figure 12. The High Efficiency Case assumes time-of-use rates, a moderate response in consumer demand (elasticity of demand equal to -0.15), higher reductions in nonfuel $O \& M$ costs and G\&A costs through 2005 (40 percent, as compared with 25 percent in the AEO97 Reference Case and in all the other competitive cases), a 15-percent reduction in the cost of generating capacity, and higher operating efficiencies for fossil fuel generating plants (heat rates lowered by 15 percent).

On an average national basis, the cost reductions and efficiency improvements in the High Efficiency Case reduce prices in 2105 by 8 percent relative to the competitive prices in the Moderate Consumer Response Case, by 11 percent relative to the regulated prices in the AEO97 Reference Case, and by 16 percent relative to the regulated prices in the No Competition Case.

\footnotetext{
${ }^{61}$ Demand is relatively low by definition in the off-peak periods. Therefore, inexpensive generating capacity is available to fill demand and marginal costs are low. A high consumer response to the low prices means that more expensive plants must be used to meet the increasing demand, pushing competitive prices higher during off-peak periods than they would be with a moderate consumer response. Marginal costs and competitive prices are still lower during off-peak than average costs and regulated prices, but higher than they would be with a more moderate consumer response to the price reductions.

${ }^{62}$ Higher prices in the High Consumer Response Case do not correspond to a higher value of energy services relative to the other demand response cases. Rather, they are indicative of the changes in assumptions concerning consumer needs and desires. While there may be greater welfare gain from the flexibility inherent in time-of-use pricing, the metric for comparison is not price. Also, it is worth noting that the difference in prices is small and less than the increase in demand. The scale of the graph may make it appear larger than it is.

${ }^{63}$ Generating capacity retirements are consistent with the AEO97 Reference Case in all cases used in this report.
} 
Competitive prices fall because marginal costs are affected by the assumed O\&M cost reductions and efficiency improvements. Also, the reduced cost of new capacity results in higher reserve margins. Higher reserve margins in the High Efficiency Case mean that new capacity enters service sooner, exerting additional downward pressure on marginal costs (and competitive prices). (See the following section, "Capital Recovery, Reserve Margins, and Capacity Additions," for a discussion of how reserve margins are calculated in this analysis and the relationship between the cost of capacity additions and reserve margins. Regional average costs and competitive prices in the High Efficiency Case are compared to those in the Moderate Consumer Response Case in the section on "Regional Prices and Stranded Costs" later in this chapter.)

As shown in Figure 12, the combined effects of marginal cost pricing, time-of-use pricing, and efficiency improvements have a potentially significant effect on the delivered price of electric power. It should be noted, however, that the prices for delivery services (transmission and distribution) do not change significantly across these cases, because it is assumed that the prices for those services will continue to be regulated. Therefore, the change in the price for generation services,

Figure 12. National Average Electricity Prices in Two Regulation Cases and Two Competitive Cases, 1998-2015

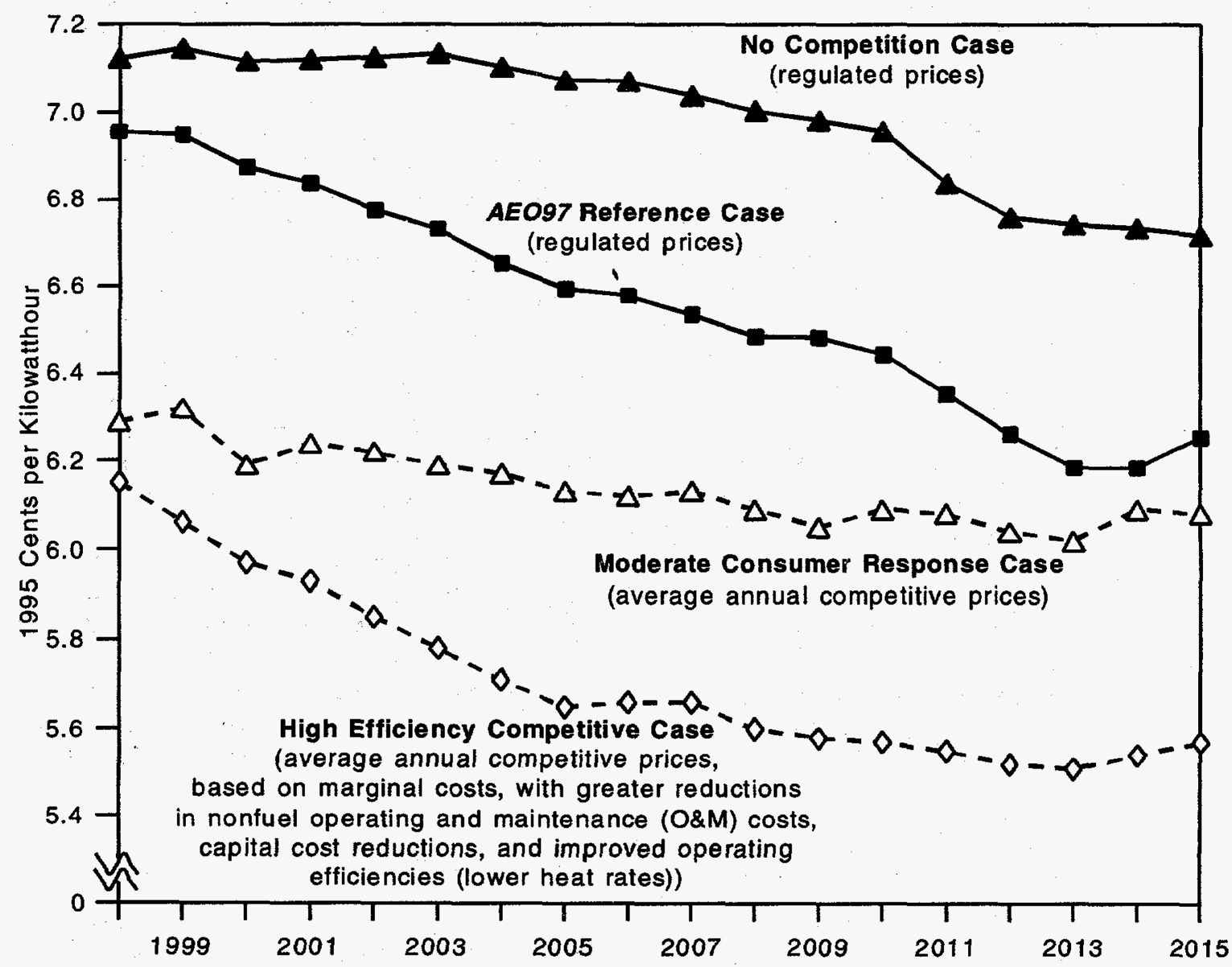

$O \& M=$ operations and maintenance costs. $G \& A=$ general and administrative costs. $T \& D=$ transmission and distribution costs.

Notes: The estimated average costs of generation services are lower than the 1997 average price published in the Annual Energy Outlook 1997 for two reasons: (1) assumed short-run elasticities of demand in the competitive case reduce average costs relative to the AEO97 costs, and (2) taxes are based on revenues, which are lower under competition than under regulation. "Other uneconomic fixed costs" include power purchase contracts and regulatory assets, such as deferred rate phase-in revenues.

Source: Energy Information Administration, Office of Integrated Analysis and Forecasting, National Energy Modeling System and Prototype Value of Capacity Model, run sets E15V03 and HIEFF, and National Energy Modeling System, runs GAFLAT.D060497A and AEO97B.D100296K. 
which drives the total price change, is much greater (relatively) than the percentage change in delivered electricity prices. Figure 13 illustrates the changes in the prices for generation services across the six cases used in this analysis for five representative years. Reductions in the price for generation services in the AEO97 Reference Case compared to the No Competition Case range from 3 percent in 1998 to 9 percent in 2005. In 1998, prices for generation services in the Flat Rates Case, Moderate Consumer Response Case, High Consumer Response Case, and High Efficiency Case are 8 percent, 12 percent, 12 percent, and 15 percent lower, respectively, than those in the AEO97 Reference Case; and in 2010 they are 5 percent, 6 percent, 6 percent, and 16 percent lower.

\section{Capital Recovery, Reserve Margins, and Capacity Additions}

The recovery of capital investments, an explicit component of regulated prices, is possible under competition when the revenues of electricity producers are higher than their variable operating costs during high demand periods. There are two sources of such "revenue premiums." The first is the difference between marginal operating costs, which determine competitive prices, and average operating costs. Marginal operating costs are higher than average operating costs because generating plants are dispatched in merit order. The cheapest plants to operate are dispatched first, and

Figure 13. National Average Prices for Electricity Generation Services in Six Cases, 1998, 2000, 2005, 2010, and 2015

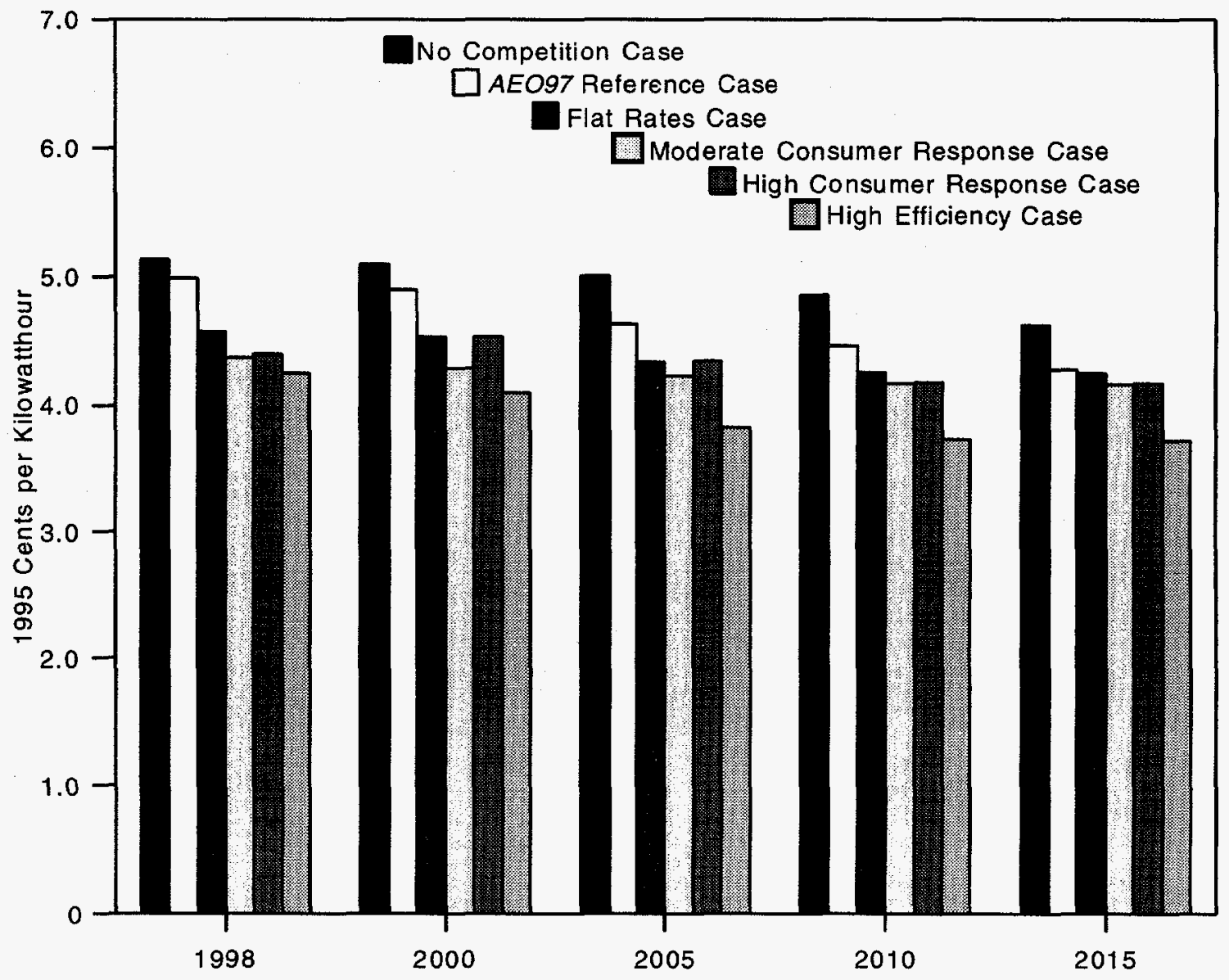

Source: Energy Information Administration, Office of Integrated Analysis and Forecasting, National Energy Modeling System and Prototype Value of Capacity Model, run sets E15V03, AEOAVG2, E50V03, HIEFF, and National Energy Modeling System, runs GAFLAT.D060497A and AEO97B.D100296K. 
when more expensive plants are operating (and setting the price), the cheaper plants receive revenues in excess of their operating costs. These additional revenues can be applied to fixed costs (capital costs for generating plants, return on investment, etc.).

The second source of revenue premiums is prices that are above marginal costs during peak periods when generating capacity is in short supply. During such periods, consumers may bid up the price of electricity to a level that reflects the market value of reliable power-a concept represented in this analysis by the reliability price adjustment. ${ }^{64}$ If generating capacity is in surplus, however, the plants that are more expensive to run will be dispatched less frequently, holding marginal costs (and prices) down. Also, when generating capacity is in surplus, prices will seldom rise above marginal costs, because demand will not approach the limits of generating capacity. When this happens, suppliers will be less likely to recover their capital investments and other sunk costs.

Some analysts have suggested that competition could increase the level of business risk to suppliers of generation services and could raise their cost of capital. If so, it is likely that less expensive plants with higher operating costs (gas-fired technologies) would be favored over more expensive plants with lower operating costs (coal-fired technologies) for new capacity additions. The projections of capacity plans in this analysis are consistent with that expectation, and similar results have been presented in a previous EIA report. ${ }^{65}$

As a sensitivity test in this analysis, the cost of capital was increased by 5 percentage points (500 basis points) ${ }^{66}$ As a result, total combined-cycle capacity in 2015 increased by 32 gigawatts (to 177 gigawatts, from 145 gigawatts in the Moderate Consumer Response Case). Offsetting the increase were reductions of 25 gigawatts of coal capacity (to 293 from 318 gigawatts) and 7 gigawatts of other capacity, including small reductions in combustion turbine and renewable technologies. However, the increase in combined-cycle capacity and reduction in coal-fired capacity had little impact on competitive prices, which rose by less than 0.1 cent per kilowatthour in most years relative to those in the Moderate Consumer Response Case.
The reason for the relatively small impact of the higher discount rate on competitive prices is that the change in capacity type had little effect on the marginal costs of generation. The difference in O\&M costs between new, highly efficient combined-cycle and coal-fired plants is not large enough to have a marked effect on marginal costs.

The role that competitive prices play in communicating the need for more capacity is illustrated in Figures 14 and 15, which show how competitive prices (as projected in this analysis) are affected by a surplus of generating capacity (Figure 14) and capacity shortages (Figure 15) in two different years in a representative region. The results shown in these figures are from the No Capacity Additions Case, which assumes that no new generating capacity will be built and that the demand for electricity will continue to grow over an extended period of time. ${ }^{67}$

Figures 14 and 15 illustrate the relationship between available seasonal capacity (the dashed lines at the top of each figure), revised demands for electricity after consumers have responded to time-of-use prices (the second line), and competitive prices, which are equal to the marginal cost of generation, adjusted for high demand periods through the reliability price adjustment (shown in the bottom half of each figure). In Figure 14, demand for electricity never approaches the limits of generating capacity, and the electricity price rarely rises above a flat rate that covers the operating costs of the cheapest capacity in service. That is, prices do not rise above marginal operating costs, and capacity that is expensive to operate is rarely, if ever, used. In this situation, the owners of capacity will have difficulty recovering their sunk costs. Stranded costs would be significant if there were a fully competitive electricity market in this example, and it is unlikely that investments would be made in generating plants, because there would be losses on the investments.

On the other hand, Figure 15 illustrates a very different environment several years later, as represented in the No Capacity Additions Case. In this example, demands have increased, some old generating capacity has retired from service, and there have been no capacity

\footnotetext{
${ }^{64}$ As mentioned previously, there is no assumption regarding the source of the reliability price adjustment. Depending on the competitive electricity market structure that evolves, this adjustment could be administratively determined (as it is in England and Wales), or it could arise naturally under competition (as does a higher price for roses on Valentine's day).

${ }^{65}$ Energy Information Administration, Annual Energy Outlook 1996, DOE/EIA-0383(96) (Washington, DC, January 1996), p. 30.

${ }^{66}$ All other assumptions in this cost of capital sensitivity test were consistent with the Moderate Consumer Response Case.

${ }^{67}$ This is not a plausible case. It is a special case to analyze the effects of capacity shortages.
} 


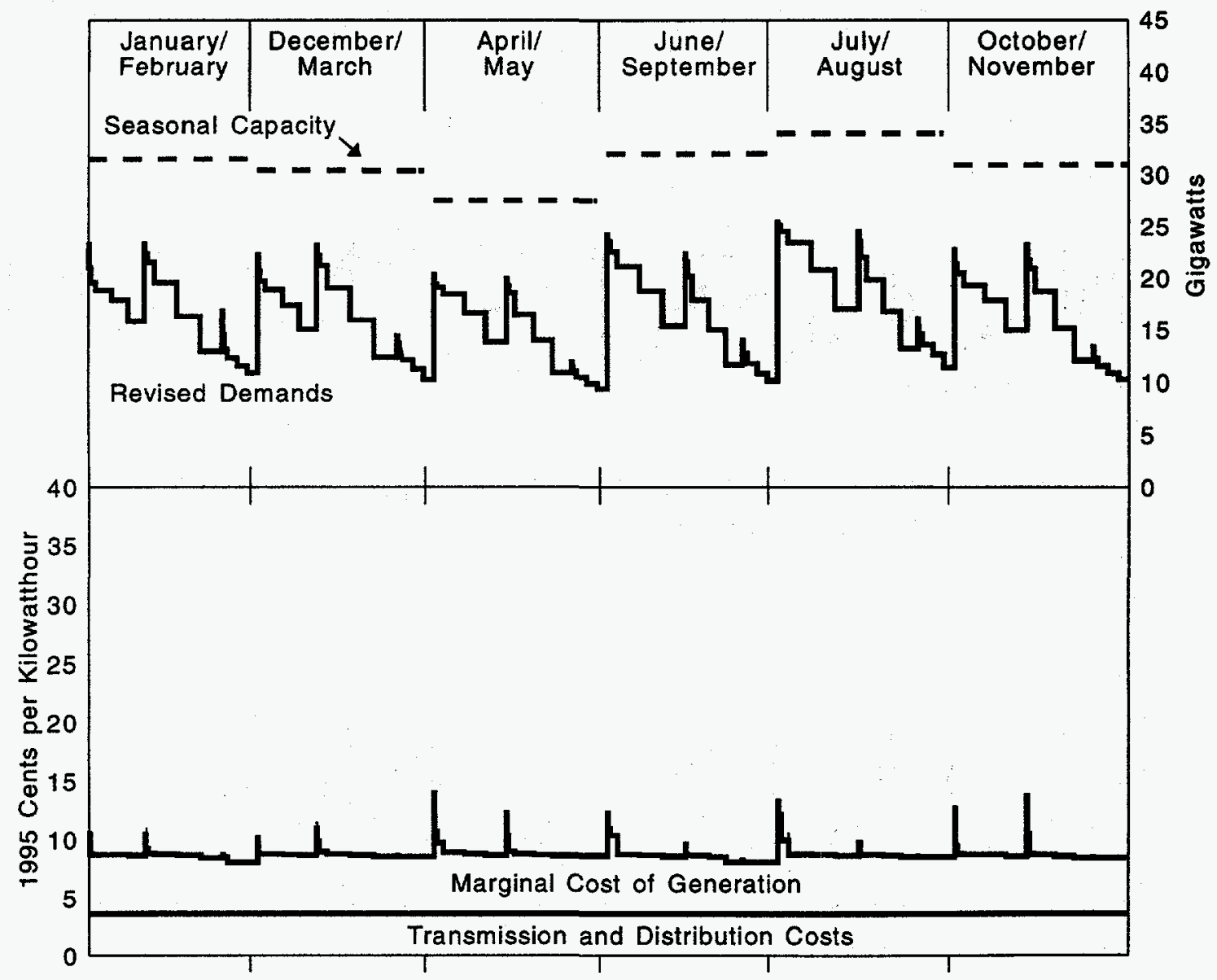

Source: Energy Information Administration, Office of Integrated Analysis and Forecasting, National Energy Modeling System and Prototype Value of Capacity Model, run set E15V03NB.

additions since 1997. Under these conditions, demand frequently approaches the limits of capacity, causing prices to spike to over 30 cents per kilowatthour during peak periods-well above marginal operating costs. The marginal costs of generation are high for long periods of time as generating plants that are expensive to operate are required to meet demand. Producers collect very high premiums above their operating costs and should have little difficulty in recovering their fixed costs. It is likely that such conditions would provide high returns on investments and strong incentives for investors to provide the capital for new generating capacity. When the new capacity became available for service, shortages would be relieved, and prices would fall.
Figure 16 shows projected average costs and competitive prices in the No Capacity Additions Case. As generating capacity becomes increasingly scarce, the average annual competitive price of electricity increases to an average of almost 12 cents per kilowatthour (1995 dollars) in 2010 from an average of just under 7 cents per kilowatthour in 1998. In the absence of sufficient generating capacity, reliability falls and the reliability price adjustment raises prices more frequently as demand approaches the limits of generating capacity. This is only an illustrative case. In reality, the price signals would provide strong incentives for new competitors to enter the market with new capacity, relieving the shortages and reducing prices until revenues and costs returned to equilibrium. ${ }^{68}$

\footnotetext{
${ }^{68}$ Some analysts argue that a "capacity externality" would prevent purely competitive electricity markets from arriving at this "optimal" reserve margin. See A. Jaffe and F. Felder, "Should Electricity Markets Have a Capacity Requirement? If So, How Should It Be Priced", The Electricity Joumal (December 1996). This analysis makes no assumption as to whether the "optimal" reserve margin will be achieved through purely competitive mechanisms, or whether regulatory intervention will be required.
} 
Figure 15. Capacity, Demands, and Competitive Time-of-Use Prices with Generating Capacity Shortages, 2005

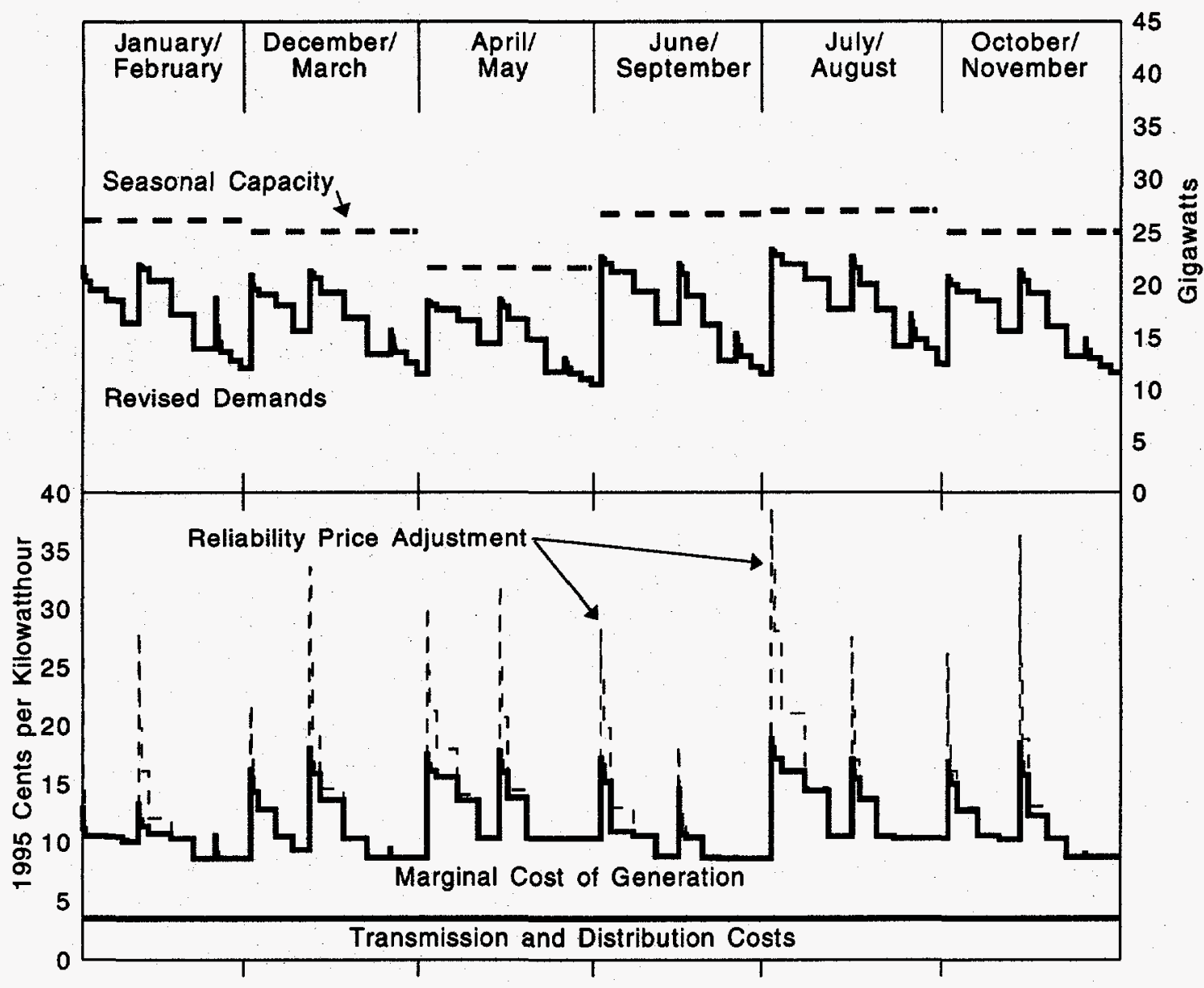

Source: Energy Information Administration, Office of Integrated Analysis and Forecasting, National Energy Modeling System and Prototype Value of Capacity Model, run set E15V03NB.

Average costs, the basis of regulated prices, show a different pattern in the No Capacity Additions Case (Figure 16). Under regulation, the costs of capacity additions are explicitly recovered in prices, and there are no supply and demand effects that raise electricity prices as a signal that capacity is needed. Thus, under regulation, prices fall slightly if there are no capacity additions, because there are no capital-related costs to add to average costs. This characteristic of regulated prices means that it is left to regulators to provide the incentives for suppliers to build sufficient generating capacity.
As consumers shift demand from peak periods to offpeak periods, reserve margin requirements increase. Table 3 demonstrates that as demands are shifted from peak to off-peak periods, a slightly higher reserve margin is required to balance the costs of additional capacity with the costs of reliability, as shown by the difference between the Moderate Consumer Response Case and the High Consumer Response Case. ${ }^{69}$ As discussed above, the costs of reliability are based on assumptions about the price consumers would pay to avoid a service disruption (value of unserved energy, or value of lost load) and the marginal reliability of the

\footnotetext{
${ }^{69}$ The reserve margins in the AEO97 Reference Case are shown for comparison. Reserve margins in the AEO97 Reference Case were determined by an analysis of industry reliability standards and practices, not the method of balancing the costs of capacity with the costs of reliability, which was used in all the competitive analysis cases in this report-except for the No Competition Case and the Flat Rates Case, which use the same reserve margins as the AEO97 Reference Case for most regions. The target reserve margin for New England (NE) is particularly high, because NE is a relatively small region in terms of electricity sales. As a result, one large generating plant unexpectedly out of service represents a large percentage of available capacity. Therefore, reserve margins must be relatively high in order to maintain the appropriate level of safety in a small region with large power plants. Likewise, Florida (FL) has a particularly "spiked" peak demand period, which results in a large difference between the regulated reserve margin and the competitive reserve margin.
} 
Figure 16. Average Costs of Electricity Production and Delivery and Competitive Prices in the No Capacity Additions Case, 1998-2010

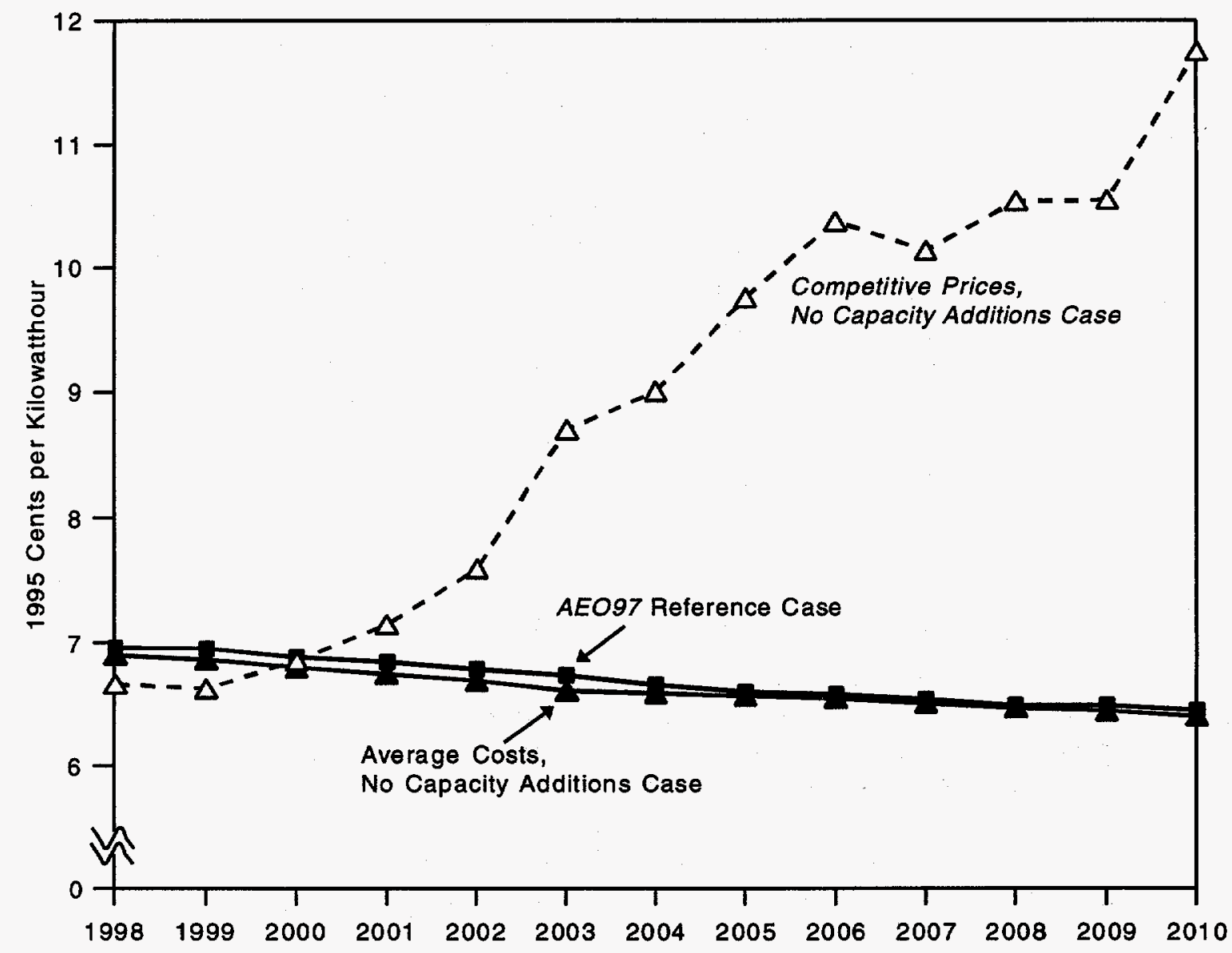

Source: Energy Information Administration, Office of Integrated Analysis and Forecasting, National Energy Modeling System and Prototype Value of Capacity Model, run set E15V03NB (No Capacity Additions), and National Energy Modeling System, run AEO97B.D100296K (Reference Case).

system (the change in expected unserved energy with a change in available capacity). Lower, flatter peak demand periods that result from demand shifts are more frequent and may last for longer periods of time than the spiked peaks that occur without load shifting. Consequently, service interruptions that result from unexpected generating capacity shortages could occur more frequently and last longer with flatter peaks than with spiked peaks, causing consumers to incur greater costs.

Also, maintaining a fixed reserve margin as a percentage of peak demand results in a lower reserve margin in terms of megawatts of capacity if peak demand falls. (A 10-percent reserve margin results in 10 megawatts of reserve generating capacity if peak demand is 100 megawatts, but only 9 megawatts of capacity if the peak demand falls to 90 megawatts.) Since generating capacity exists as fixed blocks (generating plants), maintaining a fixed percentage of reserves as peak demands fall could increase the likelihood of outages; again, this would increase the potential outage costs for consumers.

Higher potential reliability costs justify higher expenditures for reserve capacity (a higher reserve margin) if the costs of capacity are to balance the costs of a service disruption. In spite of the higher reserve margins, however, total capacity requirements may fall as a result of the reduction in peak period demand. In other words, reserve margins (the percentage difference between peak demand and total capacity) increase, but the total amount of capacity needed falls due to the lower peak demand.

As discussed above, target reserve margins are determined in this analysis as the point at which the cost of new capacity (the marginal cost of capacity) just offsets the expected costs that consumers would bear as the result of outages in the absence of that capacity. (See 
Table 3. Regional Target Reserve Margins Under Competitive Pricing in Five Cases (Percent of Total Generating Capacity)

\begin{tabular}{|c|c|c|c|c|c|c|}
\hline \multirow[b]{2}{*}{ Region } & \multicolumn{6}{|c|}{ Case Name } \\
\hline & $\begin{array}{l}\text { AEO97 } \\
\text { Reference } \\
\text { Case }\end{array}$ & Flat Rates & $\begin{array}{l}\text { Moderate } \\
\text { Consumer } \\
\text { Response }\end{array}$ & $\begin{array}{c}\text { High } \\
\text { Consumer } \\
\text { Response }\end{array}$ & $\begin{array}{c}\text { High } \\
\text { Efficiency }\end{array}$ & $\begin{array}{l}\text { High Value } \\
\text { of Reliability }\end{array}$ \\
\hline$\ldots \ldots \ldots \ldots$ & 13 & 13 & 13 & 14 & 14 & 15 \\
\hline ERCOT & 13 & 13 & 16 & 17 & 17 & 18 \\
\hline MAAC $\ldots \ldots \ldots \ldots$ & 13 & 13 & 15 & 16 & 16 & 16 \\
\hline$\ldots \ldots$ & 13 & 13 & 10 & 11 & 11 & 12 \\
\hline MAPP & 13 & 13 & 15 & 16 & 16 & 17 \\
\hline NY $\ldots \ldots \ldots \ldots \ldots$ & 15 & 15 & 16 & 17 & 17 & 18 \\
\hline NE $\ldots \ldots \ldots \ldots \ldots$ & 8 & 18 & 22 & 23 & 23 & 23 \\
\hline$\ldots \ldots \ldots \ldots$ & 4 & 13 & 14 & 15 & 15 & 16 \\
\hline STV & 13 & 13 & 15 & 15 & 16 & 17 \\
\hline$\ldots \ldots \ldots \ldots$ & 13 & 13 & 16 & 17 & 17 & 18 \\
\hline$\ldots \ldots \ldots$ & 15 & 15 & 16 & 17 & 17 & 17 \\
\hline RA $\ldots \ldots \ldots \ldots$ & 14 & 14 & 19 & 21 & 20 & 22 \\
\hline CNV .............. & 14 & 14 & 16 & 19 & 17 & 19 \\
\hline National Average $\ldots$. & 12 & 14 & 16 & 17 & 17 & 18 \\
\hline
\end{tabular}

Source: Energy Information Administration, Office of Integrated Analysis and Forecasting, National Energy Modeling System, run AE097B.D100296K (AEO97 Reference Case) and National Energy Modeling System and Prototype Value of Capacity Model, run sets AEOAVG2, E15V03, E50V03, HIEFF, and E15V06.

Appendix $C$ for the calculation of reserve margins.) The costs that consumers would bear due to outages are determined by the expected frequency and duration of the outages (estimated by expected unserved energy in kilowatthours) and the costs that consumers incur for each kilowatthour of unserved energy (value of unserved energy or value of lost load). The expected unserved energy is estimated by evaluating the relationship between the supply of generating capacity and the demand for electricity.

The value of unserved energy is not known with certainty for several reasons. Among them, consumers have not had the opportunity to reveal the costs they incur in power outages through their willingness to purchase increased reliability in a competitive electricity market. Similarly, research indicates that residential consumers have a strong "status quo bias" that causes them to place a high value on their existing level of service. Finally, the costs of an outage are affected by many factors, including the duration of the outage, the time of day or season in which it occurs, and the amount of warning consumers receive when an outage is imminent. ${ }^{70}$

In this analysis, most of the competitive cases assume a value of unserved energy of $\$ 3$ per kilowatthour. As mentioned above, this analysis assumes that the reliability of service is not affected by competition. Therefore, this value was selected because it is a conservative estimate that is consistent with the implicit value that utility planners have been using for many years (see the section on "Reserve Margin" under "Modeling Competitive Electricity Pricing" in Chapter 2). In order to determine the sensitivity of the analysis results to this assumed value, a value of $\$ 6$ per kilowatthour was used in a High Value of Reliability Case, which also assumes a moderate consumer response to competitive prices (see Table 2). Table 3 shows the increase in reserve margins that results from a higher value of reliability (in the High Value of Reliability Case, as compared with the Moderate Consumer Response Case).

\footnotetext{
${ }^{70}$ See R.S. Hartman, M.J. Doane, and C.K. Woo, "Status Quo Bias in the Measurement of Value of Service," Resources and Energy, Vol. 12 (1990); M. Munasinghe and A. Sanghvi, "Reliability of Electrical Supply, Outage Costs and Value of Service: An Overview," The Energy Journal, Vol. 9 (1988); A.A. Goett, D.L. McFadden, and C.W. Woo, "Estimating Household Value of Electrical Service Reliability with Market Research Data," The Energy Journal, Vol. 9 (1988); M.J. Doane, R. Hartman, and C.K. Woo, "Household Preference for Interruptible Rate Options and the Revealed Value of Service Reliability", The Energy Journal, Vol. 9 (1988); and C.K. Woo and K. Train, "The Cost of Electric Power Interruptions to Commercial Firms," The Energy Journal, Vol. 9 (1988).
} 
The reason for the increase is that consumers are willing to pay more for power during peak periods if it is assumed that the value of reliability is higher. A higher value of reliability implies that the costs of a service interruption are higher than in the competitive cases with a lower assumed value of unserved energy. In order to balance the higher costs of reliability with the costs of capacity, a higher reserve margin is required.

The results of the above sensitivity analysis indicate that there is not a significant impact on prices, quantities, or stranded costs with a change in the assumed value of reliability from $\$ 3$ to $\$ 6$ per kilowatthour. An increase in capacity of 17 gigawatts by 2015 (a 2-percent increase in total capacity ${ }^{31}$ ), which reflects the higher reserve margins in the High Value of Reliability Case, does not have a significant impact on national costs or prices. Costs do not increase significantly because the incremental costs associated with the 2-percent increase in generating capacity are a very small percentage of the total costs. Competitive prices do not change significantly because the costs of the additional capacity are not included in the marginal costs that determine competitive prices. The reliability price adjustment, based in part on the value of reliability, increases during peak demand periods; but the resulting increases in peak period prices do not last long enough to change the average annual competitive price significantly.

Figure 17 illustrates changes in generating capacity requirements with increases in consumer response to varying competitive prices (demand shifting). Capacity requirements in the Moderate Consumer Response Case, compared with those in the AEO97 Reference Case, reflect the effects of the reduced peak demand partially offset by the higher reserve margin requirements discussed above and shown in Table 4. In the Moderate Consumer Response Case ( -0.15 elasticity of demand), requirements for capacity additions through
2015 are more than 34 gigawatts lower-9 gigawatts less combined-cycle and 30 gigawatts less combustion turbine capacity, partially offset by a slight increase in requirements for coal and "other" capacity ${ }^{72}$ - than in the AEO97 Reference Case. The reductions in needed capacity occur in spite of the 16-percent average reserve margin in the Moderate Consumer. Response Case, as compared with the 12-percent average reserve margin in the $A E O 97$ Reference Case. The reduction in capacity requirements is due to the reduced peak period demand caused by the response to higher peak period prices in the moderate response case.

\section{Figure 17. Cumulative Capacity Additions in the AEO97 Reference Case and Two Consumer Response Cases, 2015}

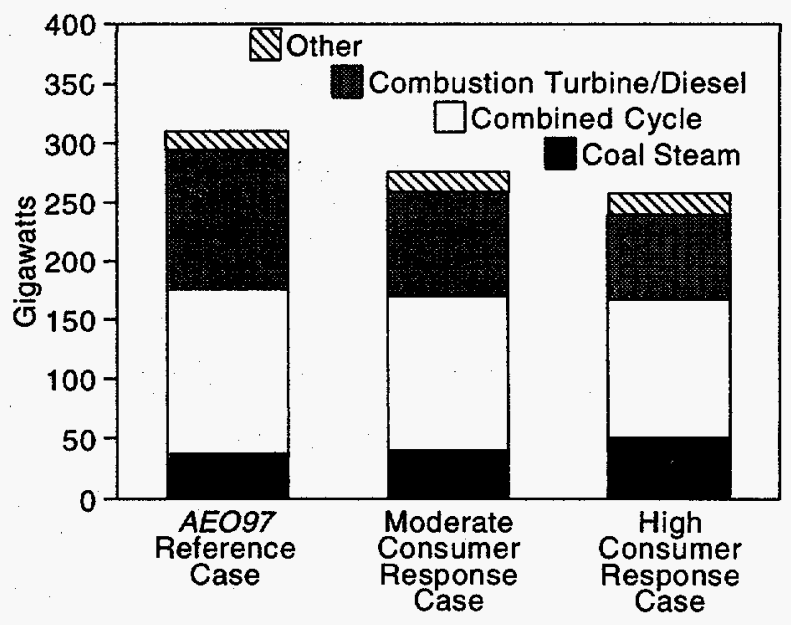

Source: Energy Information Administration, Office of Integrated Analysis and Forecasting, National Energy Modeling System and Prototype Value of Capacity Model, run sets E15V03 and E50V03, and National Energy Modeling System, run AEO97B.D100296K.

Table 4. Reserve Margins, Generating Capacity, and Electricity Demand in Three Cases

\begin{tabular}{|c|c|c|c|c|}
\hline \multirow[b]{2}{*}{ Case Name } & \multirow{2}{*}{$\begin{array}{c}\text { Average } \\
\text { Reserve Margin } \\
\text { (Percent) }\end{array}$} & \multicolumn{2}{|c|}{$\begin{array}{l}\text { Consumer Demand } \\
\text { (Billion Kilowatthours) }\end{array}$} & \multirow{2}{*}{$\begin{array}{c}\text { Installed Capacity, } 2015 \\
\text { (Gigawatts) }\end{array}$} \\
\hline & & 1998 & 2015 & \\
\hline AEO97 Reference Case & 12 & 3,168 & 4,044 & 916 \\
\hline Moderate Consumer Response Case & 16 & 3,201 & 4,027 & 881 \\
\hline High Consumer Response Case & 17 & 3,322 & 4,068 & 864 \\
\hline
\end{tabular}

Source: Energy Information Administration, Office of Integrated Analysis and Forecasting, National Energy Modeling System, run AEO97B.D100296K (AEO97 Reference Case) and National Energy Modeling System and Prototype Value of Capacity Model, run sets E15VO3 and E50V03.

\footnotetext{
${ }^{71}$ Not including cogeneration capacity, which is assumed to be unaffected in this analysis.

72“'Other" includes oil-fired steam capacity, pumped storage, fuel cells, and renewable technologies.
} 
In the High Consumer Response Case (-0.50 elasticity of demand), the reduction in capacity additions relative to the Moderate Consumer Response Case is not so dramatic, with a reduction of 18 gigawatts. Again, the largest reductions are seen for combustion turbine technology (lower by 16 gigawatts) and combined-cycle technology (lower by 14 gigawatts), both of which are fueled by natural gas. These reductions are partially offset by increases in coal-fired capacity of 11 gigawatts. Combustion turbines are generally "peaking" plants used for the short-lived demand spikes that occur during peak demand periods. Combined-cycle plants are more expensive to build but less expensive to operate (more efficient) than combustion turbines, and they are usually dispatched after coal-fired and nuclear plants but before combustion turbine plants. Thus, with peak period demands reduced by consumer responsiveness to time-of-use prices, there is a reduced need for generating technologies that are used for the periods of higher demand (generally, gas-fired generating capacity) and with off-peak period demands increased, there is a greater need for technologies that are used for periods of lower demand (generally, coal-fired capacity).

\section{Uncertainty Regarding Marginal Costs}

\section{Sensitivity to Fuel Costs}

Natural-gas-fired generating plants are most frequently the marginal, price-setting technology. As demand for electricity increases, more of the generating capacity brought on line to meet the rising demand is gas-fired, because gas technologies are generally cheaper to build than other technologies. (The difference in construction costs more than offsets the higher operating costs of gas-fired technologies during high demand periods.) Because of the higher operating costs of gas-fired technologies, the last plant dispatched (the marginal plant) during a significant portion of the year is fueled with gas, and the price of gas largely determines the operating cost of the marginal plant. As long as natural gas remains the primary fuel for marginal generating technologies, competitive prices, based on marginal costs, will be directly affected by the price of gas. Figure 18 illustrates this effect by showing the impact of variations in the (assumed) price of natural gas on competitive electricity prices in a High Gas Price Case and a Low Gas Price Case. ${ }^{73}$ Electricity price increases of as much as 0.6 cent per kilowatthour and decreases of as much as 0.5 cent per kilowatthour (10 and 8 percent, respectively, compared with the Moderate Consumer Response Case) result from the corresponding increases and decreases in natural gas prices.

Average costs (the basis of regulated prices) change little in response to changes in marginal costs. Because the total costs of generating electricity are averaged in the regulated price calculation, changes at the margin have little impact on average costs. As opposed to changes of -0.5 and 0.6 cent in the competitive prices, average costs change by less than 0.2 cent with the same variation in gas prices. The resulting discrepancies between average costs and competitive prices cannot continue indefinitely. With lower gas prices, marginal costs-and consequently prices-could fall well below average costs, and suppliers could be unable to recover their fixed costs.

If competitive prices are below average costs, then some suppliers will go out of business, their assets will be purchased at a discount, and average costs will decline eventually to the level of competitive prices. If competitive prices are above average costs, new suppliers will enter the market, either increasing average costs or lowering prices until prices and average costs converge. Therefore, if demands and production costs are the same under regulation and competition, ${ }^{74}$ then regulated prices (based on average costs) and competitive prices (based on marginal costs) should converge over the long term to the long-run marginal cost of power. However, the market mechanisms that force prices and costs to converge will affect reserve margins. Consequently, high gas prices (or other marginal costs) could cause reserve capacity to rise above the level calculated as "optimal" in this analysis. Low gas prices could have the opposite effect.

As shown in Figure 19, high gas prices make coal-fired generating technologies more competitive with gas-fired technologies (combustion turbine and combined cycle). Although coal-fired generating technologies are more expensive to build than gas-fired technologies, the increase in gas prices relative to coal prices more than compensates for the higher capacity costs in the High Gas Price Case. This illustrates that the competitive price of electricity is much more sensitive than average costs (which determine the regulated price) to changes in marginal costs.

\footnotetext{
${ }^{73}$ These cases use the projected natural gas prices from the AEO97 low and high oil and gas supply technology cases. The price of natural gas in the Moderate Consumer Response Case is assumed to be $\$ 2.53$ per million Btu (1995 dollars) in 2015 . Gas prices diverge from those in the Moderate Consumer Response Case after 2000, rising to $\$ 3.04$ per million Btu by 2015 in the High Gas Price Case and falling to $\$ 2.07$ per million Btu by 2015 in the Low Gas Price Case.

${ }^{74}$ This assumption facilitates the comparison of average and marginal cost pricing. Competitive pressures could drive costs lower.
} 
Figure 18. Average Costs and Competitive Electricity Prices in the Moderate Consumer Response Case and Two Gas Price Cases, 1998-2015

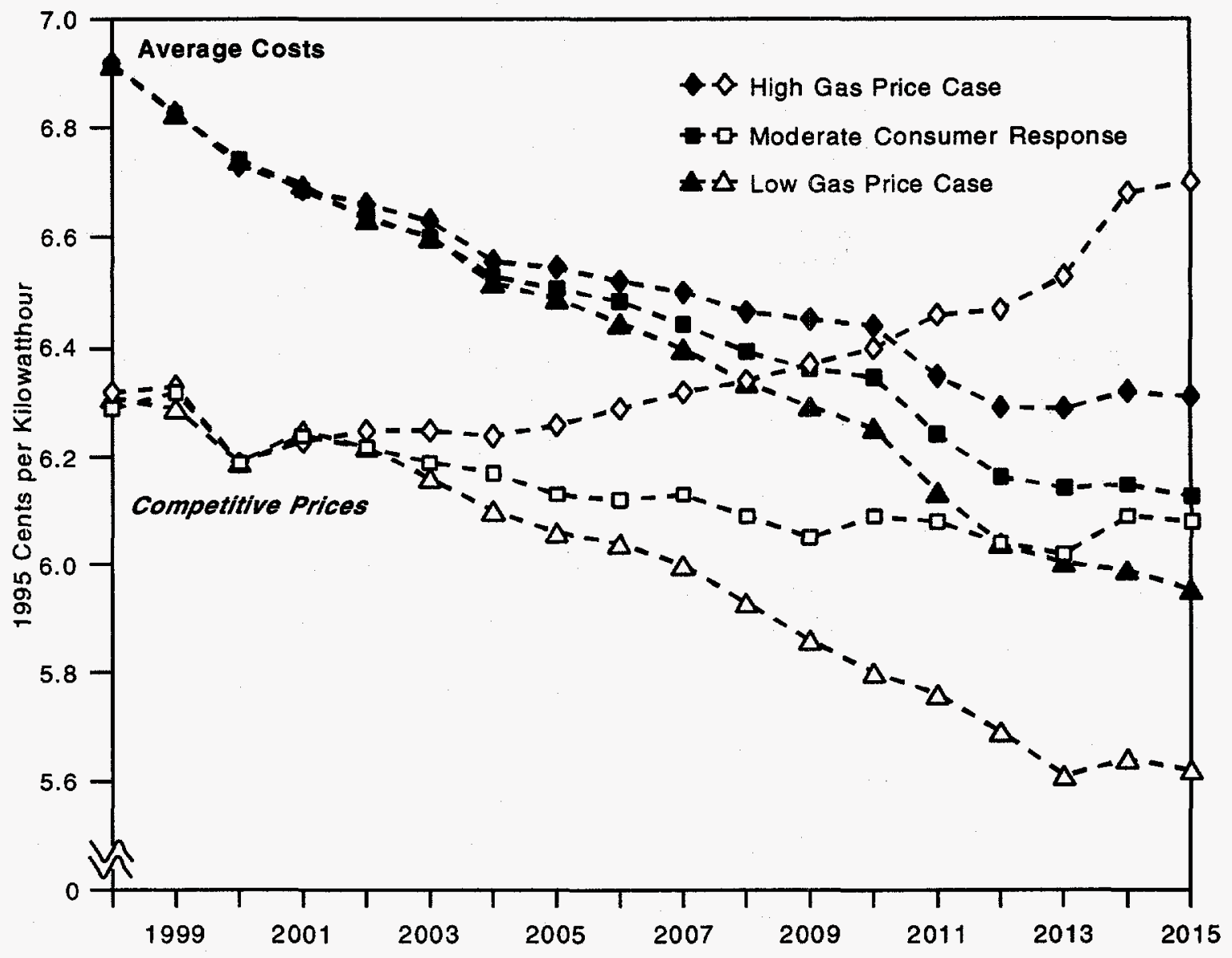

Source: Energy Information Administration, Office of Integrated Analysis and Forecasting, National Energy Modeling System and Prototype Value of Capacity Model, run sets E15V03, E15V03HIGH, and E15V03LOW.

\section{Fixed Versus Variable Costs}

As discussed earlier in this chapter, the costs that are included in competitive prices are the costs that are avoidable if the generating plant ceases operations. These costs are considered to be variable over the intermediate term. If they are not recoverable, then the plant will not run, and the owners can avoid incurring the costs. Fixed costs are not included in competitive prices, because the plant will continue operating even if they are only partially recovered. Thus, avoidable costs, variable over the intermediate term, are included in prices, but fixed costs, unavoidable over the intermediate term, are not.

For the competitive cases in this report, 50 percent of the total non-nuclear, nonfuel $O \& M$ costs are treated as variable and added to the technology-specific marginal generating costs that determine competitive prices. This computation is internally consistent because, if a generating plant is not required to meet demand, then the costs are not incurred and are not included in the calculation of marginal costs. Thus, they are variable with the level of output. The remaining nonfuel, nonnuclear O\&M costs are considered to be overhead costs. Since overhead costs are technology-independent, average G\&A (variable over the intermediate term) is included in the price for all kilowatthours of electricity in all time periods.

As discussed in Chapter 2, some costs that are not capital related are nonetheless "potentially fixed" with respect to short run decisions about operation of generating facilities. Such costs include components of what are termed nonfuel O\&M and G\&A. Whether the price of electricity reflects these costs at the marginal plant will depend on whether plant managers bid prices that include or exclude these costs. In a fiercely competitive setting, one might expect plant managers to bid prices that reflect only short run variable costs, including fuel costs, but only a portion of O\&M and G\&A costs that are incurred on an average annual 
Figure 19. Cumulative Capacity Additions in the Low and High Gas Price Cases, 2015

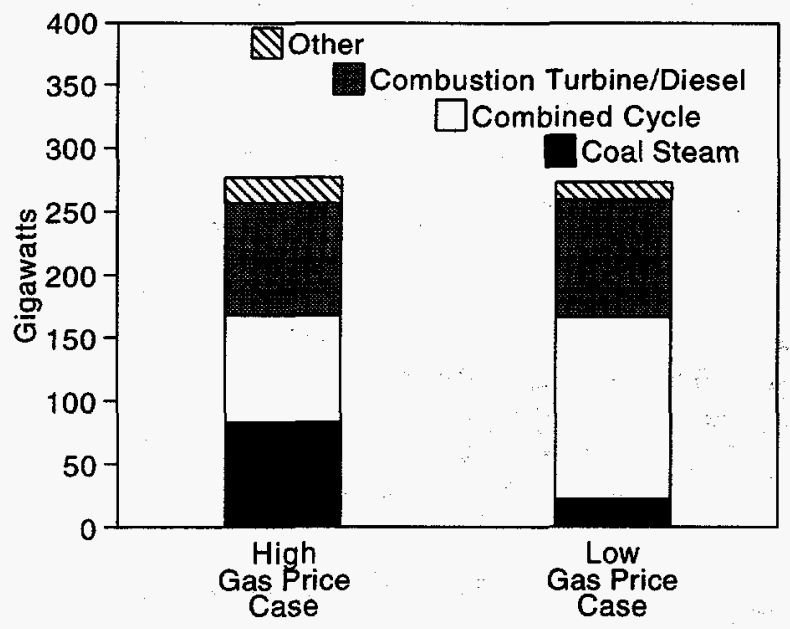

Source: Energy Information Administration, Office of Integrated Analysis and Forecasting, National Energy Modeling System and Prototype Value of Capacity Model, run sets E15V03HIGH and E15V03LOW.

basis. If plants are not able to recover all of their O\&M and G\&A costs over the course of the year, then one would expect them to cease operation. This exit from the market will reduce capacity and increase the reliability premium, a process that would be expected to lead to an equilibrium where all O\&M and G\&A costs are recovered for all operating plants annually. This equilibrating process may take some time; in particular, in a period of excess capacity one would expect aggressive pricing behavior to lead to lower prices until some units exit from the generation market. $^{75}$

In order to quantify the uncertainty surrounding O\&M and G\&A costs, two sensitivity tests were conducted (Figure 20). In the Half O\&M Case, competitive prices include only the one-half of total nonfuel, non-nuclear $O \& M$ costs that are believed to represent short-term, technology-specific operating costs (as in the other competitive cases), but the remainder is not included in the overhead costs. In the second case, the Intense Competition Case, none of the O\&M costs (neither the half considered variable over the short term nor the half considered part of G\&A) and only half of the remaining G\&A costs are included in the competitive price calculation. The reason for including half of the G\&A costs in the sensitivity analysis is that there is further uncertainty regarding the allocation of G\&A costs between the production and delivery costs associated with electric power. Data have historically been collected from vertically integrated utilities, and these overhead costs have not been reported as a separate accounting of generation, transmission, and distribution functions. All other assumptions and parameters in these two sensitivity cases are consistent with those in the Moderate Consumer Response Case.

The results of the sensitivity analysis indicate that uncertainty regarding the delineation of variable versus fixed costs in the calculation of competitive price projections accounts for a range of 0.2 to 1.0 cent per kilowatthour on a national average basis. That is, competitive price projections could be as much as 0.2 to 1.0 cent per kilowatthour lower than those in the Moderate Consumer Response Case, or 22 percent lower than the prices in the AEO97 Reference Case and 24 percent lower than those in the No Competition Case in the short term ( 2 to 3 years).

In the Intense Competition Case, end-use price projections range from 5.3 to 5.5 cents per kilowatthour (1995 cents) over the 18 years of the price projection, compared with 6.1 to 6.3 cents per kilowatthour in the Moderate Consumer Response Case. With transmission and distribution costs of 1.9 cents per kilowatthour, the price (average revenues) for wholesale generation services averages 3.4 to 3.6 cents per kilowatthour in this case, compared with 4.2 to 4.4 cents per kilowatthour in the Moderate Consumer Response Case. A wholesale price of 3.5 cents per kilowatthour would be very close to the long-run cost of power from an efficient combined-cycle generating plant operating as baseload capacity. ${ }^{76}$ In other words, it is possible that the low average annual price (relative to the other cases in this report) of 3.4 to 3.6 cents per kilowatthour could be just high enough to provide full cost recovery for the most efficient generating technology (combined cycle), operated as efficiently as possible (as baseload capacity).

On the other hand, it is less certain that this low price would provide cost recovery for less efficient technologies operated under less optimal conditions, such as combustion turbine technologies generating electricity only during peak periods. For example, gas-fired generating technologies-even the newer, more efficient designs-incur costs of more than 6 cents per kilowatthour if they are operated at capacity factors (utilization rates) lower than 30 percent. Consequently, it is likely that generating plants with higher operating costs would be forced to retire. As the need for new capacity increases, competitive prices will rise until capacity

\footnotetext{
${ }^{75}$ Correspondence with Dallas Burtraw and Karen Palmer, Resources for the Future, Washington, DC, July 1, 1997.

${ }^{76}$ The Annual Energy Outlook 1997 provides an estimate of 3.45 cents per kilowatthour (1995 dollars) as the cost of producing power from an advanced combined-cycle plant in 2015. See Energy Information Administration, Annual Energy Outlook 1997, page 51.
} 
Figure 20. Competitive Electricity Prices in the Moderate Consumer Response Case and Two Cost Uncertainty Cases, 1998-2015

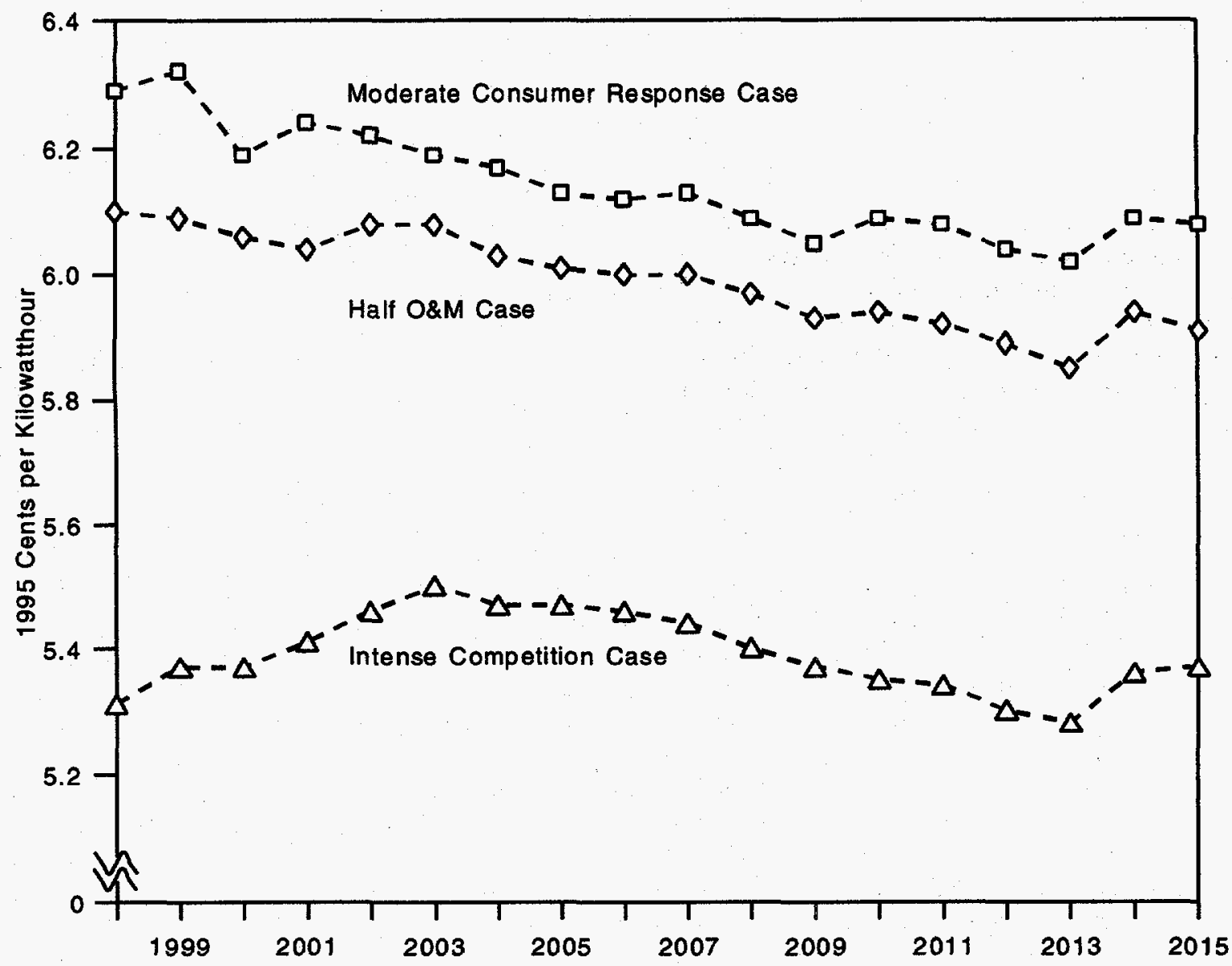

Source: Energy Information Administration, Office of Integrated Analysis and Forecasting, National Energy Modeling System and Prototype Value of Capacity Model, run sets E15V03, NOFIXHALF, and NOFXG\&A.

expansion becomes profitable. Therefore, the prices projected in the Intense Competition Case are not considered to be sustainable over the long term.

Finally, the projections in this case represent a severe reduction in the price of electricity relative to average annual prices in 1997. Even if economic theory and the assumptions of this analysis (i.e., full scale competition begins in 1998) suggest that the outcome of the Intense Competition Case are theoretically possible, these results have a low probability of occurrence relative to the other cases in this report, and are unlikely to be achieved over the short term. There are many institutional changes required and the financial implications for suppliers could be severe. In the absence of successful cost reductions and efficiency improvements, net stranded assets would be quite high relative to the other competitive cases presented in this report and recent studies from other organizations. ${ }^{77}$ The implications for stranded costs are presented in more detail in the following section of the chapter.

\section{Regional Prices and Stranded Costs}

It is possible that a national market for electricity may eventually emerge in the United States. As of today, however, transmission constraints, variations in regional policies and regulations, and differences in the pace of restructuring mean that several competitive electricity markets probably will exist simultaneously. The cost characteristics of electricity production vary regionally

\footnotetext{
${ }^{77}$ For an opposing view, see M.T. Maloney and R.E. McCormick with D.D. Sauer, "Customer Choice, Consumer Value; An Analysis of Retail Competition in America's Electric Industry" (Clemson, SC: Clemson University, July 1996); produced for Citizens for a Sound Economy Foundation, Washington, DC.
} 
because different regions have developed unique mixes of generating technologies. For this analysis, regional markets were defined according to the NERC regions and selected subregions, which were established along the boundaries formed by the transmission system in the United States (see Figure ES1 in the Executive Summary).

It was assumed for this analysis that the same transmission constraints would initially form the boundaries of regional competitive markets. The 13 regional markets represented were not assumed to be isolated. To the contrary, there is currently a fair amount of trade across NERC regions, and it is likely that price differentials between regions may increase trade opportunities. It was assumed, however, that each of the 13 regions would operate in much the same way as tight power pools do today, sharing capacity resources on a leastcost basis and operating as a single large network.

This section examines competitive prices, average costs, stranded costs, and stranded assets for each of the 13 regions in the study. Two cases are used in the regional analysis: the Moderate Consumer Response Case and the High Efficiency Case. These cases (shown in Figure 12 for the Nation as a whole) were selected because they provide a reasonable range of price projections over which to analyze regional results. A moderate consumer response to time-of-use prices is assumed in each case. The difference between the cases is the additional competition-induced cost reductions and efficiency improvements in the High Efficiency Case (see "Cost Reductions and Efficiency Improvements Due to Competition," above).

Net stranded costs were calculated in the analysis by comparing regional average costs (total costs divided by total sales to ultimate consumers) and regional competitive prices (total revenues divided by total sales to ultimate consumers). This concept is illustrated in Figure 21, which shows the average costs and competitive prices for the two cases used. The net stranded costs incurred can be identified as the difference between average costs and prices when costs exceed prices.

As discussed above, average costs and competitive prices must converge over the long term (given the same demands and efficiencies), regardless of how prices are established. That is, stranded costs eventually are reduced to zero. Figure 21 illustrates this relationship as average costs and competitive prices in each case converge or approach convergence. Competitive prices may be reduced by shifts in demand patterns resulting from time-of-use prices or other incentives. Average costs, on the other hand, are not affected in the same way by shifts in demand. While shifts in demand patterns may have significant effects on the competitive price of electricity, their effect on the total average cost of production (the basis for regulated prices) is relatively small. The difference in the impact of consumer response on average and marginal costs could have implications for stranded costs. Specifically, the level of stranded costs is related to consumer responsiveness to price changes. As consumers show an increasing level of price response, the gap between competitive prices and average costs could increase or decrease. The result is an increase or decrease in stranded costs.

The term "stranded assets" is sometimes used synonymously with "stranded costs." In this analysis, however, assets are considered to be balance sheet entities representing the value of physical or intangible items of ownership, whereas costs are defined as income statement items representing expenditures to acquire or produce something. Therefore, stranded costs (fixed costs that are not recoverable through competitive prices) result in stranded assets (reductions in the market value of income-producing assets). Stranded assets were calculated here by discounting the stream of stranded costs back to their present value. ${ }^{78}$ Because of the sensitivity of this calculation to the selected discount rate, and because the true discount rate is unknown, two rates- 6 percent and 10 percent-were used for the calculation of stranded assets. The results of the two calculations are presented as a range of potential outcomes.

In the absence of stranded cost recovery mechanisms, net stranded costs will be borne by shareholders through reductions in securities values and lower dividend payout rates and by taxpayers through reduced taxes on capital gains, dividend distributions, and corporate income. Also, as mentioned in Chapter 1, some analysts have argued that delaying restructuring would mitigate stranded costs. However, delaying restructuring or lengthening the transition period simply means that ratepayers will pay stranded costs in the form of higher prices.

Most regional prices and net stranded costs follow the national trends of converging competitive prices and average costs (which are the basis for regulated prices under the same load conditions and reserve margins) and, consequently, vanishing stranded costs. However, the relationship between average costs and competitive

\footnotetext{
${ }^{78}$ In other words, changes in the net present value of the revenue stream approximate the changes in value of the revenue-producing assets of the firm.
} 
Figure 21. National Average Costs and Competitive Prices in the Moderate Consumer Response and High Efficiency Cases, 1998-2015

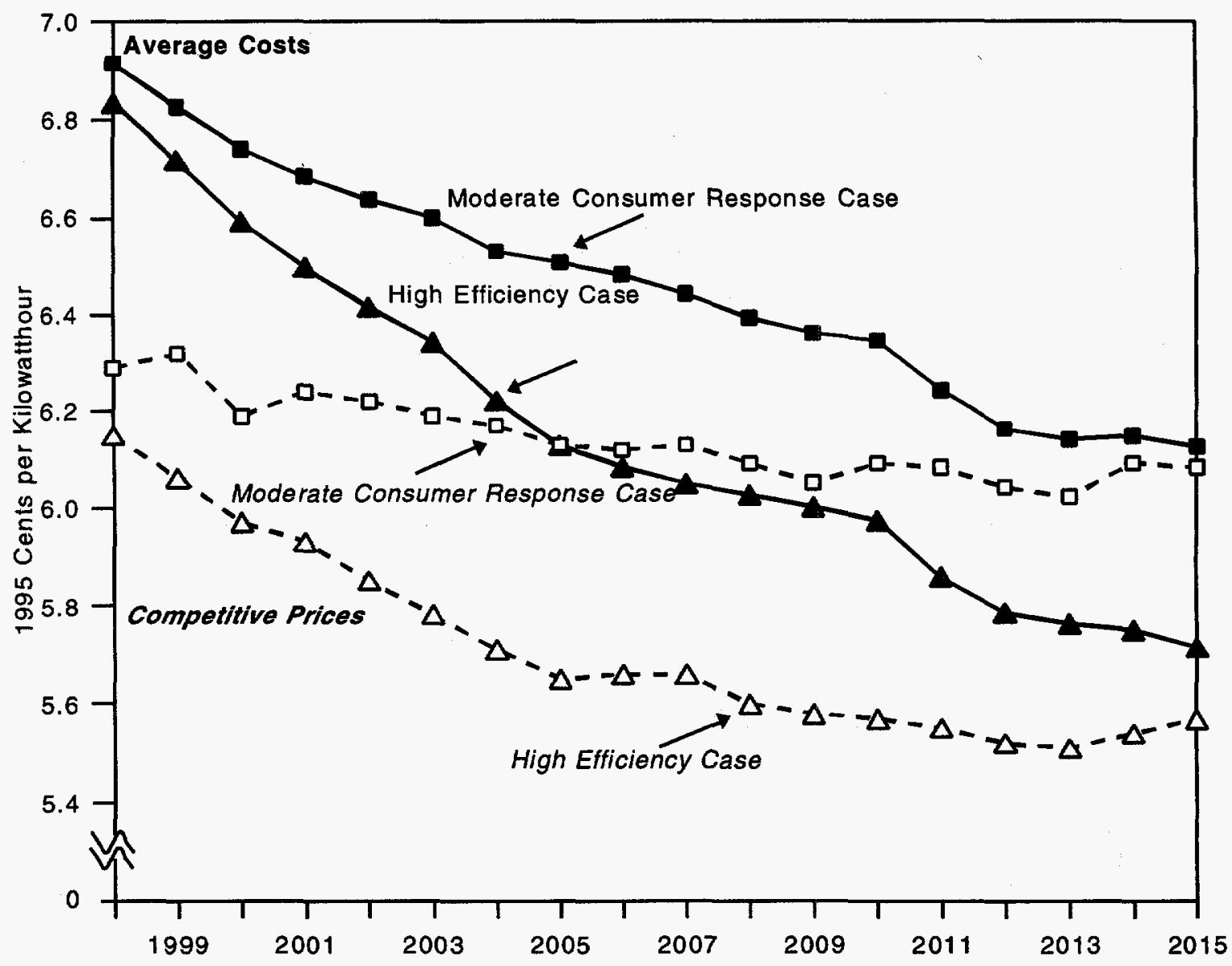

Source: Energy Information Administration, Office of Integrated Analysis and Forecasting, National Energy Modeling System and Prototype Value of Capacity Model, run sets E15V03 and HIEFF.

prices is not as well defined on a regional basis as it is on a national basis, because of the trade between regions. Flows of power and revenues from one region to another may affect the mechanisms that drive prices and average costs to converge within a given region.

The fuel mix and vintage of generating capacity, the relative costs of fuels used in generating plants, and the status of trade agreements and fuel contracts also affect the relationship between average and marginal costs in each region. Consequently, the rate at which uneconomic costs are amortized away under competition varies from region to region, thus affecting the rate at which average costs and marginal-cost-based prices converge. A stranded cost table is included in the discussion of each of the regions in the following section, and illustrates this point.

Most regions are projected to experience reductions in the price of electricity under competition, but there are two regions in which competitive prices may be higher than regulated prices. The Mid-Continent Area Power Pool (MAPP, Region 5) and the Northwest Power Pool subregion of the Western Systems Coordinating Council (NWP, Region 11) may experience price increases under competition because they have an abundance of generating capacity with low operating costs. Where competitive prices are higher than average costs, net stranded costs are negative, meaning that the market value of producers' assets increases due to competition. The following are projections of competitive prices, net stranded costs, and net stranded assets for each of the 13 regions in this analysis.

\section{Region 1: ECAR}

The NERC East Central Area Reliability Coordination Agreement (ECAR) displays the typical national pattern of converging average costs (regulated prices) and competitive prices (Figure 22). Additionally, the volatility of competitive prices, as compared with regulated 
Figure 22. Region 1 (ECAR): Average Costs of Electricity Production and Delivery and Competitive Prices in the Moderate Consumer Response and High Efficiency Cases, 1998-2015

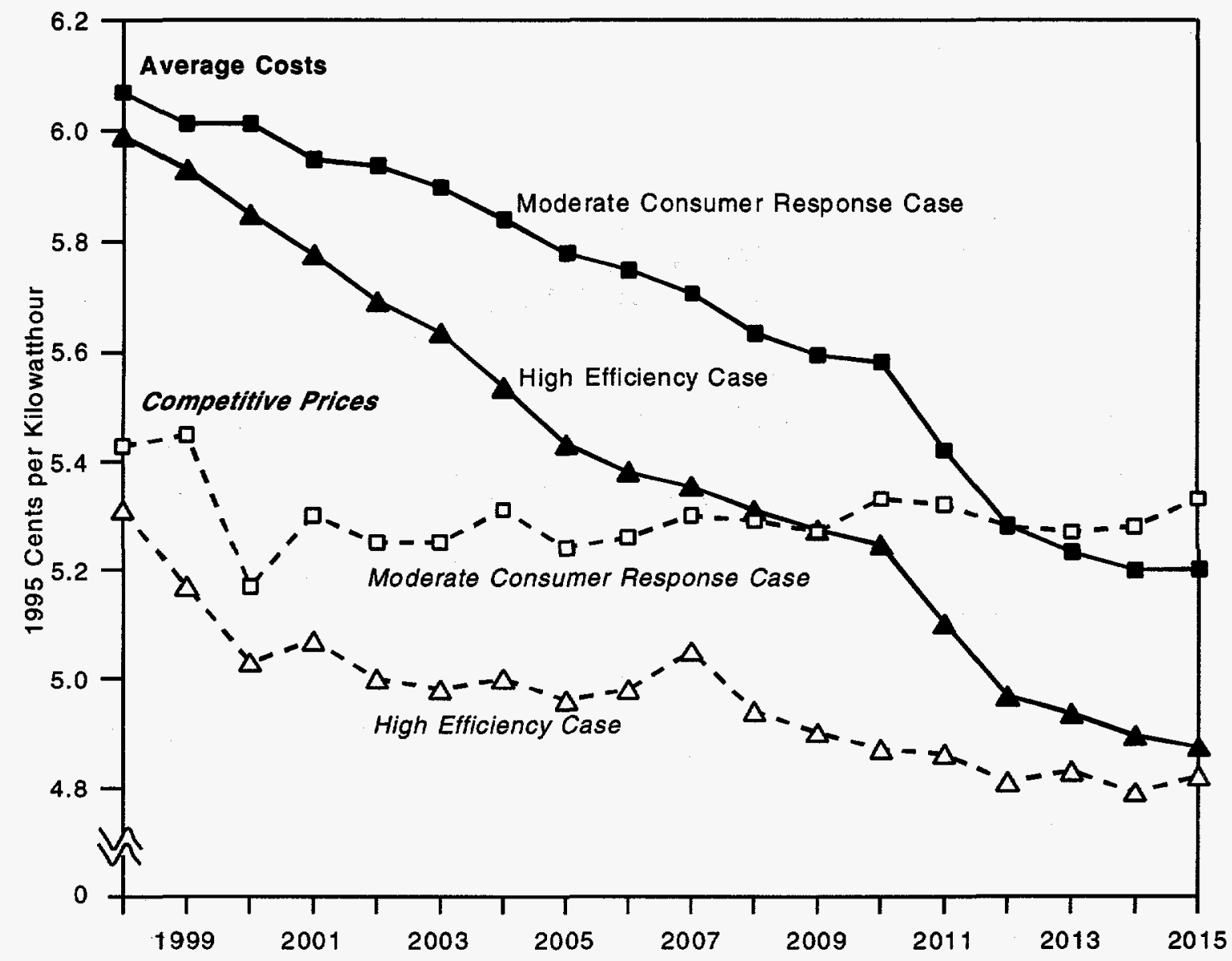

Table 5. Region 1 (ECAR): Net Stranded Costs, 1998-2015

(Million 1995 Dollars)

\begin{tabular}{|c|c|c|c|c|c|c|c|c|c|c|c|c|c|c|c|c|c|c|}
\hline Case & 1998 & 1999 & 2000 & 2001 & 2002 & 2003 & 2004 & 2005 & 2006 & 2007 & 2008 & 2009 & 2010 & 2011 & 2012 & 2013 & 2014 & 2015 \\
\hline Moderate Response & 3,020 & 2,718 & 4,095 & 3,203 & 3,438 & 3,273 & 2,713 & 2,824 & 2,562 & 2,153 & 1,860 & 1,813 & 1,356 & 511 & 66 & -225 & -468 & -773 \\
\hline High Efficiency & 3,191 & 3,632 & 3,990 & 3,497 & 3,457 & 3,319 & 2,727 & 2,460 & 2,106 & 1,581 & 1,972 & 2,060 & 2,073 & 1,272 & 845 & 603 & 530 & 271 \\
\hline
\end{tabular}

Source: Energy Information Administration, Office of Integrated Analysis and Forecasting, National Energy Modeling System and Prototype Value of Capacity Model, run sets E15V03 and HIEFF.

prices, is in evidence in this region: 1.5 gigawatts of oilfired capacity is assumed to be retired in 2000 , resulting in a price decline as new gas-fired combustion turbine capacity, which is cheaper to operate and maintain than the old oil-fired capacity, is added. In ECAR, as in other regions, the fluctuations in the competitive price from year to year are the result of changes in the mix of generating technologies over time-particularly, gasfired technologies that are frequently the last plants dispatched and, therefore, determine competitive prices. Additions of combustion turbine generating plants tend to exert upward pressure on marginal generating costs and, consequently, prices. Additions of combined-cycle plants frequently have the opposite effect, exerting downward pressure on prices, because they are cheaper to operate than the less efficient combustion turbine plants. ${ }^{79}$ However, the generating technology being displaced as the marginal technology must also be

\footnotetext{
${ }^{79}$ It should be noted that combined-cycle plants are less expensive to operate but more expensive to build than combustion turbine plants. If the plant is to be run frequently (maintain a high capacity factor), then the combined-cycle technology is preferred. If the plant is to be run less frequently (serve in the "peaker" role), then the combustion turbine technology may be preferable.
} 
Figure 23. Region 2 (ERCOT): Average Costs of Electricity Production and Delivery and Competitive Prices in the Moderate Consumer Response and High Efficiency Cases, 1998-2015

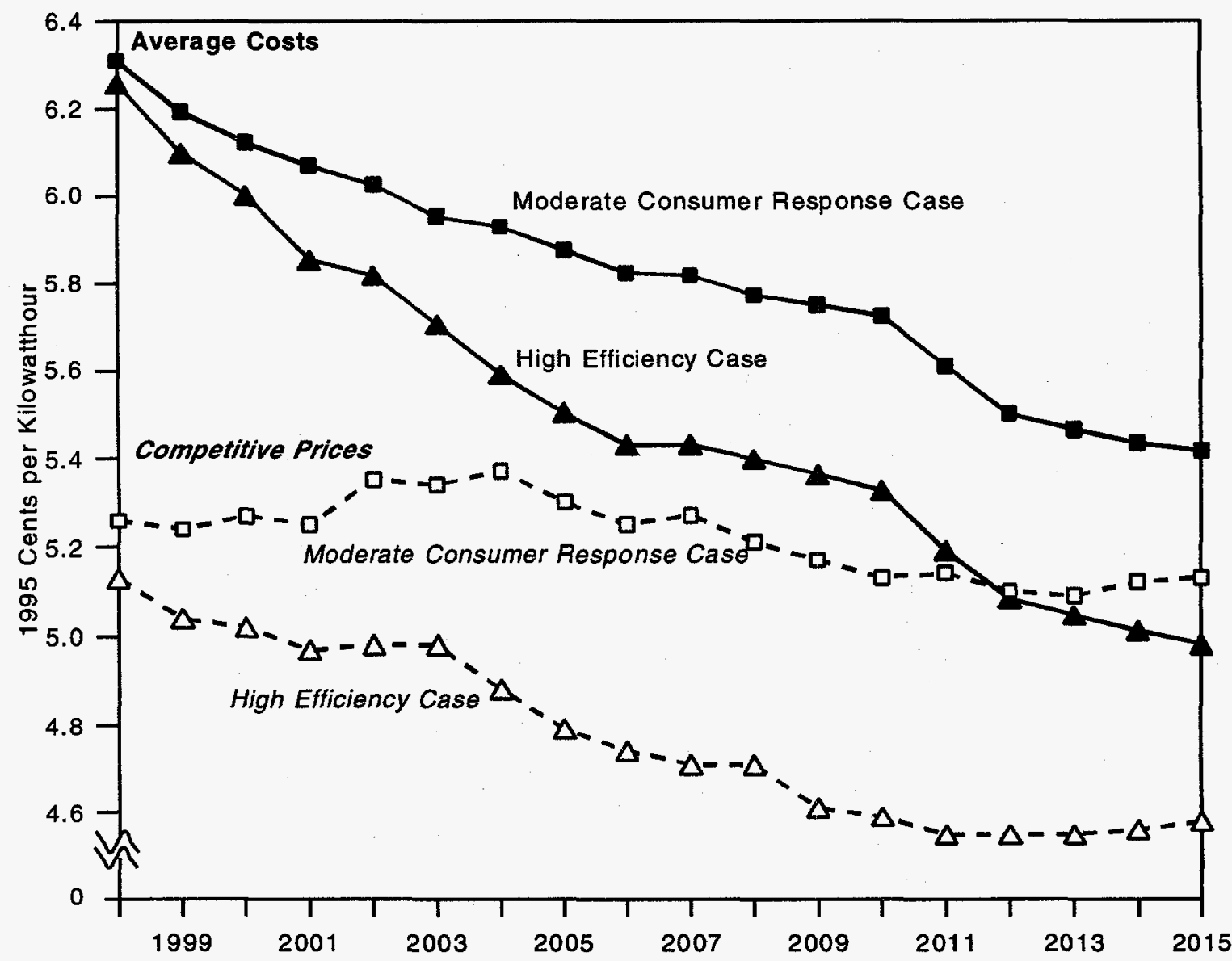

Table 6. Region 2 (ERCOT): Net Stranded Costs, 1998-2015

(Million 1995 Dollars)

\begin{tabular}{|c|c|c|c|c|c|c|c|c|c|c|c|c|c|c|c|c|c|c|}
\hline Case & 1998 & 1999 & 2000 & 2001 & 2002 & 2003 & 2004 & 2005 & 2006 & 2007 & 2008 & 2009 & 2010 & 2011 & 2012 & 2013 & 2014 & 2015 \\
\hline Moderate Response & 2,480 & 2,309 & 2,100 & 2,072 & 1,702 & 1,544 & 1,455 & 1,493 & 1,525 & 1,484 & 1,560 & 1,625 & 1,683 & 1,320 & 1,176 & 1,097 & 929 & 839 \\
\hline High Efficiency & 2,651 & 2,573 & 2,413 & 2,191 & 2,115 & 1,873 & 1,863 & 1,895 & 1,851 & 1,991 & 1,929 & 2,102 & 2,112 & 1,863 & 1,549 & 1,462 & 1,382 & 1,218 \\
\hline
\end{tabular}

Source: Energy Information Administration, Office of Integrated Analysis and Forecasting, National Energy Modeling System and Prototype Value of Capacity Model, run sets E15V03 and HIEFF.

considered. If gas technologies replace oil-fired plants, then prices will likely fall (oil is a more expensive fuel); but if gas technologies replace coal technologies (a less expensive fuel), then prices will likely rise to the extent that costs change at the margins.

Net stranded costs in 1998 are estimated to range from $\$ 3.0$ to $\$ 3.2$ billion (1995 dollars) for ECAR, falling to zero or close to zero by 2015 as average costs converge with competitive prices (Table 5). ${ }^{80}$

\section{Region 2: ERCOT}

The Electric Reliability Council of Texas (ERCOT) also shows the typical national pattern of costs and competitive prices approaching convergence (Figure 23). The effect of the higher assumed reductions in O\&M costs in the High Efficiency Case can be seen as the difference in prices in the two cases widens until 2005, then remains fairly consistent.

\footnotetext{
${ }^{80}$ Stranded costs are higher in the High Efficiency Case because the assumed cost reductions in this case have a higher impact on marginal costs than on average costs. It is possible that efficiency improvements will have the opposite effect- to reduce average costs more than marginal costs-and, hence, reduce stranded costs. For example, if the reductions in O\&M costs for coal-fired or nuclear generating technologies are greater than those for gas-fired technologies, net stranded costs could be reduced.
} 
Figure 24. Region 3 (MAAC): Average Costs of Electricity Production and Delivery and Competitive Prices in the Moderate Consumer Response and High Efficiency Cases, 1998-2015

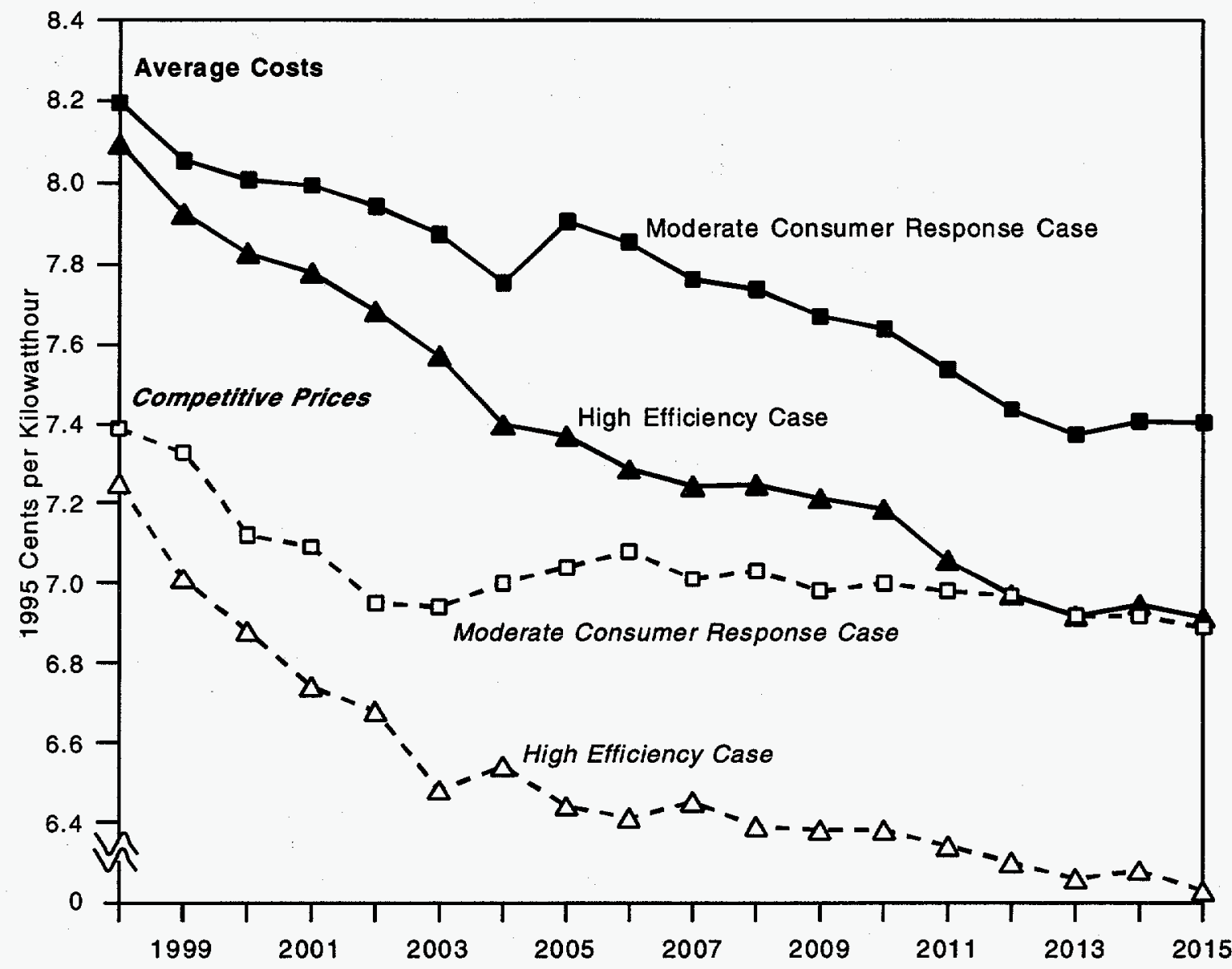

Table 7. Region 3 (MAAC): Net Stranded Costs, 1998-2015

(Million 1995 Dollars)

\begin{tabular}{|c|c|c|c|c|c|c|c|c|c|c|c|c|c|c|c|c|c|c|}
\hline Case & 1998 & 1999 & 2000 & 2001 & 2002 & 2003 & 2004 & 2005 & 2006 & 2007 & 2008 & 2009 & 2010 & 2011 & 2012 & 2013 & 2014 & 2015 \\
\hline Moderate Response & 1,752 & 1,607 & 1,998 & 2,039 & 2,266 & 2,178 & 1,777 & 2,051 & 1,848 & 1,850 & 1,741 & 1,722 & 1,612 & 1,426 & 1,176 & 1,164 & 1,287 & 1,353 \\
\hline High Efficiency & 1,859 & 2,003 & 2,149 & 2,344 & 2,308 & 2,545 & 2,043 & 2,213 & 2,098 & 1,953 & 2,104 & 2,039 & 2,038 & 1,848 & 1,730 & 1,679 & 1,708 & 1,817 \\
\hline
\end{tabular}

Source: Energy Information Administration, Office of Integrated Analysis and Forecasting, National Energy Modeling System and Prototype Value of Capacity Model, run sets E15V03 and HIEFF.

Net stranded costs in ERCOT range from $\$ 2.5$ to $\$ 2.7$ billion in 1998 and fall to $\$ 1.2$ billion or less per year by 2015 (Table 6).

\section{Region 3: MAAC}

In the Mid-Atlantic Area Council (MAAC), efficient combined-cycle generating capacity additions replace retiring old fossil steam plants, and the competitive price falls accordingly through 2003 (Figure 24). A reduction in nuclear capacity between 2003 and 2006 creates a slight increase in marginal generating costs and prices in the Moderate Consumer Response Case. As capacity additions continue to be dominated by combined-cycle technology (13 to 14 gigawatts of combined-cycle capacity enters service between 1998 and 2015), marginal generating costs and competitive prices continue to decline after 2006 in the High Efficiency Case and remain flat in the Moderate Consumer Response Case.

Net stranded costs in MAAC are in the range of $\$ 1.8$ to $\$ 1.9$ billion in 1998 (Table 7). 
Figure 25. Region 4 (MAIN): Average Costs of Electricity Production and Delivery and Competitive Prices in the Moderate Consumer Response and High Efficiency Cases, 1998-2015

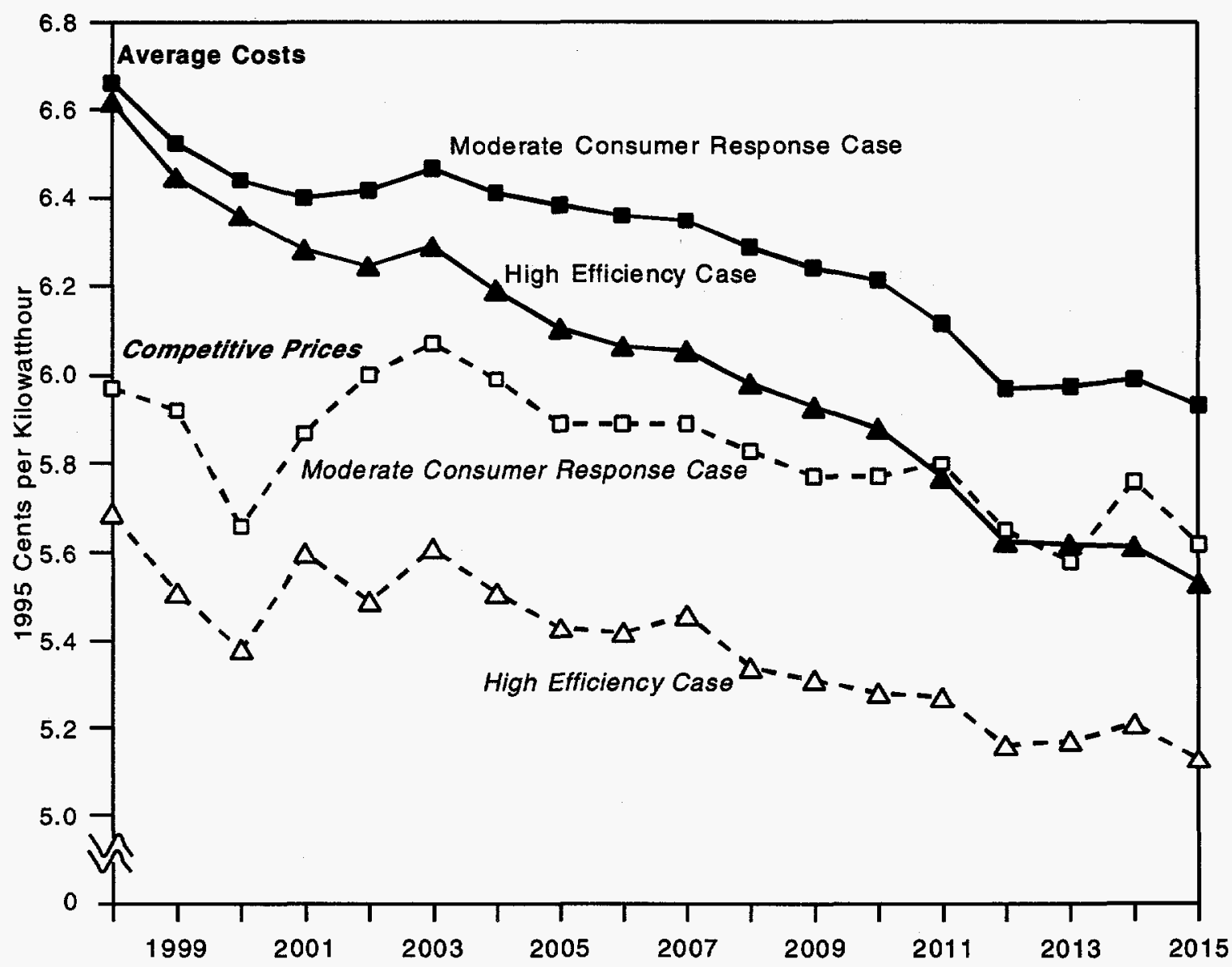

Table 8. Region 4 (MAIN): Net Stranded Costs, 1998-2015

(Million 1995 Dollars)

\begin{tabular}{lrrrrrrrrrrrrrrrrrr}
\hline \multicolumn{1}{c}{ Case } & 1998 & 1999 & 2000 & 2001 & 2002 & 2003 & 2004 & 2005 & 2006 & 2007 & 2008 & 2009 & 2010 & 2011 & 2012 & 2013 & 2014 & 2015 \\
\hline Moderate Response & 1,437 & 1,276 & 1,692 & 1,183 & 916 & 899 & 958 & 1,157 & 1,113 & 1,117 & 1,141 & 1,181 & 1,080 & 803 & 848 & 1,022 & 601 & 853 \\
High Efficiency & 1,907 & 2,009 & 2,130 & 1,492 & 1,692 & 1,539 & 1,530 & 1,593 & 1,496 & 1,412 & 1,563 & 1,537 & 1,496 & 1,245 & 1,182 & 1,201 & 1,055 & 1,090 \\
\hline
\end{tabular}

Source: Energy Information Administration, Office of Integrated Analysis and Forecasting, National Energy Modeling System and Prototype Value of Capacity Model, run sets E15V03 and HIEFF.

\section{Region 4: MAIN}

The volatility of competitive marginal-cost-based prices that could result from small changes in the capacity mix is in evidence in the Mid-America Interconnected Network (MAIN) (Figure 25). Early in the projection (1998 to 2000) increased use of gas-fired capacity displaces more costly oil-fired capacity, and competitive prices fall. Between 2000 and 2003, however, coal capacity falls by 4.0 to 5.0 gigawatts as old capacity is retired.
As gas-fired generation begins to displace less expensive coal-fired generation, the competitive price of electricity increases. In other words, as gas replaces oil, the price falls; but as gas replaces coal, the price increases to the extent that these cost changes affect marginal costs. (The slight drop in the High Efficiency Case price in 2002 is caused by a reduction in the reliability price adjustment caused by an increase in reliability ${ }^{81}$ as this new capacity enters service.) Capacity additions after $\mathbf{2 0 0 3}$ favor combined-cycle over combustion turbine

\footnotetext{
${ }^{81}$ An increase in reliability is indicated by a decrease in expected unserved energy. Expected unserved energy is calculated by comparing the configuration of generating capacity with the expected level and timing of electricity demand (see Appendix F for the calculation of expected unserved energy).
} 
Figure 26. Region 5 (MAPP): Average Costs of Electricity Production and Delivery and Competitive Prices in the Moderate Consumer Response and High Efficiency Cases, 1998-2015

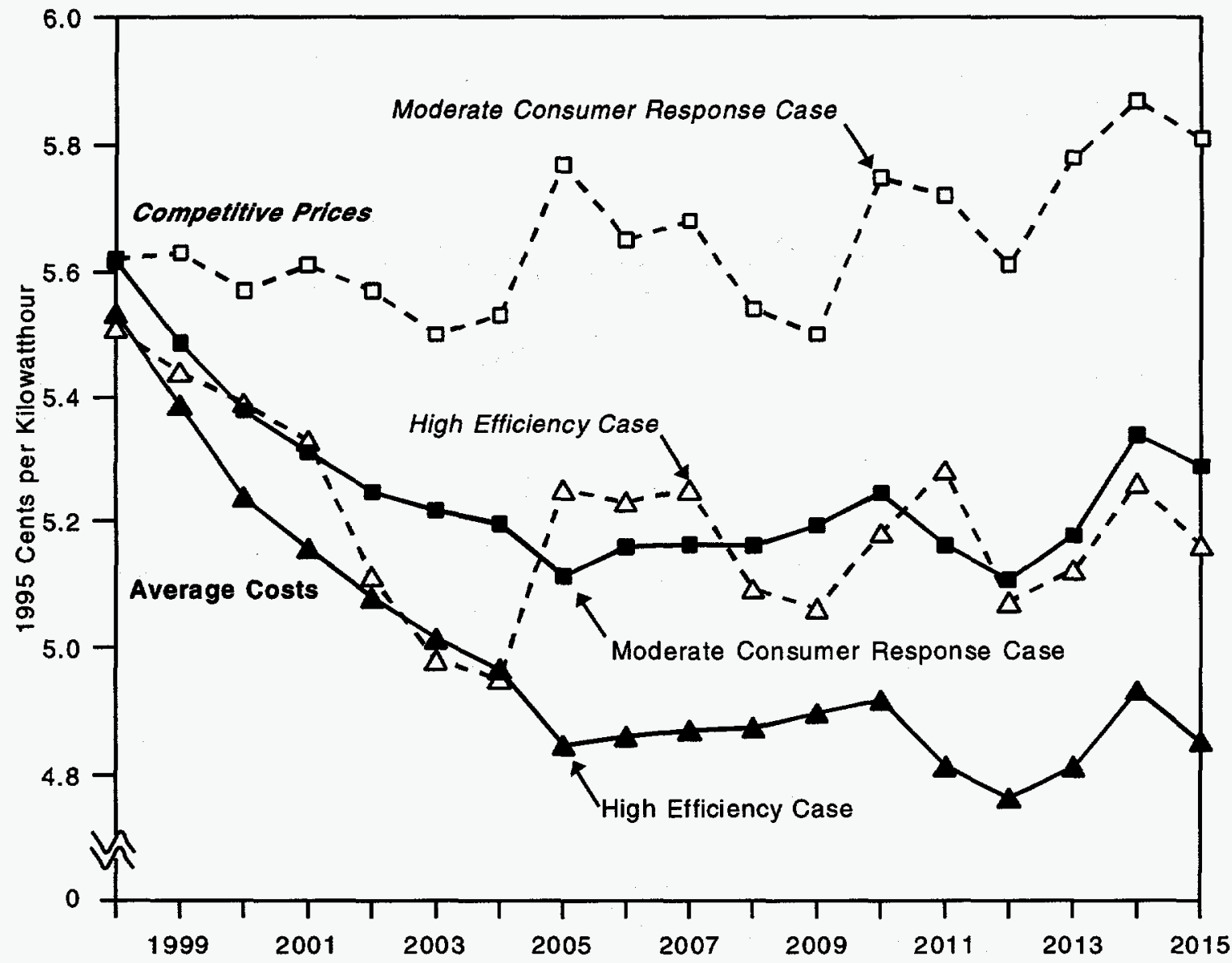

Table 9. Region 5 (MAPP): Net Stranded Costs, 1998-2015

(Million 1995 Dollars)

\begin{tabular}{lrrrrrrrrrrrrrrrrrr}
\hline \multicolumn{1}{c}{ Case } & 1998 & 1999 & 2000 & 2001 & 2002 & 2003 & 2004 & 2005 & 2006 & 2007 & 2008 & 2009 & 2010 & 2011 & 2012 & 2013 & 2014 & 2015 \\
\hline Moderate Response & 1 & -181 & -251 & -410 & -450 & -395 & -479 & -959 & -746 & -776 & -579 & -497 & -784 & -887 & -820 & -996 & -908 & -905 \\
High Efficiency & 42 & -68 & -198 & -237 & -33 & 48 & 27 & -591 & -564 & -577 & -344 & -248 & -433 & -758 & -537 & -518 & -581 & -522 \\
\hline
\end{tabular}

Source: Energy Information Administration, Office of Integrated Analysis and Forecasting, National Energy Modeling System and Prototype Value of Capacity Model, run sets E15V03 and HIEFF.

plants, further reducing competitive prices. With reductions in other costs that affect competitive prices (such as nonfuel O\&M and G\&A) through 2005, competitive prices fall by as much as 0.5 cent per kilowatthour between 2003 and 2015 in the High Efficiency Case, and slightly less in the Moderate Consumer Response Case.

Net stranded costs in MAIN range from $\$ 1.4$ to $\$ 1.9$ billion in 1998 (Table 8).

\section{Region 5: MAPP}

In the Mid-Continent Area Power Pool (MAPP), a high proportion of generating capacity is coal-fired capacity with relatively low operating costs (20.4 gigawatts out of a total of 33.5 gigawatts of utility capacity is coalfired in 1998). With more than 60 percent of its capacity fired by coal (much of it old and fully depreciated), MAPP's operating costs are so low that the average costs of producing electricity are lower than marginal costs (and competitive prices). Consequently, the competitive price of electricity may be higher than the regulated price, depending on the level of competitioninduced efficiency improvements and cost reductions (Figure 26).

Prices generally fall through 2003 in response to lower O\&M costs. These cost reductions are partially offset by 
Figure 27. Region 6 (NY): Average Costs of Electricity Production and Delivery and Competitive Prices in the Moderate Consumer Response and High Efficiency Cases, 1998-2015

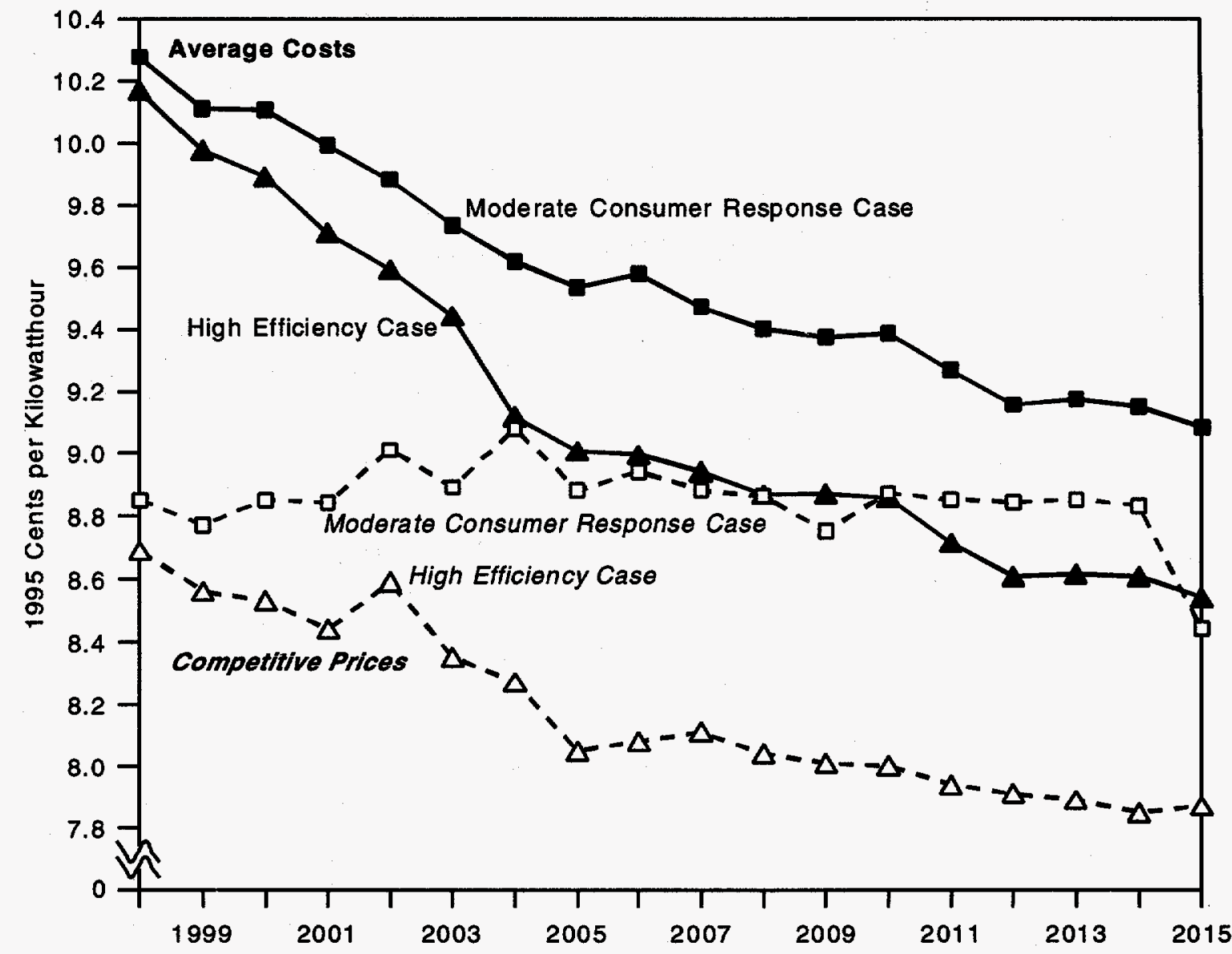

Table 10. Region 6 (NY): Net Stranded Costs, 1998-2015

(Million 1995 Dollars)

\begin{tabular}{|c|c|c|c|c|c|c|c|c|c|c|c|c|c|c|c|c|c|c|}
\hline Case & 1998 & 1999 & 2000 & 2001 & 2002 & 2003 & 2004 & 2005 & 2006 & 2007 & 2008 & 2009 & 2010 & 2011 & 2012 & 2013 & 2014 & 2015 \\
\hline Moderate Response & 1,728 & 1,626 & 1,539 & 1,401 & 1,089 & 1,055 & 673 & 845 & 809 & 760 & 702 & 806 & 685 & 546 & 413 & 424 & 431 & 845 \\
\hline High Efficiency & 1,778 & 1,729 & 1,673 & 1,553 & 1,237 & 1,365 & 1,053 & 1,203 & 1,170 & 1,068 & 1,083 & 1,114 & 1,117 & 1,008 & 916 & 970 & 992 & 895 \\
\hline
\end{tabular}

Source: Energy Information Administration, Office of Integrated Analysis and Forecasting, National Energy Modeling System and Prototype Value of Capacity Model, run sets E15VO3 and HIEFF.

increased gas-fired generation with rising demands. In 2005, prices rise suddenly when an assumed reduction in Canadian imports of wholesale power (due to the expiration of power contracts) is replaced with increased gas-fired generation. After 2005, the volatility of marginal-cost-based prices as compared to average-costbased prices is evident. Small changes in the regional capacity mix affect marginal costs and prices, even though the change in average costs is small. Nuclear retirements from 2010 through 2014 (just over 3 gigawatts of capacity) cause fluctuations in the competitive price to continue as gas-fired technologies replace the nuclear capacity (Figure 26).
With competitive prices higher than average costs, there are no stranded costs, except for very small amounts in 1998 and in 2003 and 2004 only in the High Efficiency Case (Table 9). This means that stranded assets are negative, reflecting an increase in the market value of suppliers in this region due to competition, but higher prices for consumers.

\section{Region 6: NY}

The pattern of falling average costs approaching convergence with competitive prices can be seen in the New York Power Pool (NY) projections (Figure 27). The effect of higher assumed reductions in O\&M costs is 
Figure 28. Region 7 (NE): Average Costs of Electricity Production and Delivery and Competitive Prices in the Moderate Consumer Response and High Efficiency Cases, 1998-2015

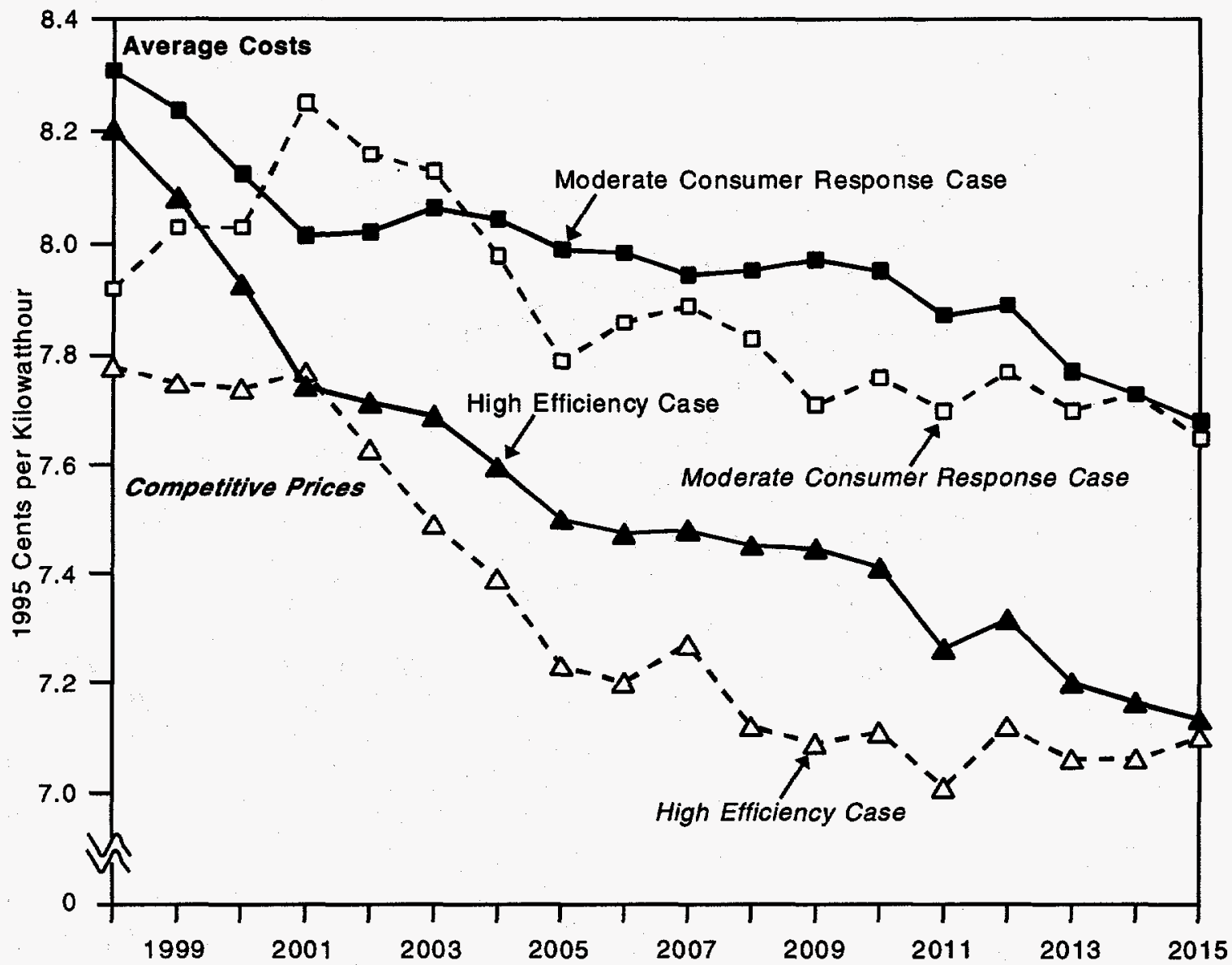

Table 11. Region 7 (NE): Net Stranded Costs, 1998-2015

(Million 1995 Dollars)

\begin{tabular}{|c|c|c|c|c|c|c|c|c|c|c|c|c|c|c|c|c|c|c|}
\hline Case & 1998 & 1999 & 2000 & 2001 & 2002 & 2003 & 2004 & 2005 & 2006 & 2007 & 2008 & 2009 & 2010 & 2011 & 2012 & 2013 & 2014 & 2015 \\
\hline Moderate Response & 414 & 226 & 108 & -249 & -148 & -63 & 60 & 219 & 143 & 73 & 139 & 305 & 217 & 198 & 134 & 84 & 5 & 25 \\
\hline High Efficiency & 440 & 351 & 211 & .23 & 98 & 220 & 225 & 302 & 306 & 236 & 382 & 408 & 336 & 289 & 228 & 155 & 108 & 27 \\
\hline
\end{tabular}

Source: Energy Information Administration, Office of Integrated Analysis and Forecasting, National Energy Modeling System and Prototype Value of Capacity Model, run sets E15VO3 and HIEFF.

evident in the High Efficiency Case compared to the Moderate Consumer Response Case, as prices in the two cases diverge through 2005. As is the case in most regions, there are short-term price effects from changes in the mix of generating technologies over time, which affect the stability of marginal costs. Additions of gasfired capacity in 2015 displace a small amount of oilfired generation, reducing marginal costs, and competitive prices fall in the Moderate Consumer Response Case.

Net stranded costs are high in NY, falling gradually from between $\$ 1.7$ and $\$ 1.8$ billion in 1998 to between $\$ 0.8$ and $\$ 0.9$ billion in 2015 (Table 10).

\section{Region 7: NE}

Competitive electricity prices in the New England Power Pool (NE) are not much lower than average costs in 1998. A high proportion of New England's generating capacity is oil-fired, which pushes generating costs higher than the national average by about 0.5 cents per kilowatthour in the early years of the projection. In response to an assumed reduction in wholesale power imports from Canada in 2001 (from 10.5 billion kilowatthours in 2000 to 2.5 billion kilowatthours in 2001) as contracts expire, generation from oil and gas increases and the competitive price rises in the Moderate Consumer Response Case. Prices do not rise in the 
Figure 29. Region 8 (FL): Average Costs of Electricity Production and Delivery and Competitive Prices in the Moderate Consumer Response and High Efficiency Cases, 1998-2015

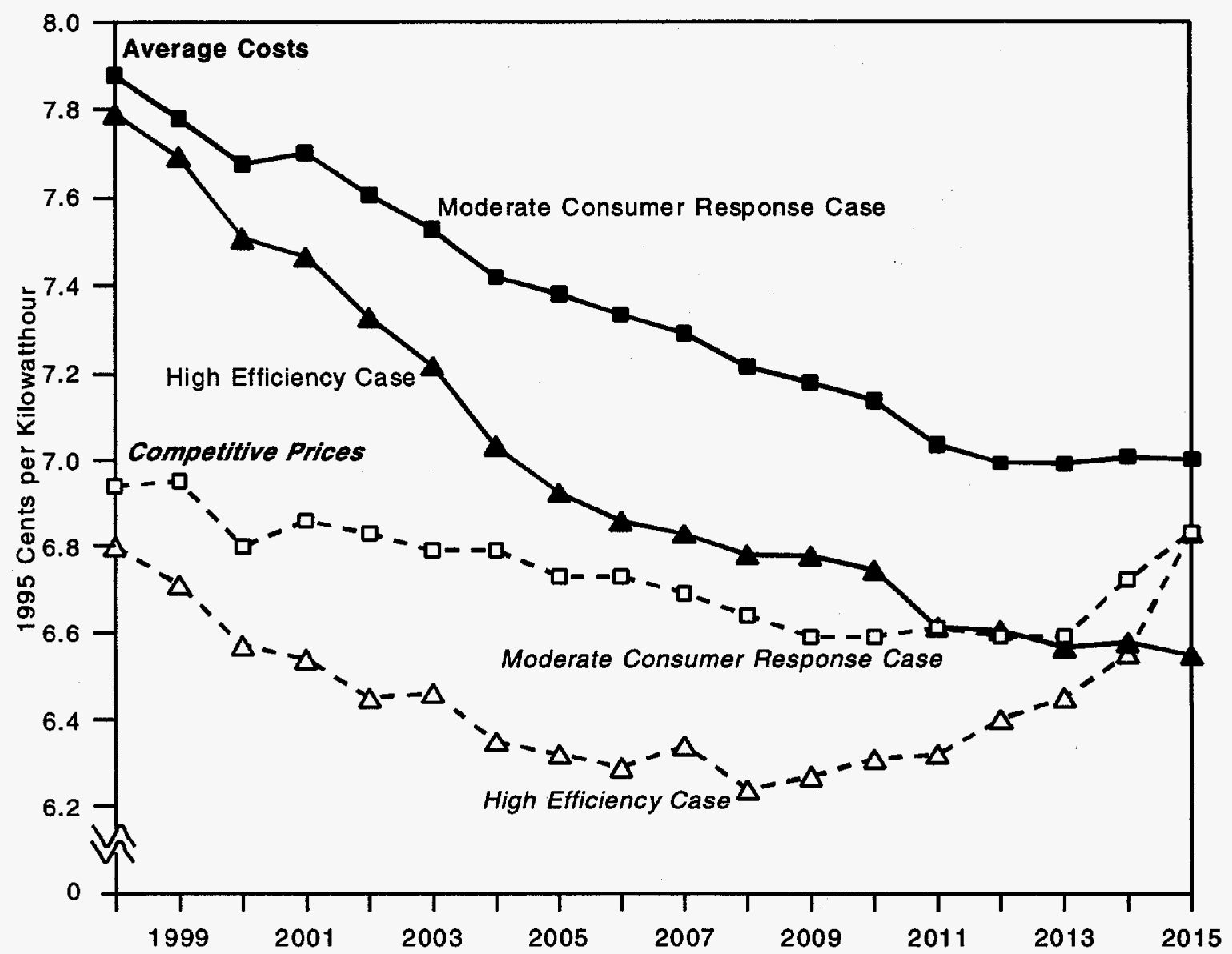

Table 12. Region 8 (FL): Net Stranded Costs, 1998-2015

(Million 1995 Dollars)

\begin{tabular}{lrrrrrrrrrrrrrrrrrrr}
\hline \multicolumn{1}{c}{ Case } & 1998 & 1999 & 2000 & 2001 & 2002 & 2003 & 2004 & 2005 & 2006 & 2007 & 2008 & 2009 & 2010 & 2011 & 2012 & 2013 & 2014 & 2015 \\
\hline Moderate Response & 1,448 & 1,309 & 1,417 & 1,359 & 1,300 & 1,238 & 1,080 & 1,117 & 1,060 & 1,080 & 1,047 & 1,087 & 1,030 & 824 & 793 & 809 & 571 & 349 \\
High Efficiency & 1,546 & 1,566 & 1,536 & 1,545 & 1,476 & 1,294 & 1,177 & 1,028 & 998 & 872 & 975 & 951 & 806 & 549 & 380 & 228 & 13 & -617 \\
\hline
\end{tabular}

Source: Energy Information Administration, Office of Integrated Analysis and Forecasting, National Energy Modeling System and Prototype Value of Capacity Model, run sets E15V03 and HIEFF.

High Efficiency Case, because a higher proportion of the increase in generation to make up for the decreased imports is gas-fired ${ }^{82}$ Oil-fired generation increases by 7 percent from 2000 to 2001 in the High Efficiency Case (from 14 to 15 billion kilowatthours) and by 23 percent in the Moderate Consumer Response Case (from 13 to 16 billion kilowatthours). The higher assumed generating efficiencies (lower heat rates) in the High Efficiency Case allow for a higher level of generation from the less expensive gas-fired capacity. After 2001 , prices fall as gas-fired generation replaces the expensive oil-fired generation when old oil-fired capacity retires and is replaced by new gas capacity (Figure 28).

Net stranded costs in the NE region are never higher than $\$ 0.4$ billion annually in the projections used for this analysis (Table 11).

\section{Region 8: FL}

Prices in the Florida subregion of the Southeastern Electric Reliability Council (FL) fall with declining

\footnotetext{
${ }^{82}$ In general, the ratio of oil-fired to gas-fired capacity is an indication of the proportion of time that oil and gas fuel the marginal capacity.
} 
Figure 30. Region 9 (STV): Average Costs of Electricity Production and Delivery and Competitive Prices in the Moderate Consumer Response and High Efficiency Cases, 1998-2015

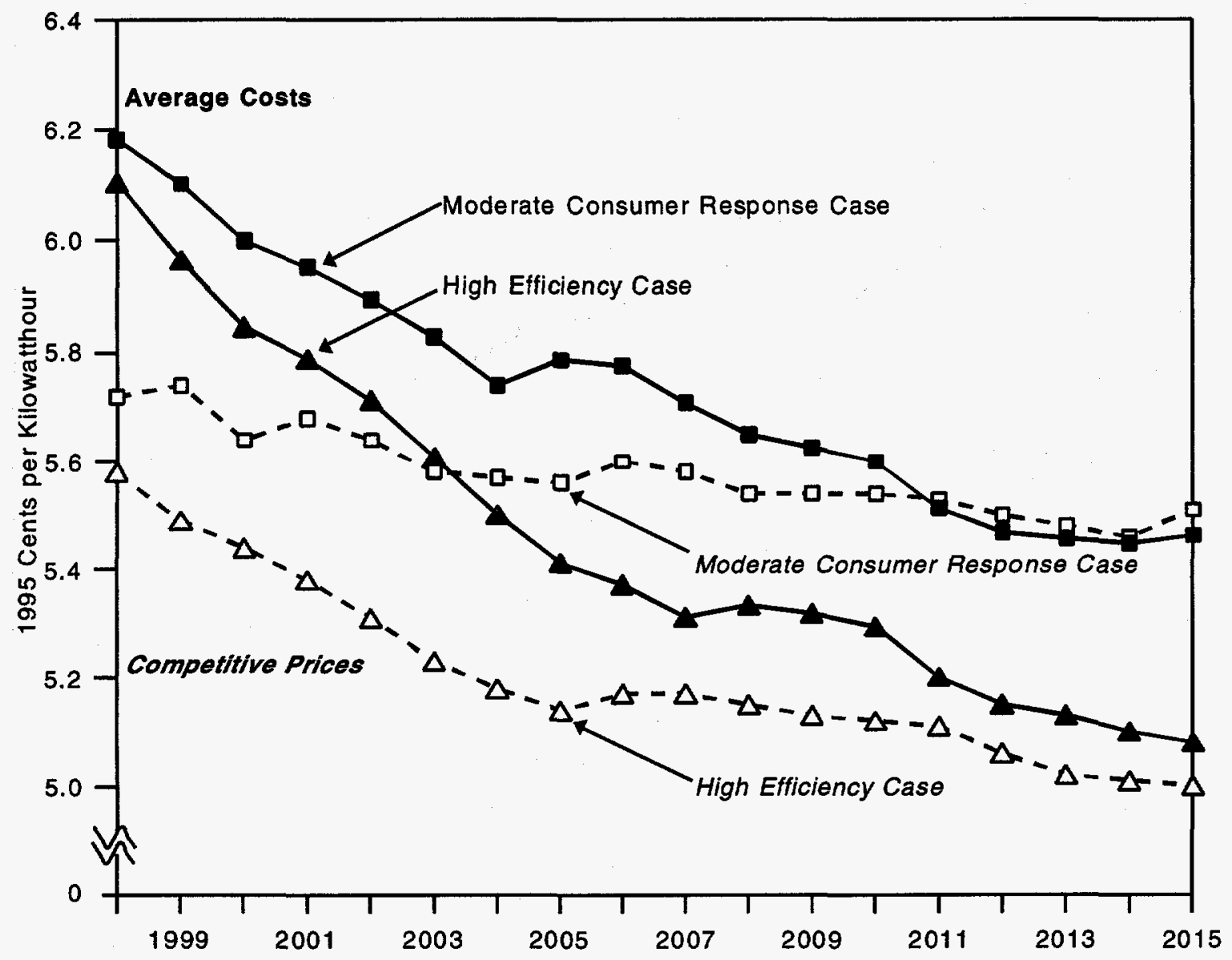

Table 13. Region 9 (STV): Net Stranded Costs, 1998-2015

(Million 1995 Dollars)

\begin{tabular}{|c|c|c|c|c|c|c|c|c|c|c|c|c|c|c|c|c|c|c|}
\hline Case & 1998 & 1999 & 2000 & 2001 & 2002 & 2003 & 2004 & 2005 & 2006 & 2007 & 2008 & 2009 & 2010 & 2011 & 2012 & 2013 & 2014 & 2015 \\
\hline Moderate Response & 2,538 & 1,979 & 2,009 & 1,586 & 1,476 & 1,442 & 1,034 & 1,475 & 1,091 & 855 & 772 & 617 & 431 & -148 & -207 & -94 & -88 & -380 \\
\hline High Efficiency & 2,938 & 2,653 & 2,360 & 2,402 & 2,381 & 2,345 & 2,038 & 1,681 & 1,308 & 937 & 1,134 & 1,142 & 1,115 & 540 & 643 & 849 & 662 & 566 \\
\hline
\end{tabular}

Source: Energy Information Administration, Office of Integrated Analysis and Forecasting, National Energy Modeling System and Prototype Value of Capacity Model, run sets E15V03 and HIEFF.

O\&M costs until 2011, when nuclear capacity begins to retire. As the nuclear capacity goes out of service (1.3 gigawatts between 2011 and 2013), reliability costs increase (through the reliability price adjustment) in spite of coal capacity additions (Figure 29). The increase in reliability costs pushes prices in the Moderate Consumer Response Case toward convergence with average costs, but the increase in the High Efficiency Case sends prices above average costs in 2015. Florida has a high, but short-lived winter peak period that may cause higher reliability costs in the later years of the projection. It is likely that the price response in the High Efficiency Case would encourage the addition of capacity if competitive prices remained above average costs.
Net stranded costs in the FL region range from $\$ 1.4$ to $\$ 1.5$ billion in 1998 (Table 12).

\section{Region 9: STV}

Prices and costs illustrate a strong tendency to converge in the Southeastern Electric Reliability Council region (excluding Florida) (STV). Prices and average costs fall in response to reductions in O\&M costs through 2005. After that, prices remain flat, but costs continue to fall (as fuel costs are reduced and uneconomic costs continue to be amortized away), converging with competitive prices by 2011 (in the Moderate Consumer Response Case) or sometime after 2015 (in the High Efficiency Case) (Figure 30). 
Figure 31. Region 10 (SPP): Average Costs of Electricity Production and Delivery and Competitive Prices in the Moderate Consumer Response and High Efficiency Cases, 1998-2015

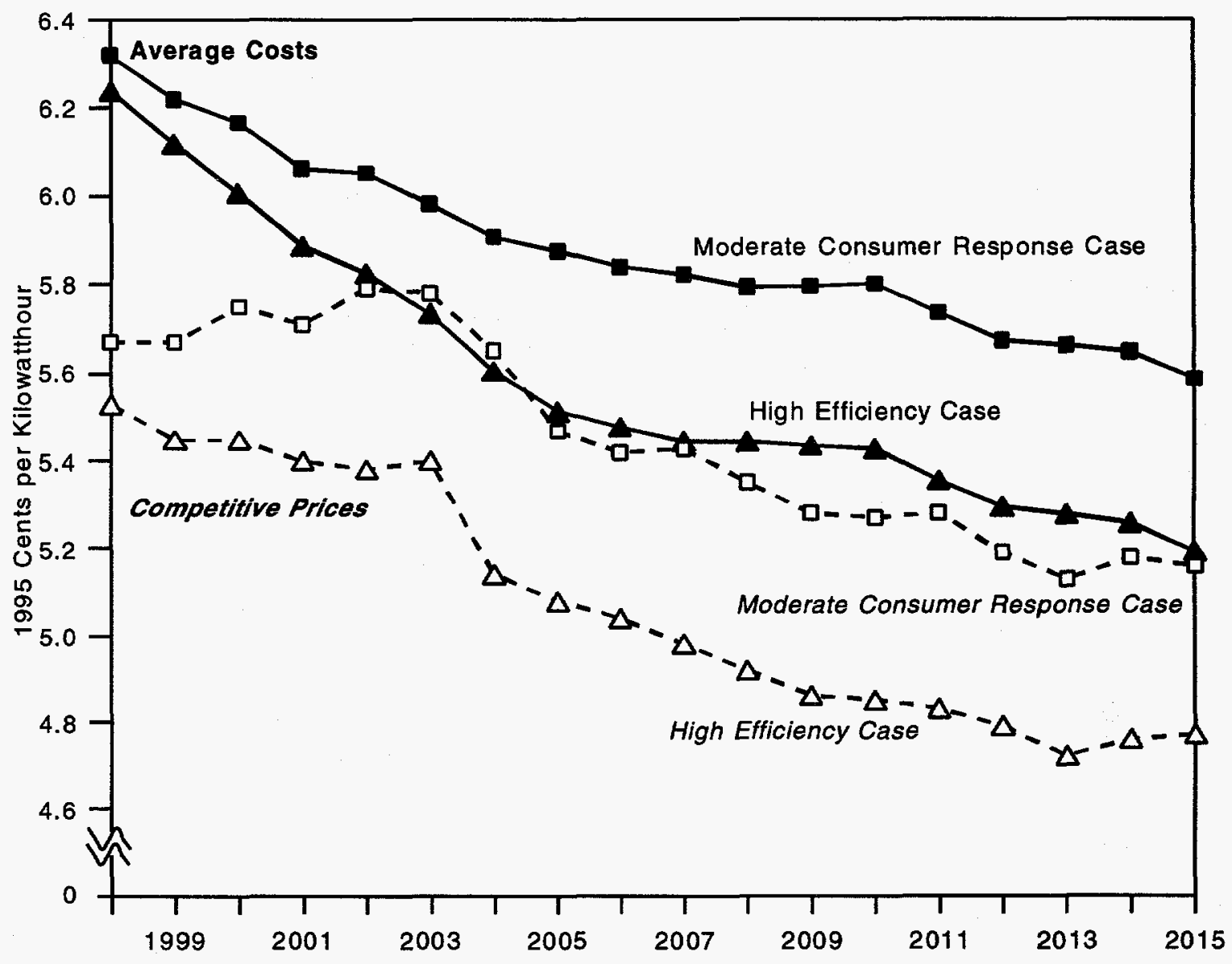

Table 14. Region 10 (SPP): Net Stranded Costs, 1998-2015

(Million 1995 Dollars)

\begin{tabular}{|c|c|c|c|c|c|c|c|c|c|c|c|c|c|c|c|c|c|c|}
\hline Case & 1998 & 1999 & 2000 & 2001 & 2002 & 2003 & 2004 & 2005 & 2006 & 2007 & 2008 & 2009 & 2010 & 2011 & 2012 & 2013 & 2014 & 2015 \\
\hline Moderate Response & 1,779 & 1,536 & 1,203 & 1,066 & 780 & 610 & 802 & 1,241 & $t, 326$ & 1,256 & 1,424 & 1,692 & 1,754 & 1,511 & 1,626 & 1,819 & 1,641 & 1,499 \\
\hline High Efficiency & 1,987 & 1,890 & 1,591 & 1,424 & 1,332 & 983 & 1,428 & 1,350 & 1,384 & 1,483 & 1,689 & 1,915 & 1,931 & 1,785 & 1,730 & 1,930 & 1,767 & 1,523 \\
\hline
\end{tabular}

Source: Energy Information Administration, Office of Integrated Analysis and Forecasting, National Energy Modeling System and Prototype Value of Capacity Model, run sets E15V03 and HIEFF.

Annual net stranded costs for the STV region are as high as $\$ 2.9$ billion in 1998 (Table 13 ).

\section{Region 10: SPP}

With 29 gigawatts of oil-fired capacity out of a total of 71 gigawatts, increases in marginal generating costs resulting from increases in demand offset reductions in O\&M costs in the Southwest Power Pool (SPP) through 2003. As a result, competitive prices increase slightly (in the Moderate Consumer Response Case) or fall slightly (in the High Efficiency Case). After 2003, however, additions of coal-fired capacity ( 3 to 9 gigawatts by 2015) and combined-cycle capacity (8 to 14 gigawatts) replacing expensive oil-fired capacity push marginal operating costs and marginal reliability costs down. Consequently, the competitive price for electricity falls between 2003 and 2015. As prices stabilize and cost reductions continue after 2013 (due to lower capital costs from the early capacity additions ${ }^{83}$ ), prices and

\footnotetext{
${ }^{83}$ Average costs calculations in this analysis follow the regulatory procedure of "front end loaded" capital recovery. This means that capital recovery on new power plants is highest in the early years of the plant's life, falling over time as accumulated depreciation lowers the plant's book value. Consequently, the return on-and return of-capital expenditures (represented in average costs and regulated prices) falls over time.
} 
Figure 32. Region 11 (NWP): Average Costs of Electricity Production and Delivery and Competitive Prices in the Moderate Consumer Response and High Efficiency Cases, 1998-2015

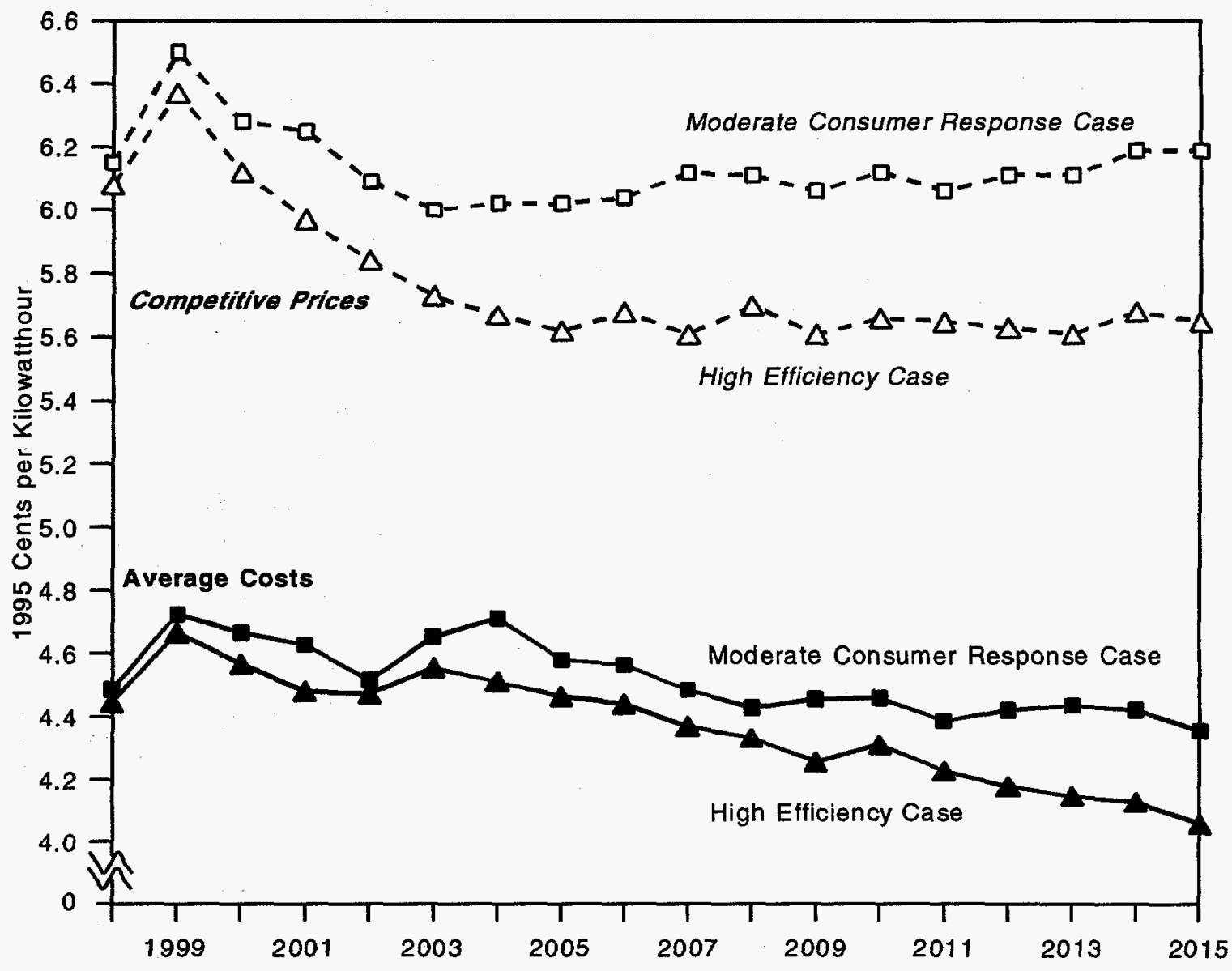

Table 15. Region 11 (NWP): Net Stranded Costs, 1998-2015

(Million 1995 Dollars)

\begin{tabular}{|c|c|c|c|c|c|c|c|c|c|c|c|c|c|c|c|c|c|c|}
\hline Case & 1998 & 1999 & 2000 & 2001 & 2002 & 2003 & 2004 & 2005 & 2006 & 2007 & 2008 & 2009 & 2010 & 2011 & 2012 & 2013 & 2014 & 2015 \\
\hline Moderate Response & $-3,251$ & $-3,536$ & $-3,287$ & $-3,333$ & $-3,299$ & $-2,885$ & $-2,868$ & $-3,203$ & $-3,271$ & $-3,693$ & $-3,855$ & $-3,736$ & $-3,900$ & $-3,991$ & $-4,030$ & $-4,067$ & $-4,333$ & $3-4,522$ \\
\hline High Efficiency & $-3,212$ & $-3,426$ & $-3,173$ & $-3,099$ & $-2,870$ & $-2,522$ & $-2,534$ & $-2,590$ & $-2,773$ & $-2,822$ & $-3,142$ & $-3,178$ & $-3,182$ & $-3,412$ & $-3,519$ & $-3,562$ & $-3,807$ & $7-4,001$ \\
\hline
\end{tabular}

Source: Energy Information Administration, Office of Integrated Analysis and Forecasting, National Energy Modeling System and Prototype Value of Capacity Model, run sets E15V03 and HIEFF.

costs illustrate a movement toward convergence (Figure 31).

Net stranded costs in SPP are as high as $\$ 2.0$ billion in 1998 (Table 14).

\section{Region 11: NWP}

The Northwest Pool subregion of the Western Systems Coordinating Council (NWP) is very similar to MAPP in terms of the relationship between competitive prices and average costs, but instead of coal-fired capacity, NWP has a large amount of hydroelectric generating capacity, which is so inexpensive to operate that the average costs of production are lower than the marginal costs. An assumed increase in exports of power to Canada (10 billion kilowatthours in 1999, up from 5 billion kilowatthours in 1998) causes an increase in the marginal costs and prices, as gas-fired generation increases. Coal-fired capacity additions and lower O\&M costs reduce marginal costs and prices through 2004, and they remain stable after that (Figure 32).

With competitive prices higher than average costs, there are no net stranded costs in NWP. As with MAPP, the market value of NWP's generating assets could increase as a result of competitive pricing (Table 15). 
Figure 33. Region 12 (RA): Average Costs of Electricity Production and Delivery and Competitive Prices in the Moderate Consumer Response and High Efficiency Cases, 1998-2015

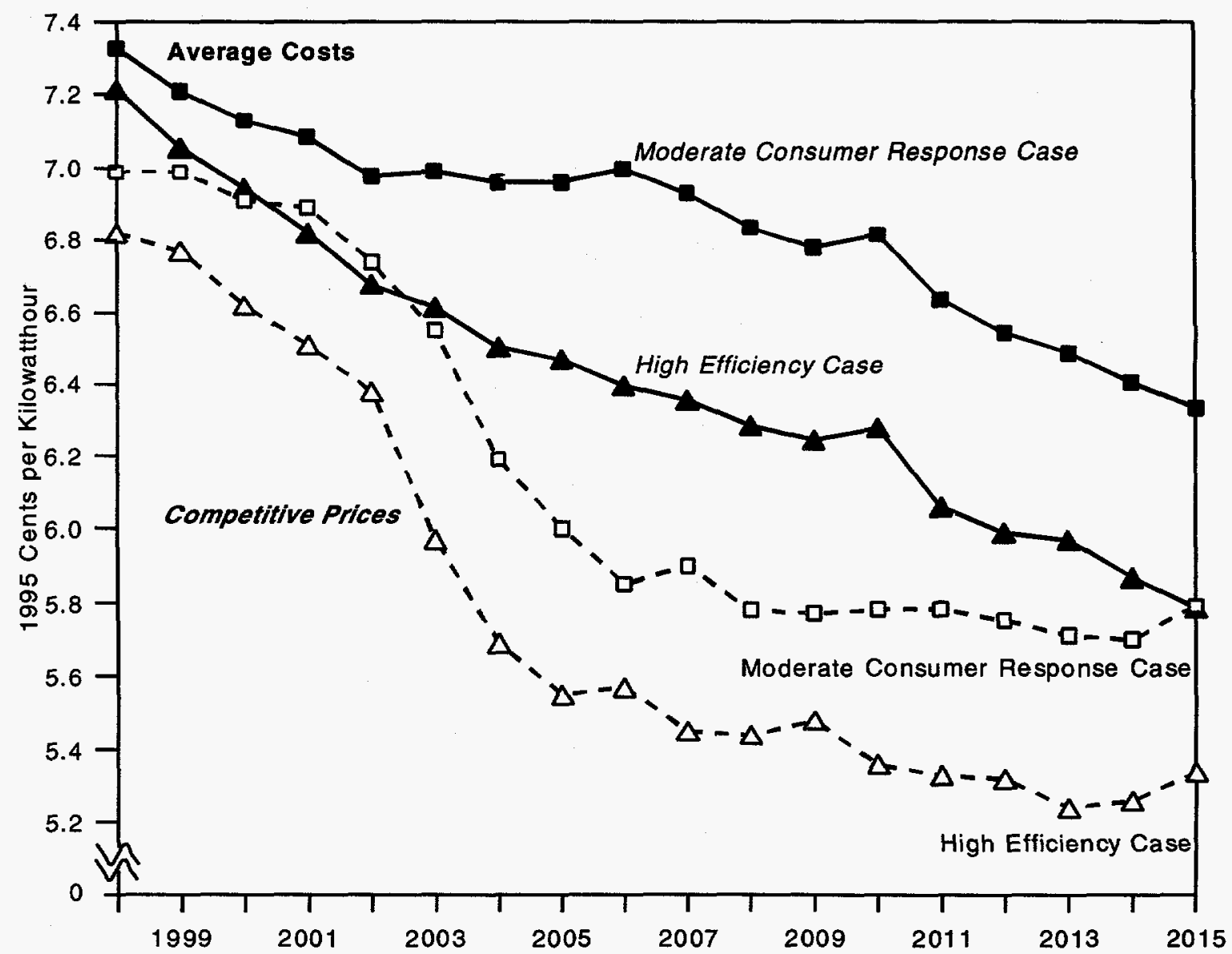

Table 16. Region 12 (RA): Net Stranded Costs, 1998-2015

(Million 1995 Dollars)

\begin{tabular}{|c|c|c|c|c|c|c|c|c|c|c|c|c|c|c|c|c|c|c|}
\hline Case & 1998 & 1999 & 2000 & 2001 & 2002 & 2003 & 2004 & 2005 & 2006 & 2007 & 2008 & 2009 & 2010 & 2011 & 2012 & 2013 & 2014 & 2015 \\
\hline Moderate Response & 326 & 223 & 232 & 198 & 254 & 464 & 847 & 1,065 & 1,309 & 1,203 & 1,232 & 1,197 & 1,250 & 1,053 & 986 & 973 & 897 & 700 \\
\hline High Efficiency & 405 & 304 & 339 & 318 & 312 & 701 & 892 & 1,038 & 938 & 1,057 & 984 & 927 & 1,111 & 880 & 804 & 910 & 770 & 558 \\
\hline
\end{tabular}

Source: Energy Information Administration, Office of Integrated Analysis and Forecasting, National Energy Modeling System and Prototype Value of Capacity Model, run sets E15V03 and HIEFF.

\section{Region 12: RA}

The Rocky Mountain and Arizona-New Mexico Power Areas (RA) show changes in the competitive price over time that result from the assumed reductions in O\&M and G\&A costs and slight changes in the generating capacity $\mathrm{mix}$ (Figure 33 ). As with most regions, the changes in the mix of technologies for generating capacity translate into fluctuations in marginal energy costs from year to year. In the early years of the projection, 1998 until about 2001, competitive prices are held high- er than they would otherwise be by the presence of 2.4 gigawatts of expensive oil-fired generating capacity. As this capacity is replaced by gas-fired combined-cycle plants, marginal costs and competitive prices fall. The slight increase in price in 2015 reflects the increase in marginal generating costs as demands increase but capacity remains stable (there are no capacity additions projected for the year 2015 in RA).

Stranded costs for the RA region are about $\$ 0.3$ to $\$ 0.4$ billion in 1998 (Table 16). 
Figure 34. Region 13 (CNV): Average Costs of Electricity Production and Delivery and Competitive Prices in the Moderate Consumer Response and High Efficiency Cases, 1998-2015

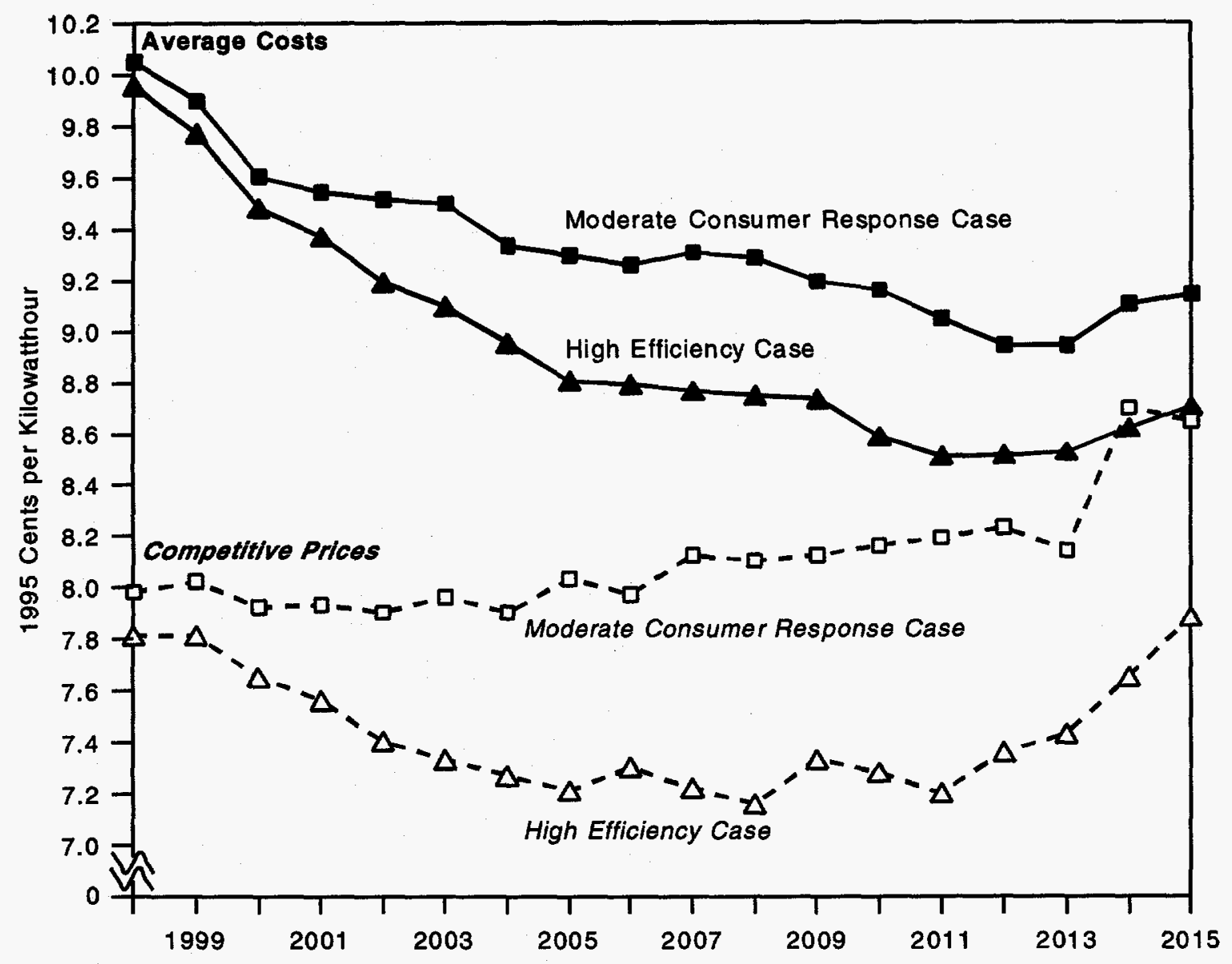

Table 17. Region 13 (CNV): Net Stranded Costs, 1998-2015

(Million 1995 Dollars)

\begin{tabular}{|c|c|c|c|c|c|c|c|c|c|c|c|c|c|c|c|c|c|c|}
\hline Case & 1998 & 1999 & 2000 & 2001 & 2002 & 2003 & 2004 & 2005 & 2006 & 2007 & 2008 & 2009 & 2010 & 2011 & 2012 & 2013 & 2014 & 2015 \\
\hline Moderate Response & 4,845 & 4,435 & 4,032 & 3,908 & 3,959 & 3,820 & 3,609 & 3,204 & 3,356 & 3,108 & 3,156 & 2,881 & 2,695 & 2,352 & 1,965 & 2,273 & 1,124 & 1,420 \\
\hline High Efficiency & 5,026 & 4,662 & 4,387 & 4,395 & 4,408 & 4,406 & 4,274 & 4,120 & 3,888 & 4,077 & 4,270 & 3,800 & 3,610 & 3,583 & 3,213 & 3,099 & 2,765 & 2,415 \\
\hline
\end{tabular}

Source: Energy Information Administration, Office of Integrated Analysis and Forecasting, National Energy Modeling System and Prototype Value of Capacity Model, run sats E15VO3 and HIEFF.

\section{Region 13: CNV}

In September 1996, the California Legislature passed legislation to restructure California's electric power industry. Assembly Bill 1890 (AB 1890) mandates the recovery of stranded costs within 10 years and a $10-$ percent decrease in electricity prices for small commercial and residential customers by the end of 1998 (see Chapter 1). The results for the California-Southern Nevada Power Area (CNV) do not incorporate the provisions of $A B$ 1890, because this analysis only projects average prices to all customers, including large commercial and industrial consumers, whose rates were not stipulated by $A B 1890$. Unless unique prices are project- ed for each of these customer classes (residential, small commercial and industrial, and large commercial and industrial), the price mandates in $\mathrm{AB} 1890$ cannot be calculated. However, the results do show that the CNV region has the largest difference of any region shown in this analysis between average generating costs and marginal generating costs. An increase in reliability costs after 2013 results from the retirement of more than 2 gigawatts of nuclear capacity in that year.

A spread of 2 cents per kilowatthour between average costs and competitive prices in 1998 causes stranded costs in the range of $\$ 4.8$ to $\$ 5.0$ billion in that year alone (Table 17). 


\section{Net Stranded Assets}

Nationally, estimates of total net stranded costs and net stranded assets under competitive pricing are lower in the Flat Rates Case and High Consumer Response Case than in either of the cases used in the regional analysis, because competitive prices are higher both in the absence of time-of-use rates and with a higher consumer response to time-of-use rates than that used in the Moderate Consumer Response Case and High Efficiency Case (Table 18).

Across all the cases considered in this analysisexcluding the High Gas Price, Low Gas Price, No Capacity Additions, High Value of Reliability, and Intense Competition cases ${ }^{84}$-the projections of net stranded assets through 2015 for the Nation as a whole range from $\$ 72.3$ billion to $\$ 168.7$ billion (Table 18). The estimates differ primarily as a result of differences in the assumptions about the degree to which consumers will be willing and able to shift demand from highpriced peak demand periods to low-priced off-peak periods and the discount rates used to calculate the present value of stranded costs. The lowest estimate is from the High Consumer Response Case, using a discount rate of 10 percent. The highest estimate is from the High Efficiency Case, ${ }^{85}$ using a discount rate of 6 percent. The range across the cases is generally consistent with estimates from other organizations (Table 19). As discussed earlier, net stranded costs could understate gross stranded costs by as much as 20 percent on a national basis.

Table 18. Net Stranded Assets Through 2015 by Region Under Competitive Pricing of Generation Services in Four Cases

(Billion 1995 Dollars)

\begin{tabular}{|c|c|c|c|c|c|c|c|c|}
\hline \multirow[b]{3}{*}{ Region } & \multicolumn{8}{|c|}{ Case Name and Discount Rate Assumption } \\
\hline & \multicolumn{2}{|c|}{ Flat Rates } & \multicolumn{2}{|c|}{$\begin{array}{l}\text { Moderate } \\
\text { Consumer } \\
\text { Response }\end{array}$} & \multicolumn{2}{|c|}{$\begin{array}{c}\text { High } \\
\text { Consumer } \\
\text { Response }\end{array}$} & \multicolumn{2}{|c|}{ High Efficiency } \\
\hline & $6 \%$ & $10 \%$ & $6 \%$ & $10 \%$ & $6 \%$ & $10 \%$ & $6 \%$ & $10 \%$ \\
\hline ECAR & 29.5 & 24.3 & 24.7 & 20.4 & 16.4 & 12.9 & 27.3 & 22.1 \\
\hline ERCOT & 9.5 & 6.8 & 18.4 & 14.5 & 17.9 & 14.1 & 22.1 & 17.2 \\
\hline MAAC & 16.4 & 12.4 & 19.3 & 14.9 & 14.0 & 10.6 & 22.3 & 17.1 \\
\hline MAIN & 17.5 & 13.4 & 12.1 & 9.4 & 11.9 & 9.2 & 17.2 & 13.4 \\
\hline MAPP $\ldots \ldots \ldots \ldots$ & -6.8 & -4.8 & -5.8 & -4.0 & -5.8 & -4.0 & -3.0 & -2.0 \\
\hline$\ldots \ldots \ldots \ldots$ & 13.1 & 10.3 & 11.0 & 8.9 & 9.5 & 7.7 & 14.0 & 11.0 \\
\hline NE . & -0.3 & -0.2 & 1.1 & 0.9 & 0.7 & 0.5 & 2.7 & 2.0 \\
\hline$\ldots \ldots$ & 8.8 & 7.6 & 12.2 & 9.6 & 9.7 & 7.7 & 11.5 & 9.5 \\
\hline STV . . & -0.5 & 0.4 & 12.5 & 10.7 & -2.3 & -0.6 & 19.1 & 15.6 \\
\hline SPP & 1.8 & 1.1 & 14.3 & 10.7 & 9.5 & 7.4 & 17.4 & 13.1 \\
\hline NWP & -36.2 & -27.1 & -38.0 & -28.3 & -33.5 & -24.0 & -33.6 & -25.3 \\
\hline$\ldots \ldots \ldots \ldots$ & 6.5 & 4.4 & 7.7 & 5.4 & 4.7 & 3.1 & 7.4 & 5.3 \\
\hline CNV. & 34.4 & 28.1 & 36.8 & 29.2 & 35.3 & 27.8 & 44.3 & 34.4 \\
\hline National Total ........ & 93.7 & 76.6 & 126.4 & 102.2 & 88.0 & 72.3 & 168.7 & 133.5 \\
\hline
\end{tabular}

Source: Energy Information Administration, Office of Integrated Analysis and Forecasting, National Energy Modeling System and Prototype Value of Capacity Model, run sets AEOAVG2, E15V03, E50V03, and HIEFF.

\footnotetext{
${ }^{84}$ The High and Low Gas Price and No Capacity Additions cases are excluded from the comparison because the extreme assumptions in these cases distort the relationship between average costs and competitive prices that are the basis of stranded costs. The High Value of Reliability Case is excluded because its results are similar to those of the Moderate Consumer Response Case. The stranded asset estimation for the Intense Competition Case is presented separately because it is an upper bound resulting from uncertainty related to the historical O\&M and G\&A data.

${ }^{85} \mathrm{As}$ mentioned earlier, stranded costs are higher in the High Efficiency Case because the assumed cost reductions in this case have a higher impact on marginal costs than on average costs. Specifically, the heat rates for fossil fuel plants (which are frequently the marginal plants) are assumed to improve in this case, but there are no assumed efficiency improvements for nuclear power plants (which affect average costs only). Some analysts believe that efficiency improvements will have the opposite effect-to reduce average costs more than marginal costs-and, hence, reduce stranded costs.
} 
Table 19. Comparison of Estimates of National Total Net Stranded Assets Through 2015 (Billion 1995 Dollars)

\begin{tabular}{|c|c|}
\hline Source & $\begin{array}{l}\text { Estimated National Total } \\
\text { Stranded Assets }\end{array}$ \\
\hline \multicolumn{2}{|l|}{ Energy Information Administration (This Analysis) } \\
\hline \multicolumn{2}{|l|}{ Flat Rates Case } \\
\hline 6-Percent Discount Rate & 93.7 \\
\hline 10-Percent Discount Rate & 76.6 \\
\hline \multicolumn{2}{|l|}{ Moderate Consumer Response Case } \\
\hline 6-Percent Discount Rate ........ & 126.4 \\
\hline 10-Percent Discount Rate & 102.2 \\
\hline \multicolumn{2}{|l|}{ High Consumer Response Case } \\
\hline 6-Percent Discount Rate & 88.0 \\
\hline 10-Percent Discount Rate ....... & 72.3 \\
\hline \multicolumn{2}{|l|}{ High Efficiency Case } \\
\hline 6-Percent Discount Rate.. & 168.7 \\
\hline 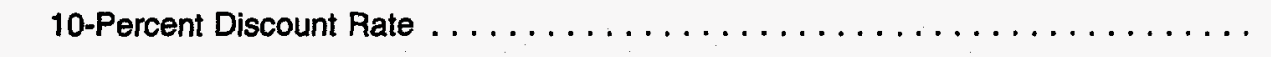 & 133.5 \\
\hline \multicolumn{2}{|l|}{ Estimates from Other Organizations } \\
\hline Resource Data International, Inc. . & 163.0 \\
\hline Moody's Investment Service & 135.0 \\
\hline Energy Online $\ldots \ldots \ldots$ & 124.2 \\
\hline Baxter and Hirst $\ldots \ldots \ldots \ldots \ldots$. & $15-256$ \\
\hline Citizens for a Sound Economy $\ldots \ldots \ldots \ldots \ldots \ldots \ldots \ldots \ldots \ldots \ldots \ldots$ & 42.0 \\
\hline
\end{tabular}

Sources: Energy Information Administration: Office of Integrated Analysis and Forecasting, National Energy Modeling System and Prototype Value of Capacity Model, run sets AEOAVG2, E15V03, E50V03, and HIEFF. Resource Data International, Inc.: Retail Power Markets in the U.S. (Boulder, CO, 1995). Moody's Investment Service: Reported in "California Electric Utility Stocks Recover from Jolt," Wall Street Journal (February 19, 1997). Energy Online: LCG Consulting, web site www.energyonline.com. Baxter and Hirst: L. Baxter and E. Hirst, Estimating Potential Stranded Commitments for U.S. Investor-Owned Utilities, ORNLCON-406 (Oak Ridge, TN: Oak Ridge National Laboratory, January 1995). Citizens for a Sound Economy: M.T. Maloney and R.E. MoCormick with D.D. Sauer, Customer Choice, Consumer Value, An Analysis of Retail Competition in America's Electric Industry, Vol. II: Analytical Techniques (Clemson, SC: Clemson University, July 1996).

In the Intense Competition Case, illustrating the uncertainty associated with the level of competitive pressure and the representation of costs that would be included in competitive prices, estimates of net stranded assets are as high as $\$ 408$ billion. ${ }^{86}$ However, this stranded asset estimate assumes that there would be no reduction in costs as a result of competitive pressures beyond those assumed in the AEO97 Reference Case, whereas it is likely that price reductions of 20 to 25 percent under competition would result in intensive efforts on the part of suppliers to reduce costs.

As discussed in Chapter 2, the treatment in prices of as much as $\$ 30$ billion annually in G\&A and nonfuel O\&M costs for investor-owned utilities in a competitive environment is not clear. ${ }^{87}$ If these costs are not recovered through prices, as is assumed in the Intense Competition Case, either they must be included in stranded costs or they must be assumed to be eliminated by suppliers.

If the $O \& M$ and $G \& A$ costs that are removed from competitive prices in the Intense Competition Case are eliminated completely from costs as well, then net stranded assets fall from $\$ 408$ billion to $\$ 110$ billion. In other words, the O\&M and G\&A costs that are potentially fixed, and therefore not included for pricing purposes, could contribute roughly $\$ 298$ billion to net stranded assets through 2015 if the costs were incurred but not recovered through prices. As mentioned previously, however, with price reductions of this magnitude it is likely that some producers would successfully reduce costs, and others would go out of business. The resulting cost reductions and price increases (from the reduction in capacity) mean that the prices projected in the Intense Competition Case should not be considered sustainable over the long term. With 
cost reductions and price increases, the stranded asset estimates would be reduced.

Further, delaying full-scale competition by 2 years, to 2000 instead of 1998, results in a reduction in the estimate of stranded assets from $\$ 408$ billion to $\$ 323$ billion through 2015. As mentioned throughout this report, such a reduction in stranded assets as the result of a 2-year delay would be applicable from the suppliers' perspective only, because consumers would pay down the uneconomic costs through electricity prices. If competition were delayed by 2 years and producers successfully reduced their nonfuel, noncapital-related O\&M and G\&A costs, net stranded assets could fall to $\$ 83$ billion.

\section{Conclusions}

In the cases considered to be most likely to occur (all of which exclude recovery of stranded costs through prices), electricity prices could be as much as 0.7 cent lower than the price projected in the AEO97 Reference Case nationally in 1998-a 10-percent reduction based on an average price of 6.9 cents per kilowatthour-and by as much as 0.7 cent per kilowatthour in 2015-an 11percent reduction based on an average price of 6.3 cents per kilowatthour (in the AEO97 Reference Case).

In the early years, all the competitive cases show price reductions, due to the absence of uneconomic costs. As mentioned previously, the price reductions described in the competitive cases relative to the AEO97 Reference Case are in addition to the price reductions that are already occurring due to the current level of limited competition in the wholesale market for electric power and the expectation of a higher level of competition in the future. ${ }^{88}$ By 2015, only the High Efficiency Case shows meaningful reductions in prices-as a result of cost reductions and efficiency improvements-in comparison with the AEO97 Reference Case projections.

Time-of-use rates, or other price-induced incentives for consumers to shift demand from peak to off-peak periods, could affect prices in either of two ways. If consumer response reduces peak period demands without having a significant effect on total demands, then marginal generating costs and competitive prices could fall. This could have the added impact of increasing stranded costs, because average costs would not be reduced as much as marginal costs. On the other hand, if consumer response to competitive time-of-use prices is so high that total demand increases as a result of higher consumption during off-peak periods that overshadows demand reductions during peak times, then average competitive electricity prices could be pushed higher (though generally not as high as regulated prices). This could reduce stranded costs, because marginal costs would increase more than average costs.

Competitive electricity prices in these results are highly sensitive to changes in marginal costs (such as the cost of natural gas) and to shortages of generating capacity, which would have much smaller effects on regulated prices. The value of reliability, as measured in this analysis, does not appear to have a large effect on the price of electricity, although it does affect how much capacity could be built, as measured by the "optimal" reserve margin. The reserve margin is also affected by assumptions regarding the level of consumer response to time-of-use prices. The greatest uncertainty surrounding the price projections presented in this report is the delineation of fixed versus variable costs with respect to short-run decisions about the operation of generating facilities. The removal from marginal generating costs of all costs that could potentially be fixed instead of variable-and, theoretically, excluded from competitive prices-could reduce the price projections by as much as 1.0 cent per kilowatthour.

The analysis in the present chapter found that, without stranded asset recovery, prices and thus revenues would fall under competition. Such decreases will have financial implications that are the subject of the following chapter. Financial aspects of restructuring are important because they could affect both the structure of the industry (i.e., the number of utilities and size of the industry) and the amount/type of capacity that is built.

\footnotetext{
${ }^{86}$ All stranded asset calculations for the Intense Competition Case assume a 6-percent discount rate.

${ }^{87}$ In Chapter 2, the discussion involved $\$ 30$ billion in nonfuel O\&M costs (generation only) and G\&A costs (related to generation, transmission, and distribution) for only the investor-owned utilities in 1995. In the analysis in this chapter, the calculations of stranded costs for the Intense Competition Case include costs for nonfuel O\&M for generation only, along with the generation allocation of $\mathrm{G} \& \mathrm{~A}$ costs for both investor-owned and public utilities (including municipal, cooperative, and Federal projects). Sixty percent of total G\&A and other overhead costs is allocated to the generation stage of production. These costs contribute $\$ 31$ billion to stranded cost estimates in 1998 in the Intense Competition Case, falling to $\$ 10$ billion by 2015.

${ }^{88}$ Also mentioned earlier, the cost reductions seen in the historic data, which provide the basis for the assumed competition-induced cost reduction between the No Competition and AEO97 Reference cases, could be the result of both competitive pressures and more effective regulation (i.e., performance-based rates).
} 


\section{Financial Implications of the Competitive, Marginal Cost Pricing of Electricity Generation}

\section{Introduction}

This chapter examines the financial implications of the competitive, marginal cost pricing of electricity. As was noted in the previous chapter, the major difference between marginal and average electricity generation costs is the inclusion in the latter of investment expenditures that turn out to have been uneconomic (i.e., stranded costs). This observation suggests that the financial impacts of the movement toward the competitive pricing of electricity will depend largely upon policy decisions about who will pay for uneconomic investments.

Recently, the Federal Energy Regulatory Commission (FERC) and a few States, most notably California, have ruled that utility shareholders can, in principle, recover their stranded costs; however, depending on the actual implementation of these rules, utilities may or may not be able to recover all of them. ${ }^{89}$ Moreover, most States and the U.S. Congress have not formulated policies and legislation to deal with stranded costs. In short, as of mid-1997, stranded cost recovery remains an open issue. As was done in Chapter 3, the analysis here makes the limiting assumption that utility shareholders will bear all stranded costs. If electricity consumers pay for some of the stranded costs, the financial impacts on utilities will be less than those shown here.

There are four other reasons why the conclusions of this chapter should be considered as the results of a "worst case" scenario from a utility shareholder's viewpoint. First, the analysis focuses on the early years (e.g., 1998), and as Chapter 3 shows, stranded costs tend to fall over time. Thus, the associated financial effects would fall over time. Second, the analysis in this report assumes that a fully competitive electricity generation market will be in place in 1998. A recent EIA report ${ }^{90}$ has shown that the later competition is implemented, the less will be the stranded costs borne by utility shareholders. Third, the analysis also assumes that electricity consumption is relatively unresponsive to price changes (i.e., a price elasticity of only -0.15), and there is some controversy about the size of the price elasticity of demand for electricity.

The third assumption is important because the larger the price elasticity, the larger would be the increase in quantity demanded (and thus the increase in generation) associated with any decrease in price. With everything else held constant, the greater the elasticity of demand, the smaller would be the reduction in revenues associated with a given price reduction. Moreover, with increased demand and generation, average fixed costs (total fixed costs divided by generation) would be lower. Unless the decreases were more than offset by increases in average variable costs, a higher price elasticity of demand would lead to a larger decrease in average total costs (the sum of average fixed and variable costs) associated with a given reduction in price. Thus, unless average variable costs increased substantially with the increase in generation, a greater elasticity of demand would lead to a smaller reduction in average income (average revenues minus average costs) associated with a given decrease in price. ${ }^{91}$

It will be noted that there have been substantial cost reductions in other deregulated industries over and above those discussed in Chapter 3 . However, because of the uncertainties in estimating such reductions, the present analysis assumed no cost reductions beyond those used in the AEO97 Reference Case. Fourth, if there are additional cost improvements that mainly affect the operating costs and performance of large

\footnotetext{
${ }^{89}$ For example, the FERC plans to allow recovery of all "verifiable" stranded costs, and the notion of what is "verifiable" can be subject to differing interpretations. Additionally, in California the stranded costs must be estimated, requiring 10- or 20-year forecasts of fossil fuel prices. History has shown that there is a great deal of uncertainty in 20-year forecasts of fossil fuel prices. Thus, there is a great deal of uncertainty in the estimation of the stranded costs.

${ }^{90}$ Energy Information Administration, The Changing Structure of the Electric Power Industry: An Update, DOE/EIA-0562(96) (Washington, DC, December 1996).

${ }^{91}$ It should also be noted that the greater the price elasticity of demand, the less would be the decrease in price associated with a given decrease in costs (supply). For more discussion of this point, see Citizens for a Sound Economy, Customer Choice, Customer Value: An Analysis of Retail Competition in America's Electric Industry (Washington, DC, July 1996).
} 
baseload power plants, the financial impacts will be less than those shown in this chapter.

Lastly, stranded costs are largely fixed amounts; thus, the issue of who pays for stranded costs is mainly a question about wealth transfer. That is, if utility shareholders are permitted full recovery of their stranded costs, shareholders will be better off and electric ratepayers (taxpayers) will be worse off. The converse is true if utilities are not permitted full recovery of stranded costs. More importantly, to a large extent, the gains and losses will be offsetting. Because the objective of this chapter is to analyze the financial implications of nonrecovery (by utilities) of stranded costs, its focus is on the welfare of utility shareholders. Readers should be aware, however, that the issue also affects the welfare of consumers.

\section{Competitive, Marginal Cost Pricing of Electricity and Bankruptcy}

A basic financial question is how the competitive pricing of electricity will affect shareholders and bondholders. The analysis in this chapter mainly examines the question of whether there would be substantial numbers of bankruptcies associated with the marginal cost pricing of electricity generation. A utility filing for bankruptcy has two options. One option is to liquidate the utility, sell all the assets to third parties, and use the proceeds to pay off creditors. When this occurs, the creditors seldom receive all that is owed them. Alternatively, a financially distressed utility may reorganize and continue to operate. "As part of this reorganization, creditors agree to a moratorium on collecting their debts. They also typically agree to reduce the dollar amount of their claims against the firm." ${ }^{192}$ In either case, bankruptcy affects both shareholders and bondholders, with the former bearing most of the costs.

To analyze the potential for bankruptcy, estimates of how the competitive pricing of electricity would affect utility profits were made. The market value of a utility's assets is related to the expected level of profitsi.e., with everything else held equal, the higher (lower) the level of expected profits, the higher (lower) would be the value of the utility's common stock. Thus, independent of the bankruptcy issue, this chapter presents an analysis of how the competitive pricing of electricity would affect the market value of a utility's assets.

Before proceeding, three general comments about bankruptcy will be made. First, over the 1987 to 1994 period, approximately 70,000 firms per year formally filed for bankruptcy; therefore, bankruptcy is a financial reality (Table 20). Second, bankruptcy sometimes involves changes in the ownership of existing assets. If a change in ownership does occur, as long as the market price of electricity exceeds a power plant's variable operating costs, the new owner will continue to operate it. If the power plant's variable costs are greater than the market price of electricity, the asset will not be economically viable regardless of who owns it. Third, prior to 1978, a firm could file for bankruptcy under Chapter 11 of the Bankruptcy Code only if it was insolvent. That requirement was removed, however, with the passage of the Bankruptcy Reform Act of 1978. Since then, a few solvent firms have taken shelter under Chapter 11 to avoid very expensive obligations, although many companies are reluctant to do so because of the costs. ${ }^{93}$ As noted in Chapters 2 and 3, some utility stranded costs are in the form of purchased power contracts above market price. In theory, utilities could use the bankruptcy process to mitigate those stranded costs.

\section{Table 20. U.S. Business Bankruptcies by Year, 1987-1994}

\begin{tabular}{c|c}
\hline Year & $\begin{array}{c}\text { Number of } \\
\text { Bankruptcies }\end{array}$ \\
\hline 1987 & 88,278 \\
1988 & 68,501 \\
1989 & 62,534 \\
1990 & 64,688 \\
1991 & 67,714 \\
1992 & 72,650 \\
1993 & 66,428 \\
1994 & 56,748 \\
\hline
\end{tabular}

Note: Personal bankruptcies are not included.

Source: U.S. Bureau of the Census, Statistical Abstract of the United States (Washington, DC, 1996).

\footnotetext{
${ }^{92}$ A. Shapiro, Modern Corporate Finance (New York, NY: McMillan Publishing, 1990), p. 999. The legal and litigation costs associated with bankruptcy can, however, be substantial. For example, the litigation costs associated with the default on bonds for the Washington Public Power Supply System (WPPSS) nuclear units 4 and 5 were above $\$ 75$ million. See D.L. Shapiro, Generating Failure: A History of Public Power in the Northwest (Washington, DC: Cato Institute, 1992).

${ }^{93}$ Examples include Continental Airlines and Johns-Manville. In the former case, the airline was able to reduce its labor costs, and in the latter the company was able to reduce potentially large product liability claims. In both cases, the cost was very high. For example, Johns-Manville had to pay between 50 and 80 percent of its equity into a fund to compensate individuals for asbestos-related injuries. Additionally, both the chairman of the board of directors and the firm's president were forced to resign. For a more detailed discussion, see A. Shapiro, Modern Corporate Finance.
} 
One major financial consequence of the competitive, marginal cost pricing of electricity that could cause bankruptcy is major revenue reductions caused by decreases in prices. Table 21 shows the projected regional changes in average revenues (prices) for three years. Since much of the analysis in this report assumes that demand is very price-inelastic (i.e., a price elasticity of -0.15 ), the percentage reductions in price (average revenue) and total revenues will be similar. Thus, to assess the potential for large numbers of bankruptcies, the question of whether utilities will be able to meet all of their fixed financial commitments if their average revenues fall by the amounts shown in Table 21 will be addressed.

Table 21 shows the estimated regional changes in average utility revenues in 1998, 2005, and 2012 that would result from a movement toward competitive, marginal cost pricing of electricity. The impacts are specific for each region. In two regions-Region 13 (California) and
Region 2 (Texas)-the 1998 reductions in average revenues (prices) are between 20 and 25 percent. In six other regions, the revenue reductions are between 10 and 20 percent. In the aggregate, by 2012 the differences between the competitive and regulated prices decrease. However, the changes in revenue reductions again vary by region.

Because of the diversity of the effects, inferences about the regional effects based upon national estimates cannot be made. Thus, this analysis first looks at a composite, or typical, utility at the regional level. However, when there are wide intraregional variations in prices and costs, there could be winners and losers, with the regional impacts averaging out to zero. Thus, inferences about the effects on a given utility within a region based on regional averages can also be very misleading. The analysis therefore also looks at groups of utilities within regions.

Table 21. Regulated and Competitive Prices for Electricity by Region and Projected Reductions in Average Revenues, 1998, 2005, and 2012 (Cents per Kilowatthour)

\begin{tabular}{|c|c|c|c|c|c|c|c|c|c|}
\hline \multirow[b]{3}{*}{ Region } & \multicolumn{6}{|c|}{ Projected Electricity Prices } & \multirow{2}{*}{\multicolumn{3}{|c|}{$\begin{array}{l}\text { Percentage Reduction } \\
\text { In Average Revenues }\end{array}$}} \\
\hline & \multicolumn{2}{|c|}{1998} & \multicolumn{2}{|c|}{2005} & \multicolumn{2}{|c|}{2012} & & & \\
\hline & Regulated & Competitive & Regulated & Competitive & Regulated & Competitive & 1998 & 2005 & 2012 \\
\hline 1 & 6.20 & 5.43 & 5.92 & 5.24 & 5.41 & 5.28 & 14 & 13 & 2 \\
\hline 2 & 6.32 & 5.26 & 5.95 & 5.30 & 5.61 & 5.10 & 20 & 12 & 10 \\
\hline 3 & 8.25 & 7.39 & 7.92 & 7.04 & 7.55 & 6.97 & 12 & 13 & 8 \\
\hline 4 & 6.85 & 5.97 & 6.69 & 5.89 & 6.02 & 5.65 & 15 & 14 & 7 \\
\hline 5 & 5.67 & 5.62 & 5.29 & 5.77 & 5.22 & 5.61 & 1 & -8 & -7 \\
\hline 6 & 10.36 & 8.85 & 9.59 & 8.88 & 9.19 & 8.84 & 17 & 8 & 4 \\
\hline 7 & 8.37 & 7.92 & 7.90 & 7.79 & 7.60 & 7.77 & 6 & 1 & -2 \\
\hline 8 & 7.85 & 6.94 & 7.43 & 6.73 & 7.19 & 6.59 & 13 & 10 & 9 \\
\hline 9 & 6.25 & 5.72 & 5.82 & 5.56 & 5.56 & 5.50 & 9 & 5 & 1 \\
\hline 10 & 6.31 & 5.67 & 5.98 & 5.47 & 5.84 & 5.19 & 11 & 9 & 13 \\
\hline 11 & 4.52 & 6.15 & 4.88 & 6.02 & 4.65 & 6.11 & -27 & -19 & -24 \\
\hline 12 & 7.43 & 6.99 & 7.17 & 6.00 & 6.65 & 5.75 & 6 & 20 & 16 \\
\hline 13 & 9.94 & 7.98 & 9.18 & 8.03 & 9.09 & 8.23 & 25 & 14 & 10 \\
\hline $\begin{array}{l}\text { National } \\
\text { Average }\end{array}$ & 6.90 & 6.30 & 6.60 & 6.10 & 6.30 & 6.00 & 10 & 8 & 5 \\
\hline
\end{tabular}

Source: Energy Information Administration, Office of Integrated Analysis and Forecasting, National Energy Modeling System. Regulated: AEO97B.D100296K (AEO97 Reference Case); Competitive: E15V03 (Moderate Consumer Response Case). 


\section{Financial Implications for a Typical Regional Utility}

Table 22 shows a composite regional income statement using all the FERC accounts for the year $1994 .^{94}$ The cost and revenue data shown are cumulative for all utilities within each region. To normalize the data, cumulative costs and revenues were divided by cumulative total sales. These data, therefore, have two interpretations. First, they represent an income statement for one large regional composite utility. Second, the per-kilowatthour data also represent sales-weighted average revenues and costs and, thus, average revenues and costs for a "typical" utility.

The analysis in Chapter 3 assumes that nonfuel operations and maintenance (O\&M) and general and administrative (G\&A) costs fall at an annual rate of 2.5 percent from 1995 to 2005 . This assumption will also be made in the present chapter. However, except for these adjustments, no attempt has been made in this analysis to construct financial statements that are completely consistent with the projections described in Chapter 3. ${ }^{95}$ The inconsistencies are likely to be small and would not substantially affect the conclusions of this chapter. As just noted, because of the use of very low elasticities, demand (generation) levels are similar in the reference and competition cases. Consequently, average costs in the two cases are similar, and unless there are competition-induced cost improvements, the cost structures in the two cases will be similar.

For three reasons, the changes in average costs per kilowatthour (total costs divided by generation) over the next few years will not be great. First, in the early years of the forecast, fossil fuel prices are expected to be relatively flat. Therefore, in real terms, the 1998 average fuel costs in the two cases will be similar to the 1994 data. ${ }^{96}$ Second, because the analysis in Chapter 3 assumed that there would be no renegotiation of labor or purchased power contracts, the 1994 data and 1998 average nonfuel operating costs should be similar. Third, over the first few years of the projections, there will be little new construction, and most of that construction will be for small, peaking power plants. In real terms, depreciation and interest costs in 1994 and in both 1998 cases should be similar. Since the real 1994 average cost data shown in Table 22 reflect the structure of real average costs in 1998 in both the competition and reference cases, the focus of the analysis is on average costs.

The cost categories shown in Table 22 are largely selfexplanatory. The O\&M costs deal with generation alone. All the operating costs dealing with transmission and distribution are shown in the category "Transmission, Distribution, and Customer Costs." The depreciation costs are for all functions (i.e., generation, transmission and distribution). Finally, on FERC Form 1 , interest expenses are reported for the entire utility and thus include borrowing costs for electricity and natural gas distribution. The interest cost data shown in Table 22 are the estimated amounts for electricity generation, transmission, and distribution. ${ }^{97}$

Before examining the financial effects of the revenue reductions shown in Table 21, a brief discussion about regional variations in costs-and thus electricity prices-is in order. A major factor underlying the current push for restructuring (particularly retail choice) is regional variation in electricity prices. Analysts have argued that the three major factors causing the variations in costs are differences in fuel prices, fuel mix (e.g., fossil-fuel-fired versus nuclear power plants), and purchased power costs. The data shown in Table 22 illustrate the importance of purchased power costs. In particular, these data suggest that in the aggregate the three regions that have the highest electricity prices also have the highest purchased power costs. A more disaggregated analysis would probably show that fuel

\footnotetext{
${ }^{94}$ At the time this analysis was begun, the 1994 data were the most recent historical data available. The FERC Form 1 contains basic financial data on privately owned utilities only. Thus, the data used here were for 146 privately owned utilities that sold power to end users. To avoid double accounting of the purchased power costs, utilities that sold power only in wholesale markets were excluded. From a financial viewpoint, 1994 was a typical year for utilities. In 1994, net income as a percentage of revenues was 10.1 percent and over the previous 3 years ranged from 9.3 to 9.9 percent. Similarly, interest, taxes, and depreciation as a percentage of revenues were relatively constant (i.e., changes were less than 2 percentage points) over the 1991 to 1994 period. As will be shown below, these ratios are important in assessing the financial effects from restructuring.

${ }^{95}$ One of the submodules in the Electricity Market Module (EMM) produces financial statements that are consistent with the electricity forecasts. For example, when a new unit is constructed, this submodule records the capital expenditures on the balance sheet and income statements. However, this module has not been integrated in the version of the model used here; therefore, no changes were made to cost factors such as interest expenses and depreciation.

${ }^{96}$ That is, in AEO97, over the 1995 to 2000 period, real natural gas prices are expected to increase by less than 2 percent per year, and coal prices are projected to remain at their 1995 levels.

${ }^{97}$ The total interest costs were prorated to electric and gas, based on the ratios of undepreciated values for electric and gas distribution assets.
} 
Table 22. Aggregate Statement of Income by Region, 1994

(Dollars per Kilowatthour of Sales)

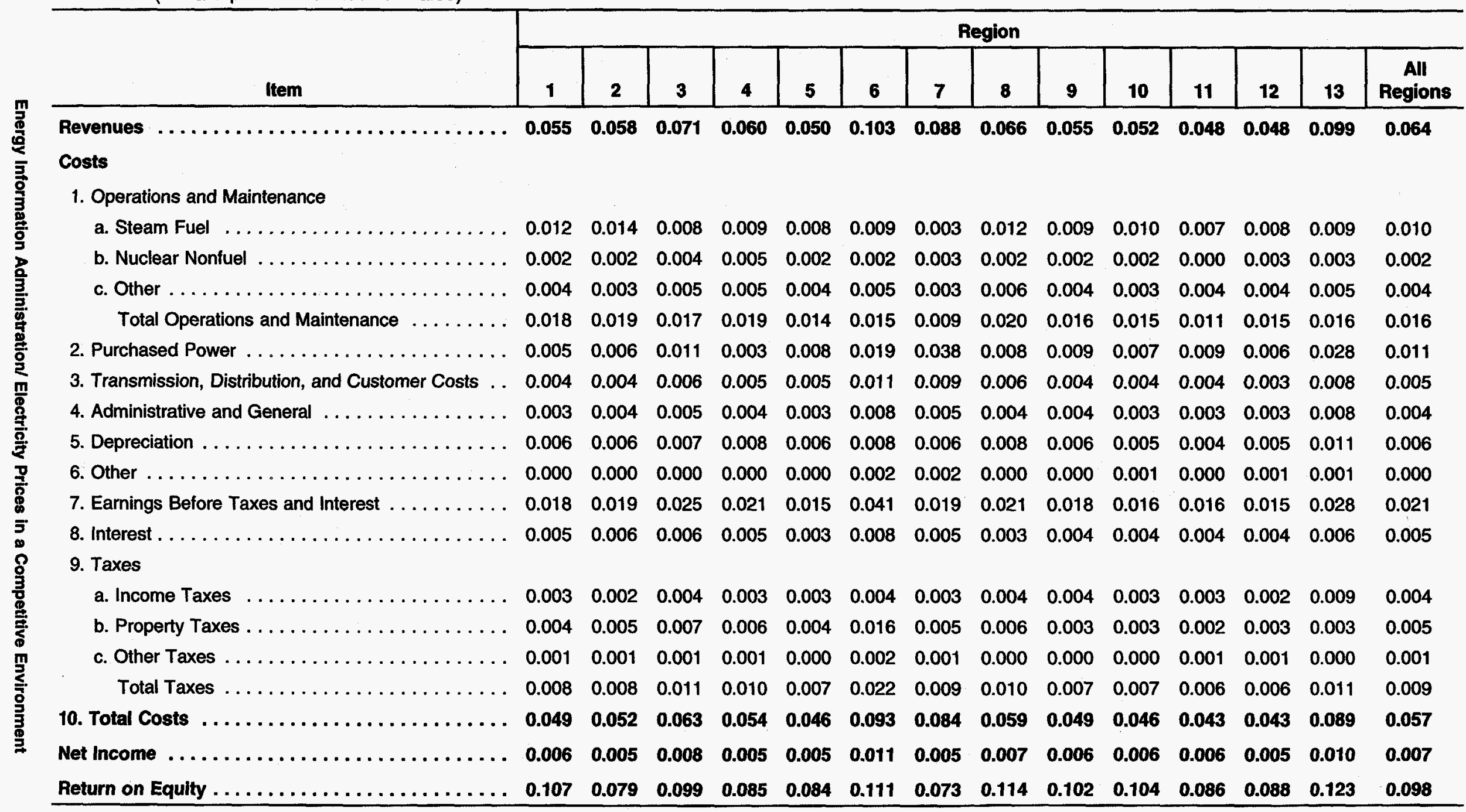

Notes: Administrative and general and nonfuel operations and maintenance costs were reduced to reflect projected cost savings. Because of independent rounding, totals may not be the same as the sum of the components.

Source: Computed from Federal Energy Regulatory Commission (FERC) Form 1. 
prices and fuel mix also "matter"; however, the importance of purchased power costs should not be overlooked. ${ }^{98}$

The two key considerations in assessing the potential for bankruptcies associated with marginal cost pricing are (1) absolute levels of income and (2) costs that are unavoidable (or non-negotiable). Because of the costplus nature of regulation, utilities tend to be profitable. Obviously, the greater the absolute level of profits, the greater will be the ability of a utility to absorb revenue decreases without facing bankruptcy. Additionally, utilities with a greater portion of costs that represent fixed (i.e., non-negotiable) obligations will be less able to absorb a revenue decrease without facing financial distress (i.e., bankruptcy).

At one extreme, the least negotiable of all the cost items are interest expenses, which represent fixed obligations to bondholders. At the other extreme, in the following sense, income and all the taxes associated with income are the most flexible items on utilities' income statements. That is, if costs (and taxes) are not affected by changes in prices, a given reduction in revenues will result in the same change in net income. Additionally, if income were to fall to zero, utilities would be paying little if any Federal and State income taxes. Lastly, property taxes are directly related to some measure of the value of the asset in question, and an asset's value is, in turn, directly related to the income generated by that asset. Thus, if income falls, the value of utilities' assets for tax purposes will fall. (In fact, most States allow some direct adjustment to the assessed value of an asset because of reductions in the asset's earning power.) $)^{99}$

Most of the other costs fall into an intermediate category. Nonfuel O\&M costs are largely labor related, and the utility industry is highly unionized. Typically, before a firm declares bankruptcy, it will attempt to renegotiate labor contracts. The experiences of other deregulated industries (e.g., airlines) indicate that labor contracts are sometimes renegotiated. More important- ly, under cost-based regulation, all labor costs are passed through to consumers, and utilities have little incentive to bargain with unions, since any reductions in labor costs are reflected in lower consumer prices rather than higher utility profits. In contrast, in competitive markets, the benefits from effective bargaining with unions will be reflected in higher utility profits. ${ }^{100}$

Independent of the bankruptcy issue, labor earnings and labor costs could be less in a competitive electric power industry. In fact, several recent analyses have found that labor earnings fell in other industries that were deregulated. For example, average earnings in the trucking industry fell by about 25 percent after deregulation. Similarly, the yearly earnings of flight attendants and pilots fell by 40 and 20 percent, respectively, after the airline industry was deregulated. Analyses of the railroad and telecommunications industries found similar results. ${ }^{101}$ Thus, based on the experience of other deregulated industries, labor earnings could fall as a result of the deregulation of the electric utility industry. These observations suggest that utilities have some flexibility in controlling labor costs. To some extent, the same could be said for fuel and purchased power contracts, especially those with above-market rates. Thus, utilities have some flexibility in reducing these costs.

In short, experience in other industries suggests that the forces of competition offer strong incentives to reduce costs. However, there has been very little analysis of operating inefficiencies in the generation of electricity. Because of the difficulties in estimating these effects, none of these potential cost improvements were considered in this analysis. If the cost improvements just discussed would largely affect plants that are not at the margin, the reduction in average costs would be greater than the reduction in marginal costs. If this occurred, the financial effects would be less than those presented in this chapter. If the opposite is true (see Chapter 3), the financial effects presented in the present chapter will be understated.

\footnotetext{
${ }^{98} \mathrm{It}$ is also interesting to observe that the three regions with the highest purchased power and total costs also have the smallest ratio of self-generation to total sales. A recent study on the effects of vertical integration on costs used the ratio of self-generation to total sales as a measure of vertical integration (see John Kwoka, "Vertical Integration and Its Alternatives: The Potential for Achieving Cost Effectiveness in Electric Power," unpublished paper, Department of Economics, George Washington University, October 1996). That analysis found that the degree of vertical integration was negatively correlated with total costs. The data shown in Table 22 are certainly consistent with that study.

${ }^{99}$ See, for example, J. Robertson, Commercial Real Estate Appraisal Techniques (New York, NY: McMillan Publishing, 1989).

${ }^{100}$ Additionally, in both the trucking and airline industries, new, lower cost entrants offered additional incentives for cost reduction. In some cases, the new entrants were not unionized. For a general discussion, see Clifford Winston, "U.S. Industry Adjustments to Economic De-Regulation," unpublished paper (Washington, DC: Brookings Institution, July 1996).

${ }^{101}$ See M. Belzer, "Collective Bargaining After Deregulation: Do the Teamsters Still Matter," Industrial and Labor Relations Review, Vol. 48, No. 4 (July 1995); P.-Y. Cremieux, "The Effects of Deregulation on Employee Earnings: Pilots, Flight Attendants, and Mechanics, 19591992," Industrial and Labor Relations Review, Vol. 49, No. 2 (January 1996); J. MacDonald and L. Cavalluzzo, "Railroad Deregulation: Pricing Reforms, Shipper Responses, and the Effects on Labor," Industrial and Labor Relations Review, Vol. 50, No. 1 (October 1996); and R.G. Ehrenberg, The Regulatory Process and Labor Earnings (New York, NY: Academic Press, 1979).
} 
Table 23 shows the same regional composite income statements with the cost items categorized by degree of flexibility. ${ }^{102}$ For clarity, only percentages of total costs are shown. At one extreme, only 11 percent or less of utilities' revenues are used to cover obligations that are truly fixed (i.e., interest payments to bondholders). ${ }^{103}$ At the other extreme, with the exception of utilities in Region 7, net income and the associated taxes are about 20 percent of revenues. Most of the costs fall into an intermediate category. Thus, 60 to 70 percent of revenues are used to cover costs that utilities can control to a limited extent.

Finally, note that depreciation costs are about 10 percent of revenues. Depreciation is included on firms income statements to reflect the costs associated with the "wear and tear" of capital assets. Depreciation costs are specified by law and are therefore fixed. However, depreciation expenses are non-cash costs in the sense that there are no out-of-pocket expenses associated with them. If a firm's cash revenues just equaled its costs exclusive of depreciation, it would show negative accounting profits but would have sufficient funds to pay all its cash costs. ${ }^{104}$

In short, with average costs held constant, a 20-percent reduction in revenues would cause income and the taxes associated with income to fall to zero. As Table 21 shows, typical utilities in Regions 2 and 13 would observe decreases in revenues of about 20 and 25 percent, respectively. The 20-percent reduction in revenues in Region 2 would cause profits to fall to zero. (Actually, as is shown below, the typical utility in that region would observe a very small after-tax loss.) The typical utility in Region 2 should be able to absorb such decreases without filing for bankruptcy. The effects of a 25 -percent reduction in revenues in Region 13 would be more severe. The income statement for the typical utility in that region would show losses. Nevertheless, as just discussed, since depreciation is a non-cash cost, the typical utility in Region 13 should be able to absorb such decreases without filing for bankruptcy.

The decreases in revenues for typical utilities in the other regions are less than 20 percent. Thus, for utilities in these regions, the movement toward competitive, marginal cost pricing would cause substantial reductions in income and the taxes associated with income. In most regions, competition would result in a period of decreased profitability. In some regions, the period of decreased profitability would be relatively short. In others, profits would be substantially reduced for at least 10 to 15 years.

These points can be illustrated using data for utilities in Region 2 (Table 24). The first column in Table 24 shows average revenues and costs in the regulated case. The second column (the competitive case) shows that, if the utilities in Region 2 were unable to reduce their average costs, they would actually incur a small after-tax loss. Moreover, both property and income taxes would fall substantially.

Additional insights into the effects of the reduction in average revenues shown in Table 21 can be obtained by analyzing utilities' statements of cash flows. Regional composite statements of cash flows are shown in Table 25. As before, all the data are cumulative values for all utilities within a region, divided by cumulative sales. (To show the absolute size of cash flows, total values for Region 1 are also shown.) The rows in Table 25 labeled "Cash Inflows" show the sources of funds. One source of cash is net income (i.e., revenues less costs and taxes). Depreciation, which is a non-cash cost recovered from ratepayers, is the second source of cash. ${ }^{105}$ The rows labeled "Cash Outflows" show the uses of funds. The first use of funds, capital expenditures, represents the cash that is reinvested in the utility. The second is dividend payments to common and

\footnotetext{
${ }^{102}$ In Table 23, it is assumed that 50 percent of utilities' asset values for tax purposes, and thus property taxes, are tied to income, in the sense that if the income derived from the plant's output fell to zero, the asset value would fall to zero. This assumption is based on a 10-percent reduction in income and a value (price) to earnings ratio of 10 .

${ }^{103}$ Actually, in times of financial distress, firms have renegotiated interest payments with bondholders. Thus, interest expenses are not completely fixed.

${ }^{104}$ The relationship between cash flows and depreciation is discussed below. Under cost of service regulation, depreciation is used to recover capital costs. However, in a deregulated environment, the primary value of depreciation is as a tax shield. That is, although depreciation is a non-cash cost, the Internal Revenue Service allows it to be included as an expense for tax purposes; thus, depreciation can be used to shield some revenue from income taxes.

${ }^{105}$ For example, suppose that a firm had revenues of $\$ 100$, cash costs (including interest) of $\$ 50$, and depreciation of $\$ 30$. Earnings before taxes would, therefore, be $\$ 20$ ( $\$ 100-\$ 50$ - $\$ 30$ ). If the marginal tax rate was 50 percent, taxes would be $\$ 10$, and earnings after taxes would be $\$ 10$. Since depreciation is a non-cash cost, this firm would have $\$ 40$ in cash (i.e., cash revenues of $\$ 100$ less $\$ 50$ in cash costs and $\$ 10$ worth of cash taxes). Thus, cash flows would be the sum of after-tax earnings (\$10) and depreciation ( $\$ 30)$. Note that a firm can have negative after-tax earnings and still have a positive cash flow. For example, if revenues fell from $\$ 100$ to $\$ 70$, pre- and post-tax earnings would be a $-\$ 10$; however, the company would still have a positive cash flow of $\$ 20$. In fact, it is not uncommon to have negative earnings and positive cash flows, a good example of this being British Energy. See James G. Hewlett, "Financing Decommissioning in a Competitive Environment: Lessons from the United Kingdom," in Nuclear Decommissioning Trusts (Boston, MA: IBC Conferences, Inc., 1996).
} 
Table 23. Aggregate Statement of Income by Region, 1994 (Percentage of Total Revenues)

\begin{tabular}{|c|c|c|c|c|c|c|c|c|c|c|c|c|c|c|}
\hline \multirow[b]{2}{*}{ Item } & \multicolumn{14}{|c|}{ Region } \\
\hline & 1 & 2 & 3 & 4 & 5 & 6 & 7 & 8 & 9 & 10 & 11 & 12 & 13 & $\begin{array}{l}\text { All } \\
\text { Regions }\end{array}$ \\
\hline $\begin{array}{l}\text { Revenues } \ldots \ldots \ldots \ldots \ldots \ldots \ldots \ldots \ldots \ldots \\
\text { Non-Cash Costs }\end{array}$ & \multicolumn{13}{|c|}{ Non-Cash Costs } & 100 \\
\hline Depreciation . . . . . . . . . . . . & 11 & 10 & 10 & 13 & 12 & 8 & 7 & 12 & 10 & 10 & 9 & 10 & 12 & 10 \\
\hline \multicolumn{15}{|l|}{ Unavoidable Costs } \\
\hline$\ldots \ldots \ldots \ldots \ldots$ & 8 & 11 & 8 & 9 & 6 & 8 & 6 & 5 & 7 & 7 & 8 & 9 & 6 & 8 \\
\hline \multicolumn{15}{|l|}{ Costs with Some Flexibility } \\
\hline$\ldots \ldots \ldots \ldots \ldots$ & 22 & 24 & 11 & 15 & 15 & 8 & 4 & 18 & 17 & 20 & 15 & 17 & 9 & 15 \\
\hline$\ldots \ldots \ldots \ldots \ldots$ & 10 & 10 & 15 & 5 & 15 & 18 & 43 & 12 & 16 & 13 & 19 & 12 & 28 & 17 \\
\hline All Operations and Maintenance $\ldots \ldots \ldots$ & 25 & 23 & 28 & 32 & 28 & 26 & 25 & 27 & 25 & 26 & 24 & 29 & 23 & 26 \\
\hline Property Taxes ... & 4 & 4 & 5 & 5 & 4 & 8 & 3 & 5 & 3 & 3 & 2 & 3 & 1 & 4 \\
\hline Total .... & 60 & 61 & 60 & 57 & 63 & 61 & 74 & 61 & 61 & 62 & 60 & 61 & 62 & 61 \\
\hline \multicolumn{15}{|l|}{ Flexible Costs } \\
\hline$\ldots \ldots \ldots \ldots$ & 11 & 9 & 11 & 9 & 9 & 10 & 5 & 10 & 11 & 11 & 12 & 10 & 10 & 10 \\
\hline Taxes on Income .. & 5 & 3 & 6 & 4 & 6 & 4 & 3 & 7 & 7 & 6 & 5 & 3 & 9 & 6 \\
\hline Property Taxes . . . . . . . . . . . . . . & 4 & 5 & 5 & 6 & 5 & 9 & 3 & 4 & 3 & 3 & 4 & 5 & 1 & 4 \\
\hline Total $\ldots \ldots \ldots \ldots \ldots \ldots \ldots$ & 21 & 18 & 22 & 19 & 20 & 23 & 12 & 22 & 22 & 21 & 21 & 18 & 20 & 20 \\
\hline
\end{tabular}

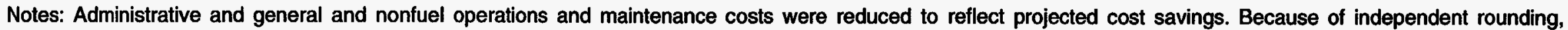
totals may not be the same as the sum of the components.

Source: Computed from Federal Energy Regulatory Commission (FERC) Form 1. 
Table 24. Effects of a 20-Percent Reduction in Revenues for Utilities in Region 2 (Dollars per Kilowatthour of Sales)

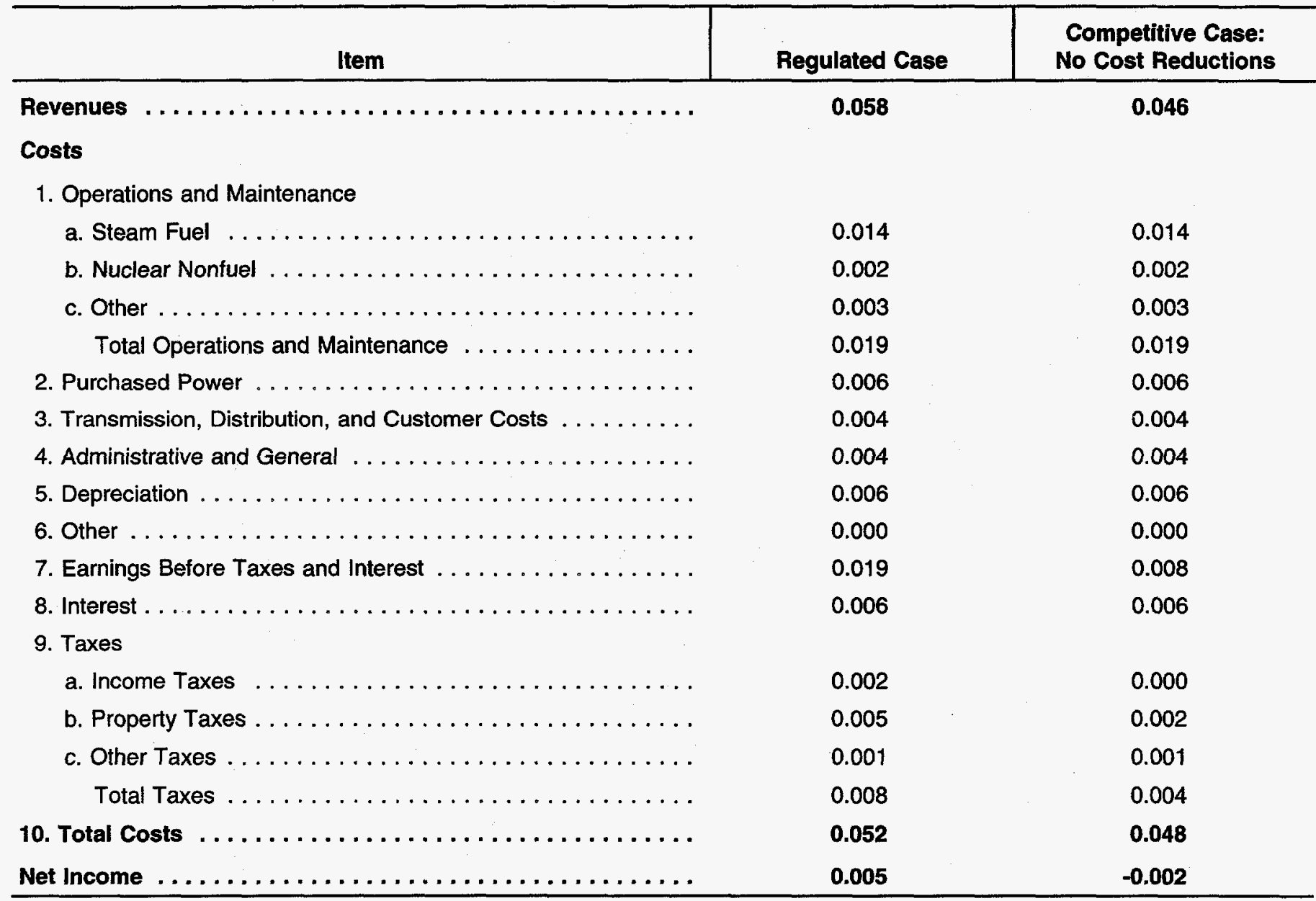

Notes: Administrative and general and nonfuel operations and maintenance costs were reduced to reflect projected cost savings. Because of independent rounding, totals may not be the same as the sum of the components.

Source: Computed from Federal Energy Regulatory Commission (FERC) Form 1.

preferred stockholders. The use entitled "Net Financing and Other" basically measures the funds obtained from new bond and stock issues, less the funds paid when bonds (and common stock) are redeemed; the net amounts of these financial transactions are small.

For example, in 1994, the utilities in Region 1 had two major sources of cash of roughly equal size-profits of about $\$ 2.6$ billion and roughly $\$ 2.6$ billion worth of depreciation charges for capital expenditures made in the past. Thus, the total sources of funds were about $\$ 5.3$ billion. Roughly $\$ 2$ billion of that amount was paid to shareholders in the form of dividends, and most of the remaining $\$ 3.3$ billion was invested in the utility in the form of capital expenditures.

The absolute and relative levels of the capital expenditures are noteworthy. In 1994, there was very little new power plant construction activity. Thus, most of the capital expenditures made in 1994 (about $\$ 3.1$ billion in
Region 1) were for retrofits and repairs of existing power plants and for upgrades and additions to transmission and distribution facilities. The costs associated with these activities were substantial. Additionally, excepting Region 2, most of the funds in all the regions were reinvested within the utility (capital expenditures) rather than paid to shareholders (dividend payments).

As noted above, the movement toward competitive, marginal cost pricing of electricity would cause substantial reductions in income, with income falling to zero in two regions. Such reductions would result in substantial reductions in cash inflows. Even with these reductions, the typical regional utility would remain solvent; however, the typical utility in a number of regions would be under financial distress. Analysts have noted that there are "costs" associated with financial distress. First, utilities might have to reduce dividends, which would result in difficulties in raising external funds for major new investment projects at 
Table 25. Regional Statement of Cash Flows, 1994 (Dollars per Kilowatthour of Sales)

\begin{tabular}{|c|c|c|c|c|c|c|c|c|c|c|c|c|c|c|c|}
\hline \multirow[b]{2}{*}{ Item } & \multirow{2}{*}{$\begin{array}{c}\text { Region } 1 \\
\text { (Thousand } \\
\text { Dollars) }\end{array}$} & \multicolumn{14}{|c|}{ Region } \\
\hline & & 1 & 2 & 3 & 4 & 5 & 6 & 7 & 8 & 9 & 10 & 11 & 12 & 13 & $\begin{array}{c}\text { All } \\
\text { Regions }\end{array}$ \\
\hline \multicolumn{16}{|l|}{ Cash Inflows } \\
\hline 1. Net Income . . . . . . . . & $2,610,642$ & 0.007 & 0.006 & 0.009 & 0.006 & 0.007 & 0.012 & 0.007 & 0.007 & 0.007 & 0.007 & 0.008 & 0.008 & 0.011 & 0.007 \\
\hline 2. Depreciation & $2,565,782$ & 0.007 & 0.006 & 0.008 & 0.008 & 0.007 & 0.009 & 0.006 & 0.008 & 0.006 & 0.005 & 0.005 & 0.007 & 0.014 & 0.007 \\
\hline 3. Other & 156,708 & 0.000 & 0.004 & 0.002 & -0.003 & 0.000 & 0.006 & 0.003 & 0.001 & 0.000 & -0.001 & 0.001 & 0.002 & 0.005 & 0.001 \\
\hline 4. Total $\ldots \ldots \ldots \ldots$ & $5,333,133$ & 0.014 & 0.015 & 0.018 & 0.011 & 0.014 & 0.027 & 0.016 & 0.016 & 0.013 & 0.012 & 0.013 & 0.017 & 0.029 & 0.016 \\
\hline \multicolumn{16}{|l|}{ Cash Outfiows } \\
\hline 1. Capital Expenditures . & $-3,065,840$ & -0.008 & -0.006 & -0.013 & -0.010 & -0.011 & -0.016 & -0.010 & -0.010 & -0.010 & -0.008 & -0.012 & -0.012 & -0.014 & -0.010 \\
\hline 2. Dividends & $-2,144,146$ & -0.006 & -0.008 & -0.008 & -0.005 & -0.006 & -0.009 & -0.005 & -0.007 & -0.006 & -0.006 & -0.006 & -0.005 & -0.010 & -0.007 \\
\hline 3. Net Financing and Other .. & $-149,346$ & 0.000 & -0.002 & 0.002 & 0.003 & 0.002 & -0.001 & -0.002 & 0.001 & 0.002 & 0.002 & 0.006 & 0.002 & -0.006 & 0.001 \\
\hline 4. Total $\ldots \ldots \ldots \ldots \ldots$ & $-5,359,331$ & -0.014 & -0.015 & -0.019 & -0.012 & -0.014 & -0.026 & -0.016 & -0.016 & -0.013 & -0.011 & -0.013 & -0.016 & -0.029 & -0.016 \\
\hline Change in Cash Position .. & $-26,198$ & 0.000 & 0.000 & 0.000 & -0.001 & 0.000 & 0.000 & 0.000 & 0.000 & 0.000 & 0.000 & 0.000 & 0.001 & 0.000 & 0.000 \\
\hline
\end{tabular}

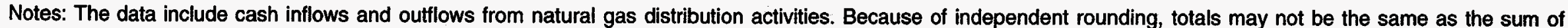
the components.

Source: Computed from Federal Energy Regulatory Commission (FERC) Form 1. 
traditional rates of return. Second, such financial constraints might cause utilities not to undertake profitable investment projects (i.e., they might not be able to raise funds to finance investment projects), which in turn could cause some reductions in reliability. Third, firms under financial distress tend to focus on the very short term. If this occurred, a firm might be "gaining shortrun profits at the expense of its reputation for providing quality products and reliable service and ultimately, its long run ability to remain competitive." ${ }^{106}$ This focus on the short term could in the long run also affect reliability.

To summarize, income and the taxes associated with income are roughly 20 percent of utilities' revenues, and depreciation-a non-cash cost-is another 10 percent of revenues. Thus, without any cost improvements other than the ones used in the reference case, utilities would be able to absorb a 30-percent reduction in revenues and still meet all their fixed financial obligations. The maximum 1998 reduction in revenues is 25 percent in Region 13. The typical utility in Region 2 will observe revenue reductions of about 20 percent. The revenue reductions in all the other regions are less than 20 percent. Revenue reductions of this size would not affect the solvency of the industry as a whole. ${ }^{107}$

Table 26 shows estimates of the reductions in after-tax income for all privately owned utilities associated with the price reductions shown in Table 21 . The initial reduction in after-tax income would be roughly 35 percent in the early years of the analysis, and over time the reductions would fall substantially. Using a discount rate of 6 percent, over the 1998 to 2012 period, in present value terms, the movement toward competitive, marginal cost pricing of electricity would result in an approximate 30-percent reduction in income. Assuming that price-to-earning ratios remain roughly constant, a 30 -percent reduction in earnings would result in a 30percent reduction in utilities' equity values. ${ }^{108}$ As was just discussed, such reductions may affect utilities' ability to finance investment projects and cause them to focus disproportionately on short-term reductions in costs.
Table 26. Estimated Changes in After-Tax Income, 1998, 2005, and 2012 (1996 Dollars per Kilowatthour of Sales)

\begin{tabular}{|c|c|c|c|}
\hline Item & 1998 & 2005 & 2012 \\
\hline Change in Revenues. & -0.0055 & -0.0046 & -0.0028 \\
\hline $\begin{array}{l}\text { Change in Total Costs, } \\
\text { Including Taxes .... }\end{array}$ & -0.0032 & -0.0028 & -0.0019 \\
\hline $\begin{array}{l}\text { Change in After-Tax } \\
\text { Income .......... }\end{array}$ & -0.0023 & -0.0018 & -0.0009 \\
\hline
\end{tabular}

Note: 1998 after-tax income in the regulated case is about $\$ 0.007$ per kilowatthour of sales.

Sources: Federal Energy Regulatory Commission (FERC) Form 1 and Energy Information Administration, National Energy Modeling System.

Included in the cost reductions resulting from the competitive, marginal cost pricing of electricity shown in Table 26 are Federal corporate income and State and local taxes. Again, these reductions are caused by the resulting decreases in profits. The near-term reductions in Federal corporate income taxes are roughly 0.12 cents per kilowatthour-i.e., from about 0.4 cents ( 4 mills) to about 0.28 cents ( 2.8 mills) - or, in the aggregate, about $\$ 3.5$ billion per year. (Reductions in State and local taxes are of the same order of magnitude.) In comparison, total Federal corporate tax revenues are about $\$ 150$ billion per year. ${ }^{109}$ Over the entire 1998-2015 period, total reductions in Federal corporate income taxes would be about $\$ 40$ billion.

The movement toward marginal cost pricing of electricity will also cause reductions in U.S. Government agencies' expenditures on electricity, which will tend to offset the reductions in tax revenues. According to the General Accounting Office, ${ }^{110}$ in 1995, all U.S. Government agencies spent approximately $\$ 3.5$ billion per year on electricity. Assuming that the price of electricity purchased by the Government also fell in the near term by about 10 percent, the competitive pricing of electricity would result in an 8.5 -percent $(\$ 300$ million per year) reduction in electricity expenditures by the Government. Such reductions in Government expenditures

\footnotetext{
${ }^{106}$ A. Shapiro, Modern Corporate Finance, pp. 166-167. Note that even firms under financial distress can borrow funds, albeit at very high interest rates. For example, as of January 1997, yields on so-called "junk bonds" were about 11 percent, whereas yields on high-quality utility bonds were about 8 percent.

${ }^{107}$ It should also be noted that electric utilities own about $\$ 25$ billion worth of natural gas distribution assets. In case of financial distress, electric utilities could obtain substantial amounts of cash by selling these assets.

${ }^{108}$ The price-to-earnings ratio is the price of a firm's common stock relative to its after-tax earning. The constant price-earnings ratio assumes that the rate used to discount future earnings back to the present is constant. Additionally, if investors' expectations about the future mirror the results of this analysis, much of the reductions in equity values will already have occurred.

${ }^{109}$ U.S. Department of Commerce, 1996 Statistical Abstract of the United States (Washington, DC, 1997).

${ }^{110}$ U.S. General Accounting Office, Energy Consumption: Federal Agencies' Electricity Use and Cost, GAO/RCED 97-97R (Washington, DC, March 1997).
} 
would mitigate the budgetary effects of the reductions in tax revenues. ${ }^{111}$

The reductions in taxes for Regions 1 and 3 were also computed. These regions were chosen because of the large number and size of the utilities in them. ${ }^{112}$ The near-term (i.e., 1998) reductions in Federal corporate taxes in these regions were about $\$ 500$ million and $\$ 400$ million, respectively. The reductions in State and local taxes were roughly the same as the reductions in income taxes.

Most discussions of stranded assets deal with the wealth transfers between electricity consumers and utility shareholders. However, the discussion just presented suggests that Federal, State, and local taxpayers will also be affected, and that the tax implications are not inconsequential.

\section{Financial Implications for Groups of Utilities}

The conclusions just presented dealt with a "typical" utility. If there are wide variations in prices and costs within a region, inferences about a single utility based on an analysis of an average utility in the region may be misleading. In other words, if there are many highand low-cost utilities, the movement toward competition could result in both "winners" and "losers," even though the average financial impacts would be zero. Thus, a more disaggregated analysis examining the distribution of average revenues and costs is needed.

The intraregional distribution of average revenues is shown in Table 27,113 which shows minimum and maximum average revenues and those for utilities in the 25th, 50th, and 75th percentiles. For each region, the first row shows average revenues, and the second row shows the number of privately owned utilities with average revenues equal to or less than the value shown in the first row. For example, in Region 1, there are a total of 22 privately owned utilities, 11 of which have revenues greater than 5.7 cents per kilowatthour, and 5 of which have revenues greater than 6.9 cents per kilowatthour. The last column in Table 27 shows the ratio of the average revenues of the utility in the 75th percentile to the one in the 25th percentile. (This ratio, called the "interquartile ratio," is a rough measure of the dispersion in revenues.) Thus, for Region 1, the average revenue for the utility in the 75th percentile is roughly 40 percent greater than that for the utility in the 25th percentile.

As shown in Table 27, the distribution of average revenues (costs) is not constant across regions. In terms of both numbers of utilities and the dispersion of revenues, the possibility of many "winners and losers" appears to be concentrated in four regions-namely, 1 , 3,4 , and 10. In all four of these regions, the interquartile ratio is over 1.35. Therefore, the dispersion in revenues is relatively large. Additionally, in each of these regions there are more than 15 privately owned utilities. (There are 19 utilities in Region 7; however, the dispersion of revenues in that region is relatively small, the interquartile ratio being only 1.12 . The dispersion in revenues in Region 6 is relatively large, but there are only 7 utilities in that region.)

In competitive power markets with unlimited trade within regions, the variation in prices (average revenues) shown in Table 27 would be reduced greatly. ${ }^{114}$ The competitive prices described in Chapter 3 and reported in Table 21 of this chapter are basically driven by the long-run marginal cost of new capacity. It is, therefore, reasonable to assume that within a region, in competitive power markets, prices would tend to converge to the ones presented in this report.

\footnotetext{
${ }^{111}$ The 8.5-percent estimate assumes that consumption would increase in response to the decrease in prices, based on a -0.15 elasticity. There are also some secondary factors that could further mitigate the budgetary effects from restructuring. For example, the reduction in electricity prices could increase profits in the commercial and industrial sectors, leading to higher tax revenues. Additionally, lower electricity prices could reduce the costs of other products purchased by the Government, thereby reducing Government expenditures. The measurement of such impacts is beyond the scope of this analysis.

${ }^{112}$ To compute the tax changes, the average effective corporate tax rate was used. There can be wide variations across utilities in effective tax rates, and it was not possible to account for those variations. Thus, the national estimates assume that all the variations average out to be zero. Additionally, there are 22 and 15 utilities in Regions 1 and 3, respectively. Hopefully, all the tax-related variations across the utilities in these regions will also average out to be zero. Finally, in terms of electricity generation, Regions 1 and 3 are the second and third largest of all the regions used in this analysis.

${ }^{113}$ Under rate of return regulation, the return on capital (profits) is a cost of service and, therefore, recovered from ratepayers. In the discussion that follows, income is viewed as a "cost." Therefore, costs and revenues are used interchangeably, in the sense that high (low) cost utilities will have relatively high (low) revenues.

${ }^{114}$ This observation assumes that there is little variation in average transmission and distribution costs within a region. Inspection of utility-level data does suggest that, in general, average operating transmission and distribution costs do not vary substantially within regions.
} 
Table 27. Distribution of Utilities by Region and Average Revenue, 1994 (Dollars per Kilowatthour)

\begin{tabular}{|c|c|c|c|c|c|c|c|c|}
\hline \multirow{2}{*}{\multicolumn{2}{|c|}{ Region }} & \multicolumn{5}{|c|}{ Number of Utilities by Ranking of Average Revenue } & \multirow{2}{*}{$\begin{array}{c}\text { Total } \\
\text { Number of } \\
\text { Utilities } \\
\text { in Region }\end{array}$} & \multirow{2}{*}{$\begin{array}{l}\text { Ratio of } \\
\text { 75th to 25th } \\
\text { Percentlie }\end{array}$} \\
\hline & & Minimum & $\begin{array}{c}\text { 25th } \\
\text { Percentile }\end{array}$ & $\begin{array}{c}\text { 50th } \\
\text { Percentile }\end{array}$ & $\begin{array}{c}\text { 75th } \\
\text { Percentile }\end{array}$ & Maximum & & \\
\hline \multirow{2}{*}{1} & Average Revenue ... & 0.041 & 0.050 & 0.057 & 0.069 & 0.086 & \multirow{2}{*}{22} & \multirow{2}{*}{1.37} \\
\hline & Number of Utilities . . & 1 & 6 & 11 & 17 & 22 & & \\
\hline \multirow[t]{2}{*}{2} & Average Revenue ... & 0.044 & 0.061 & 0.065 & 0.069 & 0.083 & \multirow{2}{*}{9} & \multirow{2}{*}{1.13} \\
\hline & Number of Utilities .. & 1 & 3 & 5 & 7 & 9 & & \\
\hline \multirow[t]{2}{*}{3} & Average Revenue ... & 0.054 & 0.070 & 0.073 & 0.098 & 0.110 & \multirow{2}{*}{15} & \multirow{2}{*}{1.41} \\
\hline & Number of Utilities .. & 1 & 4 & 8 & 12 & 15 & & \\
\hline \multirow[t]{2}{*}{4} & Average Revenue ... & 0.028 & 0.050 & 0.057 & 0.068 & 0.079 & \multirow{2}{*}{15} & \multirow{2}{*}{1.36} \\
\hline & Number of Utilities .. & 1 & 4 & 8 & 12 & 15 & & \\
\hline \multirow[t]{2}{*}{5} & Average Revenue ... & 0.042 & 0.055 & 0.059 & 0.063 & 0.068 & \multirow{2}{*}{10} & \multirow{2}{*}{1.15} \\
\hline & Number of Utilities ... & 1 & 3 & 5 & 8 & 10 & & \\
\hline \multirow[t]{2}{*}{6} & Average Revenue ... & 0.085 & 0.094 & 0.110 & 0.132 & 0.153 & \multirow{2}{*}{7} & \multirow{2}{*}{1.41} \\
\hline & Number of Utilities . . & 1 & 2 & 4 & 6 & 7 & & \\
\hline \multirow[t]{2}{*}{7} & Average Revenue & 0.078 & 0.096 & 0.103 & 0.107 & 0.124 & \multirow{2}{*}{19} & \multirow{2}{*}{1.12} \\
\hline & Number of Utilities & 1 & 5 & 10 & 15 & 19 & & \\
\hline \multirow[t]{2}{*}{8} & Average Revenue ... & 0.059 & 0.064 & 0.069 & 0.071 & 0.073 & \multirow{2}{*}{4} & \multirow{2}{*}{$1: 11$} \\
\hline & Number of Utilities .. & 1 & 1 & 2 & 3 & 4 & & \\
\hline \multirow[t]{2}{*}{9} & Average Revenue & 0.044 & 0.054 & 0.058 & 0.063 & 0.076 & \multirow{2}{*}{13} & \multirow{2}{*}{1.16} \\
\hline & Number of Utilities .. & 1 & 4 & 7 & 10 & 13 & & \\
\hline 10 & Average Revenue ... & 0.050 & 0.052 & 0.058 & 0.072 & 0.077 & 15 & 132 \\
\hline & Number of Utilities & 1 & 4 & 8 & 12 & 15 & 10 & 1.00 \\
\hline 11 & Average Revenue & 0.038 & 0.047 & 0.048 & 0.061 & 0.073 & 8 & 129 \\
\hline & Number of Utilities & 1 & 2 & 4 & 6 & 8 & 0 & 1.00 \\
\hline 12 & Average Revenue & 0.060 & 0.071 & 0.084 & 0.085 & 0.086 & 4 & 120 \\
\hline & Number of Utilities & 1 & 1 & 2 & 3 & 4 & 4 & $1 .<v$ \\
\hline 13 & Average Revenue & 0.097 & 0.097 & 0.104 & 0.106 & 0.106 & 3 & 108 \\
\hline & Number of Utilities & 1 & 1 & 2 & 3 & 3 & & \\
\hline
\end{tabular}

Notes: Administrative and general and nonfuel operations and maintenance costs were reduced to reflect projected cost savings. The data in the row titled "Number of Utilities" show the cumulative number of utilities in each region with average revenues equal to or less than the indicated level of average revenues. In some cases, the average revenue data for a given percentile will not correspond to a given plant. For example, when there are an even number of observations (as in Region 1), the 50th percentile (median) average revenue of $\$ 0.057$ per kilowatthour is the midpoint between the average revenue of the eleventh and twelfth plants when ranked in ascending order. Thus, in Region 1, there were 11 utilities with average revenues less than $\$ 0.057$ per kilowatthour. Because of independent rounding, totals may not be the same as the sum of the components.

Source: Computed from Federal Energy Regulatory Commission (FERC) Form 1. 
The second column in Table 28 shows the 1998 competitive price after adjusting for differences in the underlying data used in Chapters 3 and $4 .{ }^{115}$ Again, given all the assumptions used in this analysis, in competitive power markets, within a region, prices should converge on the ones shown in column 2 of Table 28. The next two columns in Table 28 show the reductions in average revenues for high-cost utilities, given that prices converge to the competitive prices described in this report. If this were to occur, revenues for the 25 percent of privately owned utilities (20 utilities) with highest costs in Regions $1,3,4,6$, and 10 would be reduced by roughly 40 percent or more. The revenues of some other relatively high-cost utilities in other regions would fall by about 20 percent.

In most regions, there will also be some "winners" i.e., utilities with revenue increases. The last three columns in Table 28 show the percentage changes in average revenues for relatively low-cost privately owned utilities and the number of utilities expected to experi- ence revenue increases. In 1998, excepting Region 13, some utilities should actually experience revenue increases. As in the case of high-cost utilities, over time the revenue increases would fall.

Estimates for the year 1998 of the number of privately owned utilities that would observe revenue increases and decreases if there were a movement toward competitive pricing are shown in Figure 35 . This figure shows the frequency distribution of the revenue gains and losses for the 146 privately owned utilities included in this analysis, assuming that regional competitive prices will converge to the ones shown in Table 28. As the figure shows, roughly 25 percent of the utilities would actually observe revenue increases. Conversely, roughly 20 percent of the utilities would observe revenue decreases of more than 30 percent, and for approximately 15 percent of the total, revenues would fall by more than 40 percent. Roughly 85 percent of the utilities that would observe revenue decreases of more than 30 percent are located in Regions $1,3,4$, and 10.

Table 28. Projected Changes in Average Utility Revenues by Region and Grouping, 1998 (Percent Change from Projected Revenues Assuming Regulated Prices)

\begin{tabular}{|c|c|c|c|c|c|c|}
\hline \multirow[b]{2}{*}{ Region } & \multirow{2}{*}{$\begin{array}{c}1998 \\
\text { Competitive Price } \\
\text { (Dollars per } \\
\text { Kllowatthour) } \\
\end{array}$} & \multicolumn{4}{|c|}{ Percent Change by Grouping } & \multirow{2}{*}{$\begin{array}{l}\text { Number of } \\
\text { Utilities with } \\
\text { Revenue } \\
\text { Increases }\end{array}$} \\
\hline & & $\begin{array}{c}\text { Utility in } \\
\text { 75th Percentile }\end{array}$ & $\begin{array}{c}\text { Utility with } \\
\text { Highest Average } \\
\text { Revenue }\end{array}$ & $\begin{array}{c}\text { Utility in } \\
\text { 25th Percentile }\end{array}$ & $\begin{array}{c}\text { Utility with } \\
\text { Lowest Average } \\
\text { Revenue }\end{array}$ & \\
\hline 1 & 0.050 & -39 & -73 & -1 & 18 & 5 \\
\hline 2 & 0.054 & -26 & -54 & -12 & 18 & 1 \\
\hline 3 & 0.065 & -52 & -70 & -8 & 17 & 2 \\
\hline 4 & 0.050 & -37 & -60 & -1 & 44 & 3 \\
\hline 5 & 0.059 & -8 & -15 & 6 & 29 & 5 \\
\hline 6 & 0.094 & -41 & -63 & -0 & 10 & 2 \\
\hline 7 & 0.097 & -10 & -27 & 2 & 20 & 5 \\
\hline 8 & 0.061 & -17 & -20 & -5 & 3 & 1 \\
\hline 9 & 0.053 & -18 & -43 & -1 & 18 & 3 \\
\hline 10 & 0.052 & -39 & -49 & -1 & 4 & 3 \\
\hline 11 & 0.066 & 8 & -11 & 29 & 43 & 7 \\
\hline 12 & 0.079 & -8 & -9 & 10 & 24 & 1 \\
\hline 13 & 0.083 & -27 & -27 & -17 & -17 & 0 \\
\hline
\end{tabular}

Source: Energy Information Administration, National Energy Modeling System and Federal Energy Regulatory Commission (FERC) Form 1.

\footnotetext{
${ }^{115}$ The average revenues shown in Table 22 are similar but not identical to the 1998 regulated prices reported in Chapter 3 . Probably the major reason for the differences is the fact that the data used here deal only with privately owned utilities. The prices reported in Chapter 3 are averages for private and publicly owned utilities. The percent reductions in prices shown in Table 21 along with the average revenues reported in Table 22 were used to derive the information shown in column 2 of Table 28 .
} 


\section{Figure 35. Distribution of Utilities with Projected Revenue Increases and Decreases, 1998}

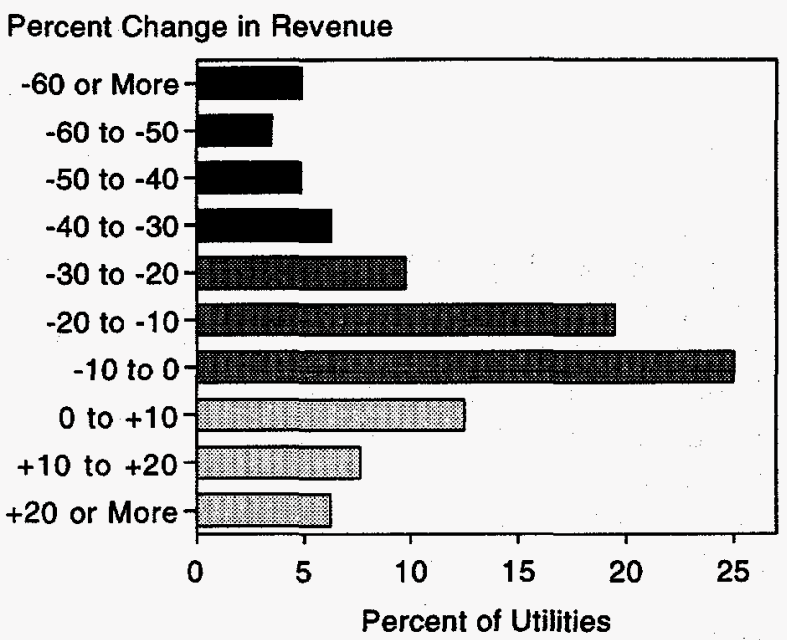

Source: Energy Information Administration, National Energy Modeling System.

Again, for a "typical" privately owned utility, competitive pricing of electricity would result in a revenue reduction of about 10 percent, which would not affect the solvency of such a utility. This may not be true, however, for relatively high-cost utilities. From Table 23 , income and the taxes directly linked to income are roughly 20 percent of revenues, and depreciation makes up roughly another 10 percent of revenues. Thus, a utility with a cost structure (i.e., fraction of total costs in the form of taxes, O\&M expenditures, depreciation, etc.) similar to the one shown here for a typical utility should be able to absorb a 30-percent decrease in revenues and still meet its fixed obligations. However, cost reductions by means of contract renegotiations and efficiency improvements would be needed to absorb revenue shortfalls greater than 30 percent, which certainly would result in financial distress.

These observations assume that the cost structures are similar for typical and high-cost utilities. Roughly 85 percent of the utilities that would observe revenue reductions greater than 30 percent are in Regions 1, 3, 4 , and 10. The issue of the cost structure of these highcost utilities was examined by deriving composite income statements for three groups of privately owned utilities (high, medium, and low costs) in each of the four regions (Tables 29, 30, 31, and 32). In each region, the utilities were ranked according to their average revenues and then placed in one of three groups. ${ }^{116}$

A comparison of the costs of the utilities in the three groups in Tables 29, 30, 31, and 32 suggests that the cost structure of the high-cost utilities is somewhat different from that of the utilities with lower costs; however, the differences are not major. More importantly, the 20 percent of the utilities with revenue decreases greater than 30 percent because of the competitive pricing of electricity ( 85 percent of which are located in these four regions) would be under serious financial distress. That is, roughly 15 to 25 percent of the revenues for these high-cost utilities cover income and the taxes associated with income (Tables 29, 30, 31, and 32). Additionally, depreciation-a non-cash cost-is also about 10 to 20 percent of revenues. Thus, roughly 25 to 35 percent of their cash revenues cover income, taxes on income, and depreciation. Unless these highcost utilities are able to renegotiate labor, purchased power, and/or fuel contracts and achieve other cost savings, they might not be able to absorb reductions in revenue greater than 30 percent. If this were to occur, some of them might have to file for bankruptcy.

The data in Tables 29, 30, 31, and 32 also give some indication about the nature of the high- and low-cost utilities in Regions 1, 3, 4, and 10. The last two rows in these tables show the undepreciated value of their nuclear and steam-fired assets as fractions of the total. In all four regions, the relatively high-cost utilities also have relatively high nuclear capital costs. As a result, the depreciation and interest costs will be higher. Additionally, since property taxes are directly tied to the capital value of the plant, these costs are also higher.

\section{Conclusions}

This chapter attempted to answer the following question: Would the competitive pricing of electricity lead to bankruptcy for many utilities? The analysis presented in Chapter 3 suggests that the competitive, marginal cost pricing of electricity would initially cause a 10percent ( $\$ 20$ billion) reduction in average revenues, and, over time, the decreases would fall. As of 1995, the after-tax income of all utilities is over $\$ 20$ billion. Additionally, utilities pay over $\$ 20$ billion in taxes, some of which are directly tied to income in the sense that if income falls taxes will also fall. In the aggregate, given

\footnotetext{
${ }^{116}$ As above, the data are cumulative for all the utilities in a given group. The data were normalized by dividing revenues by the cumulative sales of all utilities within that group. These data can be interpreted either as a composite income statement or as the income statement for a typical high (or low) cost utility. Additionally, 30 percent of the utilities located in these four regions will observe revenue increases. Thus, there are both wide variations in costs and relatively large numbers of utilities in these four regions.
} 
Table 29. Aggregate Statement of Income for Region 1 by Utility Grouping, 1994 (Dollars per Kilowatthour of Sales)

\begin{tabular}{|c|c|c|c|c|c|c|}
\hline \multirow[b]{3}{*}{ Item } & \multicolumn{6}{|c|}{ Utillty Revenue Grouping } \\
\hline & \multicolumn{2}{|c|}{ Lowest Third } & \multicolumn{2}{|c|}{ Middle Third } & \multicolumn{2}{|c|}{ Highest Third } \\
\hline & Aggregate & $\begin{array}{l}\text { Percent of } \\
\text { Total Costs }\end{array}$ & Aggregate & $\begin{array}{l}\text { Percent of } \\
\text { Total Costs }\end{array}$ & Aggregate & $\begin{array}{l}\text { Percent of } \\
\text { Total Costs }\end{array}$ \\
\hline Revenues $\ldots \ldots \ldots \ldots \ldots \ldots \ldots$ & 0.039 & & 0.054 & & 0.072 & \\
\hline \multicolumn{7}{|l|}{ Non-Cash Costs } \\
\hline Depreciation . . . . . . . . . . . . & 0.004 & 10 & 0.006 & 11 & 0.008 & 11 \\
\hline \multicolumn{7}{|l|}{ Unavoidable Costs } \\
\hline Interest & 0.002 & 6 & 0.003 & 6 & 0.008 & 11 \\
\hline \multicolumn{7}{|l|}{ Costs with Some Flexibility } \\
\hline Steam Fuel & 0.013 & 33 & 0.010 & 19 & 0.012 & 17 \\
\hline Purchased Power . . . . . . . . & 0.003 & 7 & 0.009 & 17 & 0.004 & 6 \\
\hline All Operations and Maintenance .... & 0.009 & 22 & 0.013 & 24 & 0.019 & 26 \\
\hline Property Taxes & 0.001 & 3 & 0.002 & 3 & 0.004 & 5 \\
\hline Total & 0.026 & 65 & 0.035 & 64 & 0.039 & 54 \\
\hline \multicolumn{7}{|l|}{ Flexible Costs } \\
\hline Income..$\ldots \ldots \ldots \ldots \ldots \ldots$ & 0.004 & 10 & 0.005 & 10 & 0.008 & 12 \\
\hline Taxes on Income & 0.002 & 5 & 0.003 & 5 & 0.004 & 6 \\
\hline Property Taxes ........... & 0.001 & 4 & 0.002 & 3 & 0.004 & 6 \\
\hline Total $\ldots \ldots \ldots \ldots \ldots \ldots$ & 0.007 & 18 & 0.010 & 19 & 0.017 & 23 \\
\hline Total Costs and Income $\ldots \ldots \ldots$ & 0.039 & 99 & 0.054 & 100 & 0.071 & 99 \\
\hline $\begin{array}{l}\text { Nuclear Plant Capital Costs as a } \\
\text { Percentage of Total Capital Costs ... }\end{array}$ & & 0 & & 19 & & 50 \\
\hline $\begin{array}{l}\text { Steam Plant Capital Costs as a } \\
\text { Percentage of Total Capital Costs .... }\end{array}$ & & 96 & & 75 & & 48 \\
\hline
\end{tabular}

Notes: Administrative and general and nonfuel operations and maintenance costs were reduced to reflect projected cost savings. Because of independent rounding, totals may not be the same as the sum of the components.

Source: Computed from Federal Energy Regulatory Commission (FERC) Form 1.

that utilities are relatively profitable and pay substantial amounts of income (and other) taxes, They could possibly absorb reductions of about $\$ 20$ billion without filing for bankruptcy.

Although the competitive pricing of electricity generation would not affect the solvency of the industry in the aggregate, the industry would be less profitable, and the decreased level of profitability would result in substantial reductions in the market value of utilities' common stock. The analysis in this chapter suggests that the value of utilities' common stock would fall by about 30 percent if a fully competitive industry appeared on
January 1, 1998, and they were not permitted to recover any stranded costs. Most of the revenue reductions would result from the nonrecovery of stranded costs, estimated in Chapter 3 to be in the range of $\$ 75$ to $\$ 170$ billion. Since the depreciated book value of all utility assets is over $\$ 400$ billion, the analysis in Chapter 3 also suggests that the nonrecovery of stranded costs would result in about a 20- to 40-percent reduction in the value of utilities' assets.

Another consequence of the reduction in profits would be a decrease in Federal corporate taxes and in State and local taxes. The analysis presented in this chapter 
Table 30. Aggregate Statement of Income for Region 3 by Utility Grouping, 1994 (Dollars per Kilowatthour of Sales)

\begin{tabular}{|c|c|c|c|c|c|c|}
\hline \multirow[b]{3}{*}{ Item } & \multicolumn{6}{|c|}{ Utility Revenue Grouping } \\
\hline & \multicolumn{2}{|c|}{ Lowest Third } & \multicolumn{2}{|c|}{ Middle Third } & \multicolumn{2}{|c|}{ Highest Third } \\
\hline & Aggregate & $\begin{array}{l}\text { Percent of } \\
\text { Total Costs }\end{array}$ & Aggregate & $\begin{array}{l}\text { Percent of } \\
\text { Total Costs }\end{array}$ & Aggregate & $\begin{array}{l}\text { Percent of } \\
\text { Total Costs }\end{array}$ \\
\hline Revenues $\ldots \ldots \ldots \ldots \ldots \ldots$ & 0.055 & & 0.065 & & 0.087 & \\
\hline \multicolumn{7}{|l|}{ Non-Cash Costs } \\
\hline Depreciation $\ldots \ldots \ldots \ldots \ldots$ & 0.005 & 9 & 0.007 & 11 & 0.009 & 11 \\
\hline \multicolumn{7}{|l|}{ Unavoidable Costs } \\
\hline Interest .. & 0.003 & 6 & 0.005 & 8 & 0.008 & 9 \\
\hline \multicolumn{7}{|l|}{ Costs with Some Flexibility } \\
\hline Steam Fuel & 0.010 & 18 & 0.011 & 16 & 0.004 & 4 \\
\hline Purchased Power & 0.011 & 21 & 0.007 & 11 & 0.014 & 16 \\
\hline All Operations and Maintenance $\ldots$. & 0.014 & 26 & 0.017 & 26 & 0.028 & 32 \\
\hline Property Taxes & 0.002 & 3 & 0.003 & 4 & 0.005 & 6 \\
\hline Total .. & 0.037 & 67 & 0.037 & 57 & 0.050 & 57 \\
\hline \multicolumn{7}{|l|}{ Flexible Costs } \\
\hline Income ..... & 0.005 & 9 & 0.008 & 12 & 0.010 & 12 \\
\hline Taxes on Income & 0.003 & 5 & 0.005 & 8 & 0.004 & 5 \\
\hline Property Taxes ... & 0.002 & 4 & 0.003 & 5 & 0.005 & 6 \\
\hline Total & 0.009 & 17 & 0.016 & 24 & 0.020 & 23 \\
\hline Total Costs and Income $\ldots \ldots \ldots$ & 0.055 & 100 & 0.065 & 100 & 0.086 & 99 \\
\hline $\begin{array}{l}\text { Nuclear Plant Capital Costs as a } \\
\text { Percentage of Total Capital Costs .... }\end{array}$ & & 16 & & 48 & & 77 \\
\hline $\begin{array}{l}\text { Steam Plant Capital Costs as a } \\
\text { Percentage of Total Capital Costs ... . }\end{array}$ & & 77 & & 48 & & 18 \\
\hline
\end{tabular}

Notes: Administrative and general and nonfuel operations and maintenance costs were reduced to reflect projected cost savings. Because of independent rounding, totals may not be the same as the sum of the components.

Source: Computed from Federal Energy Regulatory Commission (FERC) Form 1.

suggests that, in the near term, Federal corporate income taxes would fall by about $\$ 3.5$ billion (a 2- to $3-$ percent reduction in total Federal corporate tax revenues) because of the nonrecovery of stranded costs. A similar reduction in State and local taxes would also be observed. Thus, the nonrecovery of stranded costs would affect both utility shareholders and taxpayers.

It is important to note that the revenues of roughly 25 percent of the 146 privately owned utilities included in this analysis could initially increase. On the other hand, roughly 20 percent of the utilities will initially have revenue decreases greater than 30 percent, and 85 percent of those utilities are located in Regions 1, 3, 4, and 10. The competitive pricing of electricity could pose major problems for the 20 or so high-cost utilities in these four regions, and the resulting financial distress could result in decreased reliability (e.g., there might be service interruptions). More importantly, it is quite possible that the low-cost, more profitable utilities would simply purchase the assets of the bankrupt utilities. This would result in the acceleration of the trend toward increased consolidation of the industry, and 
Table 31. Aggregate Statement of Income for Region 4 by Utility Grouping, 1994 (Dollars per Kilowatthour of Sales)

\begin{tabular}{|c|c|c|c|c|c|c|}
\hline \multirow[b]{3}{*}{ Item } & \multicolumn{6}{|c|}{ Utility Revenue Grouping } \\
\hline & \multicolumn{2}{|c|}{ Lowest Third } & \multicolumn{2}{|c|}{ Middle Third } & \multicolumn{2}{|c|}{ Highest Third } \\
\hline & Aggregate & $\begin{array}{l}\text { Percent of } \\
\text { Total Costs }\end{array}$ & Aggregate & $\begin{array}{l}\text { Percent of } \\
\text { Total Costs }\end{array}$ & Aggregate & $\begin{array}{l}\text { Percent of } \\
\text { Total Costs }\end{array}$ \\
\hline Revenues $\ldots \ldots \ldots \ldots \ldots \ldots$ & 0.044 & & 0.053 & & 0.065 & \\
\hline \multicolumn{7}{|l|}{ Non-Cash Costs } \\
\hline Depreciation ... & 0.005 & 11 & 0.006 & 11 & 0.009 & 14 \\
\hline \multicolumn{7}{|l|}{ Unavoidable Costs } \\
\hline Interest & 0.002 & 4 & 0.003 & 6 & 0.007 & 11 \\
\hline \multicolumn{7}{|l|}{ Costs with Some Flexibility } \\
\hline Steam Fuel & 0.009 & 21 & 0.009 & 17 & 0.009 & 13 \\
\hline Purchased Power & 0.005 & 12 & 0.005 & 9 & 0.002 & 3 \\
\hline All Operations and Maintenance & 0.013 & 29 & 0.018 & 33 & 0.021 & 32 \\
\hline Property Taxes & 0.001 & 2 & 0.001 & 3 & 0.004 & 6 \\
\hline Total & 0.029 & 64 & 0.033 & 62 & 0.036 & 55 \\
\hline \multicolumn{7}{|l|}{ Flexible Costs } \\
\hline Income. & 0.005 & 11 & 0.006 & 11 & 0.005 & 8 \\
\hline Taxes on Income & 0.003 & 6 & 0.004 & 7 & 0.002 & 3 \\
\hline Property Taxes & 0.001 & 3 & 0.001 & 2 & 0.005 & 8 \\
\hline Total ... & 0.009 & 20 & 0.011 & 21 & 0.012 & 19 \\
\hline Total Costs and Income $\ldots \ldots \ldots$ & 0.044 & 100 & 0.053 & 100 & 0.064 & 98 \\
\hline $\begin{array}{l}\text { Nuclear Plant Capital Costs as a } \\
\text { Percentage of Total Capital Costs }\end{array}$ & & 17 & & 12 & & 77 \\
\hline $\begin{array}{l}\text { Steam Plant Capital Costs as a } \\
\text { Percentage of Total Capital Costs ... }\end{array}$ & & 73 & & 74 & & 22 \\
\hline
\end{tabular}

Notes: Administrative and general and nonfuel operations and maintenance costs were reduced to reflect projected cost savings. Because of independent rounding, totals may not be the same as the sum of the components.

Source: Computed from Federal Energy Regulatory Commission (FERC) Form 1.

such consolidations could increase utilities' ability to exercise market power.

Finally, any estimate of the financial effects of the restructuring of the electric utility industry follows directly from the estimated price and quantity effects (e.g., stranded costs). The "most likely" range of stranded costs derived in this report is about $\$ 72$ billion to $\$ 169$ billion. Given that the net assets of the electric utility industry are about $\$ 400$ billion, the nonrecovery of stranded costs in the range of $\$ 72$ to $\$ 169$ billion would be "painful"; however, the industry as a whole would still remain solvent. In the Intense Competition Case, on the other hand, stranded costs were estimated at about $\$ 400$ billion-an amount roughly equal to the net assets of the entire industry. As was noted in Chapter 3, given stranded assets of this size, there would be intensive efforts by suppliers to reduce costs. Without such cost reductions, it is doubtful that the industry would remain solvent. 
Table 32. Aggregate Statement of Income for Region 10 by Utility Grouping, 1994 (Dollars per Kilowatthour of Sales)

\begin{tabular}{|c|c|c|c|c|c|c|}
\hline \multirow[b]{3}{*}{ Item } & \multicolumn{6}{|c|}{ Utility Revenue Grouping } \\
\hline & \multicolumn{2}{|c|}{ Lowest Third } & \multicolumn{2}{|c|}{ Middle Third } & \multicolumn{2}{|c|}{ Highest Third } \\
\hline & Aggregate & \begin{tabular}{|l|} 
Percent of \\
Total Costs
\end{tabular} & Aggregate & $\begin{array}{l}\text { Percent of } \\
\text { Total Costs }\end{array}$ & Aggregate & $\begin{array}{l}\text { Percent of } \\
\text { Total Costs }\end{array}$ \\
\hline Revenues $\ldots \ldots \ldots \ldots \ldots \ldots$ & 0.045 & & 0.054 & & 0.060 & \\
\hline \multicolumn{7}{|l|}{ Non-Cash Costs } \\
\hline Depreciation & 0.004 & 10 & 0.005 & 12 & 0.008 & 18 \\
\hline \multicolumn{7}{|l|}{ Unavoidable Costs } \\
\hline Interest & 0.003 & 6 & 0.004 & 9 & 0.007 & 15 \\
\hline \multicolumn{7}{|l|}{ Costs with Some Flexibility } \\
\hline Steam Fuel & 0.016 & 35 & 0.010 & 22 & 0.007 & 16 \\
\hline Purchased Power & 0.002 & 5 & 0.008 & 18 & 0.008 & 19 \\
\hline All Operations and Maintenance $\ldots$. & 0.009 & 21 & 0.013 & 28 & 0.017 & 39 \\
\hline Property Taxes .. & 0.001 & 3 & 0.002 & 4 & 0.003 & 6 \\
\hline Total & 0.028 & 63 & 0.033 & 73 & 0.035 & 79 \\
\hline \multicolumn{7}{|l|}{ Flexible Costs } \\
\hline Income $\ldots \ldots \ldots \ldots \ldots \ldots$ & 0.005 & 11 & 0.007 & 15 & 0.005 & 11 \\
\hline Taxes on Income & 0.002 & 6 & 0.004 & 9 & 0.003 & 6 \\
\hline Property Taxes . & 0.001 & 3 & 0.002 & 4 & 0.003 & 6 \\
\hline Total & 0.009 & 20 & 0.013 & 28 & 0.011 & 24 \\
\hline Total Costs and Income $\ldots . . .$. & 0.045 & 100 & 0.054 & 100 & 0.060 & 100 \\
\hline $\begin{array}{l}\text { Nuclear Plant Capital Costs as a } \\
\text { Percentage of Total Capital Costs }\end{array}$ & & 0 & & 51 & & 65 \\
\hline $\begin{array}{l}\text { Steam Plant Capital Costs as a } \\
\text { Percentage of Total Capital Costs ... . }\end{array}$ & & 97 & & 46 & & 33 \\
\hline
\end{tabular}

Notes: Administrative and general and nonfuel operations and maintenance costs were reduced to reflect projected cost savings. Because of independent rounding, totals may not be the same as the sum of the components.

Source: Computed from Federal Energy Regulatory Commission (FERC) Form 1. 



\section{Conclusions and Limitations}

\section{Conclusions}

The results of this analysis indicate that average national regulated electricity prices will be at least 0.4 cent per kilowatthour (about 6 percent) higher in 1998 than they would be if prices for generation services were set under competition, based on marginal costs, and there were no changes in production costs or demand patterns resulting from increased competition, and if there were no price-based stranded cost recovery. ${ }^{117}$ Regulated prices include uneconomic costs (stranded costs) that would not be included in, or recoverable through, competitive prices. Over time, as uneconomic costs are amortized out of the total costs of producing electricity, competitive prices will be lower than regulated prices only if there are efficiency improvements and cost reductions resulting from competitive pressures that would not have occurred under regulation. However, until the extent of such efficiency improvements and competition-induced cost reductions is known with greater certainty, the long-run price reductions that may occur through competitive pricing of electricity cannot be estimated accurately.

In this analysis, reductions in operations and maintenance (O\&M) costs of 40 percent through 2005 (compared to 25 percent in the AEO97 Reference Case), reductions in the costs of new generating plants of 15 percent, and improvements in operating efficiencies (heat rates) of 15 percent resulted in a reduction in electricity prices of 11 percent in 2015 compared to the AEO97 Reference Case. Further, there is a high degree of uncertainty regarding the delineation of variable costs (included in prices under the assumptions of this analysis) and fixed costs (not included in prices). If all the potentially fixed costs that are included in prices in this analysis were removed from the price calculations, competitive price projections could be as much as 1.0 cent per kilowatthour lower than those in the other competitive cases presented in this report. This is equivalent to a 23-percent reduction relative to the AEO97 Reference Case and a 25-percent reduction relative to the No Competition Case over the short term (2 to 3 years).
Competitive prices based on marginal costs are likely to be more volatile than regulated prices based on average costs. Changes in fuel costs or demand patterns are likely to have a much stronger impact on electricity prices under competition than they have under regulation, which creates greater uncertainty about future electricity prices. For example, uncertainty about the future of natural gas prices could lead to greater uncertainty for electricity prices under competition than it would under regulation, because natural gas is frequently the fuel source for the marginal generating plants that may determine prices under competition.

Regional variation between regulated and competitive prices could be even more significant than the national differences between the two prices. Some regions could experience significant price reductions under competition; others could experience price increases. The differences are caused by varying mixes of generating technologies that affect both competitive prices and the average costs of generation services. Regions that today have low average costs, such as the Mid-Continent Area Power Pool (MAPP) and the Northwest Pool (NWP), could see electricity prices rise under competition. North American Electric Reliability Council regions that have high average costs from investments in relatively expensive generating technologies or contractual agreements above market prices could see electricity prices fall in the absence of mandated recovery of stranded costs.

The difference between competitive prices and average costs provides an estimate of uneconomic, or stranded, costs. Within the regional aggregation used for this analysis, revenue gains seen by some generating companies under competition offset the revenue losses seen by others in the same region. In other words, the results presented here show net stranded costs at the regional level, which may underestimate total stranded costs at the corporate level.

The discounted present value of net stranded costs provides an estimate of net stranded assets, or the reduction in the value of a representative firm in a specific region that would result from an inability to

\footnotetext{
${ }^{117}$ As noted throughout the report, prices would be higher still if not for the effects of the limited competition already present in the wholesale markets for electricity, the threat of increased competition in the future, and improved regulation. These higher prices are represented in the No Competition Case.
} 
recover fixed costs under competition. ${ }^{118}$ Estimates of net stranded assets vary with changes in assumptions about (1) the ability and willingness of consumers to shift consumption patterns from expensive peak demand periods to less expensive off-peak periods, (2) variations in the marginal costs of production (such as fuel costs), and (3) the time value of money (discount rates). Higher marginal costs of production (higher fuel costs) and a higher discount rate lead to lower estimates of net stranded assets. A higher degree of demand shifting from high to low cost periods and a lower estimate of marginal costs (lower fuel prices) lead to higher estimates of net stranded assets.

The results of this analysis show net stranded assetsthe reduction in the market value of the electricity generation industry as a result of competition-in the range of $\$ 72$ to $\$ 168$ billion, depending on the assumptions used. Total stranded assets could be as much as 20 percent higher than these net estimates. Also, in the Intense Competition Case, the large price reductions (22 percent relative to the AEO97 Reference Case and 24 percent relative to the No Competition Case) result in stranded assets as high as $\$ 408$ billion. However, price reductions of the magnitude illustrated in this case would likely result in significant cost reductions, which would reduce the estimates of net stranded assets.

Time-of-use rates (under competition or regulation) could reduce peak demands and, in turn, generating capacity requirements. However, in order to maintain optimal system reliability (equalize the marginal cost of an outage and the marginal cost of capacity), generating capacity requirements do not fall as much as peak demands do as a result of time-of-use rates. Flatter demand patterns generally require higher reserve margins because flatter peak period demands occur more frequently and last longer than peak period demands without time-of-use pricing. Longer or more frequent peak periods increase the costs of potential outages. Therefore, demand shifting could result in some reduction in generating capacity even as reserve margins increase.

In the aggregate, the nonrecovery of utilities' stranded costs would result in substantial reductions in net income and the taxes associated with income. If utilities could not reduce costs by efficiency improvements and more effective control of labor and fuel costs, the nonrecovery of stranded costs could cause income and all the associated taxes to fall substantially. Federal income tax receipts could fall by as much as $\$ 2.5$ billion per year on average ${ }^{119}$ over the 1998 to 2015 horizon under the assumptions of the most likely range of cases in this report. However, the experience with other deregulated industries, such as airlines and trucking, suggests that costs could be reduced substantially. If they were, income and taxes would fall substantially, but the typical utility would not be pushed into bankruptcy. Some utilities would be forced to reduce dividend payments or capital expenditures, and there could be implications for system reliability and safety, but the typical utility would remain financially viable.

In 1995, the net after-tax income associated with the electricity operations of utilities was about $\$ 20$ billion; Federal, State, and local income taxes were about $\$ 10$ billion; and State and local property and gross receipts taxes were an additional $\$ 13$ billion. In total, income and the taxes associated with income exceeded $\$ 40$ billion. In the early years of the projections described in this report, stranded costs (i.e., reductions in revenues and income) are estimated to be about $\$ 20$ billion per year. It is evident from these data that the nonrecovery of annual stranded costs of about $\$ 20$ billion would result in substantial reductions in income and taxes. In the aggregate, the nonrecovery of stranded costs would probably result in at least a few bankruptcies.

Within regions, there are wide variations in electricity costs and prices. On one hand, the nonrecovery of stranded costs is estimated to result in revenue reductions of more than 30 percent for about 20 percent of all privately owned utilities. Although revenue reductions of this size might not result in bankruptcy, they would cause financial distress for the affected utilities. On the other hand, revenues are estimated to increase for about 20 percent of privately owned utilities. It is quite possible that the low-cost, more profitable utilities would purchase the assets of high-cost utilities under financial duress. In that event, the nonrecovery of stranded costs would accelerate the trend toward consolidation of the industry. Such consolidations could increase the ability of utilities to exercise market power.

\section{Limitations and Uncertainty}

The analysis presented in this report illustrates some of the potential impacts of moving from regulated cost-ofservice electricity pricing to more competitive electricity pricing. However, considerable uncertainty exists about many issues that could influence prices. Among the

\footnotetext{
${ }^{118}$ As mentioned in Chapter 3 of this report, changes in the net present value of the revenue stream approximate the changes in value of the revenue-producing assets of the firm.

${ }^{119}$ As discussed in Chapter 4, reduced Federal tax receipts could be at least partially offset by decreased expenditures for electricity. Also, it is possible that the macroeconomic effects of competitive electricity markets could increase Federal tax receipts.
} 
issues not directly addressed in this report are the influence of market power, relative prices for various classes of customers, efficiency improvements and cost reductions due to competitive pressures, the pricing of transmission and distribution services, changing incentives to build capacity, possible changes in the cost of capital in the generation market, technological innovation that may be induced by competition, and the likelihood of alternative competitive institutions among the States. Each of these issues is discussed below.

An assumption of this analysis was that there would be an absence of market power ${ }^{120}$ on the part of suppliers and consumers. This assumption makes it possible to analyze how electricity prices could evolve under conditions of perfect competition. Under the assumptions of perfect competition, prices are determined by the relationship between supply and demand and the marginal costs of production. Since market power could cause prices to be higher (supplier market power) than those projected here, or some customers could realize a price reduction at the expense of other classes of customers (consumer market power), the potential for market power is an important concern for legislators and regulators. For example, there is evidence that market power on the part of suppliers in the United Kingdom is preventing at least some consumers from realizing the full potential for price reductions of a competitive market for electricity. Additionally, some have argued that mergers and acquisitions in the U.S. electricity industry could result in market power, which could lessen the effects of competition. This analysis did not examine the potential impacts of the existence of market power on the part of suppliers or consumers.

This study was undertaken to analyze the effects of competition on average electricity generating prices, which allows analysis of the effects that changes in costs and demands could have on average competitive and regulated prices, stranded costs, and generating capacity requirements. This report does not address the issue of how different classes of customers might fare under competitive electricity pricing. Regulators and legislators have expressed concern about the possibility that some classes of customers may realize electricity price reductions at the expense of other classes of customers. For example, large industrial and commercial consumers may exert market power by virtue of their size; they may be able to reduce their costs because they have greater flexibility to choose suppliers, or suppliers may choose to subsidize larger consumers at the expense of smaller ones. Variations in the responsiveness of different customer classes to changes in price may determine who (i.e., residential customers or industrial customers) pays the larger share of stranded costs.

Competitive pressures may result in reductions in fuel costs, purchased power costs, and labor costs; the adoption of more efficient generating technologies; and savings in any number of other costs. Such cost reductions and efficiency improvements could reduce competitive prices as well as the total costs of producing power. The assumed competition-induced cost reductions and efficiency gains that were published in the Annual Energy Outlook 1997 were included in the competitive cases in this analysis. Further cost reductions and efficiency gains were analyzed in the High Efficiency Case. However, the analysis did not address the degree to which increased competition could result in lower costs or greater efficiencies.

Prices for transmission and distribution services were assumed to be based on the average costs of providing those services. This assumption is consistent with current industry practice and is a necessary simplifying assumption for an analysis of national energy prices. Over the long term, however, prices for transmission services could be based, in part, on regional congestion. With congestion pricing, prices are based, in part, on the instantaneous demand for transmission capacity. As demand for transmission access increases, prices for transmission services increase. Congestion pricing for transmission services could affect generating capacity additions and marginal generation costs and might help to alleviate the potential for market power on the part of suppliers. Also, the pricing of transmission services could affect trade among suppliers. Increased interregional trade could expand regional markets beyond that represented in this analysis.

In this analysis, suppliers were assumed to recover the costs of investments in new generating capacity over the long term because reserve margins were set to equate the marginal costs of outages and the marginal costs of capacity. In other words, it was assumed that consumers would be willing to pay an amount for reliability of service up to the point at which the reliability costs equaled their expected outage-related costs. Capital investments-the costs of building power generating plants and other capital assets-are recovered under regulation because they are explicitly included in prices. In this analysis, capital investments are recovered under competition through the premiums above operating costs that suppliers receive. The premiums are based on the difference between average operating costs and marginal operating costs, and the extent to which prices rise above marginal operating costs

${ }^{120}$ Market power exists when a producer or consumer is able to influence prices. 
during high demand periods (represented by the reliability price adjustment).

As long as suppliers believe that they will recover the costs of building power generating plants, then there will be adequate generating resources to provide consumers with the reliability for which they are willing to pay. However, some industry experts believe that a "capacity externality" may prevent competitive prices from including the value of reliability, and that suppliers will not be able to recover their investments in generating capacity. ${ }^{121}$ If reserve capacity is a public good, then the benefits of reserve capacity are enjoyed by consumers, but the costs are borne by suppliers. Also, competitive markets may not clear with sufficient speed to include consumers' value of reliability in prices. If this is true, then this capacity externality could prevent suppliers from recovering their investments, even at the optimal reserve margin (as defined in this analysis), and competitive electricity markets would require the intervention of a regulatory authority in order to assure that adequate generating resources were built.

This analysis made no assumptions about the existence of such an externality, or the best way to compensate for it if it exists. Rather, it was assumed that competitive prices would adequately compensate suppliers for their capacity investments, without examining the issue of whether purely competitive markets would provide the market clearing function or regulatory intervention would be required.

The cost of capital ${ }^{122}$ was assumed to be the same under regulation and competition; however, the potential separation of generation services from transmission, distribution, marketing, and energy services would mean that the cost of capital for the vertically integrated utility, appropriate under regulation, might no longer be relevant. The cost of capital for the generation business may increase with greater competition, but it is also possible that at least some of this increased business risk could be offset by a reduction in regulatory risk. $^{123}$

Also, as mentioned above, prices in a competitive environment are likely to be more volatile than regulated prices over both the short term and the longer term.
The question of who would bear the cost of increased long-run volatility, how they would be compensated for it, and how it may relate to the cost of capital for competitors in the electric power industry are important issues. Volatility costs could be borne by retail customers, generating companies, distribution companies, or a host of others. The segment of the industry that pays for price volatility will pay a higher cost, either to avoid price volatility or in higher capital costs. ${ }^{124}$ Long-run price volatility may be managed through the financial markets or through contractual agreements.

Short-run price volatility is likely to lead to the emergence of new technologies for both electricity consumption and production. Competitive electricity prices can be expected to alter both consumer investment decisions and manufacturer product development decisions. For example, the potential short-run volatility in competitive electricity prices will provide consumers and producers with incentives to invest in products to better control the timing of electricity consumption. These technologies could include sophisticated electricity meters and telecommunications devices to monitor and communicate minute-to-minute electricity consumption and prices.

On the electricity supply side, there will be incentives to develop and install technologies which allow better control of the flow of electricity on the transmission and distribution system, such as the flexible AC transmission systems (FACTS) now entering the marketplace. However, while some new technologies are sure to evolve, the timing of their development and their impacts are unpredictable. This analysis addresses this issue by illustrating the importance of the level of consumer responsiveness to competitive electricity prices, but it makes no assessments as to which technologies will be most effective or have the greatest impact on consumers' price responsiveness.

It is possible that lower electricity prices under competition could stimulate second-order consequences not examined in the analysis described in this report. Such second-order effects could include, but are not limited to, macroeconomic benefits from lower electricity prices, reduced outlays for electricity by the public sector, and changes in emissions levels from power generation facilities.

\footnotetext{
${ }^{121}$ A. Jaffe and F. Felder, "Should Electricity Markets Have a Capacity Requirement? If So, How Should It Be Priced?", The Electricity Journal (December 1996).

${ }^{122}$ The cost of capital refers to the costs of borrowing funds from bondholders and the compensation to shareholders that is required to procure investments in the equities markets (common stock). Failure to compensate bondholders adequately could result in bankruptcy. Failure to compensate common shareholders adequately could make it difficult to raise funds in the future.

${ }^{123}$ Regulatory risk is the risk that regulators will disallow certain costs. In other words, under regulated pricing, suppliers may not be allowed to include some of their costs in prices if regulators believe that the costs were imprudently incurred.

${ }^{124}$ H.E. Thompson, Independent Expert Review of the Restructuring of the Electric Power Industry: A Modeling Plan Using the National Energy Modeling System (December 27, 1995, not published).
} 
Finally, this paper makes the assumption that all States will move to competitive electricity pricing in 1998. Clearly this will not happen, and the assumption is an analytic simplification. The implications of States choosing different approaches - e.g., full recovery of stranded costs versus more limited recovery, or performance- based rates versus marginal cost pricing-and timetables are unknown at this time. The tightly integrated nature of electricity networks may make it difficult for contiguous States to choose and sustain different approaches, and broader regional solutions may evolve over time. 


\section{Appendix A Calculation of Competitive Market Prices for Generation Services}

As proposed by W. Vickrey in 1971, spot or responsive pricing allows for economically optimal behavior by each customer and avoids system overload without having to resort to rationing because the price of electricity increases or decreases as system conditions change. ${ }^{125}$ True spot prices are set and communicated by suppliers of electricity services (or other services) instantaneously. Different prices can be set for each customer location at each moment. Most State proposals for restructuring of the U.S. electric power industry are modeled after the spot market in the United Kingdom (UK). ${ }^{126}$ In the UK, spot prices for generating services are set a day in advance by an Independent System Operator (ISO), on the basis of competitive bids from generating plants.

In this report, projected prices for generation services are based on a model system similar to that in the UK. Time-of-use, or spot, prices are calculated for each of the 108 time periods (in each model year and region) for which generating plants are dispatched in the Electricity Marketing Module (EMM) of the National Energy Modeling System (NEMS). The 108 periods represent projections of varying load conditions throughout the year. Therefore, prices for generation services reflect the range of system conditions under which the 13 EMM regions are expected to operate. They do not indicate the locational variations that one would expect from true spot prices, which would result from localized network congestion and other phenomena.

It is well known that the optimal spot price is equal to the marginal cost of electricity. In this model, the costs of generation to be covered comprise (1) the marginal operating costs, including maintenance and general and administrative (G\&A) costs; (2) taxes; and (3) a reliability price adjustment equal to the marginal cost of unserved energy. ${ }^{127}$ Since transmission and distribution are assumed to remain regulated, the total price is the sum of the generation costs and the average transmission and distribution costs. There is no explicit representation of capital recovery in the competitive price of electricity generation, as capital and all other costs must be recovered from the difference between the market clearing price and the operating cost of each unit. The following is a description of three components of the competitive spot prices calculated in this model.

The marginal production costs are based on estimates of the marginal costs of generation. Some costs, including fuel, other consumables, and some maintenance, vary directly with the hour-by-hour level of output of a plant. The competitive price then includes the marginal short-run operating costs; that is, the operating cost of the last plant dispatched (assumed to be the most expensive plant running) in each of the 108 time periods used in the Electricity Fuel Dispatch submodule (EFD) of the EMM. The EFD dispatches generating plants to provide the electricity demanded in each of the EMM regions in each of 108 periods of time $e^{128}$ for each region in each year.

The marginal production costs include more than just the operating costs listed above. Over the mid-term, these costs-primarily maintenance costs and overhead expenses-do change with the level of output and are therefore variable. As described in Chapter 2, delineating which costs are variable over the short run versus

\footnotetext{
${ }^{125}$ R.E. Bohn, M.C. Caramanis, and F.C. Schweppe, "Optimal Pricing in Electrical Networks Over Space and Time," Rand Journal of Economics (Autumn 1984).

${ }^{126}$ As mentioned in Chapter 1, the small number of competitors in the generation sector in the United Kingdom and the existence of transmission constraints have given suppliers an advantage over consumers (market power). The mitigation of this type of market power is essential for the efficient operation of a competitive market.

${ }^{127}$ Unserved energy is the difference between supply and demand when demand exceeds supply. If both supply and demand are stochastic, the expected amount of unserved energy is calculated using the conolution of the supply and demand distributions. Marginal unserved energy is the change in expected unserved energy relative to a change in mean generating capacity.

${ }^{128}$ The Electricity Fuel Dispatch Submodule dispatches plants to meet demand in slices of time that represent six 2-month periods divided into day, night, and evening/morning. Each such grouping is modeled as a distinct load duration curve approximated by six discrete segments.
} 
the longer run based on the standard system of accounts used by utilities is difficult. In this analysis it is assumed that 50 percent of total non-nuclear nonfuel O\&M costs should be treated as variable in the short run, and the O\&M costs of the marginal unit are added to the competitive price. The remaining portion is treated as overhead costs.

Since the G\&A (or overhead) costs are avoidabie over the mid-term, they must be recovered over the course of the year, or it would not pay to keep the plant running. Such overhead costs are relatively technologyindependent, and thus marginal and average G\&A costs are approximately equal. Furthermore, since the allocation of G\&A costs among the various stages of electricity production and delivery (generation, transmission, and distribution) is not clearly identified in the data, it is possible that G\&A costs now included in the generation stage of production may be shifted to transmission or distribution in a competitive generation environment and, thus, would be included in the marginal operating cost. Therefore, it is reasonable to include both maintenance and G\&A costs in the marginal production costs used in this analysis. Two special cases examining the sensitivity of this assumption are discussed in Chapter 3.

In the AEO97 Reference Case, all taxes other than Federal income taxes (i.e., State income taxes, sales taxes, and property taxes) are aggregated and treated as a gross receipts tax (revenue tax). The same revenue tax rate is used in the restructuring cases, regardless of the stranded cost assumptions. All taxes are ignored in the calculation of stranded costs, but they are incorporated into prices before demands are adjusted by the assumed short-run elasticities.

The reliability price adjustment reflects the cost of maintaining a margin of safety for generation to meet electricity demand. Such a cost can be quantified in several ways. ${ }^{129}$ This study evaluates the reliability price adjustment on the basis of estimates of the marginal cost of expected unserved energy. It is assumed that consumers will curtail electricity usage when the spot price of electricity exceeds their cost of unserved energy. The cost of unserved energy may be revealed through energy service contracting mechanisms, where consumers are offered varying levels of reliability (greater or lower probability of a service interruption) for varying contract prices, and through behavioral responses to spot prices by spot market participants.

Marginal unserved energy is the quantity of unserved energy satisfied by the last (or marginal) unit of generating capacity. Unserved energy is the difference between supply and demand during periods when, at a given price, demand exceeds supply. Expected unserved energy is a derived quantity based on the expectation of the joint stochastic distribution of supply and demand. Expected unserved energy does not imply a system failure. Rather, it is an expected value calculated from an uncertain amount of generating capacity and an uncertain level of demand for each pricing period. ${ }^{130}$

In this modeling exercise, the expected amount of unserved energy for each region for each dispatching period is calculated from the following inputs:

- The capacity of each generating plant in each region for each season of the year (total capacity adjusted by planned outages)

- An estimate of the probability of a forced outage for each plant

- Stochastic hourly load data (projections of electricity demands with an uncertainty factor that creates probability distributions from the deterministic values for demand). ${ }^{131}$

The cost of unserved energy (or value of unserved energy) is an input assumption, because the value of unserved energy is difficult to estimate. The costs for consumers can vary widely. Estimates range from $\$ 2$ to $\$ 25$ per kilowatthour and are affected by the type of consumer, the timing of service curtailment, the length of the interruption, and the amount of warning before curtailment begins. For example, an outage without warning during the dinner hour is much more expensive for a restaurant owner than it is for most residential consumers. Hence, a restaurant owner (and commercial consumers in general) would be willing to pay more for reliable electric power than would most residential consumers. Further, a disruption is more costly if it lasts for a longer period of time and creates

\footnotetext{
${ }^{129}$ See F.C. Schweppe, M.C. Caramanis, R.D. Tabors, and R.E. Bohn, Spot Pricing of Electricity (Boston, MA: Kluwer Academic Publishers, 1988), p. 136. Another method to quantify this component is to use a market-clearing approach, also described in Chapter 6 of Schweppe et al.

${ }^{130}$ Expected unserved energy calculations are perfornog for the system in its current state and for the system augmented by a small amount of capacity (perhaps equal to a small turbine). These calculations yield the reduction in unserved energy for each kilowatt of additional capacity that is brought into service or, stated another way, the change in unserved energy relative to a change in capacity (marginal unserved energy).

${ }^{131}$ Assumptions on demand elasticity are described in Chapter 3.
} 
costs associated with food spoilage, prolonged loss of residential heating and cooling, and the like.

As mentioned above, competitors may have the means to determine the value of unserved energy through the price discovery role of competitive markets. If the revealed cost to consumers of an outage is actually lower than the assumed value that system planners have traditionally used, it means that reserve margins may fall. Lower reserve margins could have important implications for system operating costs and electricity prices. ${ }^{132}$

Mathematically, the reliability adjustment of price is represented as:

$$
C_{r y t}=\left(\frac{\partial U E}{\partial G}\right)_{r y t} \cdot V(U E)
$$

where:

$C_{r y t}=$ reliability adjustment of price, year $y$, pricing period $t$ for region $r$ (cents per kilowatthour),

$\left(\frac{\partial U E}{\partial G}\right)_{r y t}=$

= change in unserved energy with respect to a change in generating capacity (reduction in unserved energy that results from an increase in capacity) in region $r$, year $y$, dispatch period $t$ (kilowatthours per kilowatt per hour), and

$V(U E)=$ assumed value of a kilowatthour of unserved energy (cost to consumers of a kilowatthour of electricity during a blackout, in cents per kilowatthour).
The reliability adjustment of spot prices for each pricing period, region, and year of the projection is calculated by multiplying the change in unserved energy per kilowatt of additional generating capacity (marginal unserved energy), calculated as described in the previous paragraphs, multiplied by the assumed value of unserved energy.

In summary, the spot price of electricity under competition is represented as:

$$
P c o m p_{r y t}=E_{r y t}+C_{r y t}+G A_{r y}+T a x_{r y t}+T D_{r y},
$$

where:

$$
\begin{aligned}
P_{\text {comp }}= & \text { the competitive price of delivered electricity } \\
& \text { in region } r, \text { year } y, \text { period } t \text { (cents per kilo- } \\
& \text { watthour), } \\
E_{r y t}= & \text { the marginal operating cost in region } r, \\
& \text { year } y \text {, period } t \text { (variable operating costs of } \\
& \text { the last plant dispatched in period } t \text {, in } \\
& \text { cents per kilowatthour), } \\
C_{r y t}= & \text { the reliability adjustment of price in region } \\
& r, \text { year } y, \text { period } t \text { (cents per kilowatthour) } \\
G A_{r y}= & \text { general and administrative costs for region } \\
& r, \text { year } y \text { (cents per kilowatthour) } \\
T a x_{r y t}= & \text { recovery of Federal income taxes and all } \\
& \text { other taxes in region } r, \text { year } y, \text { period } t \\
& \text { (cents per kilowatthour), and } \\
T D_{r y}= & \text { average transmission and distribution costs } \\
& \text { in region } r, \text { year } y \text { (cents per kilowatthour). }
\end{aligned}
$$

${ }^{132}$ Energy Information Administration, Annual Energy Outlook 1996, DOE/EIA-0383(96) (Washington, DC, January 1996 ), p. 30. 


\section{Appendix B Stranded Costs and Stranded Cost Recovery}

Stranded costs are the difference between revenues under competition and the costs of providing service, including the inherited fixed costs from the previous regulated market. Inherited costs from the regulated market include purchased power costs and capital recovery on plants, equipment, and regulatory assets. To calculate stranded costs, the algorithm described in this paper determines the degree to which revenues under competition fail to fully recover the fixed costs that were incurred under regulation after accounting for the fixed and variable costs of production under competition.

Three additional assumptions were made in the calculation of stranded costs. First, given the regionality of the models used in this analysis, only net regional stranded costs were calculated. That is, losses experienced by some companies were assumed to be offset by gains of other companies in each region. The actual level of stranded costs is likely to be higher than that calculated here due to this simplifying assumption. Second, it was assumed that the recovery of stranded costs would have no effect on demands. Stranded costs in the model are calculated after the market-determined prices and demand responses are calculated. Finally, it was assumed that taxes would neither increase nor mitigate stranded costs or stranded cost recovery outside the effects of the current tax code. The assumption of 100percent tax recovery in competitive prices makes it unnecessary to include taxes in the stranded cost calculation.

Using these assumptions, stranded costs are the difference between revenue in the competitive case less the sum of the fixed and variable costs of providing electric service under competition, and the fixed cost obligations-primarily capital recovery (annual depreciation expense), return to investors (return on ratebase), purchased power contracts and regulatory assets (deferred capital recovery under rate phase-in plans, for example) -that were incurred under regulation. The production costing function within the EMM provides the fixed cost obligations per kilowatthour based on the new price-revised demands from the competitive pricing algorithm. The model calculates stranded costs by first determining revenues under competition, then subtracting cash costs such as operation and maintenance (O\&M) costs, including fuel costs and power purchases-including long-term (firm) purchased power contracts above market price. What remains is the return on investment and capital recovery on existing equipment (undepreciated investments that may qualify for stranded cost recovery) and the return and capital recovery on unamortized regulatory assets. ${ }^{133}$ The costs remaining after all revenues are exhausted are stranded costs.

The cost components and sources of revenue that form the basis for the stranded cost calculation are discussed in Chapter 3 and reviewed here. The variable costs of producing electricity-fuel costs, variable O\&M costs, and short-run wholesale power purchase costs (economy trades)-must be recovered, or the company will discontinue operations in the short term. ${ }^{134}$ Therefore, the price of electricity in the model allows for the recovery of these costs. The remaining items on the cost side will not necessarily cause the firm to discontinue operations, but they will have a negative impact on shareholder wealth if they are not fully recovered. As mentioned above, these fixed costs include capital recovery (through the annual depreciation expense), return on capital (the regulatory equivalent to return on ratebase) and all other fixed obligations, such as power purchase contracts and the amortization of regulatory assets. The revenues that will be used to recover these costs are calculated from the prices and quantities that are outputs of the competitive pricing algorithm.

The annual stranded cost calculation in this analysis is represented as costs minus revenues:

\footnotetext{
${ }^{133}$ The capital costs associated with the recovery of post-1998 investments in plant and equipment (the capitalized costs of investments that were made after the onset of restructuring) are included in the stranded cost calculation because they are assumed to have been profitable (achieve the necessary return on invested capital), not because they are assumed to qualify for stranded cost recovery.

${ }^{134}$ Power purchase contracts priced above market prices are not included in the price-determining costs, because they are by definition a source of stranded costs.
} 


$$
\begin{aligned}
S C_{r y}= & \left(F O M_{r y}+G A_{r y}+T a x_{r y}+V O M_{r y}+D E P_{r y}\right. \\
& \left.+R E T_{r y}\right)-\left(P_{c o m p}-T D_{r y}\right),
\end{aligned}
$$

where

$S C_{r y}=$ stranded costs in region $r$, year $y$ (cents per kilowatthour),

FOM $_{r y}=$ average fixed O\&M costs in region $r$, year $y$ (cents per kilowatthour),

$G A_{r y}=\mathrm{G} \& \mathrm{~A}$ costs related to generation for region $r$, year $y$ (cents per kilowatthour),

Tax $x_{r y}=$ recovery of Federal income taxes and all other taxes in region $r$, year $y$ (cents per kilowatthour),

$V O M_{r y}=$ average variable $O \& \mathrm{M}$ costs in region $r$, year $y$, including total costs of fuel and short-run O\&M costs and firm purchased power contracts above market price entered into under regulation (a source of stranded costs) (cents per kilowatthour),

$D E P_{r y}=$ depreciation expense in region $r$, year $y$, which represents the recovery of investments in plant and equipment, including uneconomic investments and regulatory assets incurred under regulation (a source of stranded costs) (cents per kilowatthour),

$R E T_{r y}=$ return to investors in region $r$, year $y$, including return on the unamortized costs of plant, equipment, and regulatory assets (a source of stranded costs) (cents per kilowatthour),

$T D_{r y}=$ average transmission and distribution costs (and prices) in region $r$, year $y$ (cents per kilowatthour), and the revenue component is defined by

$$
\begin{aligned}
P_{c o m p}= & \text { the weighted average competitive price of } \\
& \text { electricity in region } r \text {, year } y \text {, (cents per } \\
& \text { kilowatthour). }
\end{aligned}
$$

The right side of the stranded cost equation consists of two terms: (1) the total generation costs per kilowatthour less (2) the total generating revenues per kilowatthour. However,

$$
P_{c o m p} r y=E_{r y}+C_{r y}+G A_{r y}+T a x_{r y}+T D_{r y} .
$$

Since $G A_{r y}$ and $T D_{r y}$ are assumed to be the same under cost of service and competitive pricing, they cancel out of the equation.

Income taxes would only be collected on the difference between revenues and costs under either competition or regulation, and revenue tax rates are assumed to be equal and cancel out. Therefore, there is no need to include taxes in the calculation, and the annual stranded cost calculation for region $r$ can be reduced to:

$$
\begin{aligned}
S C_{r y}= & \left(F O M_{r y}+V O M_{r y}+D E P_{r y}+R E T_{r y}\right) \\
& -\left(E_{r y}+C_{r y}\right),
\end{aligned}
$$

where

$$
\begin{aligned}
E_{r y}= & \text { sales weighted average annual marginal } \\
& \text { costs of generation in region } r, \text { year } y \text { (cents } \\
& \text { per kilowatthour), and } \\
C_{r y}= & \text { revenue from reliability price adjustment } \\
& \text { (sales weighted marginal costs of operating } \\
& \text { reserves) in region } r, \text { year } y \text { (cents per kilo- } \\
& \text { watthour). }
\end{aligned}
$$




\section{Appendix C Reserve Margin Calculations}

The optimal reserve margin is set by the condition in the model:

$$
(\partial U E / \partial G) \cdot V(U E)=A_{t}
$$

where:

$A_{t}=$ annual carrying cost (dollars per kilowatt per year) of the least expensive generating capacity (combustion turbine), and

$$
(\partial U E / \partial G) \cdot V(U E)=\underset{\text { Marginal cost of unserved energy }}{\text { (dollars per kilowatt per year). }}
$$

This is analogous to the "capacity payment" term used in setting the Pool price in the U.K. system. ${ }^{135}$

The reserve margin is used to determine the amount of new capacity that is added over the course of a single scenario.

Reserve margins are optimal in the following sense. If this value of additional capacity were less than the resulting change in mitigated consumer costs, then consumers would not be willing to pay the increases in electricity prices during peak periods that would justify investments in additional capacity. On the other hand, if reserve margins were such that the average electricity revenues to generators exceeded the marginal costs of production and other necessary cash costs (fixed O\&M, G\&A, and taxes) by an amount greater than the costs of new capacity, then producers would continue to add capacity until there was no economic advantage in doing so.

The value of an additional kilowatt of capacity will vary with the marginal change in expected unserved energy, or with changes in the assumed value of unserved energy $(V(U E))$. Therefore, any changes in assumptions regarding elasticities of demand (affecting the $\partial U E / \partial G$ term), forced outage rates (again, affecting the $\partial U E / \partial G$ term), or the value of unserved energy $(V(U E))$ will change the target reserve margin used in the projections of electricity prices and production costs.

\footnotetext{
${ }^{135}$ See A. Henney, A Study of the Privatization of the Electricity Supply Industry in England and Wales (London, UK: EEI Limited, 1994), p. 111.
} 


\section{Appendix D \\ Economic Analysis of Results}

Introduction of competition to the electricity market may have significant impacts on the price and consumption of electricity. It may also involve transfer of wealth between producers and consumers. That is, consumers may pay more or less for the same amount of electricity, and producers may have a commensurate change in revenues while the cost of production remains very nearly the same. However, the goal of competition is to provide a net overall benefit to everyone, both producers and consumers. One way of quantifying this benefit is through the notion of an improvement in overall social welfare. ${ }^{136}$ Examining the change in social welfare is a way of quantifying (through a monetary measure) the net social worth of a particular policy. The effect of competition on this measure is discussed below. Even without relying on such a measure, the effect of competition on producers and consumers can be qualitatively described.

The relationship between supply and demand resulting in a market equilibrium is typically displayed using supply and demand curves, as illustrated in Figure D1,

Figure D1. Illustration of the Economic Consequences of Deregulation

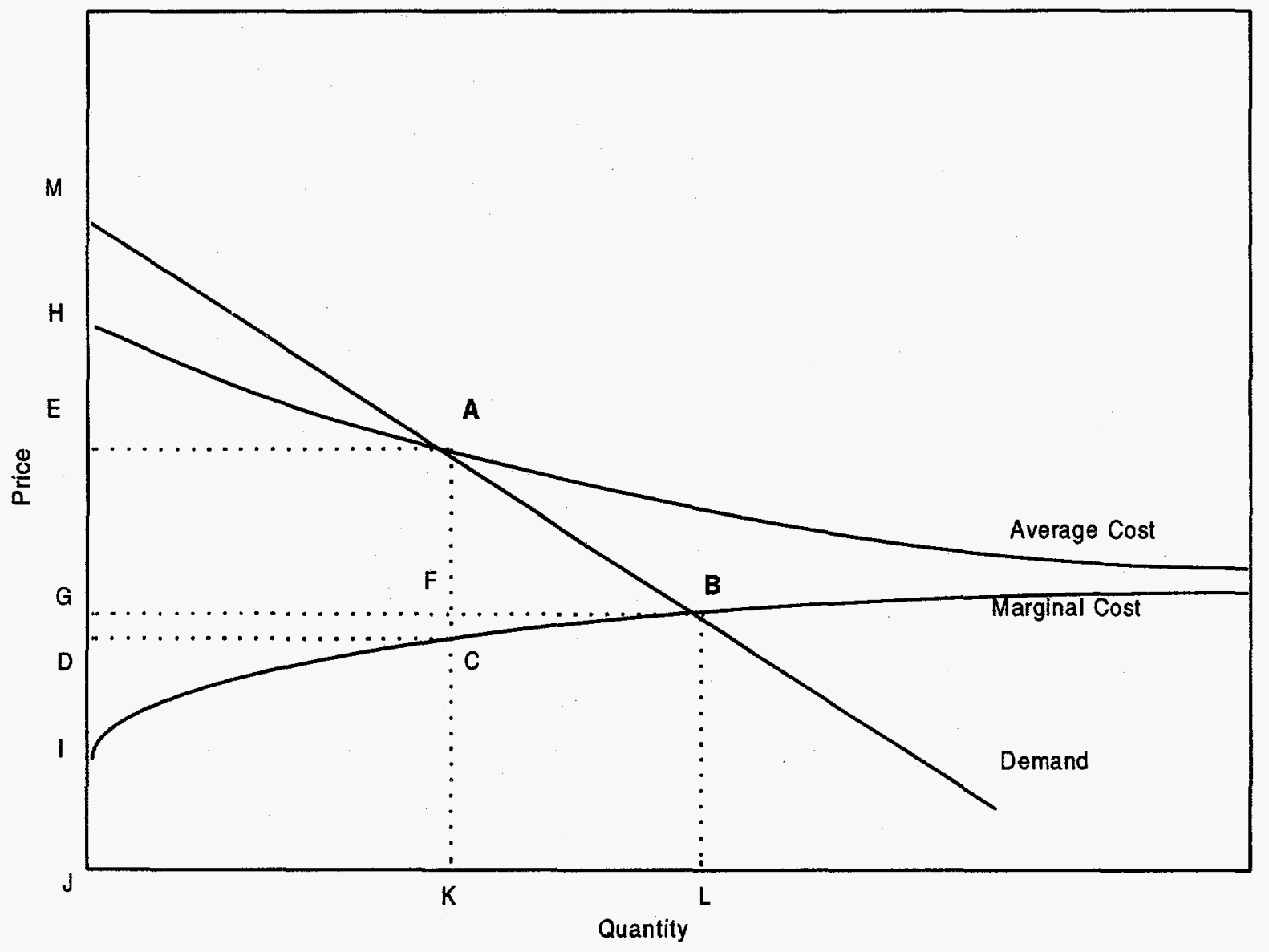

${ }^{136}$ M.A. Crew and P.R. Kleindorfer, Public Utility Economics (New York, NY: St. Martin's Press, 1979), p. 6. 
which shows the relationship between the competitive and regulated equilibria and graphically displays some of the conclusions of this report. In particular, it shows the relationship between the change from the competitive and regulated equilibrium prices and the effect on stranded costs and overall social welfare.

There are three curves in Figure D1: a demand curve running through $M, A$ and $B$; a marginal cost curve connecting $\mathrm{I}, \mathrm{C}$, and $\mathrm{B}$; and an average cost curve running through $\mathrm{H}$ and $\mathrm{A}$. The demand curve intersects the average cost supply curve (the supply curve under regulation) at point $A$ and the marginal cost supply curve (the supply in a competitive market) at point $B$. However, Figure D1 shows only a part of the whole picture. Two factors would tend to lower the marginal cost curve. Under competition, producers would tend to reduce their costs in order to maximize profits. Thus, costs would tend to decline over the course of the projection. As discussed in Chapter 5, however, the effect that competition would have on efficiency of electricity production is generally beyond the scope of this study (although one illustrative case is given in Chapter 3). Second, over the range of demand elasticities chosen for this study, the effect of demand elasticity is to shift demand away from the peak periods while leaving overall consumption approximately constant. This is reflected in the nearly vertical demand curve $A B$ in Figure D2. As explained in Chapter 3, demand shifting lowers marginal costs far more than average costs.

The dashed line in Figure D2 represents the marginal cost curve shifted downward as a result of increased price elasticity. At relatively low elasticities, the increase causes additional demand shifting without significantly changing aggregate demand. As a result, the competitive price is shifted downward from $C$ to $C^{\prime}$. Consumers pay less for electricity, and producers receive less, while total consumption and average costs remain approximately constant. Thus, when overall

Figure D2. Effect of Deregulation with Small Aggregate Demand Shift

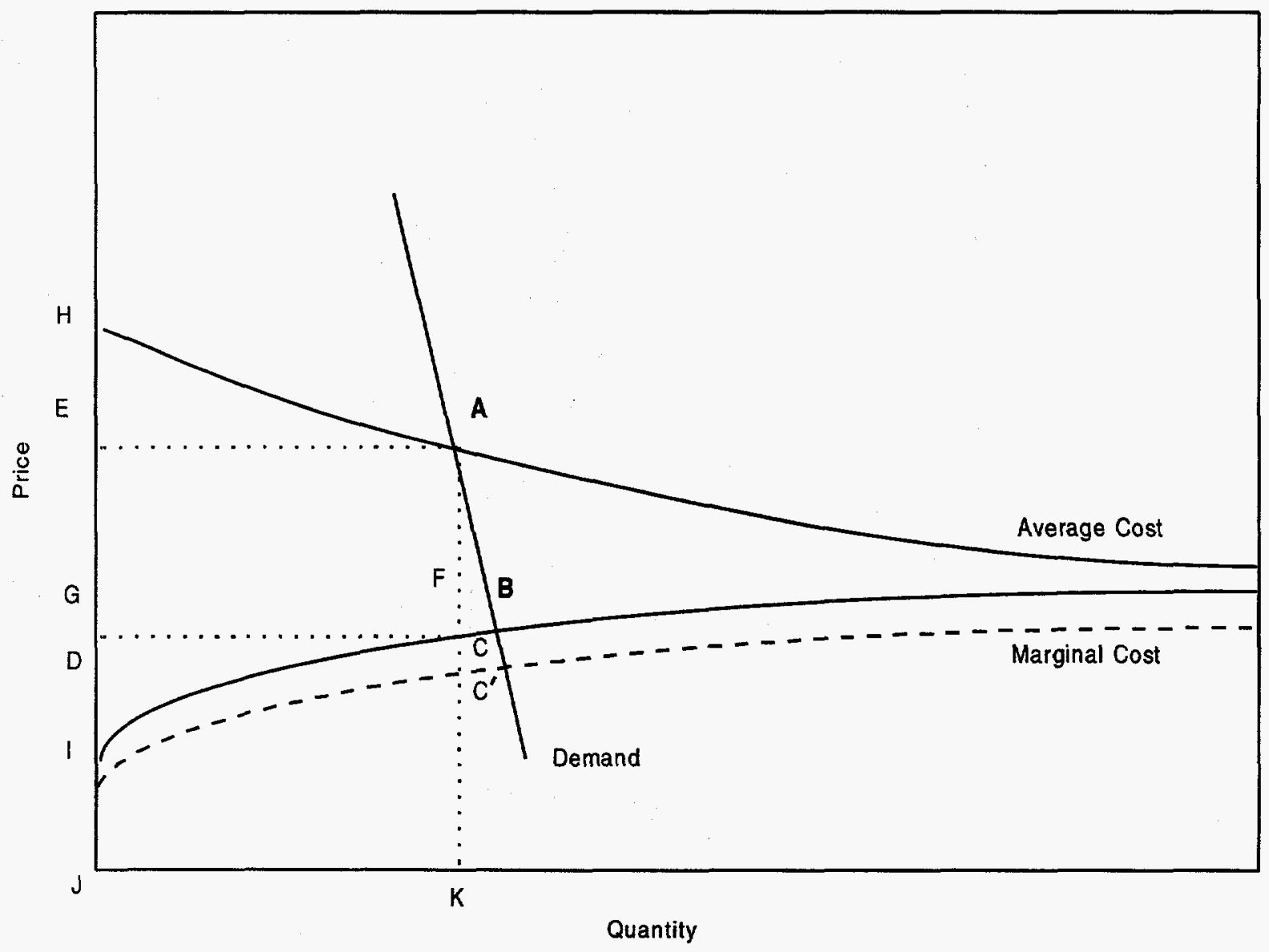


demand remains essentially constant, stranded costs increase with increasing elasticity, as was observed in the study.

Consumers would pay significantly less for the same amount of electricity they use now. Producers would receive correspondingly less revenue for the electricity they produce. Since producers' costs would decline far less than their revenues, their profits (and ability to recover stranded costs) would also decline. The decline in profits would be seen by consumers in the form of lower prices. That is, wealth would be transferred from producers to consumers.

The intersection of the average cost curve and the demand curve gives the regulated price $E$ at quantity $K$ in Figure D1, while the intersection of the marginal cost curve and the demand curve gives the competitive price $G$ at the quantity L. As previously shown, the average cost is above the marginal cost of electricity, leading to the conclusion that the equilibrium regulated price $\mathrm{E}$ is above the equilibrium competitive price $\mathrm{G}$. However, the change in consumption depends on the slope of the demand curve $A B$.

In contrast to the demand curve in Figure D2, the effect of competition shown in Figure D1 is more subtle. Suppose the demand curve runs along the line $A B$ in Figure D1. In this case, consumers show a great deal of responsiveness to price. Not only is the equilibrium price at point $B$ lower under deregulation, but the demand has increased in response to the lower price.

The consequences of these effects can be displayed as follows. Since the axes of the graph are price and quantity, any area represents a revenue or expense. A standard measure of the benefits of electricity to consumers, called the "consumer's surplus," is represented by the area under the demand curve above the market clearing price. This is equal to the area EAM in the regulated case. This area represents the total amount consumers would pay for electricity if each kilowatthour were priced exactly at the customer's value (JKAM) minus the amount actually paid (JKAE). Similarly, producer's surplus is defined as the area above the marginal cost curve but below the market clearing price. In the competitive case, the producer's surplus is GBI-the difference between the total revenue received under competition (GBLJ) and the marginal costs incurred (IBLJ). This difference is the amount of money producers have to contribute to fixed costs and profit.

Now, the effect of demand elasticity on the various components of general welfare can be seen. The consumer's surplus under competition has increased from the area EAM to GBM. Thus, the net improvement in the consumer's surplus is represented by the area inside EABG. Because of the demand response to price, demand increases to $L$, and the market clearing price is $G$ rather than $D$. That is, the revenue loss on the original demand level $K$ in the competitive environment is EAFG, but there is the added value of CFB from the increased demand.

The area in CFB represents the excess of revenues over marginal costs for production of electricity to meet the increase in demand from $K$ to $L$. The net loss in revenues, also known as stranded costs, is EAFG - CFB. This is a net wealth transfer to consumers. Since the consumer's surplus increases by EABG and the producer's surplus decreases by EAFG - CFB, the net overall increase in social welfare, that is, the net improvement in both consumer and producer surplus, is given by the area $A B C$.

Two general conclusions can be drawn from these diagrams. First, if the demand elasticity is relatively small, most changes in consumption will consist of shifts from peak to off-peak periods, with aggregate consumption remaining constant, as seen in this analysis. However, if the aggregate consumption increases with lower price, two other effects become significant: (1) while moving to marginal cost pricing may impose stranded costs, they will at least be partially mitigated by any resulting increase in demand; and (2) given the relationship between marginal and average cost pricing shown here, the demand response to marginal cost pricing will always yield improvements in the overall social welfare measured by the sum of producer's and consumer's surplus. 


\section{Appendix E NEMS and VALCAP: Iterative Convergent Pricing Model}

The initial implementation of the pricing algorithm uses the National Energy Modeling System (NEMS) and an offline model, the Prototype Value of Capacity Model (VALCAP). VALCAP runs with inputs created during a NEMS run. Then, after VALCAP is run, NEMS is rerun with load shapes (varying demand levels) adjusted by VALCAP. This iterative process between NEMS and VALCAP is outlined in Figure E1. Steps 1 and 3 make use of the NEMS model. Steps 2 and 4 use VALCAP.

Step 1. NEMS is run using the traditional cost-of-service regulation algorithms. The following values are stored for use by VALCAP:

- Regional regulated electricity prices (for use in step 2B below)

- Capacity expansion plans (for use in step 2A)

- The operating cost of the last plant dispatched in each of 108 time periods (for calculating the energy component of price)

- Hourly load data (for step 2A).

Step 2A. The market price of electricity for each of the 108 dispatched time periods is determined using the sum of the energy component from step 1 and the reliability (quality of service) component calculated as described in Appendix A.

Step 2B. A new demand for each of the 108 dispatch time periods per year is calculated from:

- An assumed elasticity of demand (a varying input assumption)
- Original hourly demands based on the cost-of-service reference case run (step 1)

- Original cost-of-service price (step 1)

- New competitive price (energy component from step 1 or $2 \mathrm{C}$; reliability adjustment from step $2 \mathrm{~A}$ ).

After the second iteration of this process, a check for convergence of prices and quantities is made. If competitive electricity prices and demand quantities for two consecutive iterations of steps $2 \mathrm{~B}$ and $2 \mathrm{C}$ remain within the specified domain of convergence, then the exogenous model saves the hourly load data (from step 2B), the adjusted demand by slice, and the two components of the competitive price of electricity and proceeds to the next region or year of the simulation (step 2A). If convergence is not achieved, then the model proceeds to step $2 \mathrm{C}$.

Step 2C. A reduced form of the dispatch algorithm is used to determine the marginal cost component of the competitive price based on the new demand levels (from step 2B). Steps $2 \mathrm{~B}$ and $2 \mathrm{C}$ are repeated until convergence is reached.

Step 3. The EMM is run using the revised demand levels (load shapes and aggregate demand) from step 2. The results of this run include new dispatch decisions and capacity planning decisions based on the revised load shapes and quantities.

Step 4. The VALCAP program, encompassing steps $2 A$ through $2 C$, is run again using the dispatch and capacity planning decisions from step 3 . Final prices are calculated from this run. 
Figure E1. Competitive Price Algorithm

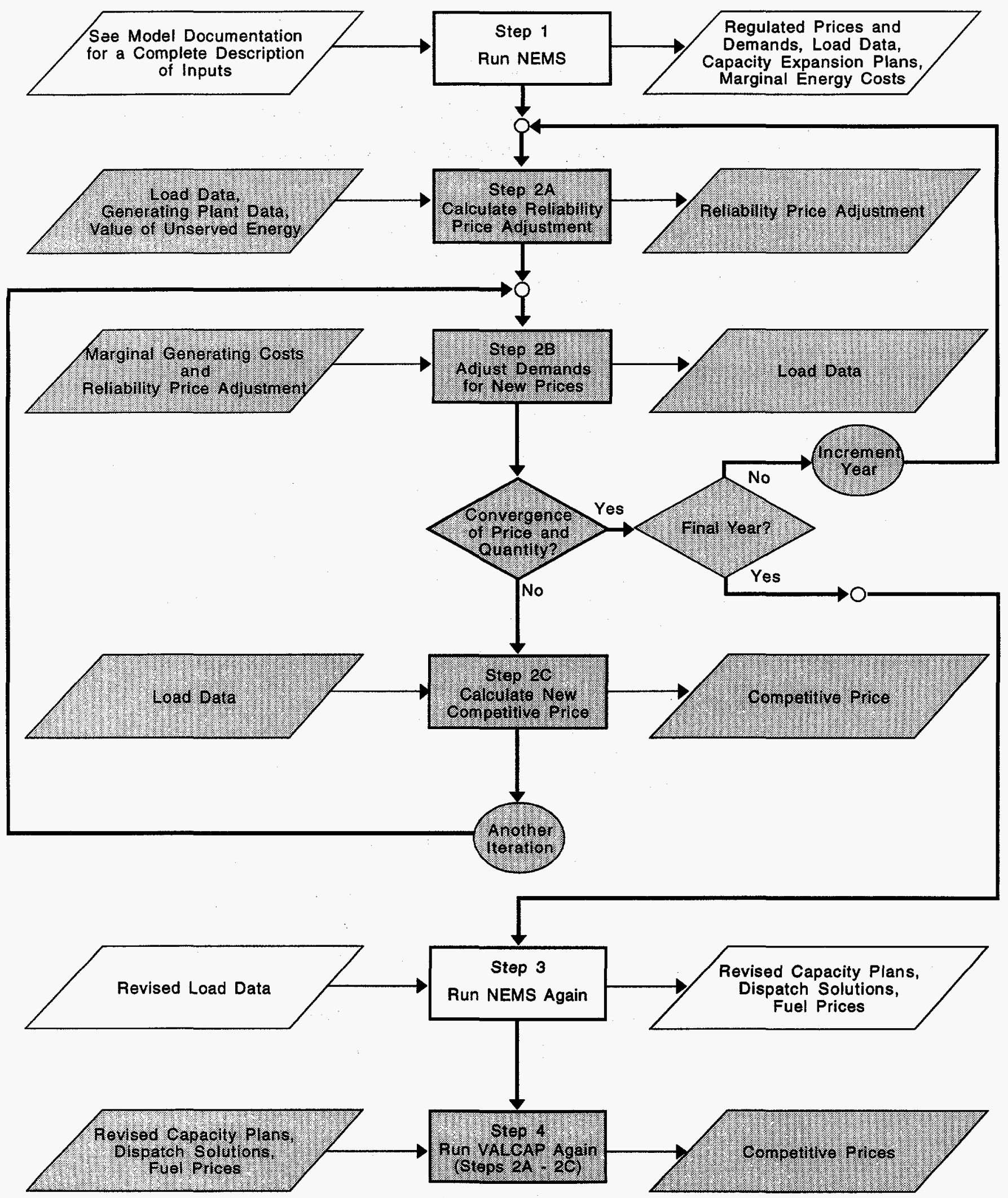




\section{Appendix $F$ \\ Calculation of Marginal Expected Unserved Energy in VALCAP: Mathematical Specifications}

The key calculation in the reliability adjustment of price is the calculation of the expected value of unserved energy. There are two steps in the process. First, probability distributions for generating capacity and demand are created for each dispatch time period (108 per year), region, and year. The distribution for demand is a normal distribution, with the mean based on actual hourly demand data and a standard deviation assumed to be equal to 5 percent of the mean (the load uncertainty factor). The distribution for capacity is determined using data for each generating plant and an assumed probability of a forced outage. The forced outage rate varies by plant type (generating technology).

The individual generating plants, $C_{i}$, are represented as independent Bernoulli random variables with distinct parameters, $p_{i}$, equal to their equivalent forced outage rates. The regional generating capacity is represented by

$$
G=\Sigma C_{i}
$$

Since the distribution of $G$ cannot be described analytically from the individual distributions of each plant, it is approximated numerically from its first four cumulants ${ }^{137}$ using the Gram-Charlier expansion. ${ }^{138}$

In the second step, the expected value of unserved energy is calculated as follows:

$$
\text { Let } \begin{aligned}
L= & \text { stochastic load curve, } \\
G= & \text { stochastic generating capacity, and } \\
U E= & L-G \text { for } l>g, 0 \text { otherwise, since surplus } \\
& \text { capacity }(G-L \text { for } g>l) \text { does not contrib- } \\
& \text { ute to the unserved energy calculation. }
\end{aligned}
$$

If it is assumed that $L$ and $G$ are independent, the expected value of unserved energy is:

where:

$$
\begin{aligned}
E[U E] & =\iint_{l>g}(l-g) L(l) G(g) d l d g \\
& =\int_{0}^{\infty} \int_{0}^{l}(l-g) G(g) d g L(l) d l,
\end{aligned}
$$

$U E=$ kilowatthours of unserved energy,

$l, d l, g, d g=$ variables of integration,

$L(l)=$ density function for load (demand), and

$G(g)=$ density function for generating capacity.

In the VALCAP program, this double integral is evaluated numerically using a modified trapezoidal quadrature rule for dispatch time period $t$, region $r$, in year $y$ :

$$
\begin{aligned}
& U E_{\text {try }}=\sum_{i=1}^{n_{t}} \sum_{j=1}^{i} p\left(\text { load }_{i, t}\right) \cdot p\left(\text { gen }_{j, t}\right) \\
& \cdot\left(\operatorname{load}_{i, t}-\operatorname{gen}_{j, t}\right),
\end{aligned}
$$$$
\text { where: }
$$

$$
\begin{aligned}
& p\left(\text { load }_{i, t}\right)=\text { probability that load is in bin } i \text { for } i=1, \ldots \\
& n_{t} \text { (number of bins in dispatch time period } \\
& t) \text {, dispatch time period } t \\
& p\left(\text { gen }_{j, t}\right)=\text { probability that capacity is in bin } j \text { (where } \\
& j \leq i) \text { for dispatch time period } t \\
& \begin{aligned}
\operatorname{load}_{i, t}= & \text { midpoint of load level in bin } i \text {, dispatch } \\
\text { time period } t &
\end{aligned} \\
& g e n_{j, t}=\text { midpoint of capacity level in bin } j, \text { dispatch }
\end{aligned}
$$

hours $s_{t}=$ number of hours in dispatch time period $t$.

\footnotetext{
${ }^{137}$ Cumulants are linear combinations of the moments of a random variable. If two random variables are independent, the sum of the cumulants is equal to the cumulant of their sums. Thus, by summing the cumulants representing the individual plants, the cumulants characterizing the regional generating distribution can be found. A complete description of this technique can be found in J.P. Stremel, R.T. Jenkins, R.A. Babb, and W.D. Bayless, "Production Costing Using the Cumulant Method of Representing the Equivalent Load Curve," IEEE Transactions on Power System Analysis, Vol. PAS-99, No. 5 (September/October 1980).

${ }^{138}$ See M. Kendall, A. Stuart, and J.K. Ord, Advanced Theory of Statistics (London, UK: Oxford University Press, 1987 ), p. 88.
} 
This double integral is evaluated twice, once with an additional increment of perfectly reliable capacity. The term $(\partial U E / \partial G)$ is then approximated by $\Delta U E / \Delta G$ and used in the calculation of the reliability adjustment described above. 


\section{Glossary}

This glossary has been compiled from several sources, including: Energy Information Administration, Performance Issues for a Changing Electric Power Industry, DOE/EIA-0586 (Washington, DC, January 1995); Public OnLine Group, "Restructuring Glossary," web site ee.notes.org/glossary.htm; and T.J. Brennan et al., A Shock to the System: Restructuring America's Electricity Industry (Washington, DC: Resources for the Future, July, 1996).

Ancillary Services: Six distinct services identified by the Federal Energy Regulatory Commission (FERC) as necessary to provide electricity service to consumers: reactive power, load following, loss compensation, energy imbalance, scheduling and dispatch services, and system protection (operating reserves).

Bilateral Trade: A direct transaction between a power producer and a user or broker outside a centralized power pool or POOLCO. See Power Pool.

Capacity: The amount of electric power delivered or required for which a generator, turbine, transformer, transmission circuit, station, or system is rated by the manufacturer.

Capacity Externality: Externality associated with maintaining sufficient reserve capacity to prevent loss of service, or outages. See Externalities.

Combined Cycle: An electric generating technology in which electricity is produced from otherwise lost waste heat exiting from one or more gas (combustion) turbines. The exiting heat is routed to a conventional boiler or to a heat recovery steam generator for utilization by a steam turbine to generate electricity. This process increases the efficiency of the electric generating unit.

Competitive Pricing: Pricing based on a competitive, or spot, market. Thus the price reflects the actual cost of producing the incremental unit of power at that instant, rather than the average cost over the course of a year.

Congestion Pricing: A system for pricing transmission service based in part on the instantaneous demand for transmission capacity.

Consumer's Surplus: In economics, the difference between the total value consumers receive from the purchase of electricity, as described by their demand curve, and the total amount they pay for it

Control Area: An electric system that directly controls its generation to continuously meet demand and fulfill exchange obligations and that helps regulate and stabilize the frequency of its interconnection's electric voltage and current.
Cost of Capital: The cost of borrowing funds from bondholders and the compensation to shareholders that is required to procure investments in the equities markets (common stock).

Cost-of-Service Regulation: A pricing concept traditionally used for designing electric rate schedules. Rates are set so that the revenues from retail sales of electricity cover its generation, transmission, and distribution costs plus a fair rate of return on invested capital.

Demand (Electric): The rate at which electric energy is delivered to or by a system, part of a system, or piece of equipment, at a given instant or averaged over any designated period of time.

Deregulation: The reduction or elimination of regulation from an industry or sector of an industry.

Economic Efficiency: The optimal level of production and consumption of goods and services. This generally occurs when prices of products and services reflect their marginal costs.

Economies of Scale: The existence of decreasing average long-run costs of production with increases in output.

Electric Utility: Any company or state agency with a monopoly franchise (including any municipality), which sells electric energy to end-use customers. Includes the Tennessee Valley Authority but does not include other Federal power marketing agencies.

Energy Imbalance: An ancillary service that involves ensuring that the system is kept in balance when actual demand and supply do not equal the amounts contracted or scheduled for. For example, if a contract calls for the delivery of 100 megawatts to a particular customer between 8 and 9 am, but the customers demand actually rises to 110 megawatts, an additional 10 megawatts must be supplied to keep the system in balance.

EPACT: The Energy Policy Act of 1992. EPACT created a new class of power generators, exempt wholesale generators (EWGs), which are exempt from the provisions of the Public Utilities Holding Company Act of 
1935, and grants authority to FERC to order and condition access by eligible parties to the interconnected transmission grid.

Exempt Wholesale Generator (EWG): An electricity producer which, under the Energy Policy Act of 1992, is exempt from certain financial and legal restrictions stipulated in the Public Utility Holding Company Act of 1935.

Externalities: Factors affecting society that are not included in the monetary cost of a product (e.g., air pollution caused by electricity generation).

Federal Energy Regulatory Commission (FERC): The Federal agency that regulates the price, terms, and conditions of power sold in interstate commerce and regulates the price, terms, and conditions of all transmission services. FERC is the Federal counterpart of State utility regulatory commissions.

Forced Outage Rate: The fraction of time for which a generating unit is required but cannot be in service due to an unplanned event.

Frequency Regulation: The maintenance of an interconnection's required frequency by the controller.

Gas-Fired Generator: A plant in which the prime mover is a gas turbine. A gas turbine typically consists of an axial-flow compressor that feeds compressed air into one or more combustion chambers, where liquid or gaseous fuel is burned. The resulting hot gases are expanded through the turbine, causing it to rotate. The rotating turbine shaft drives the compressors as well as the generator, producing electricity.

General and Administrative (G\&A) Expenses: Generally, overhead costs that cannot directly be assigned to a particular process or product.

Generation (Electricity): The process of producing electric energy from other forms of energy; also, the amount of electric energy produced, expressed in watthours (Wh).

Gross Generation: The total amount of electric energy produced by the generating units at a generating station or stations, measured at the generator terminals. See Net Generation.

Independent System Operator (ISO): A neutral operator responsible for maintaining an instantaneous balance of the grid system. The ISO performs its function by controlling the dispatch of flexible plants to ensure that loads match resources available to the system.

Investor-Owned Utility (IOU): A profit-making company, owned by stockholders, that provides utility services. A designation used to differentiate a utility owned and operated for the benefit of shareholders from municipally owned and operated utilities and rural electric cooperatives.

Load (Electric): The amount of electric power delivered or required at any specific point or points on a system. The requirement originates at the energy-consuming equipment of the consumers.

Load Diversity: The practice of attracting customers whose peak consumption of electricity occurs at different times of the day so that the cumulative difference between peak and off-peak demand levels is reduced. Load diversity reduces the cost of operating the system and reduces the capital investments needed to ensure its reliability.

Load Duration Curve: A plot of system load versus hours with the value of the abscissa being the number of hours the load exceeds the ordinate.

Load Following: An electric system's ability to regulate its generation to follow the minute-to-minute changes in its customers' demand.

Load Shifting: The process of moving electricity consumption from time periods of peak demand to periods of lesser demand.

Loss Compensation: An ancillary service that involves generating additional electricity, beyond the amount demanded by end users, to compensate for losses that occur on the transmission and distribution system. In other words, if a system has a 5-percent loss rate, 105 megawatthours would have to be generated to meet a 100-megawatthour customer need.

Loss of Load Probability: The probability that an outage will occur in any particular time interval.

Marginal Cost: The cost to the utility of providing the next (marginal) kilowatthour of electricity, irrespective of sunk costs.

Marginal Cost Pricing: Pricing based on the marginal cost of production of electricity.

Marginal Unserved Energy: The amount of unserved energy that is reduced by adding an increment of capacity.

Market Power: The ability of a firm to raise its price above the marginal cost of production. In a fully competitive market, prices will be set at the cost of production of the most expensive (marginal) unit produced.

National Energy Modeling System (NEMS): The midterm energy analysis tool of the Energy Information Administration used to prepare projections of energy markets.

Natural Monopoly: A situation in which one firm can produce a given level of output at a lower total cost 
than can any combination of multiple firms. Natural monopolies occur in industries that exhibit decreasing average long-run costs due to size (economies of scale). According to economic theory, a public monopoly governed by regulation is justified when an industry exhibits natural monopoly characteristics.

Net Generation: Gross generation less the electric energy consumed at the generating station for station use.

Nonbypassable: A surcharge imposed in such a way that consumers cannot avoid paying it, whether they stay with their current utility or choose a new supplier.

North American Electric Reliability Council (NERC): A council formed in 1968 by the electric utility industry to assure the reliability and adequacy of the bulk power supply in the electric utility systems of North America. NERC consists of nine regional councils and encompasses essentially all the power regions of the contiguous United States, Canada, and a small portion of Mexico. There is also one affiliate member in Alaska, the Alaskan System Coordination Council.

Operating Reserves: The reserve generating capacity necessary to allow an electric system to recover from generation failures and provide load following and frequency regulation.

Operations and Maintenance (O\&M) Costs: All costs of operating a plant, excluding capital recovery and return on investment.

Optimal Reserve Margin: The reserve margin at which the cost of adding an additional increment of capacity equals the incremental reduction in outage costs.

Peak Demand: The maximum load during a specified period of time.

Perfect Competition: An economic model in which producers and consumers compete to buy and sell goods, no market power is exerted, and prices at equilibrium are equal to the marginal cost of production.

Performance-Based Regulation (PBR): Any rate-setting mechanism that links rewards (generally profits) to desired results or targets.

Plant: A facility with prime movers, electric generators, and auxiliary equipment for converting mechanical, chemical and/or nuclear energy into electric energy. A plant may contain more than one type of prime mover. Electric utility plants exclude facilities that satisfy the definition of a qualifying facility under the Public Utility Regulatory Policies Act of 1978.

Power Pool (POOLCO): An entity established to coordinate short-term operations to maintain system stability and achieve least-cost dispatch. The dispatch provides backup supplies, short-term excess sales, reactive power support, and spinning reserve. Historically, some of these services were provided on an unpriced basis as part of members' utility franchise obligations. Coordinating short-term operations includes the aggregation and firming of power from various generators, arranging exchanges between generators, and establishing (or enforcing) the rules of conduct for wholesale transactions. The pool may own, manage, and/or operate the transmission lines ("wires") or be an independent entity that manages the transactions between entities. Often, the power pool is not meant to provide transmission access and pricing, or settlement mechanisms if differences between contracted volumes among buyers and sellers exist.

Price Elasticity: Variation in consumers' demand based on price. The price elasticity is expressed as a function of the ratio of percent change in consumers' demand to the percent change in price.

Producer's Surplus: The difference between the revenue received and the total cost of production of power from the sale of electric power.

Public Utility Commission (PUC): A State authority responsible for the regulation of retail sales of electricity.

Public Utility Holding Company Act of 1935 (PUHCA): A Federal law that prohibits acquisition of any wholesale or retail electric business through a holding company unless that business forms part of an integrated public utility system when combined with the utility's other electric business. The law also restricts ownership of an electric business by nonutility corporations.

Public Utility Regulatory Policies Act of 1978 (PURPA): A Federal law that requires utilities to buy electric power from private "qualifying facilities" at an avoided cost rate. The avoided cost rate is equivalent to what it would have otherwise cost the utility to generate or purchase the power itself. Utilities must further provide customers who choose to generate their own electricity a reasonably priced backup supply of electricity.

Qualifying Facility (QF): A wholesale generating plant that, under PURPA, was allowed to sell its electric output to a local utility at avoided cost rates. To become a $\mathrm{QF}$, the independent power supplier had to produce electricity with a specified fuel type (cogeneration or renewables) and meet certain ownership, size, and efficiency criteria established by the Federal Energy Regulatory Commission.

Rate of Return Regulation: A regulatory system whereby electricity prices are set to allow the providers just enough sales revenue to recover the expected total costs 
incurred in producing or acquiring electricity, including a rate of return equal to the utility's cost of capital.

Ratebase Regulation: See Rate of Return Regulation.

Reactive Power Generation: The production of electric current that leads or lags the phase of the electric voltage. Reactive power supplies the charging power for electromagnetic loads and the reactive needs of the transmission system.

Real-Time Pricing: The instantaneous pricing of electricity based on the cost of the electricity available for use at the time the electricity is demanded by the customer.

Regulatory Compact: A theory which holds that in exchange for building the generation, transmission, and distribution infrastructure necessary to fulfill an obligation to serve all customers in a franchise service area, the utility is guaranteed a return on those investments.

Reliability: Electric system reliability has two components: adequacy and security. Adequacy is the ability of the electric system to supply customers at all times, taking into account scheduled and unscheduled outages of system facilities. Security is the ability of the electric system to withstand sudden disturbances, such as electric short circuits or unanticipated loss of system facilities.

Reserve Margin: The percent of generating capacity needed above the expected maximum demand.

Retail Wheeling (Competition): The transmission of electricity from a wholesale supplier to a retail customer by a third party.

Rural Electric Cooperative: An electric utility legally established to be owned by and operated for the benefit of those using its service. The utility company will generate, transmit, and/or distribute supplies of electric energy to a specified area not being serviced by another utility. Such ventures are generally exempt from Federal income tax laws. Most electric cooperatives have been initially financed by the Rural Electrification Administration, U.S. Department of Agriculture.

Social Welfare: A monetary measure of the general well-being of a society. One definition of social welfare is the equally weighted sum of producers' and consumers' welfare.

Spot Market: A market in which goods are traded for immediate delivery.

Steam-Electric Plant: A plant in which the prime mover is a steam turbine. The steam used to drive the turbine is produced in a boiler that burns fossil fuels.

Stranded Assets: The reduction in market value estimated by the discounted present value of stranded costs. This analysis provides an estimate of net stranded assets through the analysis of net stranded costs.

Stranded Costs: The difference between revenues under competition and costs of providing service, including the inherited fixed costs from the previous regulated market.

Time-of-Use Rates: The pricing of electricity based on the estimated cost of electricity during a particular time block. Time-of-use rates are usually divided into three or four time blocks per 24-hour period (on-peak, midpeak, off-peak, and sometimes super off-peak) and by seasons of the year (summer and winter). Real-time pricing differs from time-of-use rates in that it is based on actual (as opposed to projected) prices, which may fluctuate many times a day and are weather-sensitive, rather than varying with a fixed schedule.

Transmission and Distribution (T\&D): Transmission is the process of conducting the flow of electricity at high voltages from the points of generation to the location of groups of electricity users, such as residential neighborhoods, industrial parks, and commercial centers. Distribution of electricity is the process of transforming high-voltage electricity to lower voltages and then physically delivering it to households, industrial facilities, commercial establishments, government offices, and other electricity users.

Unserved Energy: The amount of energy demanded at a certain price that cannot be supplied with available capacity.

Value of Unserved Energy: The total monetary value per kilowatthour that consumers place on an outage. These costs can be measured in three categories: rationing costs, disruption costs, and lost consumer surplus. Rationing costs are incurred by the utility in determining how to allocate electricity when a scarcity of supply occurs. Disruption costs are the direct costs to the consumers of a shortage. Lost surplus costs express the amount the consumer would be willing to pay if electricity were available.

Variable Operating Costs: Operating costs that depend directly on the level of power produced from a plant.

Voltage Control: The regulation of transmission voltage by adjusting generator reactive output and transformer taps, and by switching capacitors and inductors on the transmission and distribution systems.

Wheeling: The transmission of power to customers. Wholesale wheeling is the transmission of bulk power over the grid from one wholesale supplier to another wholesale supplier by a third party. Retail wheeling is the transmission of power from a wholesale supplier to end users, such as homes, businesses, and factories. 


\section{Index}

A

Ancillary services 2, 14, 105

Annual Energy Outlook 1997 (AEO97) iii, xii, xiii, xiv, xv, xvi, 11, 14, 16, 22, 24-27, 32-34, 37, 39-41, $43,61-63,65,66,83-85,90$

Assembly Bill 1890 (California, AB 1890) xiv, 7, 59

Average-cost-based prices 24, 52

Average cost pricing (see also Average-cost-based prices) 12,99

Avoidable costs 21, 42

Avoided costs 3, 107

\section{B}

Bankruptcy ix, xvi, 17, 64, 65, 68, 69, 77, 78, 84, 86

\section{C}

California-Southern Nevada Power Area (CNV,

Region 13) xiv, 39, 59, 60, 65, 69, 73, 76

Capacity expansion xiii, 101

Capacity externality 36, 86, 105

Capital recovery $6,16,18,21,24,26,29,33,34,56$, $89,93,107$

Congestion $14,85,89,105$

Consumer surplus 108

Cost of capital xi, 2, 17, 35, 85, 86, 105, 108

Cost-of-service regulation (see also Ratebase regulation) $x i, 21,26,101,105$

Cumulant 103

\section{E}

East Central Area Reliability Coordination Agreement (ECAR, Region 1) xiv, 39, 46-48, 60, $69,71,72,74,75,78$

Economies of scale 1, 2, 105, 107

Elasticity of demand 24, 25, 30-32, 40, 41, 63, 101

Electric Reliability Council of Texas (ERCOT, Region 2) xiv, 39, 48, 49, 60, 65, 69, 71, 73

Electricity Market Module (EMM) xiv, 9, 66, 89, 93, 101

Embedded costs 11, 12

Energy Policy Act of 1992 (EPACT) 2-4, 105, 106

Exempt wholesale generator (EWG) 106
$\mathbf{F}$

Federal Energy Regulatory Commission

(FERC) xiv, xvi, 2-5, 7, 14-16, 26, 63, 66, 67, 70-73, 75, 76, 78-81, 105-106

Federal Power Act of 1935 (FPA) 2

FERC Order 888 3-5

FERC Order 8893

Fixed costs xi, xii, xiii, 1, 16, 17, 21, 22, 25, 32, 33, $35,36,41-43,45,63,83,84,93,99,108$

Flat Rates Case xii, xiii, 24, 26-28, 30, 31, 34, 37, 60, 61

Florida (FL, Region 8) xiv, 37, 39, 54, 55, 60

Forced outage 90, 95, 103, 106

$\mathbf{G}$

General and administrative (G\&A) costs $x i i, x v, 17$, $21,26,32,33,42,43,51,58,60-62,66,89,90,94$, 95,106

\section{H}

Half O\&M Case 25, 43

High Consumer Response Case xii, xiii, 24, 31, 32, $34,37,40,41,60,61$

High Efficiency Case xii, xiii, xvi, 25, 32-34, 45, $48-56,60-62,85$

High Gas Price Case 25, 41

High Value of Reliability Case 25, 39, 40, 60

I

Independent system operator (ISO) 4-8, 89, 106

Intense Competition Case ix, xii-xv, 25, 43, 44, 60, $61,80,84$

\section{$\mathbf{L}$}

Loss of load probability 106

Lost load 29, 37, 39

Low Gas Price Case 25, 41

\section{M}

Marginal cost pricing i, iii, 6, 12-14, 33, 41, 63-65, $68,69,71,73,77,87,99,106$

Marginal-cost-based prices 24, 46, 50, 52 
Market power ix, xi, 7, 11, 14, 80, 84, 85, 89, 106, 107

Mid-America Interconnected Network (MAIN, Region 4) xiv, 39, 50, 51, 60, 80

Mid-Atlantic Area Council (MAAC, Region 3) xiv, $39,49,60,79$

Mid-Continent Area Power Pool (MAPP, Region 5) xiv, 39, 46, 51, 57, 60, 83

Moderate Consumer Response Case xii, xiii, xv, 24, $25,30,32-35,37,40-45,49,51,53-56,60,61,65$

\section{$\mathbf{N}$}

National Energy Modeling System (NEMS) iii, xiii, $x v, 9,21-23,27-31,33,34,36-40,42-44,46-61,65$, $73,76,77,86,89,101,106$

Natural monopoly 106,107

Net stranded assets (see also Stranded assets) xiv, $\mathrm{xv}, 44,46,60-62,83,84,108$

Net stranded costs (see also Stranded costs) 16, 23, 25-27, 45-60, 83, 108

New England Power Pool (NE, Region 7) xiv, 37, $39,53,54,60,69,74$

New York Power Pool (NY, Region 6) xiv, 39, 52, $53,60,64,68,74$

No Capacity Additions Case 24, 35-38

No Competition Case xii, xiii, 26, 27, 34, 37, 43, 83, 84

North American Electric Reliability Council (NERC) xiii, 12, 23, 45, 46, 83, 107

Northwest Pool (NWP, Region 11) xiv, 39, 46, 57, 60,83

Operations and maintenance (O\&M) costs $x i, x i i$, $x v$, xvi, 16-18, 21, 25, 26, 32, 33, 35, 42, 43, 48, $51,52,55-58,60-62,66,68,77,83,90,93-95,107$ Optimal reserve margin (see also Reserve margin) $15,16,29,86,95,107$

$\mathbf{P}$

Perfect competition $x i, 85,107$

Performance-based rates xiii, 4, 62

Performance-based regulation (PBR) 4-6, 107

POOLCO 105, 107

Power exchange (PX) 4-6

Power pool xiv, 6-8, 46, 51-53, 56, 83, 105, 107

Producer surplus 99

Profits xvi, 1, 4, 6, 14, 21, 32, 64, 68, 69, 71, 73, 74, $78,98,99,106,107$

Public Utility Holding Company Act of 1935 (PUHCA) 2, 3, 106, 107

Public Utility Regulatory Policies Act of 1978 (PURPA) 2, 3, 107
$\mathbf{R}$

Rate of return 1, 2, 74, 105, 107, 108

Ratebase regulation (see also Cost-of-service regulation) 108

Reliability price adjustment xi, xii, 6, 12, 15, 18, 19, $21,23,29,35,36,40,50,55,86,89,90,91,94$, $101,103,104$

Reserve margin (see also Optimal reserve margin) $6,15,16,18,24,26,29,33,34,36-41$, $45,62,84-86,91,95,107,108$

Retail wheeling 4,108

Risk 17, 18, 35, 86

Rocky Mountain and Arizona-New Mexico Power Areas (RA, Region 12) xiv, 39, 58, 60

\section{S}

Southeastern Electric Reliability Council Region (excluding Florida) (STV, Region 9) xiv, 39, 55, 56,60

Southwest Power Pool (SPP, Region 10) xiv, 39, 56, $57,60,81$

Spot market 6, 11, 15, 89, 90, 108

Spot prices 6, 89-91

Stranded assets (see also Net stranded assets) ix, xiv, $x v, 4,17,44-46,52,60-62,74,80,83,84,108$

Stranded costs (see also Net stranded costs) ix, $x$, xii, xiv, 1, 3-5, 7, 13, 16, 19, 21, 23-27, 33, 35, 40, $44-64,78-80,83-85,87,90,93,94,98,99,108$

$\mathbf{T}$

Taxes xi, xvi, 7, 16, 21, 22, 33, 45, 66-71, 73, 74, 77-81, 84, 89-91, 93-95

Time-of-use (rates, prices) iii, xi, xii, xiii, xvi, 12 , $13,16,18,23-33,35-37,41,45,60,62,84,89,108$

$\mathbf{U}$

Uneconomic costs ix, $x, x i i, x v i, 7,16,23,46,55$, 62,83

United Kingdom (UK) 6-8, 69, 85, 89

Unserved energy (see also Value of unserved energy) xii, $18,21,23,24,29,37-40,50,89-91$, $95,103,106,108$

V

VALCAP iii, 101, 103

Value of lost load (see also Value of unserved energy) $29,37,39$

Value of unserved energy $18,29,37,39,40,90,91$, 95, 103, 108

Variable costs $x i, 17,42,62-64$ 